\title{
The Response of Brewster Glacier to Five Decades of Climate
}

\author{
By \\ Merijn S. Thornton

\begin{abstract}
A thesis
submitted to Victoria University of Wellington

in partial fulfilment of the requirements for the degree of

Master of Science in Geology.
\end{abstract}

Victoria University Wellington

2017 
To my friend, Matt, and Opa, Jim. 


\section{Abstract}

Small perturbations in climate can produce measurable changes to the size of a glacier. Documenting such changes is important for quantifying water storage changes, and understanding glacier-climate interactions. By using all available geodetic data, such as Landsat imagery, Shuttle Radar Topography Mission, GNSS and photogrammetric techniques, as well as ground penetrating radar for the construction of a bed DEM, it is found that Brewster Glacier decreased in volume from 1967 to 2017 , losing 56\% of its volume, with a period of volume increase of $\sim 10 \%$ from 1986 to 1997 . The overall pattern of geodetic mass balance is similar to the glaciological mass balance record, however, the geodetic method tends to show more negative values by an average of $\sim 0.6 \mathrm{~m}$ w.e. Contrary to many other New Zealand glaciers, which experienced an advance from 1983 to 2008, Brewster Glacier continued to retreat by $390 \mathrm{~m}$ during the study period, at an average rate of $7.8 \mathrm{~m} \mathrm{a}^{-1}$, but at a significantly reduced rate of $\sim 2 \mathrm{~m} \mathrm{a}^{-1}$ from 1997 until 2005. By comparing the records of Brewster Glacier and Fox and Franz Josef glaciers, we explore the differences in response and reaction times resulting from glacier area-altitude distribution, and climatic setting. Furthermore, DEMs produced by this study are now available for use by a New Zealand wide glacier monitoring programme. 


\section{Acknowledgements}

Thank you firstly to my supervisors for providing sound advice, and showing a great deal of patience. Thank you to Lauren Vargo for the SfM models and for providing a sounding board for ideas relating to this project. Thank you to Aleksandr Beliaev for all of the IT support you provided me. Thank you to my sister Anneke Thornton for your helpful feedback. Thank you to my partner Isaura for all the love and support you gave me during this testing year (and all the baking you did for me!). Thank you to the two examiners for their helpful suggestions. Last but not least, thank you to my parents Dita and Steve for everything you have done for me. 


\section{Contents}

Abstract $\quad$ iii

Acknowledgements $\quad$ V

Contents vii

List of Figures $\quad$ xvii

List of Tables $\quad$ xix

1 Introduction $\quad 1$

1.1 Study motivations . . . . . . . . . . . . . . . . . . . . . 1

1.2 Overview . . . . . . . . . . . . . . . . . 6

1.3 Processes of accumulation and ablation . . . . . . . . . . . 6

1.4 Mass balance . . . . . . . . . . . . . . . . . . . . . . . . 8

1.5 Mass balance measurement methods . . . . . . . . . . . . . . . . . . 10

1.5.1 The geodetic method . . . . . . . . . . . . . . . . 10

1.5.2 The glaciological method . . . . . . . . . . . . . . . 11

1.5.3 Hydrological method . . . . . . . . . . . . . . . . . . . . 12

1.5.4 Equilibrium Line Altitude (ELA) method . . . . . . . . . . . . 13

1.6 Glacier response to mass balance changes . . . . . . . . . . . . . . . . . 14

1.7 Factors which affect glacier behavior . . . . . . . . . . . . . . . . . . . 14

1.8 Worldwide glacier records . . . . . . . . . . . . . . . . . . 16

1.9 The response of New Zealand glaciers to changes in climate . . . . . . . 16

1.10 Brewster Glacier . . . . . . . . . . . . . . . . . . . . . . . 18

1.10.1 Previous research on Brewster Glacier . . . . . . . . . . . . . . 20

1.10 .2 Study objectives . . . . . . . . . . . . . . . . . 22

1.10.3 Data objectives . . . . . . . . . . . . . . . . . . . 22

1.10.4 Research investigations . . . . . . . . . . . . . . . 23

2 Methods $\quad 25$

2.1 Glacier surface . . . . . . . . . . . . . . . . . . 26

2.1.1 New Zealand Map Series Topographic map (NZMS) . . . . . . . 27 
2.1.2 NZTopo topographic map . . . . . . . . . . . . . . . . . . 28

2.1.3 Shuttle Radar Topography Mission (SRTM) . . . . . . . . . . . 28

2.1.4 ASTER GDEM Version 2 . . . . . . . . . . . . . . . . . 29

2.1.5 Global Navigation Satellite System (GNSS) . . . . . . . . . . 29

2.1.6 Structure from Motion $(\mathrm{SfM})$. . . . . . . . . . . 30

2.2 Spatial interpolation of GNSS data . . . . . . . . . . . . . . . 32

2.2.1 Cokriging . . . . . . . . . . . . . . . . . 33

2.3 DEM debias . . . . . . . . . . . . . . . . . . . . . . . . . 37

2.4 Glacier bed . . . . . . . . . . . . . . . . . . . . . . . . 38

2.4.1 Ground Penetrating Radar . . . . . . . . . . . . . . . . . . . 39

2.4 .2 GPR acquisition . . . . . . . . . . . . . . . 41

2.4.3 GPR processing . . . . . . . . . . . . . . . 43

2.4.4 Data interpretation .................. 44

$2.4 .5 \mathrm{SfM} \ldots \ldots \ldots \ldots 4 . \ldots \ldots$

2.4.6 Bed DEM construction . . . . . . . . . . . . . . . . 46

2.5 Glacier Perimeter . . . . . . . . . . . . . . . . . . . . 51

2.5 .1 SfM digitisation . . . . . . . . . . . . . . 51

2.5.2 Landsat digitisation . . . . . . . . . . . . . . 51

2.5.3 Topographic map perimeter digitisation . . . . . . . . . . . 54

2.5.4 Area calculation . . . . . . . . . . . . . . . 55

2.6 Terminus position estimation _. . . . . . . . . . . . . 56

2.7 Volume calculation . . . . . . . . . . . . . . . . . . 56

3 Results $\quad 59$

3.1 Surface elevation . . . . . . . . . . . . . . . . . . . . . 59

3.2 The glacier bed . . . . . . . . . . . . . . . . . . 65

3.3 Area . . . . . . . . . . . . . . . . . 67

3.4 Terminus position . . . . . . . . . . . . . . . 69

3.5 Volume . . . . . . . . . . . . . . . . . . . . . . 70

4 Discussion $\quad 73$

4.1 Relationship between geodetic and direct mass balance estimates . . . . 73

4.2 Volume change and response time . . . . . . . . . . . . . . 76

4.3 Brewster Glacier in the context of local climate . . . . . . . . . . . . 83

4.4 Comparison to other New Zealand glacier records . . . . . . . . . . . . 88

4.5 Further considerations . . . . . . . . . . . . . . . . . . . . . 92

5 Conclusions 93

5.1 Completed study objectives . . . . . . . . . . . . . . . . 95

5.1 .1 Data objectives . . . . . . . . . . . . . . . . . 95

5.1 .2 Research investigations . . . . . . . . . . . . . . . . 95 
5.2 Future work . . . . . . . . . . . . . . . . . 97

$\begin{array}{ll}\text { Appendices } & 99\end{array}$

$\begin{array}{ll}\text { A Spatial interpolation techniques } & 101\end{array}$

$\begin{array}{ll}\text { B Images for perimeter interpretation } & 113\end{array}$

$\begin{array}{ll}\text { C Surface datasets } & 123\end{array}$

$\begin{array}{ll}\text { D Radar profiles } & 137\end{array}$

$\begin{array}{ll}\text { E Supplementary figures } & 163\end{array}$

$\begin{array}{ll}\text { Bibliography } & 171\end{array}$ 


\section{List of Figures}

1.1 a Estimates of the worldwide change of glacier storage relative to the year 2000. b Rates of mass change $\mathbf{c}$ Mean mass change rates between 2003 and 2009. Error shading and error bars represent $90 \%$ confidence intervals. Figure taken from Marzeion et al. (2017), p.121. . . . . . . 2

1.2 Glacier facies showing the transformation of snow to ice. Figure taken from Benn and Evans (2010), p.33. . . . . . . . . . . 8

1.3 The yearly mass balance cycle and associated definitions (Cuffey and Paterson, 2010),p.100. . . . . . . . . . . . . . . . .

1.4 Brewster Glacier (inset showing location). Image derived from a Structure from Motion model (2016). . . . . . . . . . . . . .

1.5 Results of a mass balance study by Willis et al., personal communication,

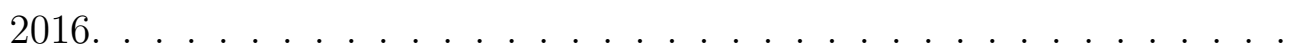

2.1 SfM uses feature matching on multiple overlapping images of an area of interest in order to create a 3D image. Figure taken from Westoby et al.

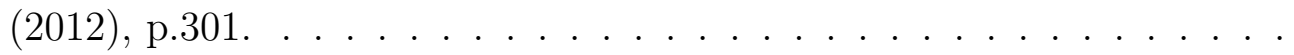

2.2 Map showing elevation standard error for January, 1997 GNSS points (a), and elevation standard error for November 2007 (b). . . . . . . . 36

2.3 Glacier periphery topographic error for SRTM (2000) . . . . . . . . . 38

2.4 Spatial extent of the three GPR datasets used in this study. . . . . . . 42

2.5 GPR processing flow showing main steps used to increase the signal to noise ratio of radar profiles. . . . . . . . . . . . . . . . 43

2.6 Interpreted (a), and non-interpreted (b) radargrams for profile 1303 (Figure D.2) . . . . . . . . . . . . . . . . . . . . .

2.7 Point elevation estimates (a) and difference frequency histogram (b) for SfM and 1997 GPR. Perfect agreement would result in the line of best fit coinciding with the $\mathrm{Y}=\mathrm{X}$ line.

2.8 Point elevation estimates (a) and difference frequency histogram (b) for 1997 GPR (DC bias corrected) and 2012 GPR. Perfect agreement would result in the line of best fit coinciding with the $\mathrm{Y}=\mathrm{X}$ line. . . . . . . . 
2.9 Point elevation estimates (a) and difference frequency histogram (b) for 1997 GPR (DC bias corrected) and 2016 GPR. Perfect agreement would result in the line of best fit coinciding with the $\mathrm{Y}=\mathrm{X}$ line. . . . . . . .

2.10 Point elevation estimates (a) and difference frequency histogram (b) for 2012 GPR and 2016 GPR. Perfect agreement would result in the line of best fit coinciding with the $\mathrm{Y}=\mathrm{X}$ line. . . . . . . . . . . . .

2.11 The effects of contrast enhancement. The red line represents the digitised perimeter. . . . . . . . . . . . . . . . . .

2.12 Digitised perimeters derived from Landsat (red), and Structure from Motion model (green) for March 2016. Background image is Landsat (a), and $\operatorname{SfM}(b) . \ldots \ldots \ldots . \ldots \ldots 54$

2.13 Method for determining the terminus position. . . . . . . . . 57

3.1 Surface contours derived from all 5 DEM types used in this study. All surfaces show a similar topographic pattern with the possible exception of the NZMS surface. . . . . . . . . . . . . . . . .

3.2 Rate of surface elevation change for the 1967 to 1986, a period of surface lowering, 1986 to 1997, a period of surface elevation increase, and 1997 to 2017 , a period of surface lowering. . . . . . . . . . . . . . .

3.3 Mean surface elevation of all surfaces, clipped to the 2017 glacier extent. Error bars represent $95 \%$ confidence intervals in the mean. Confidence intervals for the 1967, 1986, and 2000 DEMs were calculated assuming 300,250 , and 2500 points respectively.

3.4 Bed DEM constructed from GPR and SFM data, and interpolated using ordinary kriging.

3.5 Interpreted (a), and non-interpreted (b) radargrams for profile 0038 (Figure D.3) . . . . . . . . . . . . . . . . . 66

3.6 Kriging standard error for bed DEM _ . . . . . . . . . . . 67

3.7 Glacier periphery topographic error for NZDEM SoS v1.0 (1986). . . . 68

3.8 Area change history of Brewster Glacier:1967-2017. Error bars are 1 standard deviation. . . . . . . . . . . . . . . . . . . . 69

3.9 Terminus retreat of Brewster Glacier:1967-2017 _ . . . . . . . . . . 70

3.10 Volume change history of Brewster Glacier:1967 to 2017. Error bars represent the $95 \%$ confidence interval as a function of surface elevation only. . . . . . . . . . . . . . . . . . .

3.11 Volume change history of Brewster Glacier:2005 to 2017. Blue circles show winter volume. Red squares show summer volume. Error bars represent the $95 \%$ confidence interval as a function of surface elevation only. 
4.1 The glaciological mass balance record of Brewster Glacier derived by Cullen et al. (2016) (red crosses) compared to the volume record derived in this study (blue circles). Error bars for the geodetic method relate to the uncertainty in the mean elevation (95\% confidence interval), and the uncertainty of density, assumed to be $\pm 75 \mathrm{~kg} \mathrm{~m}^{-3}$ as given by Huss (2013) (Figure 4.2) . . . . . . . . . . . . . . . . . .

4.2 Modeled density conversion factors. Solid lines show conversion factors for an increase in mass balance, and dotted lines show the conversion factor for a decrease in mass balance. The shaded area represents \pm 2 standard deviations. Note the high density conversion factor variation for short observational periods. Figure taken from Huss (2013), p.882. . 75

4.3 Distributed volume change of Brewster Glacier: 1967 to 2017. . . . . . 76

4.4 Distributed volume change of Brewster Glacier: March 2016 to November 2016 (a) and November, 2016 to March, 2017 (b). . . . . . . . . . . 77

4.5 Map showing location of lines and points along which the surface is sampled, shown in subsequent Figures, 4.7, 4.8,4.9,4.6. . . . . . . . 78

4.6 Surface elevation change for point locations shown in Figure 4.5 . . . .

4.7 Surface elevation change history of Brewster Glacier along cross-section line A in Figure 4.5 from 1967 to 2017. Where there is more than one surface for a given year, only the surface representing the end of summer is shown. Figure E.1 shows all surfaces. . . . . . . . . . . . . . . . .

4.8 Surface elevation change history of Brewster Glacier along cross-section line B in Figure 4.5 from 1967 to 2017. Where there is more than one surface for a given year, only the surface representing the end of summer is shown. Figure E.3 shows all surfaces. . . . . . . . . . . . . . . .

4.9 Surface elevation change history of Brewster Glacier along cross-section line C in Figure 4.5 :1967 to 2017. Where there is more than one surface for a given year, only the surface representing the end of summer is shown. Figure E.5 shows all surfaces. Of note is the poor alignment of the 1967, 1986, and 2000 surfaces. This is especially the case for the 1967 surface where the glacier surface crosses the bed. Also note the unusual surface topography of the 1967 surface. . . . . . . . . . . . . . 82

4.10 The strongest negative correlation coefficients are for a lag of $\sim 17$ years. 83

4.11 Temperature records of three stations located on the West Coast of the South Island.

4.12 Rainfall records of three stations located on the West Coast of the South Island . . . . . . . . . . . . . . . . . . . .

4.13 Summer ablation plotted against ELA. With the exception of the 2011/12 season (top right), there is a strong correlation of ELA and summer ablation. 
4.14 Comparison of New Zealand Glacier length records. . . . . . . . . . . .

4.15 Landsat 8 image of Fox and Franz Josef glaciers, March 2017. These glaciers lie $\sim 90 \mathrm{~km}$ to the north of Brewster Glacier.

5.1 This study created a time-series of volume, length and area from 1967, to 2017.

A.1 Synthetic scatter plot of a measured variable $(Z)$ at a head and tail for lag $=1$ (top) and lag $=2$ (bottom). The spatial autocorrelation between the head and tail can be described by the correlation coefficient $(0.98$ for $\operatorname{Lag}=1,0.78$ for $\operatorname{lag}=2) \ldots \ldots \ldots \ldots$

A.2 Main parts of a theoretical semi-variogram. If no spatial coorelation exists, the variance would be represented by a horizontal line. In practice, the theoretical semi-variogram is the line of best fit around which the experimental semi-variogram points are scattered. Figure taken from Bohling (2005a).

B.1 2015 perimeter (red line) digitised from sfm model developed from aerial photographs taken March, 2015. . . . . . . . . . . . . . . . 114

B.2 2016 perimeter (red line) digitised from sfm model developed from aerial photographs taken March, 2016. . . . . . . . . . . . . . 115

B.3 2014 perimeter (red line) digitised from Landsat 8 images with the aid of aerial photographs. Background image taken on the 12th of March, 2014.

B.4 2014 perimeter (red line) digitised from Landsat 8 images with the aid of aerial photographs. Background image taken on the 7th of February, 2014

B.5 Aerial photograph used to guide interpretation of perimeter. Photograph taken 11th of March, 2014. . . . . . . . . . . . . . . . 117

B.6 Aerial photograph used to guide interpretation of perimeter. Photograph taken 11th of March, 2014. . . . . . . . . . . . . . . . 117

B.7 2013 perimeter (red line) digitised from Landsat 7 images with the aid of aerial photographs. Background image taken on the 28th of February,

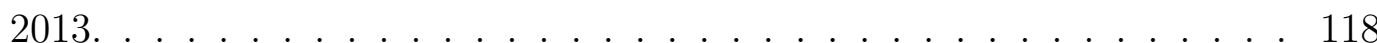

B.8 2013 perimeter (red line) digitised from Landsat 7 images with the aid of aerial photographs. Background image taken on the 7th of March, 2013. . . . . . . . . . . . . . . . . . . 118

B.9 Aerial photograph used to guide interpretation of perimeter. Photograph taken on the 12th of March, 2013. 
B.10 2012 perimeter (red line) digitised from Landsat 7 images with the aid of aerial photographs. Background image taken on the 10th of February, 2012 .

B.11 2012 perimeter (red line) digitised from Landsat 7 images with the aid of aerial photographs. Background image taken on the 13th of March, 2012.

B.12 2012 perimeter (red line) digitised from Landsat 7 images with the aid of aerial photographs. Background image taken on the 20th of March, 2012.

B.13 2012 perimeter (red line) digitised from Landsat 7 images with the aid of aerial photographs. Background image taken on the 29th of March, 2012.

B.14 Aerial photograph used to guide interpretation of perimeter. Photograph taken on the 21st of March, 2012.

C.1 January, 1997 GNSS track.

C.2 February, 2005 GNSS track.

C.3 November, 2007 GNSS track.

C.4 April, 2008 GNSS track. 125

C.5 November, 2008 GNSS track. 125

C.6 March, 2009 GNSS track. 126

C.7 November, 2009 GNSS track. 126

C.8 March, 2010 GNSS track. 127

C.9 October, 2010 GNSS track. . . . . . . . . . . . . . . . . . 127

C.10 March, 2011 GNSS track. 128

C.11 November, 2011 GNSS track. 128

C.12 March, 2012 GNSS track. 129

C.13 October, 2010 GNSS track. 129

C.14 February 2013 GNSS track. 130

C.15 November, 2013 GNSS track.

C.16 April, 2014 GNSS track.

C.17 December, 2014 GNSS track.

C.18 March, 2015 GNSS track.

C.19 New Zealand Map Series (NZMS) map.

C.20 Shuttle Radar Topography Mission (SRTM) DEM.

C.21 Top: No. of images that were used to calculate each pixel value. Bottom:

Surface topography of Brewster glacier according to ASTER GDEM V2. 133

C.22 Glacier periphery topographic error for NZMS (1967) . . . . . . . . . . 134

C.23 Glacier periphery topographic error for NZDEM SoS v1.0 (1986). . . . 134

C.24 Glacier periphery topographic error for SRTM (2000) . . . . . . . . . . 135 
C.25 NZMS error histogram. . . . . . . . . . . . . . . . . . . 135

C.26 NZDEM_SoS_v1.0 error histogram. . . . . . . . . . . . . . . . . . 136

D.1 1997 GPR profiles. . . . . . . . . . . . . . . . . . 137

D.2 2012 GPR profiles. . . . . . . . . . . . . . . . . . . . . 138

D.3 2016 GPR profiles. . . . . . . . . . . . . . . . . . 138

D.4 Interpreted (a), and non-interpreted (b) radargrams for profile 0002 (Figure D.2) . . . . . . . . . . . . . . . . . . . . . . 139

D.5 Interpreted (a), and non-interpreted (b) radargrams for profile 0007 (Figure D.2) . . . . . . . . . . . . . . . . . . . . . . . . . . . 139

D.6 Interpreted (a), and non-interpreted (b) radargrams for profile 0008 (Figure D.2) . . . . . . . . . . . . . . . . . . . . . 140

D.7 Interpreted (a), and non-interpreted (b) radargrams for profile 0009 (Figure D.2) . . . . . . . . . . . . . . . . . . . . . . 141

D.8 Interpreted (a), and non-interpreted (b) radargrams for profile 0011. . . 142

D.9 Interpreted (a), and non-interpreted (b) radargrams for profile 0011. . . 143

D.10 Interpreted (a), and non-interpreted (b) radargrams for profile 0012 . . . 144

D.11 Interpreted (a), and non-interpreted (b) radargrams for profile 0013. . . 145

D.12 Interpreted (a), and non-interpreted (b) radargrams for profile 0016. . . 146

D.13 Interpreted (a), and non-interpreted (b) radargrams for profile 0017. . . 147

D.14 Interpreted (a), and non-interpreted (b) radargrams for profile 0022. . . 148

D.15 Interpreted (a), and non-interpreted (b) radargrams for profile 0029 . . . 149

D.16 Interpreted (a), and non-interpreted (b) radargrams for profile 0030. . . 150

D.17 Interpreted radargram for profile 0033. . . . . . . . . . . . . . . . 151

D.18 Interpreted radargram for profile 0035 . . . . . . . . . . . . . . . . 151

D.19 Interpreted radargram for profile 0037. . . . . . . . . . . . . . . . . . . 152

D.20 Interpreted radargram for profile 0039 . . . . . . . . . . . . . . . . . . . 152

D.21 Interpreted radargram for profile 0040 . . . . . . . . . . . . . . . 152

D.22 Interpreted (a), and non-interpreted (b) radargrams for profile 1301. . . 153

D.23 Interpreted (a), and non-interpreted (b) radargrams for profile 1302. . . 154

D.24 Interpreted (a), and non-interpreted (b) radargrams for profile 1306. . . 155

D.25 Interpreted (a), and non-interpreted (b) radargrams for profile 1307. . . 156

D.26 Interpreted (a), and non-interpreted (b) radargrams for profile 1308. . . 157

D.27 Interpreted (a), and non-interpreted (b) radargrams for profile 1309. . . 158

D.28 Interpreted (a), and non-interpreted (b) radargrams for profile 1311. . . 159

D.29 Interpreted (a), and non-interpreted (b) radargrams for profile 1312 . . 160

D.30 Interpreted (a), and non-interpreted (b) radargrams for profile 1313. . . 161

E.1 Surface elevation change history of Brewster Glacier along cross-section line A in Figure $4.5: 1967$ to 2017 . . . . . . . . . . . . . . . . . 163 
E.2 Surface elevation change history of Brewster Glacier along cross-section line A in Figure 4.5 for years 1967, 1987, 1997, 2000, and 2017. . . . . . 164

E.3 Surface elevation change history of Brewster Glacier along cross-section line B in Figure $4.5: 1967$ to 2017 . . . . . . . . . . . . . . . . . 165

E.4 Surface elevation change history of Brewster Glacier along cross-section line B in Figure 4.5 for years 1967, 1986, 1997, and 2000. . . . . . . . 166

E.5 Surface elevation change history of Brewster Glacier along cross-section line C in Figure 4.5 :1967 to 2017 . . . . . . . . . . . . . . . . . 167

E.6 Surface elevation change history of Brewster Glacier along cross-section line C in Figure 4.5 for years 1967, 1986, 1997, and 2000 . . . . . . . 168

E.7 2017 slope DEM, derived from the 2017 SfM DEM. . . . . . . . . . . . 169 


\section{List of Tables}

1.1 The number of homes, businesses, and the length of road within certain limits of sea level for Auckland (blue), Wellington (yellow), Christchurch (red) and Dunedin (green) (Wright, 2015). . . . . . . . . . . 4

2.1 Datasets used in this study. . . . . . . . . . . . . . 25

2.2 Surface datasets through time. The vertical resolution of the NZMS and NZTopo (from which the NZDEM_sos_v1.0 is based from) is $100 \mathrm{ft}$ and $20 \mathrm{~m}$ vertically. Accuracy is in terms of the vertical and is taken as one standard deviation of the error distribution histogram. Cokriging errors are one standard error. . . . . . . . . . . . . . . . . . . . . . .

2.3 Physical constraints of materials encountered in the study area. Modified from Plewes and Hubbard (2001). . . . . . . . . . . . . . . . 40

2.4 Variogram parameters for simple bed kriging. . . . . . . . . . . . 50

3.1 Mean standard errors of surfaces used in this study. . . . . . . . . . . . 60

3.2 Mean surface elevation change resulting from ablation between 2007-2017. 64

3.3 Mean surface elevation change resulting from accumulation between 2008-2016. . . . . . . . . . . . . . . . . . 6 64

A.1 Covariance function parameters for GNSS points. . . . . . . . . . . 110

A.2 Covariance function parameters used for GNSS points cross covaried with SfM points . . . . . . . . . . . . . . . . . . . 111

A.3 Covariance function parameters used for SfM points. . . . . . . . . . 112 


\section{Introduction}

\section{$1.1 \quad$ Study motivations}

Alpine glaciers and small ice caps make up an important constituent of the cryosphere, with $0.7 \pm 0.2 \mathrm{~m}$ sea level equivalent (Meier et al., 2007; Dyurgerov and Meier, 2005). Furthermore, they are major contributers to recent sea level rise (Dangendorf et al., 2017; Jacob et al., 2012). Sea level rise in turn has numerous repercussions, including increased pressure on social and biological systems (Vaughan et al., 2013a). An example of this is the expected displacement of people in low lying areas. With an estimated 600 million people living within 10 m of sea level (McGranahan et al., 2007), Nicholls et al. (2011) estimated that a rise in sea level of $2 \mathrm{~m}$ by 2100 may force the displacement of 187 million people. Additionally, changes in the mass of glaciers and ice caps can have large implications for the regional water cycle, local tourism, water resources, and local hazards (Zemp et al., 2015; Vaughan et al., 2013a; Chinn, 2001).

In recognition of their vulnerability to warming, Vaughan et al. (2013b) compiled glacier mass balance budgets for the period of 2003-2009 for the Intergovernmental Panel of Climate Change (IPCC) fifth assessment report (AR5), in order to estimate their global contribution to recent and potential future sea level rise. They concluded that the average rate of ice loss from glaciers around the world, excluding glaciers

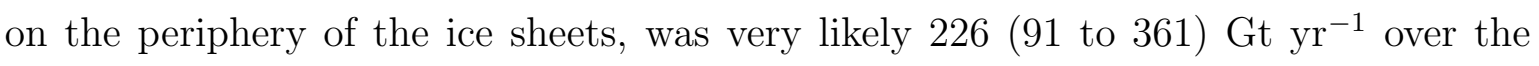

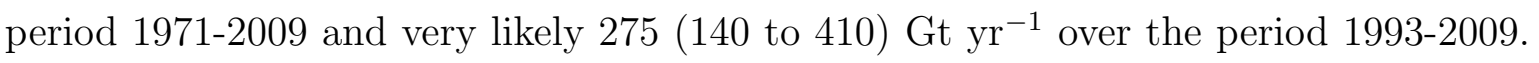
These rates of ice loss equate to 0.63 (0.25 to 1.01$) \mathrm{mm} \mathrm{a}^{-1}$ and 0.77 (0.39 to 1.15) $\mathrm{mm} \mathrm{a}^{-1}$ of sea level rise for the two periods respectively. Furthermore, by analysing global inventories of glacier mass balance change, Gardner et al. (2013) estimated that glaciers have contributed approximately 30\% towards sea level rise between 2003 and 
2009. Figure 1.1 shows a comparison of estimates of the change in glacier storage, and the resultant contribution to sea level.

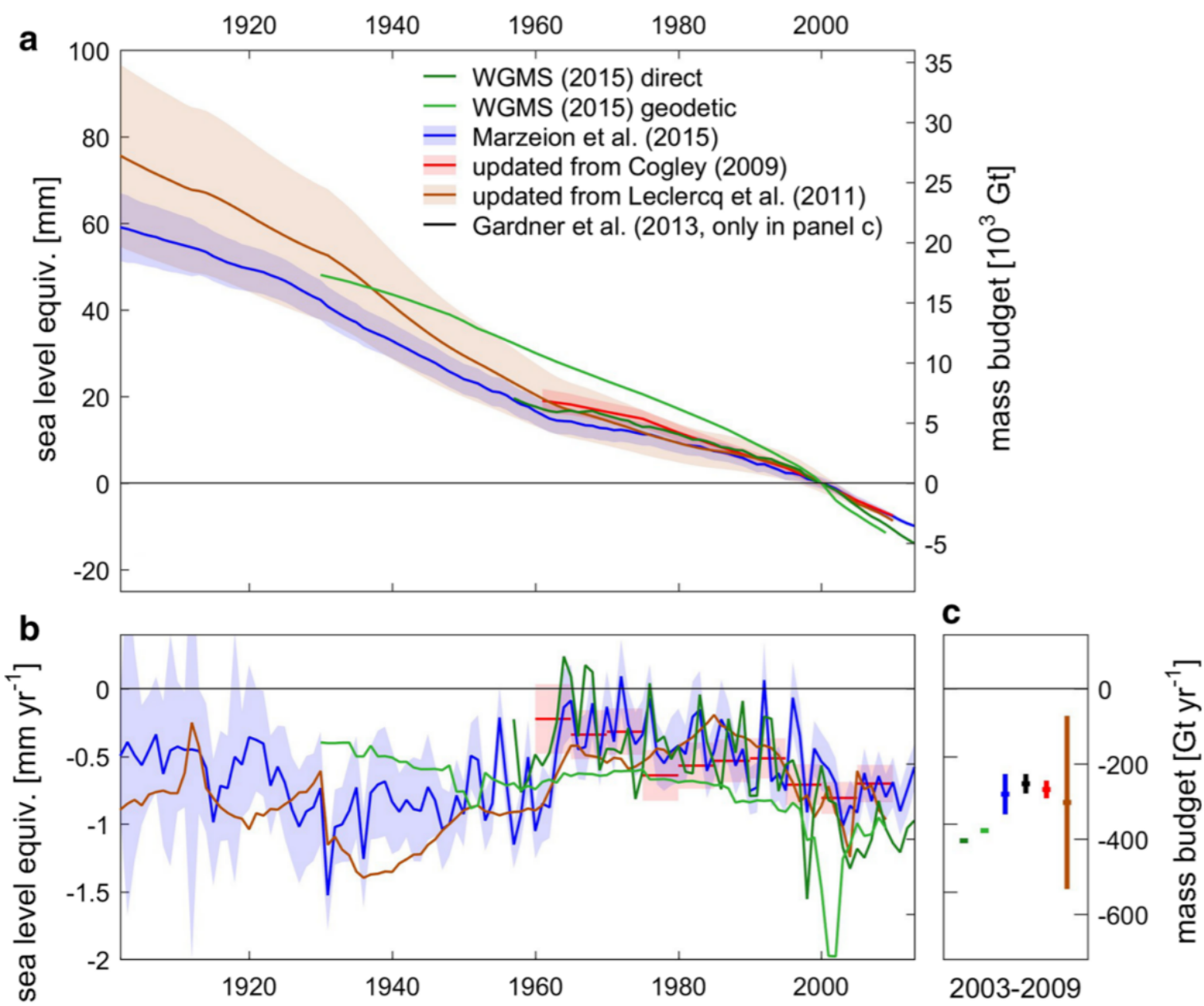

Figure 1.1: a Estimates of the worldwide change of glacier storage relative to the year 2000. b Rates of mass change $\mathbf{c}$ Mean mass change rates between 2003 and 2009. Error shading and error bars represent $90 \%$ confidence intervals. Figure taken from Marzeion et al. (2017), p.121.

Another recent study has estimated the effective future contribution of sea level rise for all glaciers including those with a proportion of ice volume below sea level (Huss and Hock, 2015). Huss and Hock (2015) estimate that between the period 2010 to 2100 , glaciers (excluding the ice sheets) will contribute $91 \pm 26 \mathrm{~mm}$ for a warming scenario of $\sim 1^{\circ} \mathrm{C}$ and $178 \pm 26 \mathrm{~mm}$ for a warming scenario of $\sim 3.7^{\circ} \mathrm{C}$. The IPCC (AR5) predicts with medium confidence that 15 to $55 \%$ of glacier volume will be lost for all glaciers, excluding those on the periphery of Antarctica, for a temperature rise of $\sim 1^{\circ} \mathrm{C}$ and 37 to $81 \%$ of glacier volume for a temperature rise of $\sim 3.7^{\circ} \mathrm{C}$ by 2100 (Vaughan 
et al., 2013b). Additionally, glaciers are likely to play a significant role in the drainage of marine based ice from over deepened parts of West Antarctica, East Antarctica and Greenland (Alley et al., 2005; Joughin and Alley, 2011). One such glacier, Thwaites Glacier, has been recognised as being capable of emptying the portion of ice resting below sea level (known as "the weak underbelly of West Antarctica"), which would result in a sea level rise of $\sim 3.3 \mathrm{~m}$ over a timescale of 100's of years (Vaughan et al., 2006; Alley et al., 2005).

At the national scale, the high consequences of sea level rise, and large uncertainties regarding the magnitude of ice loss make it imperative that glacier processes are thoroughly understood in order to guide policy decisions and better plan for the future. In a report compiled by the parliamentary commission, the impacts of rising sea levels on New Zealand were assessed (Wright, 2015). The report states that, with a projected New Zealand sea level rise of $28.6 \mathrm{~cm}$ by 2065, extreme sea level heights, considered 100 year events today, will become once a year events in Wellington and Christchurch, and would occur on average every 2 and 4 years for Dunedin and Auckland respectively. Moreover, a rise in sea level of $70 \mathrm{~cm}$ would increase the frequency of a 100 year high tide flooding event to every high tide in Wellington. These estimates are based on sea level rise alone, with no consideration for the change in the size and frequency of storm events, which are also expected to increase (Easterling et al., 2000). Such sea level rises become more destructive when high tides coincide with storm surges (e.g. Karim and Mimura (2008)). Of particular concern is the impact this will have on Dunedin, where 2683 homes lie less than $50 \mathrm{~cm}$ above sea level (Table 1.1). The report also discusses the effect of rising sea level on coastal erosion, ground water contamination, increased groundwater level (especially in Dunedin), as well as the increased hazard of tsunamis. In addition to an increase in hazards, glacier change has economic importance. This is especially true in New Zealand where hydroelectric generation supplies New Zealand with over half of its electricity (Mason et al., 2010). For the tourism industry, changes in glaciers are important for both scenic value, and as a potential source of hazards (Purdie et al., 2015a; Chinn, 2001; Purdie, 2013; McColl et al., 2017; Stewart et al., 2016). 


\begin{tabular}{|l|c|c|c|}
\hline & $\mathbf{0 - 5 0} \mathbf{~ c m}$ & $\mathbf{5 0 - 1 0 0} \mathbf{~ c m}$ & $\mathbf{1 0 0 - 1 5 0} \mathbf{~ c m}$ \\
\hline Homes & 108 & 457 & 795 \\
\hline Businesses & 4 & 13 & 43 \\
\hline Roads (km) & 9 & 18 & 29 \\
\hline Homes & 103 & 1920 & 2985 \\
\hline Businesses & 1 & 20 & 139 \\
\hline Roads (km) & 2 & 21 & 35 \\
\hline Homes & 901 & 3629 & 5427 \\
\hline Businesses & 5 & 58 & 130 \\
\hline Roads (km) & 40 & 77 & 84 \\
\hline Homes & 2683 & 604 & 317 \\
\hline Businesses & 116 & 29 & 40 \\
\hline Roads (km) & 35 & 17 & 20 \\
\hline
\end{tabular}

Table 1.1: The number of homes, businesses, and the length of road within certain limits of sea level for Auckland (blue), Wellington (yellow), Christchurch (red) and Dunedin (green) (Wright, 2015).

In addition to the hazards associated with glacier change, alpine glaciers are sensitive indicators of climate change (Oerlemans, 2005)- defined by Oerlemans and Hoogendoorn (1989) as a relatively high change in the mass of a glacier for a change in temperature, cloudiness, albedo, and precipitation. The small volume of alpine glaciers generally make them more responsive to climate change than ice sheets and larger glaciers which have more thermal inertia (Benn and Evans, 2010; Raper, 1993). Furthermore, compared to polar ice masses, their temperature is relatively close to the melting point (Anderson et al., 2008). Research has tended to focus on Northern Hemisphere glaciers (e.g.Porter (1986); Maisch (2000); Zemp et al. (2009)). Of the 30 glaciers containing a continuous measurement record since 1976, only one of these glaciers is located in the Southern Hemisphere (Zemp et al., 2009). Furthermore, this glacier, located in the Northern Andes, is only $\sim 0.4 \mathrm{~km}^{2}$, compared to the average area of reference glaciers of $7.25 \mathrm{~km}^{2}$. One important region for studying Southern Hemisphere glaciers is the Southern Alps of New Zealand, which contains 3134 inventoried glaciers (Chinn et al., 2014). In particular, understanding the maritime glaciers of the Southern Alps is important due to the temperate and high precipitation climate of the area, and thus sensitivity of these glaciers (as a result of large accumulation rates and similarly large ablation rates), as well as the overall consensus that these glaciers are 
understudied (Zemp et al., 2015; Giesen and Oerlemans, 2013; Zemp et al., 2009). The high sensitivity of these glaciers mean that small perturbations in climate can produce measurable changes.

New Zealand glaciers contain an estimated total ice mass of 74.7 Gt (Radic et al., 2014) which equates to $\sim 0.21 \mathrm{~mm}$ sea level equivalent (Radić and Hock, 2010). The uncertainty of this estimate is $47 \%$ and is due to a limited number of glacier thickness measurements which are available to use for scaling purposes, and a similarly limited number of glacier-climate observations. Although this small estimated mass means that New Zealand glaciers will contribute a negligible amount towards sea level rise, New Zealand glaciers provide insights into the processes and dynamics of maritime glaciers in general. New Zealand glaciers are also important to monitor as they do not always follow the mass balance patterns of the Northern Hemisphere glaciers, as evidenced by a re-advance phase in the 1980s and 1990s (Zemp et al., 2015; Purdie et al., 2014; Mackintosh et al., 2017), as well as other older inconsistencies (Schaefer et al., 2009; Kaplan et al., 2010).

This study aims to use all available data to reconstruct the volume history of Brewster Glacier, a small maritime glacier located in the Southern Alps of New Zealand, over the period 1967 to 2017. While most mass balance records are recent, occurring in the last decade, and derived from satellite measurements only (Zemp et al., 2015; Vaughan et al., 2013a), this study will provide a framework in which we can compare rates of recent change with those further back in time. Additionally, this study provides the opportunity to acquire new measurements, such as global navigation satellite system (GNSS) datasets to map surface elevation, and radar datasets to construct a bed digital elevation model (DEM). This is important as a longer measurement record allows better identification of trends and anomalies (Zemp et al., 2015). The compilation of a comprehensive surface elevation dataset will allow a thorough comparison with other mass balance datasets of Brewster Glacier, and the climate record of nearby weather stations. This will ultimately provide a better understanding of glacier responses to climate in the Southern Alps, and contribute to mass balance records for glaciers in the Southern Hemisphere. 


\subsection{Overview}

Glaciers form when the climatic and geographic setting allows multi-year accumulation of snow. This snow metamorphoses and compacts into ice, and flows under the force of gravity to lower, warmer elevations. As changes to the geographic setting typically occur over geological time, decadal changes in glacier length, area, and volume are strongly linked to changes in climate (Zemp et al., 2015; Oerlemans, 2001; Vaughan et al., 2013a). This is because a glacier's change in mass is determined by the balance of inputs and outputs, both of which are functions of climate (Paterson, 1994b). Mass is added to a glacier, mainly as snow, and lost from a glacier, by calving or melting. The main climatic factors impacting mass changes of glaciers, are therefore precipitation and temperature. Subsequently, a well understood glacier can act as a calibrated instrument which gives insight into climate variability. Understanding of climate-glacier interactions is also important for extrapolating mass-balance models into the future to estimate the magnitude of sea level rise that glaciers may contribute towards (e.g. Gregory and Oerlemans (1998)). Mass balance records of glaciers are especially valuable when the glacier's energy balance is also well understood, as mass balance changes can then be interpreted in terms of material and energy inputs and outputs (Benn and Evans, 2010). In such a case, numerical mass balance/climate models can be tested and calibrated against past mass balance measurements, and the different climate parameters can be evaluated for relative importance.

\subsection{Processes of accumulation and ablation}

Accumulation is the addition of material to a glacier by way of avalanche, wind redistribution, rime formation, freezing of rain, and most commonly, snow (Paterson, 1994b). Due to the near-surface temperature dependency of snow/rain, snowfall is highly seasonal. The threshold at which precipitation falls as snow or rain tends to be slightly above zero due to precipitation rapidly falling from higher, colder elevations (Benn and Evans, 2014). Particularly high amounts of precipitation occur on the West Coast 
of the South Island, New Zealand, due to the combination of orographic uplift and frequent cyclonic weather systems (O'Hare et al., 1997). The amount of precipitation tends to vary with distance from the coast (Benn and Evans, 2010). For the Southern Alps, westerly winds prevail, and precipitation increases eastwards for a short distance, followed by a sudden decrease which tapers off towards the east (O'Hare et al., 1997). Snow delivered by avalanching or wind distribution can make up a large amount of a glacier's accumulation budget where a glacier is surrounded by steep topography, or in an area of low wind speed respectively (Dadic et al., 2010). Rime formation, another important accumulation process in cool, humid conditions, occurs when supercooled water droplets, transported by wind, freeze onto exposed surfaces (Loewe, 1938).

In general, snow metamorphoses into ice much more rapidly in temperate regions, than in cooler regions (Wakahama, 1968). This is because melt water percolates downwards and refreezes when the surrounding snow is below $0^{\circ} \mathrm{C}$, especially at night time when temperatures drop sufficiently (Wakahama, 1968). The intermediate step between snow and ice in a temperate setting is firn, defined by (Paterson, 1994b) as 'wetted snow that has survived one summer without being transformed to ice'. Firn becomes ice when all air passages between the grains no longer interconnect (Schwander et al., 1997), and further compaction of the ice results in compression of the trapped air bubbles and an increase in density (Shumskiy, 1960). The transformation of snow to ice changes the density from as little as $50-70 \mathrm{~kg} \mathrm{~m}^{-3}$ to $830-917 \mathrm{~kg} \mathrm{~m}^{-3}$ (Paterson, 1994a). Based on the processes of the snow-ice transformation, a number of different near surface facies may be present on a temperate glacier (Müller, 1962; Nolin and Payne, 2007) (Figure 1.2).

Ablation is the process of mass loss by melting followed by run-off, wind redistribution, sublimation, iceberg calving for water-terminating glaciers, and dry calving for land terminating glaciers (Benn and Evans, 2010). Of these, melting and calving are the most important processes in temperate environments (Benn and Evans, 2010). Ice melt is dependent on a number of energy fluxes. These fluxes are shortwave radiation, long wave radiation, sensible heat transfer, latent heat transfer, and energy acquired from rain (Benn and Evans, 2010). 


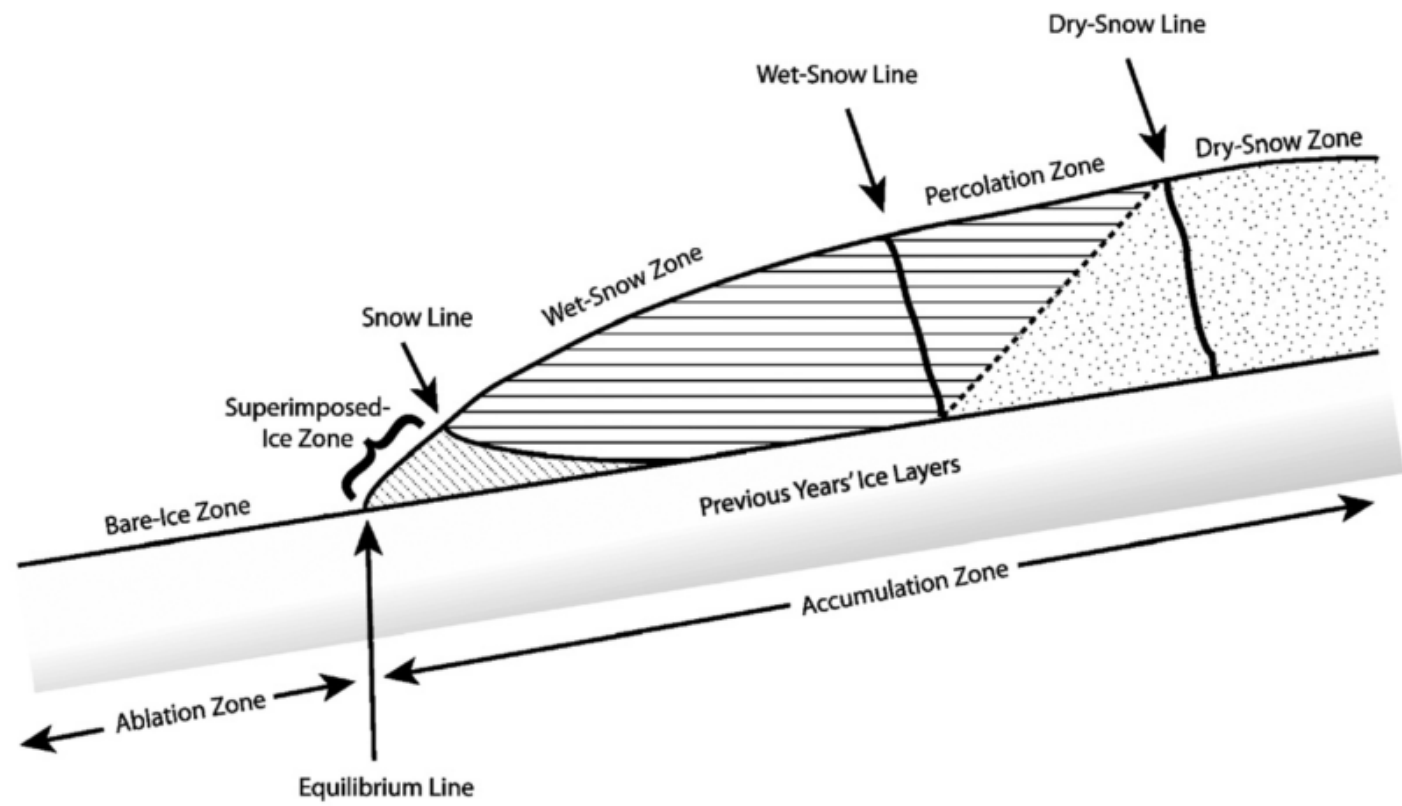

Figure 1.2: Glacier facies showing the transformation of snow to ice. Figure taken from Benn and Evans (2010), p.33.

\subsection{Mass balance}

The easiest way to assess climate records from glaciers is to measure the terminus position. This method however, gives a climate signal which represents an integral of previous climate, and is complicated by the varying hysteresis of glacier termini to climate changes (Chinn, 1995). Measuring the changes in mass balance of a glacier provides a more direct link between climate and glacier interaction (Chinn, 1995). Estimating the changes in mass balance of a glacier requires that the temporal and spatial change in the mass of a glacier be considered (Paterson, 1994b). These mass changes are primarily controlled by the accumulation, and the ablation of material, with a negligible contribution from flow changes. For land terminating glaciers, net balance at a point $\left(b_{n}\right)$ is the sum of accumulation $(c)$, and ablation $(a)$. This can be represented by Equation 1.1.

$$
b_{n}=c+a=\int_{t_{1}}^{t_{2}}(\dot{c}+\dot{a}) d t
$$




$$
b_{n}=c_{w}+a_{w}+c_{s}+a_{s}=\int_{t_{1}}^{t_{m}}(\dot{c}+\dot{a}) d t+\int_{t_{m}}^{t_{2}}(\dot{c}+\dot{a}) d t
$$

$c$ and $a$ are the integral of the accumulation rate $(\dot{c})$ and the ablation rate $(\dot{a})$ over a certain time period in water equivalent thickness units. The yearly net mass balance of a glacier is the yearly sum of both winter and summer accumulation $\left(c_{w}\right.$ and $\left.c_{s}\right)$, plus the respective winter and summer ablation $\left(a_{w}\right.$ and $\left.a_{s}\right)$ (Figure 1.3). Ideally, mass balance measurements should be calculated over a balance year, the time between two successive minima $\left(t_{1}\right.$ and $\left.t_{2}\right)$, centred around a maxima $\left(t_{m}\right)$ (Paterson, 1994b). A glacier can then be divided into two parts, depending on whether $b_{n}$ is greater or less than 0 . If, in a given location, $b_{n}$ is greater than zero over a given year, that location contributes to the accumulation area. Likewise, if $b_{n}$ is less than 0 , that location is part of the ablation area (Paterson, 1994b). The line separating the areas of net ablation and net accumulation is the equilibrium line, where $b_{n}=0$. So far, definitions have

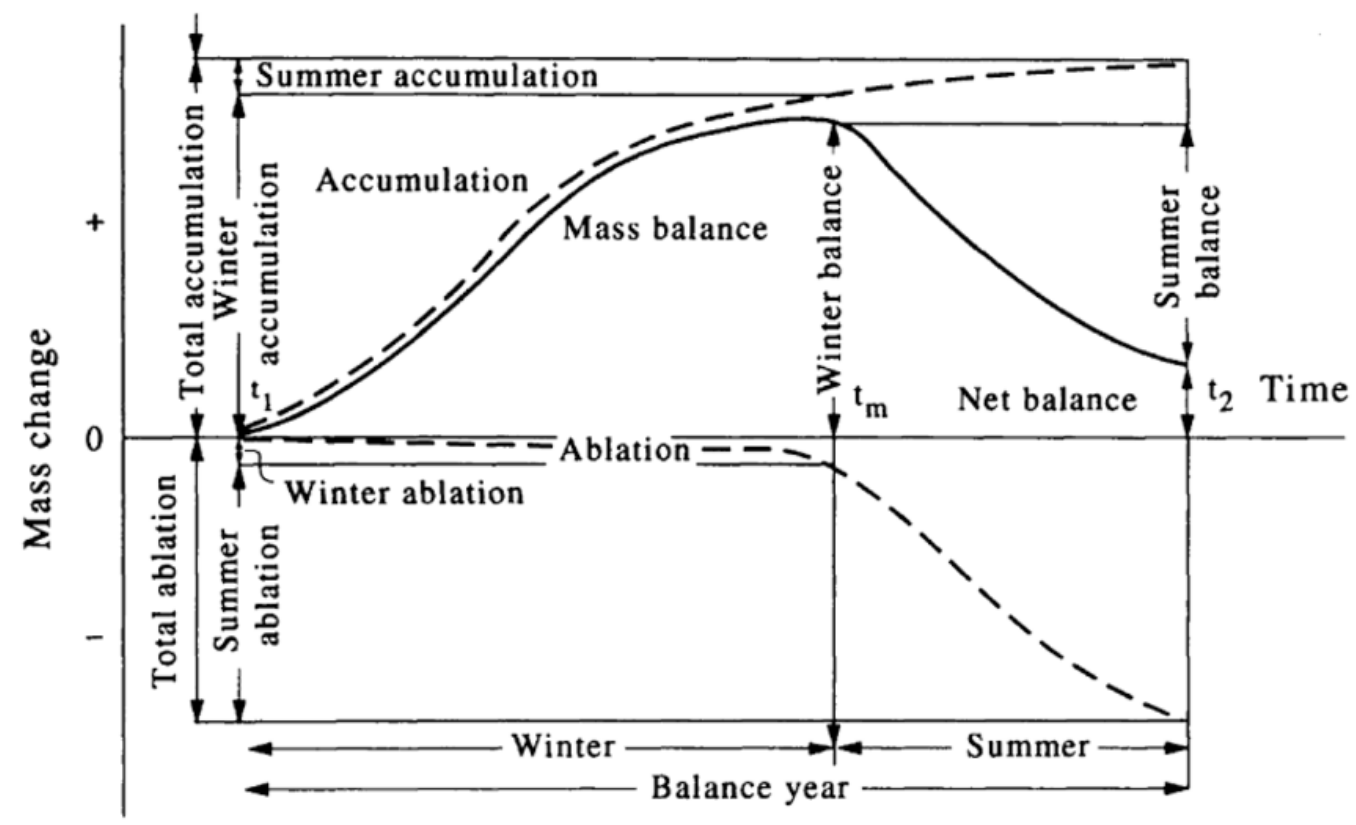

Figure 1.3: The yearly mass balance cycle and associated definitions (Cuffey and Paterson, 2010),p.100.

related to specific points on the glacier. For the net balance of an area $\left(B_{n}\right)$ (usually the entire glacier), one must multiply the area, $(S)$, by the average net balance of that 
area $\left(\overline{b_{n}}\right)$ as in Equation 1.2 (Benn and Evans, 2010; Paterson, 1994b).

$$
B_{n}=\overline{b_{n}} S
$$

In practice, it is logistically more convenient to use a measurement year instead of a balance year. The measurement year is defined by a fixed date which is chosen to closely approximate the balance year. Averaged over several years, the measurement year should closely match the balance year (Paterson, 1994b) .

\subsection{Mass balance measurement methods}

There are numerous ways to measure the mass balance of a glacier. Methods can be separated into geodetic, glaciological, hydrological, and the equilibrium line method. As a result of biases in the application of the different methods, as well as assumptions (such as density), there may be differences in the results obtained between the different methods. For example, it has been found that glaciological methods obtain measurements which tend to be more negative when compared to geodetic methods of the same area (Zemp et al., 2015). Marzeion et al. (2017) suggest that the difference between the direct observations (glaciological) and geodetic observations are because of a bias for glaciological observation methods being applied to glaciers where mass loss is more negative than the global mean. For New Zealand glaciers, the sample size is too small to compare values obtained from glaciological versus geodetic methods in great detail (Zemp et al., 2015). In the following subsection, the various methods are outlined.

\subsubsection{The geodetic method}

The geodetic method of mass balance measurement is the focus of this study. Geodetic methods use elevation surveys, satellite data, aerial photographs, or maps derived from aerial photographs to calculate changes in surface elevation and therefore changes in volume of glaciers (assuming negligible changes in bed elevation) (Benn and Evans, 
2010). Unlike the glaciological method described below, geodetic methods allow excellent measurement coverage as they do not necessarily rely on human access onto the glacier. Therefore, glacier records can be acquired over the whole glacier, and over a period that spans decades (Zemp et al., 2015). Recent advances in geodetic methods have enabled the construction of datasets for glaciers that previously had few or no records available (Cogley, 2009). This allows the volume changes to be estimated for under represented calving glaciers (Cogley, 2009). Unfortunately, geodetic methods generally do not distinguish between snow and ice making changes in mass difficult to estimate (Benn and Evans, 2010). Estimating changes in mass requires assumptions of density, which may vary depending on the glacier, and intervening time period (Huss, 2013). Another limiting factor of geodetic methods is the acquisition cost of aerial photographs. This means that photographs may be taken at sparse intervals, or even be non existent for certain glaciers. Older datasets may also have unquantifiable uncertainties (Benn and Evans, 2010). All orthophotographs must be ground truthed, and the accuracy of satellite imagery can be tested by comparing the known coordinates of stable terrain (e.g. rock outcrops) with those given by the image.

\subsubsection{The glaciological method}

The glaciological method (also known as direct measurement) for estimating massbalance is primarily based on stake and pit measurements. This in-situ method involves measuring the accumulation and ablation of snow, firn and ice (Zemp et al., 2015). To measure accumulation, the previous summer surface must be identified. This often manifests itself as a thin layer of dirty ice or by changes in density, hardness or grain size. The thickness and density of the annual accumulation must then be measured. To measure ablation, a stake measurement is used to measure the amount of ice lost. For pure volume changes, ice density is not required and both accumulation and ablation thicknesses can be measured by reference to stakes which are drilled into the ice (Paterson, 1994b). Glacier wide net balance is derived by a representative set of points. Points of equal net balance are then connected by contours, and interpolated across the glacier. Combined with an elevation dataset, information about mass balance/volume 
changes can then be derived as a function of varying elevation intervals, known as the mass balance gradient (Benn and Evans, 2010). The total net balance over the entire glacier $\left(B_{n}\right)$ can be defined by the sum of the net balance in each elevation interval $\left(b_{n i} \Delta S_{i}\right)$ as shown in Equation 1.3.

$$
B_{n}=\sum_{i} b_{n i} \Delta S_{i} \quad(\text { Cuffey and Paterson, 2010) }
$$

The disadvantage to this method is that only a limited number of points can be sampled. This is restricted by time and labour requirements, and difficulty of terrain such as in areas that are heavily crevassed or too steep for safe access.

In New Zealand, glaciological mass balance measurements have been made for Ivory Glacier between 1969 and 1975 (Anderton and Chinn, 1978), Rolleston glacier 2010 to the present (with additional measurements taken back to 2005 (Stumm, 2011; Purdie et al., 2015b)), and Brewster Glacier from 2004 to the present (Cullen et al., 2016) (which will be discussed in greater detail in Section 1.10). Glaciological measurements have also been made on parts of the Haupapa/Tasman Glacier (from 1965 to 1975, and 2004) (Chinn et al., 2005a; Anderton, 1975; Kirkbride, 1989; Purdie et al., 2011), Kā Roimata o Hine Hukatere/Franz Josef Glacier (Anderson and Mackintosh, 2012), and Te Moeka o Tuawe/Fox Glacier (Purdie et al., 2008), however the size of these glaciers prohibits a glacier-wide glaciological study.

\subsubsection{Hydrological method}

This method exploits the fact that the mass balance of a glacier is the change in the amount of water equivalent snow and ice volume being stored within the glacier (Janssen and Rizos, 2003; Kuhn, 2003). The change in the mass of a glacier, is therefore derived from measurements of stream discharge. For this method to be accurately applied, the precipitation, runoff, and evaporation must be easily quantifiable (Collins, 1984). Unfortunately, the difficulty in quantifying these factors accurately, especially for larger glaciers, inhibits this method for many applications. Additionally, high relative errors result due to the change in mass balance being calculated from the 
difference of large (precipitation and drainage) values (Hagg et al., 2004). Furthermore, the lack of a suitably long hydrological record for Brewster Glacier inhibits this method for this study.

\subsubsection{Equilibrium Line Altitude (ELA) method}

At the equilibrium line of a glacier, accumulation exactly equals ablation, and net balance is therefore zero (Benn and Evans, 2010). The altitude that this occurs at is called the equilibrium line altitude (ELA). the end of summer snow line is often used to represent the ELA, and Chinn (1995) (p.192) identifies this line as "the upper margin of a discoloured concentration of dust". Meier (1961) found that, upon a four year study on South Cascade Glacier in western Washington, curves of net budget as a function of altitude do not vary greatly in character from year to year. Meier (1961) deduced that it was possible to quantitatively predict the entire net budget of a glacier with knowledge of the ELA, and the net budget at a fixed location. To do this accurately, one also needs a topographic map of the glacier surface and knowledge of the net budget curve of the full altitudinal extent of the glacier (Meier, 1961). Annual ELAs have been measured in New Zealand with yearly aerial photographs for 47 index glaciers dating back to 1977 as part of the End of Summer Snowline (EoSS) surveys (Chinn, 1995). The EoSS programme attempts to obtain ELA positions from oblique aerial photographs taken at the end of each summer (March-April). During this time, glacier mass is assumed to be at a minimum and thus the altitude of the snowline is expected to be at a maximum (Chinn, 1995). To extend these measurements to obtain mass balance relies on the knowledge of the mass balance gradient, which is generally not known. A problem with the ELA mass balance method arises during particularly hot summers when there is no snow on the glacier at the end of summer, or when unseasonal early snow falls during image capture. 


\subsection{Glacier response to mass balance changes}

Following a change in climate, the glacier equilibrates asymptotically to the new conditions. The rate at which it equilibrates depends on the magnitude and duration of the change in climate (Vaughan et al., 2013a; Raper, 1993; Cuffey and Paterson, 2010), and the area-elevation distribution of the glacier (Cuffey and Paterson, 2010). Furthermore, there is non-linear relationship between climate and glacier mass. For example, in a study using a calibrated energy-balance model for Nigardsbreen, a maritime glacier in Norway, Oerlemans (1992) predicted that the glacier would retreat by up to $6.5 \mathrm{~km}$ over 200 years for a temperature increase of $1^{\circ} \mathrm{C}$, with approximately half of this retreat attained within 50 years. The same glacier would only advance $3 \mathrm{~km}$ for a temperature decrease of the same magnitude. Such a non-linear response is partly attributed to the area-elevation distribution, where a large proportion of the glacier is centred around the equilibrium line (Oerlemans, 2001).

\subsection{Factors which affect glacier behavior}

The varying physical characteristics of glaciers and their surrounding environments lead to vastly different responses of glaciers throughout the world. Within the North Cascades National Park Complex (USA), Granshaw and Fountain (2006), estimated area and volume change (using area-volume relationships) of 321 glaciers for the time periods 1958, and 1998. They found that a large number of glaciers show varying volume and area changes with $79 \%$ of glaciers decreasing in area, $19 \%$ remaining the same size, while the remaining $2 \%$ glaciers that increased in area, were at higher elevations. Varying area and volume changes of glaciers within close proximity is thought to be due to differences in the volume (Granshaw and Fountain, 2006), surface gradient (Cuffey and Paterson, 2010), the proportion and thickness of debris (Kayastha et al., 2000), the presence or absence of a proglacial lake (Salinger et al., 2008), the aspect of the glacier (Benn and Evans, 2010), and local micro climates (Oerlemans, 2010).

The two glacier attributes that can most profoundly alter glacier response to forcing 
are debris cover and proglacial lake development/calving. Debris cover complicates the response of glaciers to climate change by either enhancing melt rates for thin debris cover, or reducing it in the case of thick debris cover. Additionally, the effect of debris cover with varying thickness is non-linear (Östrem, 1959; Kayastha et al., 2000; Brook and Paine, 2012). The reason for this non-linear relationship is twofold. Firstly, when thick enough, debris has the effect of thermally insulating glacial ice, and acting as a thermal barrier between ice and the atmosphere (Nakawo and Young, 1981; Mattson, 1993). Secondly, debris cover absorbs shortwave radiation due to its decreased albedo, and can therefore increase the rate of ablation. The point at which the insulating effect dominates over the absorption effect has been measured to be approximately $3 \mathrm{~cm}$ (Brook and Paine, 2011). In practice, debris thickness and thus insulation increase towards the terminus of the glacier as more englacial debris is exhumed (Kirkbride, 1989). In a study comparing the effects of numerous topographic and climatic variables for the glaciers of the Southern Alps of New Zealand, Anderson and Mackintosh (2012) found that the only topographic effect directly related to glacier sensitivity, relative to either temperature or precipitation changes, was the presence of debris $\left(R^{2}=0.5\right.$ and 0.43 respectively), with the presence of debris reducing the glaciers sensitivity to both changes in temperature and precipitation. Worldwide observations have shown an increase in glacial surface area covered by debris (Bolch et al., 2008; Basnett et al., 2013). Furthermore, Anderson and Mackintosh (2012), point out that previous estimates of glacier sensitivity to climate do not take into account the effects of debris. This is particularly important for the Southern Alps of New Zealand, where debris covers a substantial proportion of glaciated area (Chinn, 1996).

Another important factor for glacier mass balance is the presence or absence of supraglacial and proglacial lakes. Supraglacial lakes form from the accumulation of surface melt and/or the collapse of englacial conduits (Kirkbride and Warren, 1999). During progressive growth of the supraglacial lakes, ice walls free of debris become exposed, thus causing an increase in ablation. This can lead to the eventual destruction of the glacier terminus, and formation of a proglacial lake, confined by lateral and terminal moraines (Basnett et al., 2013). The initiation of calving represents a threshold 
where topography, as well as climate, becomes a strong control on terminus position (Kirkbride, 1993). This has lead to the rapid terminus retreat of many New Zealand glaciers such as Mueller, Tasman, Hooker, and Murchison glaciers (Kirkbride, 1993).

\subsection{Worldwide glacier records}

Worldwide glacier records have shown a global trend of glacier retreat since the Little Ice Age (LIA) (Zemp et al., 2015). This trend is punctuated by intermittent terminus readvances in places such as New Zealand (Purdie et al., 2014), and Scandinavia (Andreassen et al., 2005), where relatively short, decadal response times are common. The overall global mass balance trend since the LIA can be summarised by; ice loses of a few decimetres w.e. $\mathrm{a}^{-1}$ between 1850-1900, ice loses of 0.4 m.w.e. $\mathrm{a}^{-1}$ between 1940 and 1980, and an increased rate of ice loss to $>0.5$ m.w.e. $\mathrm{a}^{-1}$ during the period 2000-2010 (Zemp et al., 2015). Figure 1.1 shows that there is generally good agreement between different studies of the contribution to sea level rise of glaciers, particularly from the period 1960 to present. This is a result of increased data availability, and advances in methodology and methodology consistency (Marzeion et al., 2017).

\subsection{The response of New Zealand glaciers to changes in climate}

New Zealand glacier records date back to the early 1860s for Haupapa/Tasman Glacier (Brodrick, 1891; Haast, 1864), followed a few years later by Te Moeka o Tuawe/Fox and Kā Roimata o Hine Hukatere/Franz Josef Glaciers (Harper, 1896). Haast (1864) explored, made sketches and wrote detailed notes on many of New Zealand's glaciers in the 1860s including the Ashburton, Mueller, Classen, Godley, and Murchison glaciers. Many of these glaciers were also photographed by Edward Percy Sealy during expeditions in 1867 and 1870 (Harper, 1893). Gellatly (1985), used these historical accounts in order to reconstruct a glacier length history for the six main glaciers of the Ao- 
raki/Mt Cook region from 1862 to 1985 . From this, it was concluded that a glacial advance reached its maximum in the 1860 s, followed by recession until the mid 1880 s, after which some small glaciers advanced, while the large glaciers continued to retreat. A period of stability ensued from 1905 to 1940, after which widespread retreat occurred up until the publication of the study.

Strong differences in length histories between glaciers have been found in New Zealand. For example, the widely studied Te Moeka o Tuawe/Fox and Kā Roimata o Hine Hukatere/Franz Josef glaciers have retreated by 2.8 and $2.5 \mathrm{~km}$ respectively between 1890 to 2014, punctuated by relatively short lived advances (Purdie et al., 2014). In comparison Haupapa/Tasman Glacier's terminus position has changed very little from its LIA position until the 1980s (Dykes et al., 2010). Instead, ablation of the lower tongue decreased the surface gradient of Haupapa/Tasman Glacier by $2^{\circ}$ (Dykes et al., 2010), providing the ideal preconditions for lake formation, and thus, subsequent rapid terminus retreat at an average rate of $\sim 140 \mathrm{ma}^{-1}$, and at rates of up to $300 \mathrm{ma}^{-1}$ since lake formation (Purdie et al., 2016).

New Zealand glacier length records are also, at times, inconsistent with the global record. Mackintosh et al. (2017) details a glacial advance period of at least 58 New Zealand glaciers, including Te Moeka o Tuawe/Fox and Kā Roimata o Hine Hukatere/Franz Josef Glaciers, which show a nearly continuous advance between 1983 to 2008. In addition to these recent records, New Zealand moraine records extend glacier records into the Quaternary (e.g. Suggate (1990)). One such study found that by dating a number of moraines using ${ }^{10} \mathrm{Be}$ exposure dating for Haupapa/Tasman, Mueller and Hooker Glaciers, there had been at least 15 advance pulses during the last 6500 years (Schaefer et al., 2009). The timing of these advances are important, as they are not synchronous with the Northern Hemisphere record, suggesting differences between the Hemispheres (Schaefer et al., 2009). Moreover, these studies highlight the importance of Southern Hemisphere, and more specifically New Zealand climate records (Anderson and Mackintosh, 2012; Chinn et al., 2012). In a study which compared the mass balance of Kā Roimata o Hine Hukatere/Franz Josef glacier to temperature and precipitation, Anderson and Mackintosh (2006) found that temperature ( $\mathrm{r}=0.86)$ is a stronger control 
on mass balance than precipitation $(\mathrm{r}=0.41)$. Similar results have been attained for other New Zealand Glaciers such as Brewster Glacier (Anderson et al., 2010), Te Wae Wae Glacier (Stocking Glacier) (Salinger et al., 1983), and Haupapa/Tasman Glacier (Purdie et al., 2011). This is important as glacial advance periods within New Zealand have shown strong correlations with regional cooling (Gellatly, 1985; Mackintosh et al., 2017).

Because of the variability of New Zealand Glaciers, detailed records of individual glaciers are highly valuable. A detailed photographic record of 47 glaciers in the South Island, dating back to 1977, is available as a result of the EoSS programme (Chinn et al., 2005b). This record consists of annual aerial photographs taken of each index glacier with the goal of assessing the ELA (Chinn et al., 2005b). In a report comparing the correlation of ELAs of individual glaciers to the average E0SS ELA record of the Southern Alps between 1977 to 2014, Willsman et al. (2015), found that correlations varied between correlation coefficients of 0.67 (Snowy Ck) to 0.93 (Barrier Pk). One such glacier is Brewster Glacier, with a correlation coefficient of 0.83 , which suggests that the ELA of this glacier is representative of Southern Alps glaciers.

\subsection{Brewster Glacier}

Brewster Glacier is a temperate glacier located in the north of Mt Aspiring National Park, in the Southern Alps, New Zealand (lat. $44^{\circ} 05$ S, long. $169^{\circ} 27 \mathrm{E}$.). The glacier flanks the south to southwest face of Mt Brewster, flowing for approximately $2 \mathrm{~km}$ before terminating above two small lakes (Figure 1.4). The bedrock of the area is schist, which has been carved into glacial geomorphic features such as roches moutonées, whalebacks, and drumlins. The mean monthly temperatures ranges from $-2.6^{\circ} \mathrm{C}$ in July to $5.1^{\circ} \mathrm{C}$ in February, with a mean annual temperature of $1.2^{\circ} \mathrm{C}$ (Cullen and Conway, 2015). The lower part of the glacier receives $\sim 6 \mathrm{~m}$ of precipitation of which it is estimated that $\sim 42 \%$ falls as snow (Cullen and Conway, 2015). Brewster Glacier is easily accessible via a four hour walk from Haast Pass. This, coupled with the relatively small surface area of approximately $2 \mathrm{~km}^{2}$ and the traversable nature as a result of the 


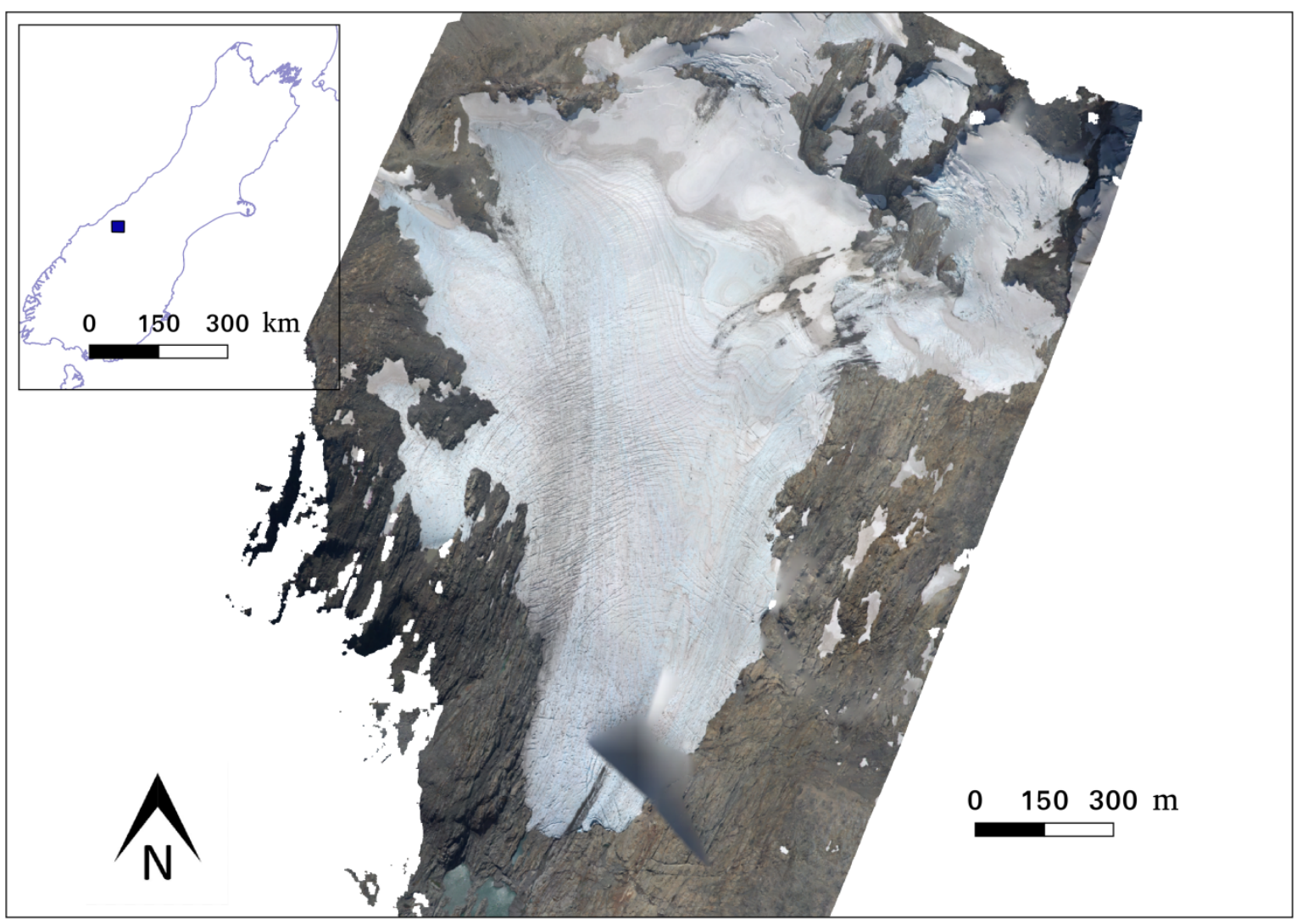

Figure 1.4: Brewster Glacier (inset showing location). Image derived from a Structure from Motion model (2016).

low surface gradient which prevails over $\sim 80 \%$ of the surface (Figure E.7 in Appendix E), makes Brewster Glacier ideal for field studies. As such, Brewster Glacier is among New Zealand's best studied glaciers, with biannual glaciological and geodetic surveys carried out since 2004 and 2007. As well as this, oblique aerial photographs exist since 1978 as part of the EoSS programme (Chinn et al., 2005b). Previous studies of Brewster Glacier include observations of ice-climate interactions (Anderson et al., 2010; Gillett and Cullen, 2011; Conway et al., 2015), subglacial drainage systems (Willis et al., 2009), and both geodetic and glaciological mass balance (Willis et al., 2012; Cullen et al., 2016). By both drawing from the results of such an abundance of studies, and using 4 different datasets in this study (topographic maps, Shuttle Radar Topography Mission, GNSS and SfM), the changes of Brewster Glacier can be evaluated using a more holistic approach than for studies of other lesser studied glaciers, where only one method is used. 


\subsubsection{Previous research on Brewster Glacier}

As part of a study to assess the subglacial drainage system of Brewster Glacier, Willis et al. (2009) used ground penetrating radar (GPR) data collected in 1997 in order to construct a bed DEM. This GPR data consists of six transverse profiles which run parallel to one another, separated by $\sim 200$ to $500 \mathrm{~m}$. At the same time, a GNSS survey of the glacier surface was also carried out. The bed and surface DEMs were made using the triangular interpolation network (TIN) method. Both dye tracing and a hydraulic potential model were used to investigate the nature of subglacial water flow throughout the summer melt season. They concluded that a complex drainage system was present, which evolved through time from a high pressure system in early summer, to a lower pressure system later in the melt season. The GPR and GNSS data, acquired in January 1997, will be used in this study to supplement other such data.

Using the same GPR and GNSS datasets as Willis et al. (2009), unpublished work by Willis et al. (2012) produced surface DEMs from a topographic map (1986) and another GNSS survey acquired in 2005 (Figure 1.5). They found that Brewster Glacier underwent a positive mass balance change from $1986\left(\sim 0.125 \mathrm{~km}^{3}\right)$ to $1997(\sim 0.140$ $\left.\mathrm{km}^{3}\right)$, and a negative mass balance change from 1997 to $2005\left(\sim 0.123 \mathrm{~km}^{3}\right)$. From
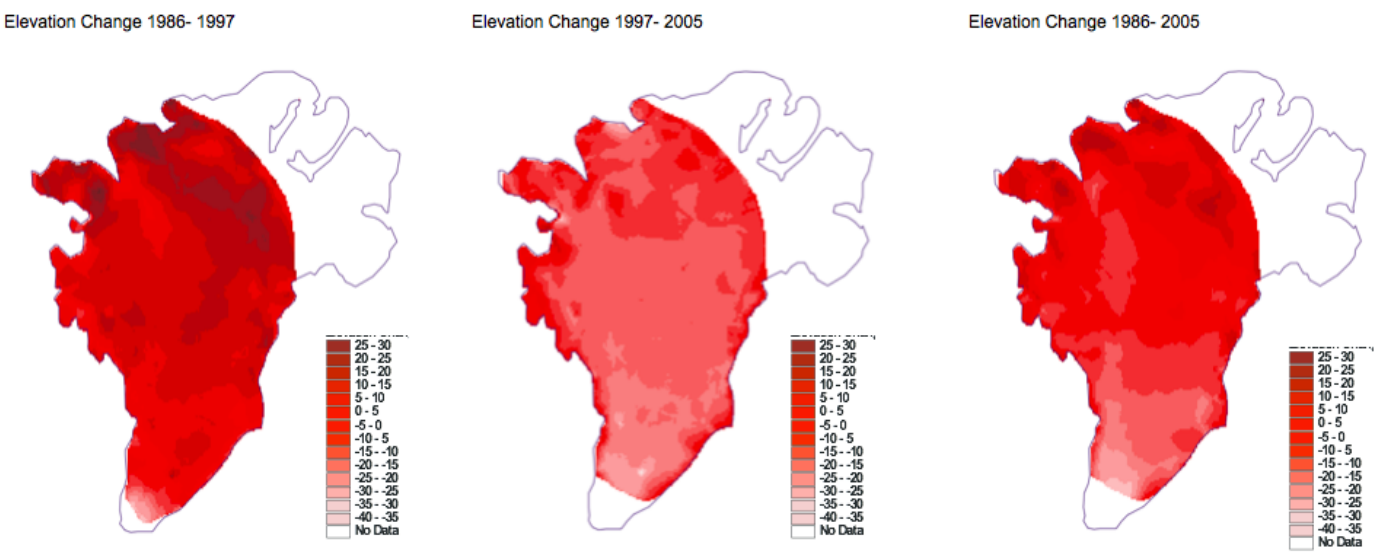

Figure 1.5: Results of a mass balance study by Willis et al., personal communication, 2016. 
this result, they concluded that there was an overall negative net balance from the period 1986 to 2005 of $\sim 0.002 \mathrm{~km}^{3}$. In addition to the datasets used by Willis et al. (2012), biannual GNSS datasets exist from 2007 to the present. This study will use these datasets to significantly improve on these results in both the temporal and spatial domain.

As well as having an extensive geodetic dataset, Brewster Glacier has the longest continuous glaciological mass balance record of any glacier in New Zealand. To measure ablation, a comprehensive stake network has been maintained on the glacier from February 2004 until the present. From 2004 to 2008, this network consisted of 33 stakes, 19 of which extended up the centre of the glacier from 1650 to 1950 m.a.s.l, the remainder of which followed four transverse profiles of between two to four stakes (Anderson et al., 2010). The network was reduced to 15 stakes in 2008 for logistical reasons (Cullen et al., 2016). Accumulation is measured from snow probing and snow pits, the latter of which density can be measured (Anderson et al., 2010). Cullen et al. (2016) created a mass balance time series by using 11 years of the glaciological record. Differences in spatial density through time were partially accounted for by the use of co-kriging, a geostatistical method which uses covariance between two variables as an estimator for winter balance (covariance between elevation and snow depth) and summer balance (covariance between snow depth and summer ablation). From the observational data, they saw sufficient multi-year similarity in the spatial patterns of both winter and summer balance, which justified using this approach. They found that over the period of 2005-15, the average balances were 2484 (winter), -2586 (summer), and -102 (annual) mm w.e. They found a strong relationship between summer balance and annual balance $\left(R^{2}=0.87\right.$ at the $95 \%$ confidence interval) suggesting that summer balance is the dominant control of yearly net balance. They noted that improvements to their mass balance record could be achieved with validation from a geodetic-derived mass balance record.

Brewster Glacier, along with Rolleston Glacier, are New Zealand's only glaciers where biannual mass balance measurements are reported to the World Glacier Monitoring Service (WGMS). Mass balance measurements of Brewster Glacier have been 
reported to the WGMS since 2004 (as well as a non continuous measurement record prior to 2004). The rarity of long mass balance records in New Zealand, and more broadly, the Southern Hemisphere, makes this record highly valuable. Furthermore, GNSS surveys carried out since 1997, as well two topographic maps which document surface elevation change, which means that this record can be extended to 1967 using geodetic methods. Understanding and quantifying mass balance changes of Brewster Glacier during the last 50 years has the potential of contributing to the understanding of responses of similar glaciers throughout the world.

\subsubsection{Study objectives}

The overarching goal of this study is to create a geodetic volume record for Brewster Glacier between the years 1967 and 2017 using all available data. The high temporal and spatial resolution of this study extends beyond both the glaciological mass balance record, and the EoSS record. A glacier length record is also compiled, which provides a dataset to assess changes in climate and the reaction time of Brewster Glacier. The study objectives can be split into data objectives and research investigations.

\subsubsection{Data objectives}

A surface elevation time series is created using all surface elevation datasets available from 1967 - 2017, including topographic maps, GNSS and satellite data, and Structure from Motion (SfM) (a photogrammetric technique). A bed DEM is constructed using GPR, as well as stable terrain DEMs of areas which were previously covered by ice. From the bed DEM and the surface elevation time series, a volume time series is made. To construct a terminus position and area time series, satellite and GNSS data, as well as topographic maps, and orthophotographs is used. By using geodetic data, the mass balance record can be extended further back in time than by using other, more temporally limited methods. 


\subsubsection{Research investigations}

Using the data products mentioned above, the following investigations are made:

- Comparison of the volume change record. How does the volume change record from Brewster Glacier compare with the direct mass balance record?

- Explore volume/length relationships. What is the relationship between glacier volume, and length change?

- Glacier length/climate interaction What can the Brewster Glacier length record tell us about climate?

- Comparison of Brewster Glacier length changes with the wider New Zealand glacier length record. How does Brewster Glacier's length changes compare with other New Zealand glaciers? 


\section{Methods}

In order to create a time series of volume change, this study incorporates a variety of datasets. These datasets can be separated into three groups - surface, bed, and perimeter (Table 2.1). The surface datasets gives information on time-dependent distributed surface elevation change. The bed datasets are stationary in time. Finally, the perimeter/terminus datasets are time-varying and are used to calculate area and terminus position. All three datasets are required to calculate glacier volume, and in order to do this, the bed DEM is subtracted from a surface DEM. Although the bed and surface DEMs should be the same elevation outside of the glacier area, this is not always the case due to measurement/interpolation errors (mainly for the surface DEM). The glacier thickness is therefore clipped by the appropriate perimeter polygon in order to exclude volume errors from outside of the glacier area. Glacier volume is then calculated by multiplying the mean glacier thickness by the area of the glacier. This chapter describes all processing steps for all datasets.

\begin{tabular}{|l|}
\hline Surface datasets \\
\hline Structure from Motion DEM \\
\hline Topographic maps (NZMS \& NZTopo) \\
\hline Shuttle Radar Topography Mission (SRTM) \\
\hline Global Navigation Satellite System (GNSS) \\
\hline Bed datasets \\
\hline Ground Penetrating Radar (GPR) \\
\hline Stable terrain from DEMs \\
\hline Perimeter/terminus datasets \\
\hline Structure from Motion orthophotograph \\
\hline Landsat \\
\hline Topographic maps (NZMS \& NZTopo) \\
\hline Global Navigation Satellite System (GNSS) \\
\hline
\end{tabular}

Table 2.1: Datasets used in this study. 


\subsection{Glacier surface}

Surface elevation changes are the product of accumulation and ablation, as well as glacier flow (Hooke, 2005), and are of uppermost importance for studying volume change. To create a surface elevation time series, a number of different data types are used (Table 2.2). Processing of glacier surface datasets is done using the following steps:

1. Interpolation of point elevation data to gridded (raster) data (if required)

2. Spatial interpolation of (if required)

3. Bias correction (if required)

\section{Uncertainty estimation}

Vertical datums describe the shape of a surface at which the elevation is zero. These surfaces can vary by several metres within the study area. This project uses datasets which are referenced to a number of different vertical datums (Table 2.2). If ignored, these differences could lead to large errors in DEM elevation, and thus volume estimates. If required, vertical measurements were processed in order to be referenced to the GRS80 ellipsoid ${ }^{1}$. Rasterisation is the process of converting vector data (such as GNSS point elevations) to gridded raster data, and this is necessary for discrete elevation measurements such as foot survey GNSS data. As a raster represents a continuous surface, and GNSS data represent discrete points, a spatial interpolation technique must be employed. Bias correction applies for datasets already in raster format, and is determined by an analysis of the difference between the portion of the raster representing stable terrain, and an accurate DEM of stable terrain (discussed in Subsection 2.3). The bias will typically be represented by a normal distribution, from which the mean is interpreted as the bias. The error uncertainty for raster datasets is taken as the standard deviation of this normal distribution. For GNSS data and

\footnotetext{
${ }^{1}$ In this study, the WGS84 and the GRS80 ellipsoids are treated as equal. The only difference between these two ellipsoids is a difference of inverse flattening of $1.4 \times 10^{-6}$ resulting in a difference in the semi-minor axis of $0.1 \mathrm{~mm}$
} 
interpolated datasets, uncertainty is dependent on the measurement error, spatial continuity of the data, interpolation and is discussed in Section 2.2. In the following, datasets are described in chronological order.

\begin{tabular}{|c|c|l|l|l|}
\hline Dataset & Data type & Resolution & accuracy (m) & Vertical datum \\
1967 & NZMS & $1 \mathrm{~m}$ & 27.6 & Mean sea level \\
January 1997 & NZDEM_SoS_v1.0 & $15 \mathrm{~m}$ & 9.16 & NZVD2009 \\
February 2000 & GNSS & - & 6.4 & GRS80 \\
February 2005 & SRTM & $30 \mathrm{~m}$ & 7.59 & EGM96 \\
November 2007 & GNSS & - & 7.2 & GRS80 \\
January 2008 & GNSS & - & 3.3 & International 1924 \\
April 2008 & GNSS & - & 3.3 & International 1924 \\
November 2008 & GNSS & - & 3.3 & International 1924 \\
March 2009 & GNSS & - & 3.3 & International 1924 \\
November 2009 & GNSS & - & 3.3 & EGM96 \\
March 2010 & GNSS & - & 3.3 & EGM96 \\
October 2010 & GNSS & - & 3.3 & EGM96 \\
March 2011 & GNSS & - & 3.3 & GRS80 \\
November 2011 & GNSS & - & 3.3 & GRS80 \\
March 2012 & GNSS & - & 3.3 & GRS80 \\
October 2012 & GNSS & - & 3.3 & International 1924 \\
March 2013 & GNSS & - & 3.3 & GRS80 \\
November 2013 & GNSS & - & 3.3 & GRS80 \\
April 2014 & GNSS & - & 3.3 & GRS80 \\
December 2014 & GNSS & - & 3.3 & GRS80 \\
March 2015 & GNSS & - & 3.3 & GRS80 \\
March 2015 & SfM & 0.5 & 3.3 & GRS80 \\
March 2016 & GNSS & - & 2.59 & GRS80 \\
March 2016 & SfM & 0.5 & 3.3 & GRS80 \\
November 2016 & GNSS & - & 0.42 & GRS80 \\
March 2017 & SfM & 0.5 & 3.3 & GRS80 \\
\hline
\end{tabular}

Table 2.2: Surface datasets through time. The vertical resolution of the NZMS and NZTopo (from which the NZDEM_sos_v1.0 is based from) is $100 \mathrm{ft}$ and $20 \mathrm{~m}$ vertically. Accuracy is in terms of the vertical and is taken as one standard deviation of the error distribution histogram. Cokriging errors are one standard error.

\subsubsection{New Zealand Map Series Topographic map (NZMS)}

NZMS topographic maps are based on aerial photographs taken in 1966 and 1968 as well as a field check in January 1970. This dataset is therefore assigned the date of 1967. NZMS is at a scale of 1:63360, and has a contour interval of $100 \mathrm{ft}(30.5 \mathrm{~m})$. In order to convert this map to a raster DEM, contours were manually digitised by the 
author, then converted the vector contours to a $0.5 \mathrm{~m}$ resolution raster by triangular interpolation. NZMS is referenced to the International 1924 ellipsoid, but uses local mean sea level as the vertical datum. In order to convert the vertical datum to GRS80, a vector conversion grid of mean sea level in Lyttelton between 1918 and 1933 (this is the closest tide gauge to the study area), and the GRS80 ellipsoid was downloaded from the LINZ data service (LINZ, 2017). The offsets between the two datums ranged from 9.91 to $9.96 \mathrm{~m}$. This grid was then converted to raster, and added onto the NZMS raster DEM prior to the surface being used for analysis.

\subsubsection{NZTopo topographic map}

NZTopo maps are derived from aerial photographs taken in 1986, and are stereoscopically projected at a scale of 1:50,000. Here we use a 15 m DEM (NZDEM_SoS_v1.0) (Columbus et al., 2011), derived from digitised contours from the NZTopo map. This DEM was created by the use of ANUDEM interpolation, a hydrologically correct technique which incorporates data points by use of a 2D thin plate smoothing spline (Columbus et al., 2011). This DEM is referenced to NZVD2009. In order to reference vertical elevations to GRS80, an array of points with $25 \mathrm{~m}$ spacing were entered into the LINZ coordinate conversion tool (LINZ, 2016). The resulting output was converted to a raster to give the difference between the NZVD2009 vertical datum and the GRS80 ellipsoid. The offsets between the two datums ranged from 10.53 to 10.62 m over the study area. This raster was then added onto the NZDEM_SoS_v1.0 DEM before the surface was used for analysis.

\subsubsection{Shuttle Radar Topography Mission (SRTM)}

The Shuttle Radar Topography Mission (SRTM) produced a DEM which covers $90 \%$ of Earth's land surface. This was accomplished by using shuttle-mounted single-pass Synthetic Aperture Radar (SAR) interferometry over an 11-day timespan in February, 2000 (Van Zyl, 2001). SAR works by taking two images at slightly different elevations accomplished in the case of SRTM by a $60 \mathrm{~m}$ boom (Van Zyl, 2001). Single pass 
SAR denotes that the two images were taken (at known locations) at the same time (Van Zyl, 2001). Topography is deciphered using the phase difference of the returning radar signal (Van Zyl, 2001). SRTM heights are referenced to the EGM96 geoid. A $30 \mathrm{~m}$ spaced array of points was entered into the UNAVCO geoid height calculator (UNAVCO, 2017). The output of this was converted into a raster file and added to the SRTM raster layer.

\subsubsection{ASTER GDEM Version 2}

ASTER GDEM is a global DEM constructed using stereo imaging techniques from multiple images dated between 2000 and 2010 (Tachikawa et al., 2011). Due to cloud cover, various parts of the glacier have been imaged more frequently than other parts. This has resulted in an undulating surface as an artifact of differential image averaging (Figure C.21). This ASTER DEM also represents a temporally averaged DEM over the image acquisition period (Frey and Paul, 2012). As the image timestamps are unknown, and are not equal over the entire glacier, both the time and elevation accuracy must be treated with caution. For this reason, ASTER GDEM Version 2 is omitted from further analysis.

\subsubsection{Global Navigation Satellite System (GNSS)}

The Global Navigation Satellite System (GNSS) is a geolocation technique which utilises binary signals sent in the form of radio frequency carrier waves from 4 or more satellites of known location (Blewitt, 1997). The technique is based on trilateration, whereby the distance from the satellite to the receiver is given by the pseudorange. The pseudorange is calculated by the time difference between transmission of the signal (based on satellite atomic clock time communicated through the carrier signal) and the time of signal retrieval, multiplied by the speed of light (Leick et al., 2015). Receiver clock error is the main source of inaccuracy in the technique, but can be solved through the use of 4 or more satellite receiver functions to reduce this error to approximately $5 \mathrm{~m}$ for single frequency GNSS (Leick et al., 2015) (e.g. hand held GNSS receivers). 
Added precision is available through the use of post processed kinematic (PPK) dual frequency GNSS. Rather than using time delays of binary signals, the dual frequency method uses phase shifts from the carrier wave. The carrier wave is transmitted at 1575.42 MHz, corresponding to a wavelength of $19 \mathrm{~cm}$. By comparing the signal received by a base station and the same signal received by the rover, it is possible to compute positions to up to $\sim 4.3 \mathrm{~cm}$ accuracy (RMS error) (Lee et al., 2017).

All GNSS data acquired before 2016 had already been processed into a usable format using the PPK method. For subsequent datasets, the raw files were converted to RINEX using the UNAVCO Teqc software (Estey and Weir, 2014), then processed using the precise point positioning (PPP) tool on the Natural Resources Canada website (NRCan, 2016). PPP is a technique whereby receiver and transmitter parameters, such as the orbits of GNSS satellites and satellite clocks, are estimated from a globally distributed network of receivers (Zumberge et al., 1997). GNSS tracks can be viewed in Appendix C. A number of earlier GNSS datasets were saved relative to the NZGD1949 reference system, which uses the International 1924 ellipsoid as the vertical datum. These were converted to NZGD2000 (which is referenced to the GRS80 ellipsoid) using the LINZ online coordinate conversion tool (LINZ, 2016). The method of spatial interpolation of GNSS data will be described in Section 2.2.

\subsubsection{Structure from Motion (SfM)}

Structure from Motion (SfM) is a low cost photogrammetric technique whereby a high resolution DEM is constructed from multiple overlapping images (Koenderink and Van Doorn, 1991). The technique is similar to stereoscopic photogrammetry, relying on algorithms to match features in aerial photographs which are taken from different angles (Figure 2.1) (Westoby et al., 2012). The technique differs from ordinary stereoscopic photogrammetry in that multiple images are used as opposed to only 2 images (Westoby et al., 2012). Furthermore, parameters such as camera orientation and position are solved automatically during image processing (Westoby et al., 2012). If the constituent images contain no camera position coordinates, the 3D model is created in a model coordinate system and scale. A 'real world' coordinate system and scale can 


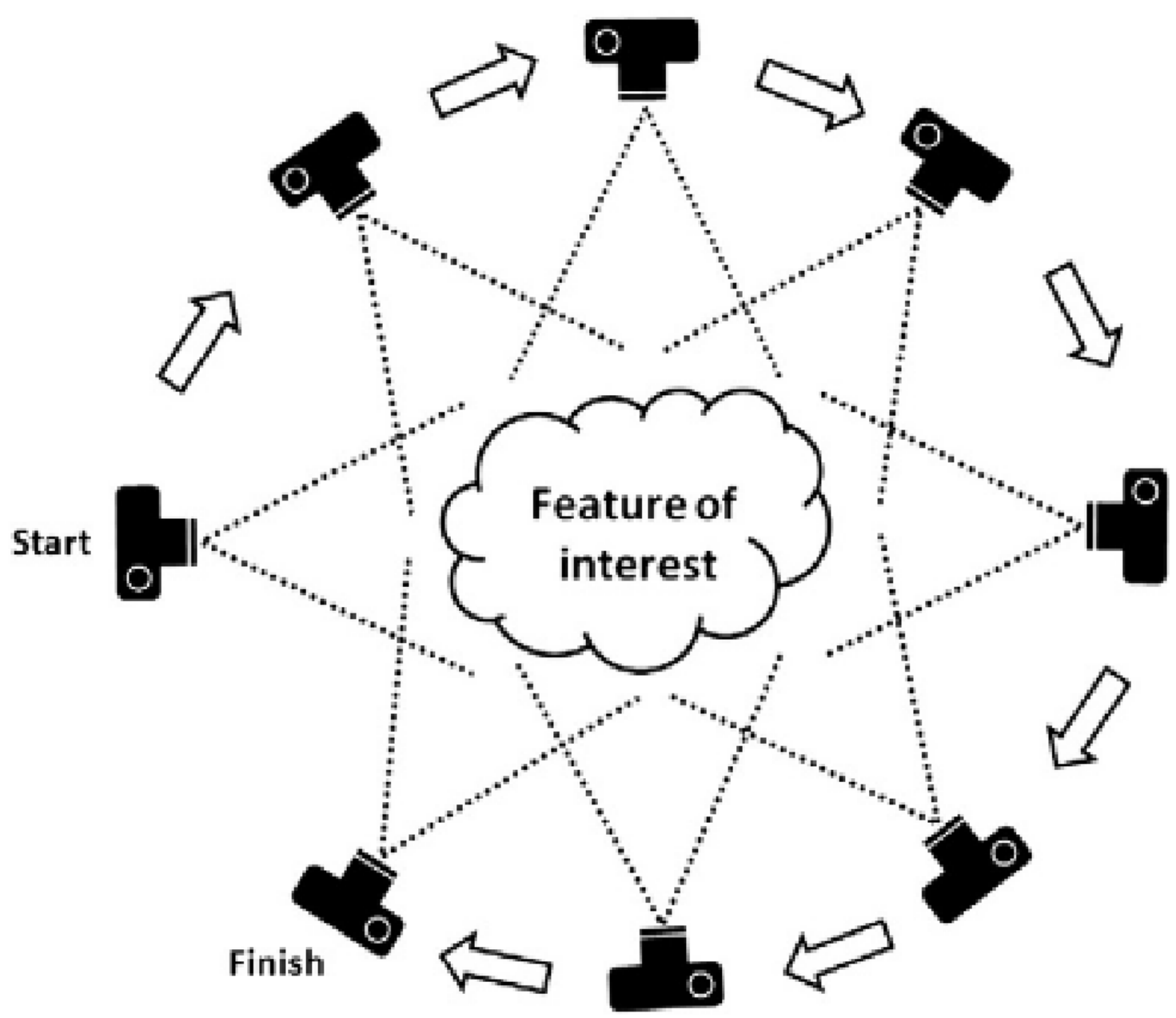

Figure 2.1: SfM uses feature matching on multiple overlapping images of an area of interest in order to create a 3D image. Figure taken from Westoby et al. (2012), p.301.

be assigned to the 3D image by the use of ground control points (GCPs) obtained from easily identifiable features within the 3D image (Westoby et al., 2012), or with knowledge of camera positions (Koenderink and Van Doorn, 1991). The SfM technique has been in use since the 1990s, however it is considered under-utilised in the geoscience field (Westoby et al., 2012). Nevertheless, SfM has been used in previous glacier mass balance studies (e.g.(Piermattei et al., 2016, 2015)). Here we use high resolution SfM DEMs derived from aerial photographs obtained during three flights (March 2015, 2016, 2017). These were processed for DEM construction using PhotoScan software by Vargo et al. (2017). 


\subsection{Spatial interpolation of GNSS data}

Spatial interpolation is a complicated topic. For this reason, Appendix A provides a brief introduction to kriging, and related subjects such as measures of spatial continuity. Spatial interpolation is used to predict certain values, such as elevation, at points within a region of sampled values ( $\mathrm{Li}$ and Heap, 2014). The degree of accuracy of the predicted value will be inversely proportional to the variability of the data, and the suitability of the applied method (Isaaks and Srivastava, 1989). Fortunately, in the case of Brewster Glacier, the majority of the ice surface topography has a gently varying slope. This increases the chance of accurate surface elevation estimates. A wide range of spatial interpretation methods exist. The most appropriate interpolation method is not always obvious and depends on factors such as the nature and structure of the data, the size and distribution of samples, and the computing power available (Li and Heap, 2014). The vast majority of methods follow the basic formula shown in Equation 2.1 ( $\mathrm{Li}$ and Heap, 2014),

$$
\hat{z}\left(x_{0}\right)=\sum_{i=1}^{n} \lambda_{i} z\left(x_{i}\right)
$$

where $\hat{z}$ is the estimate of the primary variable at the interpolated location $x_{0}, n$ is the number of sampled points used to estimate $\hat{z}, \lambda$ is the sampled point's weighting, and $z$ is the value of the primary variable at a samples location $x_{i}$.

Broadly speaking, there are two classes of methods which can be used to estimate unknown values; deterministic, and probabilistic (Isaaks and Srivastava, 1989). Deterministic methods are used when there is enough knowledge of the phenomenon so that the unknown value can be determined. This is usually not the case in Earth science (Isaaks, 1989). Probabilistic methods use random variables to model the sample data as if it were generated by a random process (Isaaks and Srivastava, 1989; Haining et al., 2010). An advantage to the probabilistic approach is that the model recognises uncertainties and these uncertainties can be estimated (Isaaks and Srivastava, 1989). This study uses a probabilistic method, cokriging. 


\subsubsection{Cokriging}

Probabilistic methods take advantage of spatial dependency between data points (Bohling, 2005a; Goovaerts, 1997). Simply put, two points close together are more likely to be more related than two points far away from each other (Tobler, 1970). The chosen method of spatial interpolation for the GNSS data is cokriging ${ }^{2}$. Cokriging exploits the cross-correlation between two or more variables, in order to further minimise estimation error variance of the primary variable (Isaaks and Srivastava, 1989). Cokriging is essentially the dot product of two matrices represented by Equation 2.2,

$$
\begin{gathered}
\mathrm{C} \\
{\left[\begin{array}{cc}
C_{\epsilon\{u i, u j\}} & C_{\epsilon\{v i, u j\}} \\
C_{\epsilon\{u i, v j\}} & C_{\epsilon\{v i, v j\}}
\end{array}\right] \cdot\left[\begin{array}{l}
\lambda_{a i} \\
\lambda_{b i}
\end{array}\right]=\left[\begin{array}{c}
C_{\epsilon\{u 0, u j\}} \\
C_{\epsilon\{u 0, v j\}}
\end{array}\right] \text { (Rivoirard and Cours, 2003) }}
\end{gathered}
$$

where the $\mathrm{C}$ matrix describes the cross correlation between a combination of primary and secondary variables. In this study, the $\mathrm{C}$ matrix represents the covariance between the elevation of the glacier surface given by GNSS data $(u)$ for a given year, and the elevation of the glacier surface given by the SfM DEM $(v)$. The W matrix describes the weighting assigned to the primary variable $(a)$ and secondary variable (b) to give the correlation between the variable to be estimated $(u 0)$ and the primary and secondary variables (D matrix ${ }^{3}$. Covariance model parameters used in this study are shown in Tables A.1 to A.3. Cokriging is especially useful for this study, where some GNSS datasets only contain $\sim 10$ points ${ }^{4}$. Therefore, by using the 2017 SfM DEM as the secondary dataset, we obtain information about the spatial continuity of the glacier surface to guide interpretations of the under sampled GNSS datasets (primary variable). This method assumes that the 2017 glacier surface spatial continuity is representative of the spatial continuity of all other years.

All GNSS datasets were cokriged against the 2017 SfM DEM, chosen for its high

\footnotetext{
${ }^{2}$ There are many other interpolation methods, some of which are discussed in Appendix A.

${ }^{3}$ In most cases, the $\mathrm{W}$ matrix must be resolved. This is done using the dot product of $\mathrm{C}^{-1}$ and $\mathrm{D}$

${ }^{4}$ Although, datasets with few points will still be inaccurate, information from a secondary dataset will improve the accuracy much more than any other method.
} 
resolution and accuracy. This allowed exploitation of the covariance between the comparatively under sampled GNSS data and the high resolution 2017 SfM DEM. In order to increase data points for kriging, the nodes of the perimeter datasets for each year were used to sample elevation from the 2017 SfM DEM. For end of winter surveys (October to December datasets), the increased elevation as a function of snow depth for both the sampled perimeter nodes, and the 2017 SfM points to be kriged against, needed to be accounted for. Cullen et al. (2016) found that elevation was an appropriate linear predictor for snow depth up until 2000 m.a.s.l, after which there is a decline in the snow depth gradient for Brewster Glacier. For all sampled nodes, additional elevation was added in accordance to the appropriate $y=m x+c$ (Where $y$ is the snow depth, $m$ is the gradient (typically $\sim 13 \mathrm{~mm} \mathrm{~m}^{-1}$ ), $x$ is the elevation, and $c$ is the $y$-intercept) equation for points below 2000 m.a.s.l, and $y=m 2000+c$ for points above 2000 m.a.s.l to account for the fact that the DEM that these points were sampled from, was constructed during a time of approximate snow minima.

Cokriging was done in Arcmap using the geostatistical analyst wizard (Johnston et al., 2001). In order to satisfy the assumption of stationarity, both the GNSS data, and the SfM DEM to be kriged against needed to be detrended. The built in detrending Arcgis surfaces were considered for this task, but ultimately rejected, as it was found that their over-simplification made them unsuitable for the task (maximum 3rd order polynomial). Instead the data were detrended using the 1986 NZDEM_SoS_V1.0. This DEM was chosen for detrending as it was more accurate than the NZMS DEM, and higher resolution than the SRTM DEM. Detrending with a SfM DEM resulted in residual data which was not of a normal distribution (normal distributions are essential for modeling data as a random variable (Isaaks and Srivastava, 1989)). Adjustments of factors such as covariance-function parameters, and search neighbourhood parameters, were done iteratively with the goal of creating a surface with low standard errors and an even standard error distribution (Tables A.1, A.2, A.3). Once this was achieved, the cokriged raster DEM was added to the 1986 NZDEM_SoS_V1.0 surface, to give an interpolated surface. Uncertainties in elevation are given by the standard error maps. Figure 2.2 shows standard error maps for a dense GNSS coverage dataset, and a sparse 
Methods

GNSS coverage dataset. 


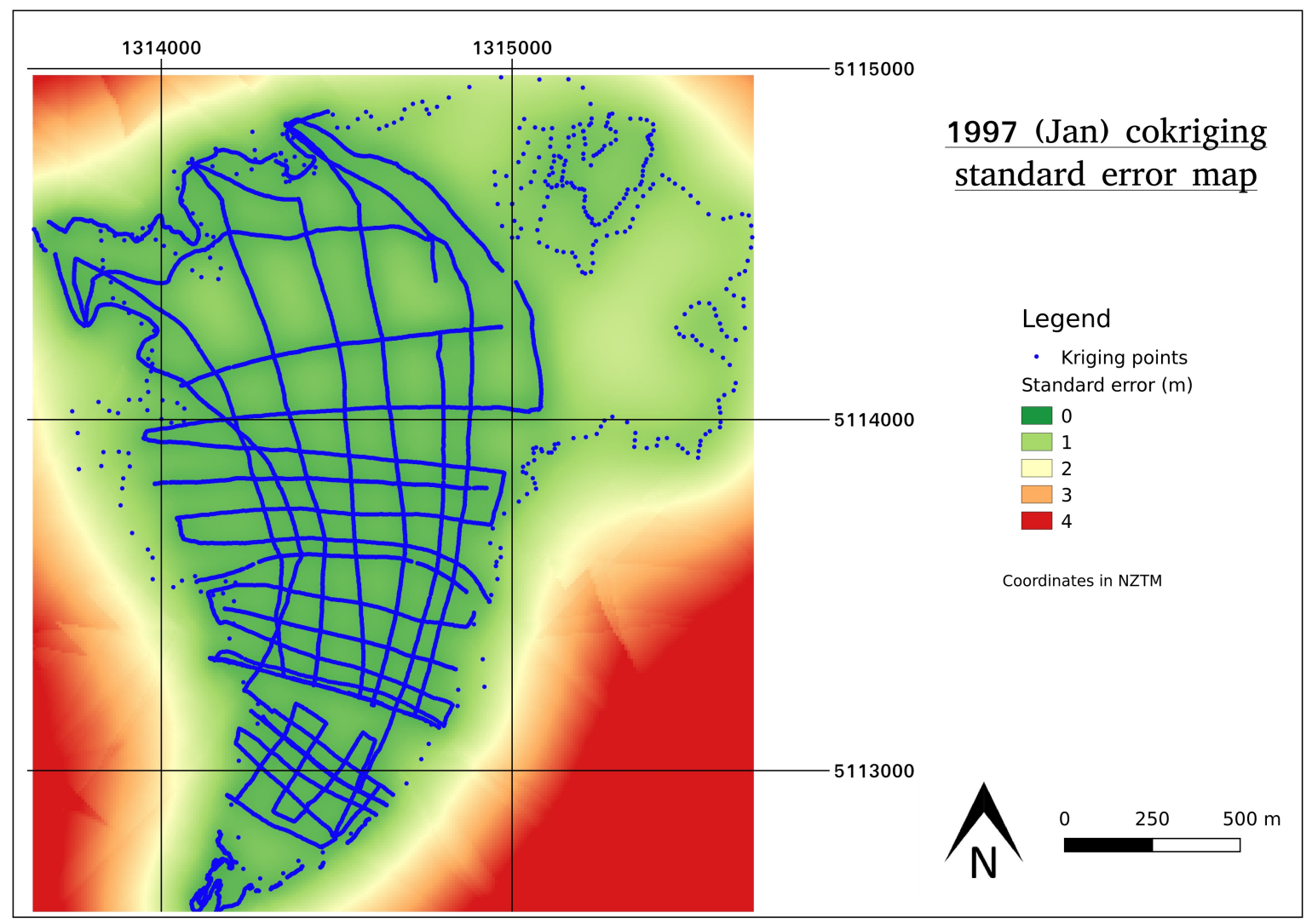

(a)

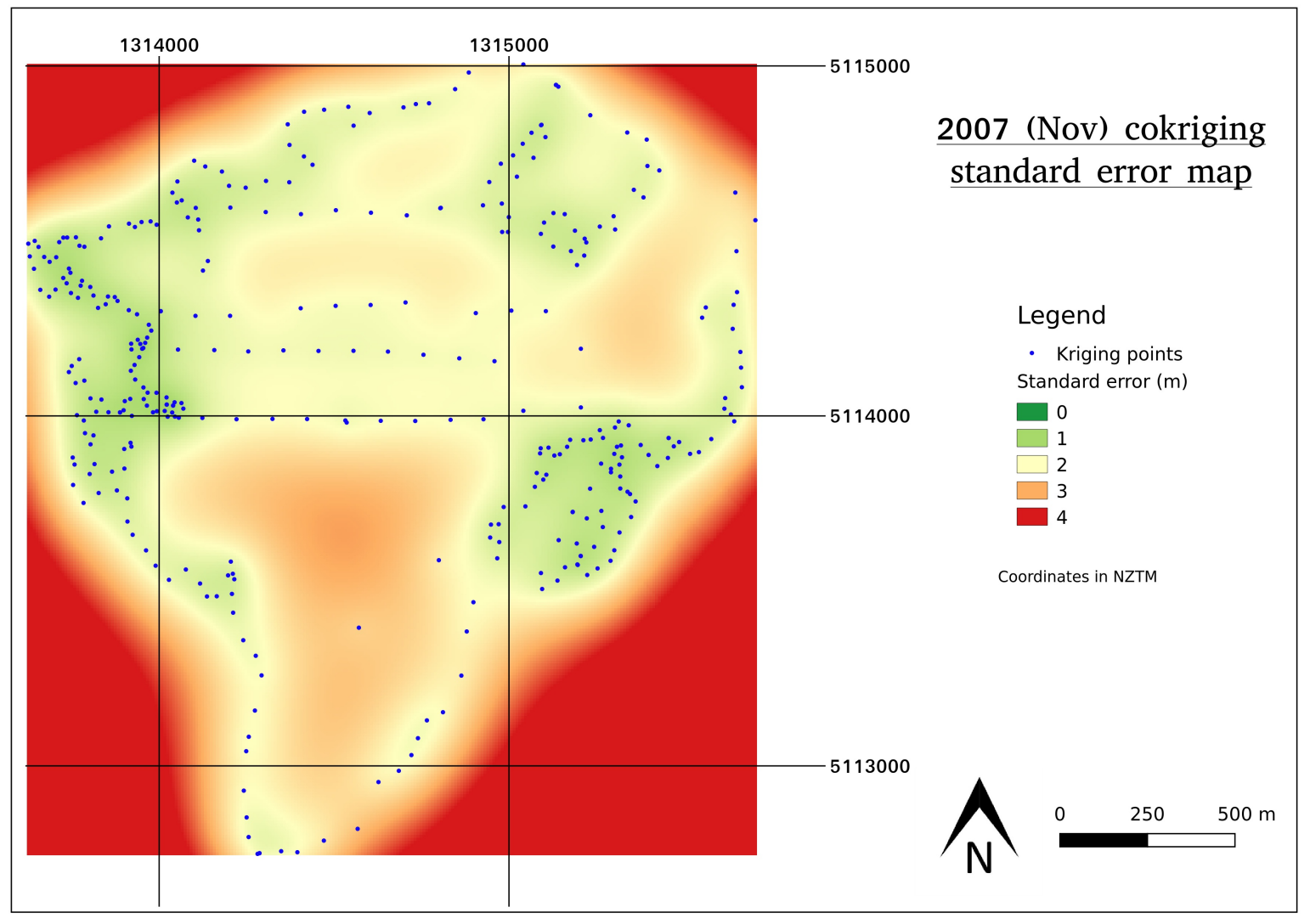

(b)

Figure 2.2: Map showing elevation standard error for January, 1997 GNSS points (a), and elevation standard error for November 2007 (b). 


\subsection{DEM debias}

The SfM surfaces are the highest accuracy surfaces used in this project. As such, the area surrounding the glacier can be used as a stable terrain (snow/ice free terrain) benchmark for comparison with other surfaces (SRTM, NZTopo, and NZMS) which also contain stable terrain. To quantify the average elevation difference between the SfM models, a mean SfM DEM of the stable terrain area surrounding the glacier was constructed from all three SfM DEMs. The only area of this DEM that was deemed acceptable for raster comparison (low variance DEM), was the area where the total root squared difference of all of the layers was less than $6 \mathrm{~m}\left(D E M_{L V}\right)$. This is represented by Equation 2.3,

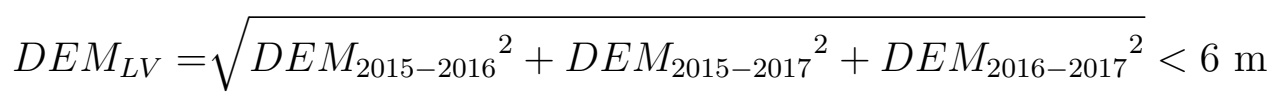

where $D E M_{2015-2016}, D E M_{2015-2017}, D E M_{2016-2017}$ are the difference between the 2015 and 2016, 2015 and 2017, and 2016 and 2017 SfM DEMs respectively. Areas which have a total root squared difference of greater than $6 \mathrm{~m}$ are masked, whereas areas with a root squared difference of less than $6 \mathrm{~m}$ are assigned a 1 value. The reliable stable terrain DEM is then constructed by multiplying the $D E M_{L V}$ with the mean stable terrain SfM DEM. A total root squared difference of $6 \mathrm{~m}$ was chosen, as this cut out a small portion of area from the mean SfM DEM ( 5\%) where at least one of the constituent DEMS showed a large erroneous value, while leaving the majority of the mean SfM DEM available for comparison. The reason why a small area of stable terrain SfM DEMs had large errors is because these areas were not the primary target of interest, and therefore, the number of constituent images which make up the SFM DEMS for these peripheral areas were significantly less than that of the glacier area. By subtracting the reliable mean SfM DEM from either the NZMS, NZDEM_SoS_v1.0, or SRTM DEM, a raster of elevation error of the DEMs was created. These are shown in Appendix C as Figures C.22, C.23, C.24 for the NZMS, NZDEM_SoS_v1.0, and SRTM error surfaces respectively. The error histograms for these surfaces show a normal 
distribution with a mean bias of $-9.14,2.92$, and $-13.56 \mathrm{~m}$ and standard deviations of 27.6, 9.16, and $7.59 \mathrm{~m}$ for the NZMS, NZDEM_SoS_v1.0, and SRTM error surfaces respectively (Figures C.25 C.26 in Appendix C and Figure 2.3 below). The mean bias was corrected for by assuming that this bias also applies to the glacier surface. Of note is the high bias error of the SRTM DEM (13.65 m). Berthier et al. (2006), in a study comparing topographic data from the French Alps to the SRTM DEM, reported altitudinal biases of $-7 \mathrm{~m}$ per $1000 \mathrm{~m}$ elevation. The SRTM bias observed in this study is consistent with the findings of Berthier et al. (2006) given the mean elevation of the study area $\sim 1850 \mathrm{~m}$. No obvious altitudinal bias pattern can be seen in the limited altitudinal range of the study area.

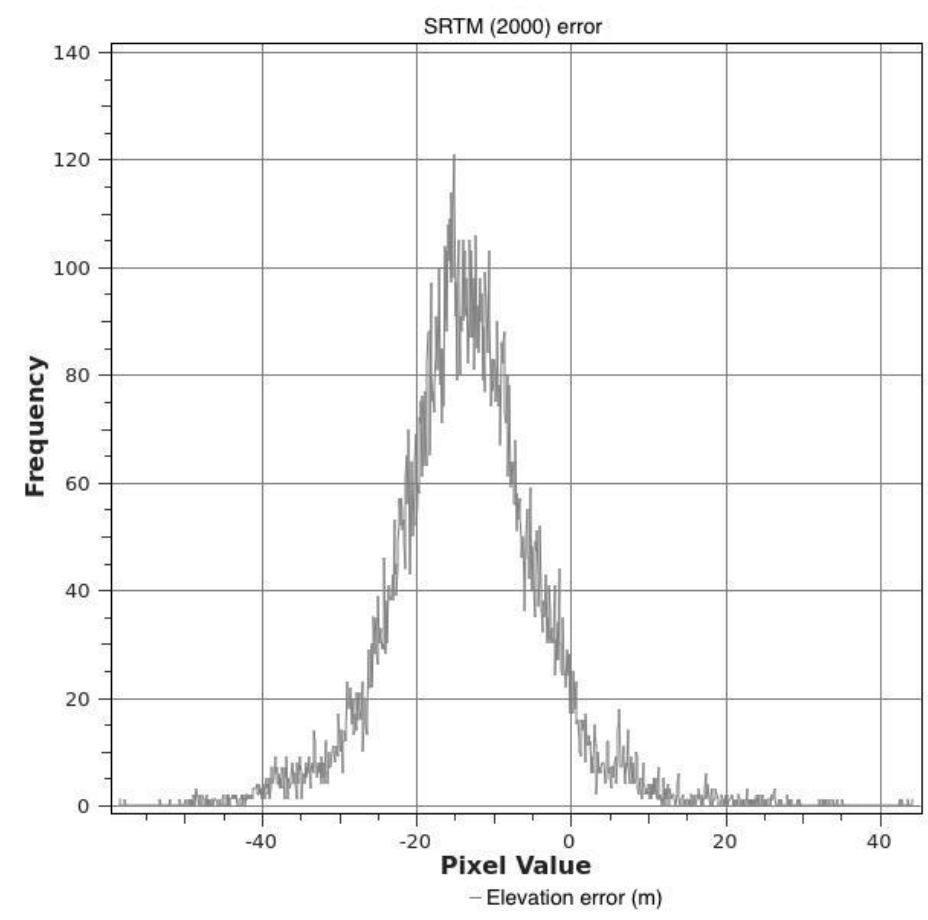

Figure 2.3: Glacier periphery topographic error for SRTM (2000).

\subsection{Glacier bed}

The bed of Brewster Glacier is assumed to be invariant through time. This means that the construction of only one bed DEM is required for the whole temporal range of this study. The construction of the bed DEM was predominantly done by the use of data obtained from Ground Penetrating Radar (GPR). However, as the bed is considered 
to be only the surface over which the glacier lies, the subsequent melting of ice exposes topography which was formerly covered by ice. Therefore, exposed topography revealed through SfM DEMs constitutes an important part of bed elevation for times when the glacier covered a larger area.

\subsubsection{Ground Penetrating Radar}

Ground Penetrating Radar (GPR), a form of radio echo sounding, is a non-destructive technique suitable for a wide range of applications within Earth science. The technique is lightweight, robust and highly portable, allowing it to be used in a wide range of conditions and settings (Jol and Bristow, 2003). The first uses of GPR date back to 1910 when Gorrhelf Leimbach and Heinrich Löwry applied the technique to locate buried objects (Löwy and Leimbach, 1910). By 1930, the first application of GPR was used in glacial geophysics, when Stern (1930) used the method to measure the thickness of a glacier. More recently, studies using GPR have achieved depths of up to $1500 \mathrm{~m}$ in temperate environments (Nolan et al., 1995). Even greater depths have been sounded in the mapping of ice sheet thickness in polar regions (e.g. Fretwell et al. (2013)).

\section{Physical basis of GPR}

Radar (radio detection and ranging) relies on the reflection of electromagnetic energy, most commonly in the frequency range of 1 to $1000 \mathrm{MHz}$ (Plewes and Hubbard, 2001). This energy consists of oscillating electric and magnetic fields which lie at right angles to each other (Kip, 1962). In the case of GPR, this energy is emitted as short pulses, by changing electrical charges in the antenna, the timing of which is controlled by the control unit (Gruber et al., 1996). The propagation of radar is controlled by two main electrical properties of a material, electrical conductivity, and electrical permittivity (Plewes and Hubbard, 2001). Conductivity describes how well a material can transmit an electrical charge, and is predominantly controlled by the presence of ionic impurities (Matsuoka et al., 1997). Permittivity describes how well a material can store an electrical charge, which impedes the transmission of an electrical charge (Plewes and Hubbard, 2001). Permittivity is normally described in terms of relative permittivity, 


\begin{tabular}{ccccc} 
Material & $\begin{array}{c}\text { Relative permittivity } \\
\epsilon_{r}\end{array}$ & $\begin{array}{c}\text { Conductivity } \\
\sigma\left(m S m^{-} 1\right)\end{array}$ & $\begin{array}{c}\text { Velocity } \\
\left(\mathrm{x} 10^{8} m s^{-} 1\right)\end{array}$ & $\begin{array}{c}\text { attenuation } \\
\alpha\left(d B m^{-} 1\right)\end{array}$ \\
\hline Air & 1 & 0 & 3.0 & 0 \\
\hline Fresh water & 80 & 0.5 & 0.33 & 0.1 \\
\hline Granite & $4-6$ & $0.01-1$ & 1.3 & $0.01-1$ \\
\hline Ice & $3-4$ & 0.01 & 1.68 & 0.01 \\
\hline
\end{tabular}

Table 2.3: Physical constraints of materials encountered in the study area. Modified from Plewes and Hubbard (2001).

which compares the permittivity of a material relative to the dielectric constant (the electrical permittivity of free space). Along with frequency, these 3 properties control the velocity of radio waves in ice (Plewes and Hubbard, 2001). This is shown by Equation 2.4,

$$
V=c / \sqrt{\left\{\left(\epsilon_{r} / 2\right)\left(\left(1+\left((2 \pi f) \sigma \epsilon_{r}\right)^{2}\right)+1\right)\right\}}
$$

where $V$ is the speed of the radio waves, c is the speed of radio waves through a vacuum $\left(3.0 \times 10^{8} \mathrm{~m} \mathrm{~s}^{-1}\right), \epsilon_{r}$ is the relative permittivity, $f$ is the frequency of the waveform, and $\sigma$ is the electrical conductivity. Not all of the radar signal is reflected back to the receiver. Energy is lost due to geometrical spreading $\left(\propto 1 / r^{2}\right.$, where $r$ is the distance traveled), refracted and defracted by englacial objects, impurities and englacial inhomogeneities (often called clutter), or subjected to dielectric absorption (Corr et al., 1993). Table 2.3 shows some physical constraints for materials relevant to the field area.

Energy is generated as a pulse by the transmitter, and reflected energy is received by the receiver. With knowledge of the velocity of radio waves through ice, and the time taken for a reflected signal to be be received by a receiver, $(t)$, the depth (D) of the reflector can be obtained (Equation 2.5) (Bristow et al., 2013).

$$
D=(v \times t) / 2
$$

If both the receiver and transmitter are moved along a surface, an image of subsurface dielectric properties can be made (Daniels, 1996). This image can then be interpreted in terms of subsurface structures. 
GPR is a technique commonly used in glaciological studies. The short wavelengths, and generally small depths to be measured, coupled with the low permittivity of ice, render this technique useful for a range of glaciological measurements (Gruber et al., 1996). Most glaciology studies which utilise GPR are concerned with glacier bed characteristics and ice thickness (e.g. Linsbauer et al. (2016); Bohleber et al. (2017); Raymond et al. (2006); Moran et al. (2000)), englacial hydrology (e.g. Irvine-Fynn et al. (2006); Moorman and Michel (2000); Stuart et al. (2003); Miège et al. (2016)), or the investigation of dielectric properties of ice and underlying substrate (e.g. Matsuoka et al. (2012); Jacobel et al. (2009)).

\subsubsection{GPR acquisition}

Three GPR datasets are used in this study (Figure 2.4). In 1997, ice thickness was estimated using an impulse transmitter linked to broadband resistivity loaded dipolar antennas which produced a central frequency of $5 \mathrm{MHz}$ (Figure D.1) (Willis et al., 2009). In 2012 (Figure D.2) and 2016 (Figure D.3), a Mala ProEx ${ }^{\mathrm{TM}}$ system connected to a $25 \mathrm{MHz}$ transmitter antenna was used. As the 1997 profiles had been processed prior to this study, the following sections relate to the 2012 and 2016 datasets only. The radar surveys were carried out on skis, whereby the skier carried the control unit in a back pack, carried the monitor in front via a neck strap, and towed the antennas behind via a harness. Timing was recorded by a Garmen eTrex ${ }^{\circledR}$ hand held unit, and position recorded with a Trimble dual frequency GNSS unit, post processed in order to obtain a more accurate location. 


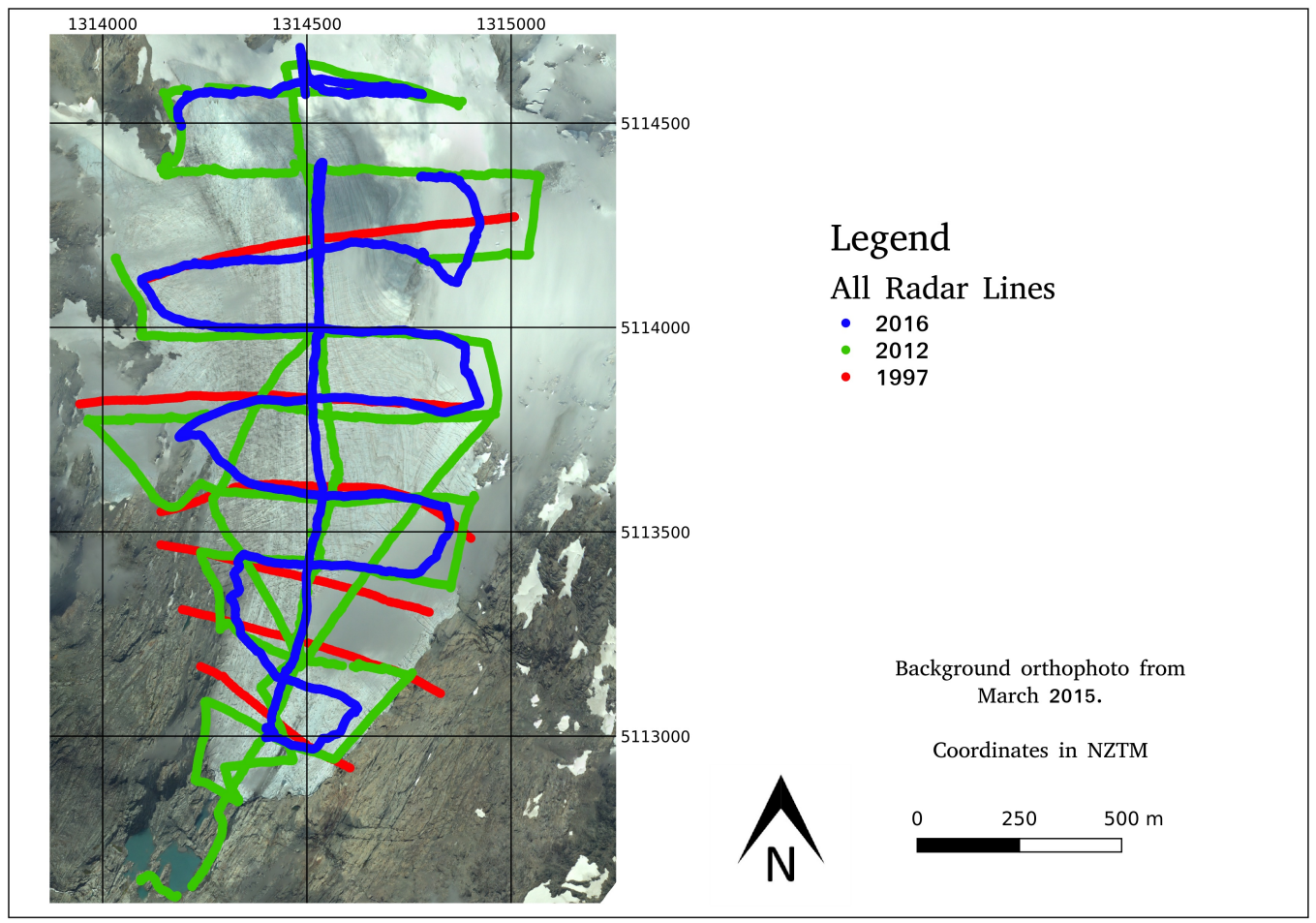

Figure 2.4: Spatial extent of the three GPR datasets used in this study.

GPR acquisition settings (2012 and 2016):

- Antenna: $25 \mathrm{MHz}$ unshielded. $25 \mathrm{MHz}$ (the lowest frequency antenna available) was considered a low enough frequency to penetrate to the maximum estimated bed depth of $\sim 100 \mathrm{~m}$. The minimum reflector thickness must be $6.7 \mathrm{~m}$ assuming that the vertical resolution $=0.25 \lambda$ where $\lambda$ is the wavelength (Kearey et al., 2013).

- Time window length The time window length was $2100 \mathrm{~ns}$, allowing depths of up to $176 \mathrm{~m}$ to be sounded.

- Number of stacks Traces were stacked 16 times (2012) and 64 times (2016). The more traces that are stacked, the higher the signal to noise ratio, as coherent signal is positively reinforced, and random noise is destructively canceled out (Kearey et al., 2013). However, a greater number of stacks leads to a decrease in 
spatial sampling.

- Time interval The time interval used was 0.1s (2012) and 1.6s (2016). A short time interval ensures high spatial along-track resolution, and stacking of the same, or close to the same reflection point.

\subsubsection{GPR processing}

The first step in data processing was to convert the raw data files into segy format. Radar data was then processed using Globe Claritas, a seismic processing software package developed by GNS Science (Maslen, 2013). The goal of GPR processing is to reduce noise and increase signal. The processing flow used to achieve this is shown in Figure 2.5.

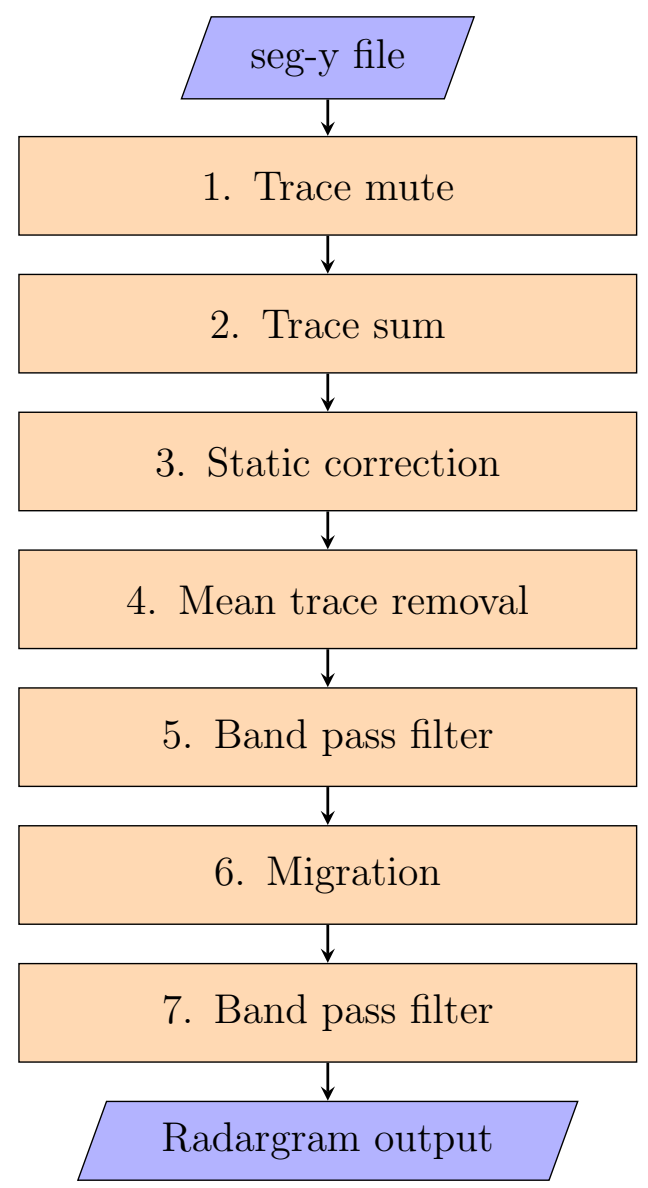

Figure 2.5: GPR processing flow showing main steps used to increase the signal to noise ratio of radar profiles. 
Firstly, a trace mute was applied in order to obtain an across-trace continuous record. Traces recorded when the GPR unit was not moving were muted (Step 1 in Figure 2.5). These traces were identified by their perfectly horizontal reflections, and were recorded for subsequent removal. Following this, traces were stacked to increase the ratio of coherent signal (which is positively reinforced) to random noise (which cancels out). A static correction was then applied in order to shift the direct arrival to the top of the trace. The static shift was determined by digitising the first reflected arrival using a cross correlation function. A mean trace removal filter was applied, which is a horizontal filter that removes the mean value of adjacent traces (Bristow and Jol, 2003). Although more noise reduction results when more traces are averaged, this comes at the cost of signal loss for reflectors. An across-trace averaging python script (Step 4 in Figure 2.5) was used with the amount of traces used (12 to 24) varying with each profile. A zero-phase band pass butterworth filter (Frequencies: 2-5-90-120 $\mathrm{MHz}$ ) (Amplitudes: 0.05-0.95-0.95-0.05) was then applied which removes the majority of wavelets frequencies below $5 \mathrm{MHz}$ and above $90 \mathrm{MHz}$. This was applied before and after migration. Migration is a process that restores reflectors to their true origin, in order to preserve reflector geometry (Kearey et al., 2013). The need for migration arises because of the assumption that reflections arrive from directly below the receiver. In reality, energy is emitted within a cone of aproximately $90^{\circ}$ angle (Plewes and Hubbard, 2001). Migration collapses hyperbolas within the radargram, and shallows the dip of dipping reflectors (Kearey et al., 2013). Profiles were migrated in the time-distance domain with an input velocity of $168 \mathrm{~m} / \mu \mathrm{s}$ (the same velocity used in the $1997 \mathrm{GPR}$ data (Willis et al., 2009)).

\subsubsection{Data interpretation}

Bed horizons were digitised based on reflection strength (relative to surrounding reflections), and lateral continuity. For areas of steep bed morphology, the bed was interpreted as a series of strong point reflections. No interpretation was inferred where a convincing reflection was absent. For deeper reflections, bed picks were chosen with guidance about expected depth based on the lower frequency 1997 GPR dataset. In 
order to interpret deeper reflections, an automatic gain control (AGC) was applied. As this used a sliding window to balance out amplitude along a trace, reflector character could be altered. As such, AGC was used with caution. An example of an interpreted radargram is shown in Figure 2.6.

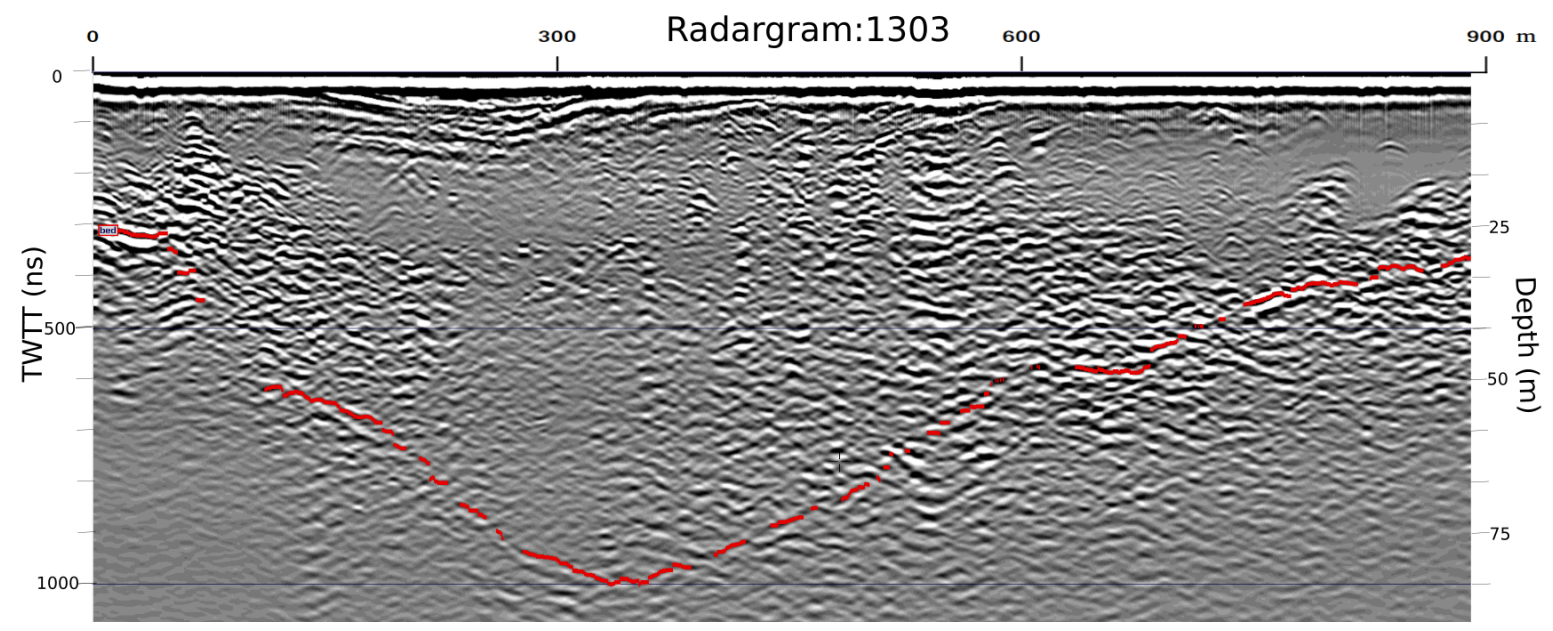

(a)

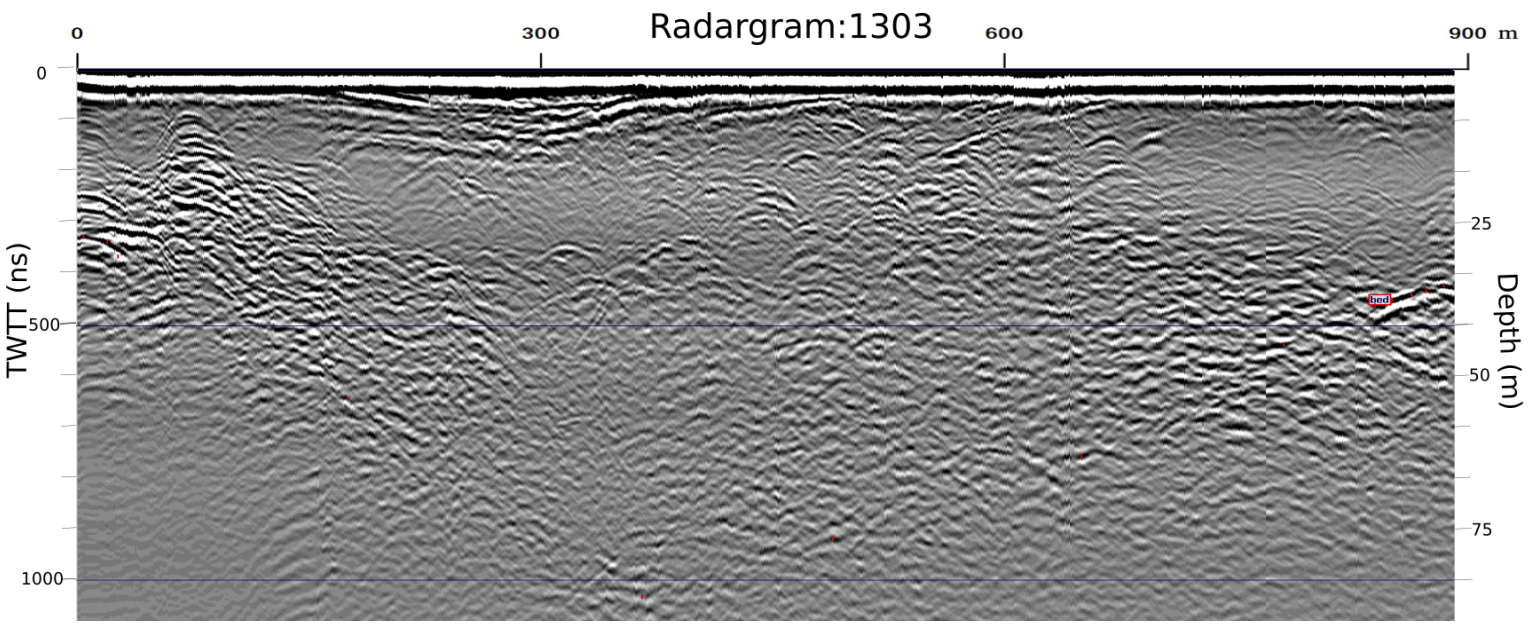

(b)

Figure 2.6: Interpreted (a), and non-interpreted (b) radargrams for profile 1303 (Figure D.2).

Bed picks were output as two way travel times with a location and coordinates. Depths were calculated using Equation 2.5, assuming a velocity of $168 \mathrm{~m} / \mu \mathrm{s}$, then subtracted from the surface elevation (recorded at the time of the GPR survey) to give bed elevation in the form of X,Y,Z coordinates relative to the GRS80 ellipsoid. 


\subsubsection{SfM}

SfM (described in section 2.1.6) forms an important dataset for bed elevation. This is because as the glacier recedes, part of the bed becomes exposed. From 1967 to 2016, $1.15 \mathrm{~km}^{2}$ of bed became exposed.

\subsubsection{Bed DEM construction}

Firstly, in order to identify any discrepancies between the datasets, all radar points were converted to raster using the triangular irregular network (TIN) interpolation technique. In certain areas, sharp discontinuities in the TIN DEM show that there is poor agreement between the datasets, particularly the case between the 1997 GPR and the later datasets. This was further investigated by comparing point elevation estimates from where GPR profiles overlap. Furthermore, the subsequent exposure of stable terrain, which was previously sampled by the 1997 GPR profiles, enabled a test of the accuracy of the 1997 dataset (Figure 2.7).

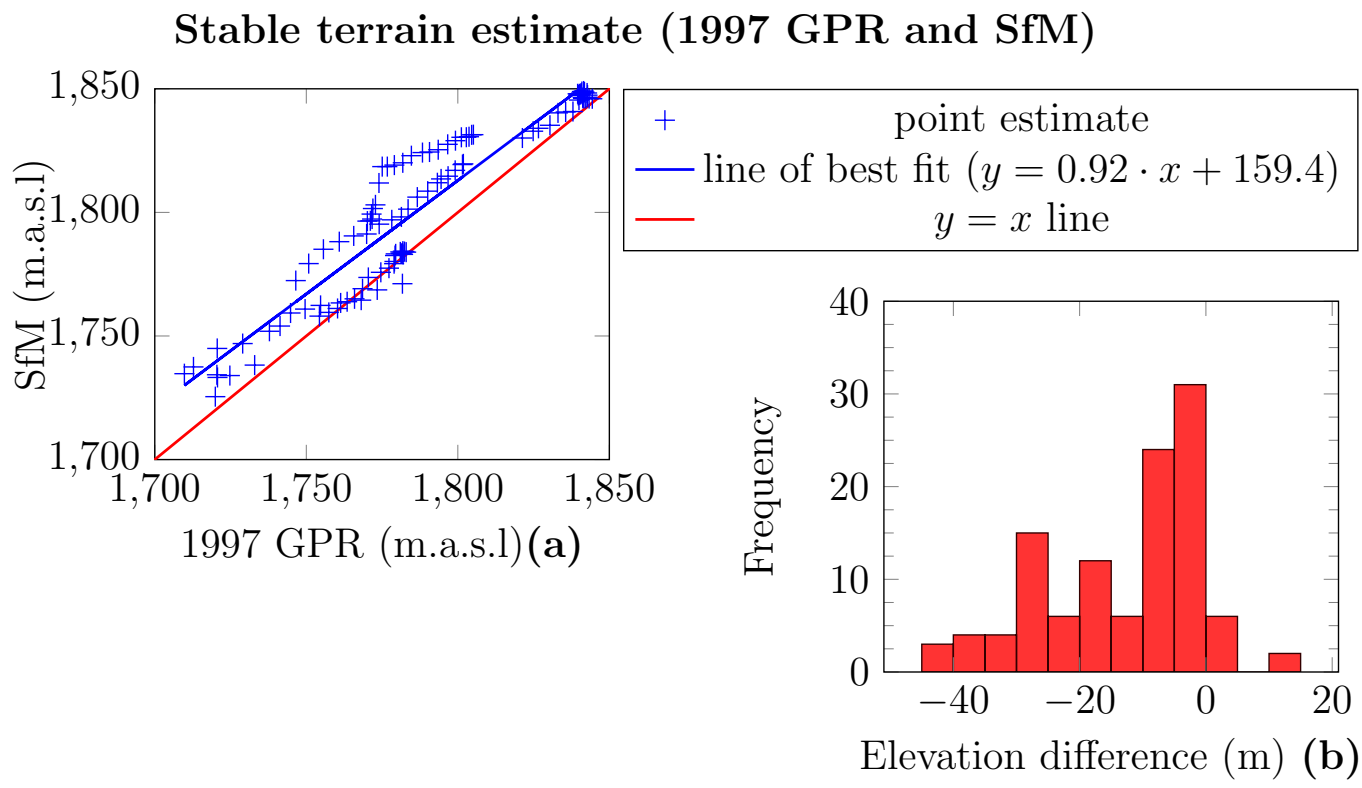

Figure 2.7: Point elevation estimates (a) and difference frequency histogram (b) for SfM and 1997 GPR. Perfect agreement would result in the line of best fit coinciding with the $\mathrm{Y}=\mathrm{X}$ line.

The results of this test show an offset between depth estimates from the 1997 GPR 
and SfM DEM. The gradient of the line of best fit (0.92) is very similar to the gradient of the $y=x$ line (1), suggesting that this error does not vary with elevation or snow depth. This offset is therefore interpreted as a combination of DC bias error (difference between the initiation time of recording and the time of the trigger), and error from picking a different part of the direct wave, resulting in the 1997 GNSS underestimating bed elevation by a mean of $13.58 \mathrm{~m}$ and a median of $8 \mathrm{~m}$. In light of this observation, $13.58 \mathrm{~m}$ (the mean difference) was added onto all 1997 bed elevation picks. The mean difference was chosen as a correction over the median difference, as there did not appear to be any obvious outliers. Comparison of the sounding depths for the 1997 (DC bias corrected) and 2012 datasets (Figure 2.8), shows a difference distribution, which is poorly fit by a normal distribution according to the Kolmogorov-Smirnov Comparison at $\mathrm{P}=0.00$ (which compares a empirical distribution to a normal distribution) ${ }^{5}$. The

\section{Bed point elevation estimate (1997 GPR and 2012 GPR)}

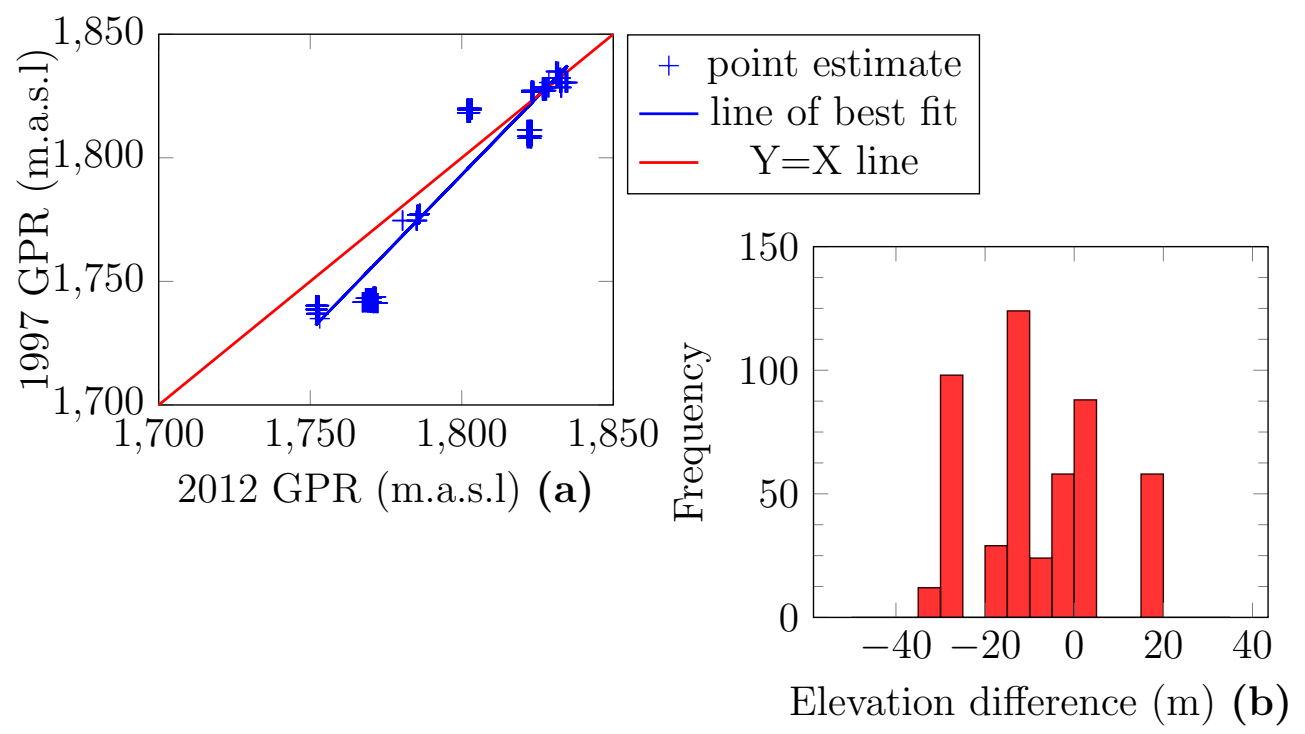

Figure 2.8: Point elevation estimates (a) and difference frequency histogram (b) for 1997 GPR (DC bias corrected) and 2012 GPR. Perfect agreement would result in the line of best fit coinciding with the $\mathrm{Y}=\mathrm{X}$ line.

mean difference is $-8.6 \mathrm{~m}$, with a $95 \%$ confidence interval for the actual mean difference of -9.9 to $-7.4 \mathrm{~m}$. The median is $-11.28 \mathrm{~m}$. Likewise, the difference in sounding depth for the 1997 (DC bias corrected) and 2016 GPR datasets is also poorly fit by a normal

\footnotetext{
${ }^{5}$ Although the number of GPR intersection points is quite high $(n>30)$, the clumping of points around GPR profile lines means that the number of GPR intersections is effectively much less.
} 
distribution at $\mathrm{P}=0.00$ (Figure 2.9).

Bed point elevation estimate (1997 GPR and 2016 GPR)

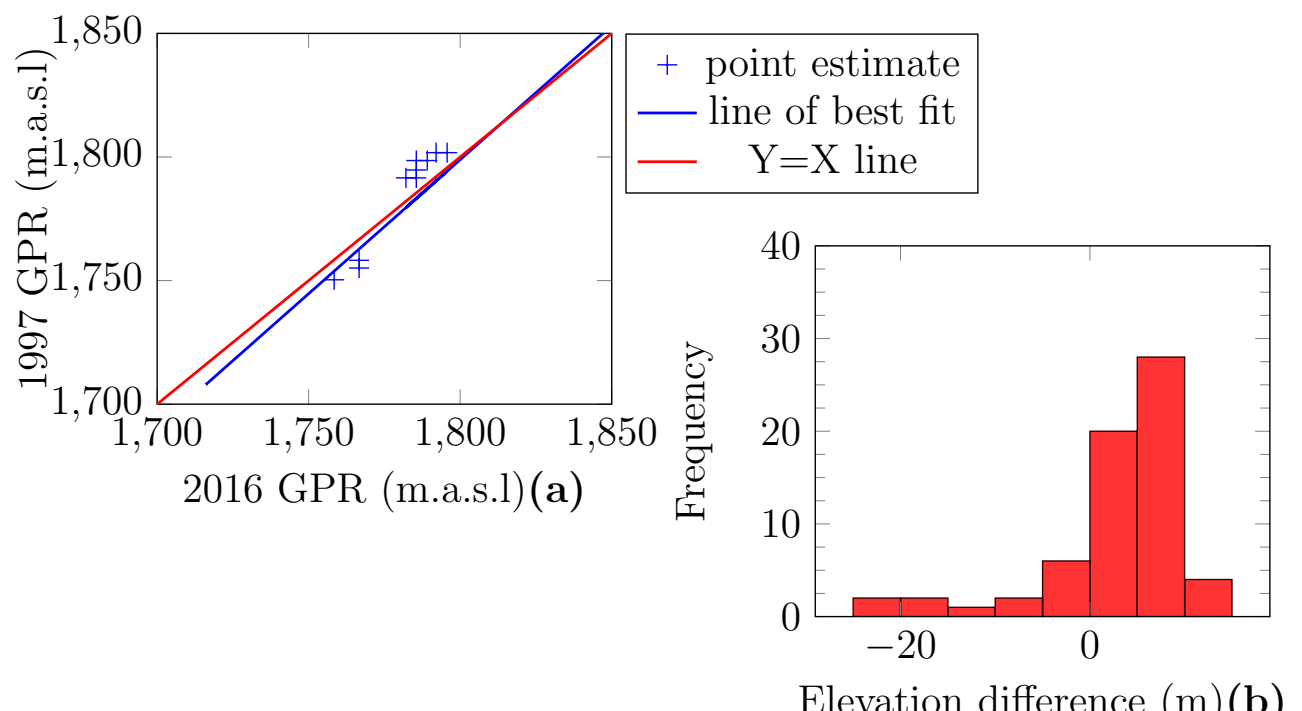

Figure 2.9: Point elevation estimates (a) and difference frequency histogram (b) for 1997 GPR (DC bias corrected) and 2016 GPR. Perfect agreement would result in the line of best fit coinciding with the $\mathrm{Y}=\mathrm{X}$ line.

The 1997-2016 mean difference is $3.3 \mathrm{~m}$ and the actual mean lies between 1.4 and 5.2 $\mathrm{m}$ at the $95 \%$ confidence interval while the median is $4.9 \mathrm{~m}$. The difference in sounding depths for the 2016 and 2012 datasets has a distribution, which is also unlikely to be that of a normal distribution according to the Kolmogorov-Smirnov Comparison at $\mathrm{P}=0.00$. The mean difference is $-2.4 \mathrm{~m}$, with a $95 \%$ confidence interval for the actual mean difference of -3.3 to $-1.5 \mathrm{~m}$. The median is $-0.4 \mathrm{~m}$. There appears to be no systematic offsets between the GPR datasets (once a DC bias correction has been applied to the 1997 GPR).

Although these statistics are useful, they are not robust as the number of points where they overlap are not great. Differences are more likely to be over estimated than underestimated. This is because overlapping points were defined as being within $10 \mathrm{~m}$ (planimetrically) of one another. Given that the average slope sounded by the 2012 and 2016 GPR was $24.5^{\circ}$ and slopes up to $68^{\circ}$ were sounded, these result in vertical offset estimation errors of $4.45 \mathrm{~m}$ (mean) and $25 \mathrm{~m}$ (max) assuming an offset distance of 10 


\section{Bed point elevation estimate (2016 GPR and 2012 GPR)}

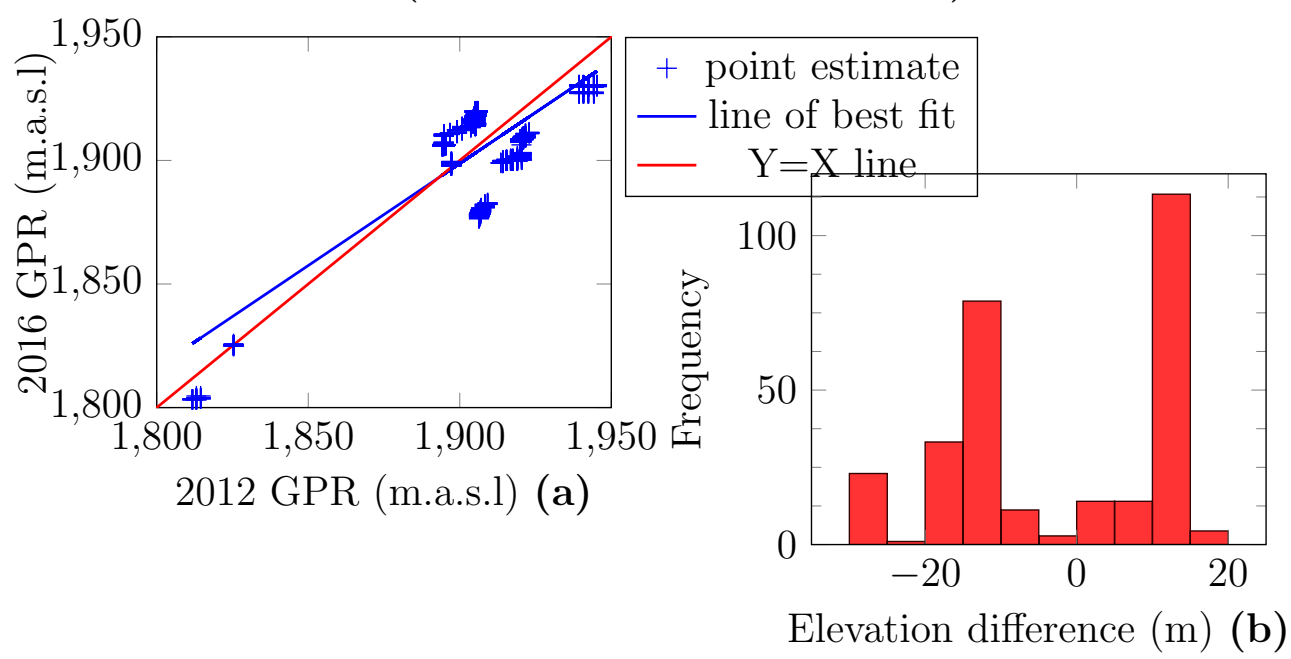

Figure 2.10: Point elevation estimates (a) and difference frequency histogram (b) for 2012 GPR and 2016 GPR. Perfect agreement would result in the line of best fit coinciding with the $\mathrm{Y}=\mathrm{X}$ line.

$\mathrm{m}^{6}$. This may explain the bimodal distribution of the frequency distribution graphs, specifically that of Figure 2.10 which compares 2012 sounding depths to 2016 sounding depths. The difference in elevation estimated by the 1997 GPR (DC bias corrected) and later GPR profiles (Figs $2.8 \& 2.9$ ) is likely to be due to the different frequencies of the surveys. The 1997 dataset used a $5 \mathrm{MHz}$ antenna which corresponds to a wavelength of $33.6 \mathrm{~m}$, whereas the later datasets used a $25 \mathrm{MHz}$ antenna, corresponding to a wavelength of $6.7 \mathrm{~m}$. Lower frequency signal is associated with greater penetration depths, but poorer resolution (vertical resolution $\approx 1 / 4$ wavelength) (Kearey et al., 2013). Additionally, differences in bed elevation may be due to different ice conditions (which may alter the velocity of radio waves) and, interpretation differences. Where datasets of poor agreement overlap, one of the datasets was omitted depending on the source frequency, expected depth of the bed, and confidence in bed picks. In areas of expected shallow ice depth, the higher frequency GPR is favoured, whereas for areas of expected deeper ice depth, the lower frequency GPR is favoured. Expected ice depth is determined by nearby GPR depths, as well as knowledge of glacially carved U-shape valley geometry. This is done to ensure DEM construction uses bed picks of the highest

\footnotetext{
${ }^{6}$ This can be thought of as a triangle where the bed is the hypotenuse, the surface is the adjacent, and the depth difference is the opposite.
} 
confidence.

The bed DEM was constructed using two spatial interpolation methods. The final result is an amalgamation of 3 DEMS:

1. Kriged DEM. A comparison study by Arun (2013) found kriging to be the most accurate spatial interpolation technique for DEM construction. Kriging was therefore chosen as the main technique for the bed DEM and was constructed using only GPR data, and the 2016 perimeter nodes, with elevation sampled from the 2016 SfM DEM. This was also found to be the best method to accommodate depth variability between radar lines. However, high standard errors occur on the south west face of Mt Brewster. This error could be problematic due to the expected shallow ice depth as a result of the steep terrain, and knowledge of ice-free nature of other similar glacial horn features. This area was therefore excluded from the DEM. The errors observed in Figures 2.7 to 2.10 are incorporated into the model as a nugget (Table 2.4).

\begin{tabular}{|l|c|}
\hline \multicolumn{2}{|c|}{ Bed kriging } \\
\hline no. lags & 12 \\
\hline Lag size $(\mathrm{m})$ & 124.83 \\
\hline Range $(\mathrm{m})$ & 924.36 \\
\hline Partial sill & 0.65 \\
\hline Nugget & 0.24 \\
\hline
\end{tabular}

Table 2.4: Variogram parameters for simple bed kriging.

2. TIN DEM. A TIN DEM was constructed for the southwest face of Mt Brewster from SFM elevation, and sampled perimeter nodes.

3. SfM DEM. For the area outside the 2016 glacier perimeter, no spatial interpolation technique is required.

These DEMs were converted to XYZ vector points. To facilitate smooth suturing of the tripartite DEM, a gap of 10 m between all DEM parts was implemented. The DEM was then constructed as a TIN of $1 \mathrm{~m}$ resolution. 


\subsection{Glacier Perimeter}

In order to evaluate the glacier area for each year, either Landsat images, topographic maps, or orthorectified aerial photographs were used to identify the perimeter. For each of these datasets, the perimeter was digitised, allowing the calculation of the area, and terminus position. To differentiate between snow and glacial ice, only datasets representing the end of summer, where snow cover is assumed to be at a minimum, were used.

\subsubsection{SfM digitisation}

High resolution SfM orthophotos were created by Vargo et al. (2017) for the years 2015 and 2016. The high resolution $(0.1 \times 0.1 \mathrm{~m}$ pixel size $)$ allowed highly accurate perimeter digitisation, and thus area estimations.

Digitisation of SfM orthophotos was done manually for the years 2015 and 2016. The desired perimeter quality obtainable due to high orthophoto resolution renders this technique highly time consuming. As a result, an automatic technique similar to that of Otsu (1975) was used for the 2017 orthophoto where a threshold of band1 + band $2+$ band $3+$ band $4>800$ was used, in recognition of white light reflecting high proportions of all visible wave lengths. Some manual editing was required in areas of dirty ice and low light areas.

\subsubsection{Landsat digitisation}

The Landsat programme is a mission initiated by the National Aeronautics and Space Administration (NASA) in order to image the Earth (NASA, 2017). The program uses satellites with passive source multi spectral scanners to do this. There have been 8 Landsat missions ranging from Landsat 1, launched in 1972, to Landsat 8, launched in 2013. Landsat 5 has a spatial resolution of $30 \mathrm{~m}$ whereas Landsat 7 and 8 have a spatial resolution of $15 \mathrm{~m}$.

Landsat images are useful due to their high temporal resolution. However, there 
are also some disadvantages:

- Firstly, as Landsat uses passively sourced sensors, the image relies on abundant natural sunlight. Depending on the the time of the day that an image was captured, shadowing effects on the southwest face of Mt Brewster could effect the outcome of the image. In order to partially negate this issue, contrast enhancement was used. It was found that by lowering the maximum pixel value, and thus pixel range, the contrast between snow/ice and bedrock was increased. This can be observed in Figure 2.11. Additionally, in some images, the glacier is partly covered by clouds.

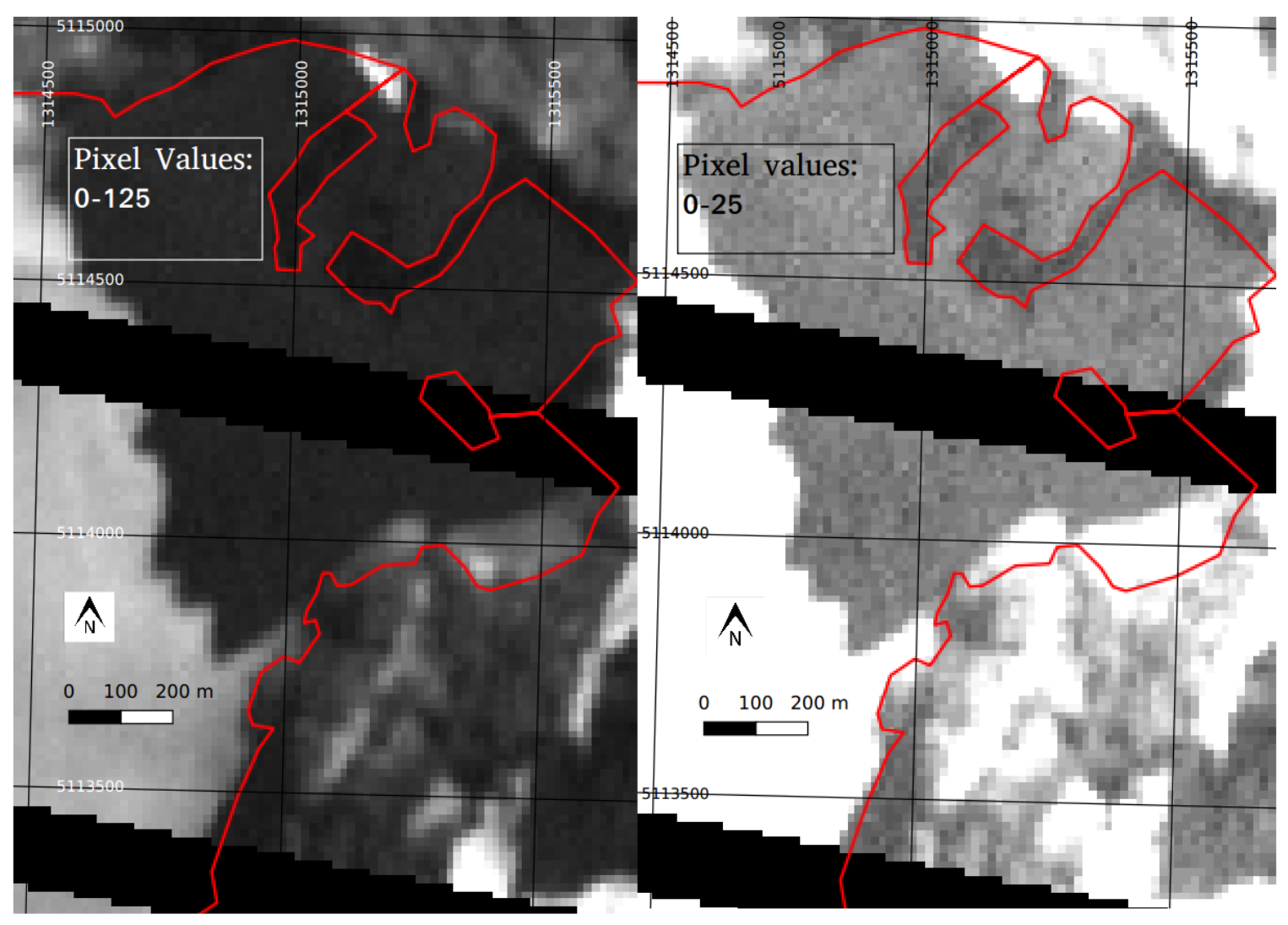

Figure 2.11: The effects of contrast enhancement. The red line represents the digitised perimeter.

- Secondly, all Landsat 7 images from 2003 onwards contain data gaps of up to $22 \%$. This is due to the failure of the Scan Line Corrector (SLC) mechanism, which corrects for the forward motion of the satellite (Scaramuzza and Barsi, 2005). 
All of these disadvantages can be dealt with by using multiple images for certain timestamps. An added benefit of using multiple images is that it ensures that the perimeters capture the minimal snow/ice extent possible. All images digitised can be viewed in Appendix B.

\section{Landsat errors}

All digitised nodes from polygons have an uncertainty associated with them. This is due primarily to;

- Image resolution. The highest band resolution of Landsat 7 and 8 is $15 \mathrm{~m}$. Furthermore, pixel values may be affected by scattered light from surrounding pixel areas. This means that an ice-rock boundary may be gradational over several pixels.

- Geolocation errors. Some Landsat images show an offset of up to $30 \mathrm{~m}$ compared to GNSS derived measurements. These errors will not affect area measurements, but will effect volume and terminus position estimates.

- Human error. Human errors are affected by the quality of the image, and the scale to which digitisation is carried out.

Figure 2.12 shows an example of perimeters derived from both a Landsat image and an SfM model. In order to quantify the errors of the defining nodes of a Landsat derived polygon, a comparison of the 2016 SfM derived polygon and the 2016 Landsat derived polygon was made. This was done by extracting the nodes from the SfM polygon (3046 points), and calculating the shortest distance from each node to the Landsat polygon. Nodes that were found to lie within (outside) the Landsat polyon were assigned positive (negative) signs. Errors ranged from -140 m to $55 \mathrm{~m}$. The large negative errors are attributed to nodes which lie in the shadow of the south-west face of Mt Brewster and are due to low cell contrast associated with low reflected light levels. A Kolmogorov-Smirnov test found the errors to have a normal distribution. 


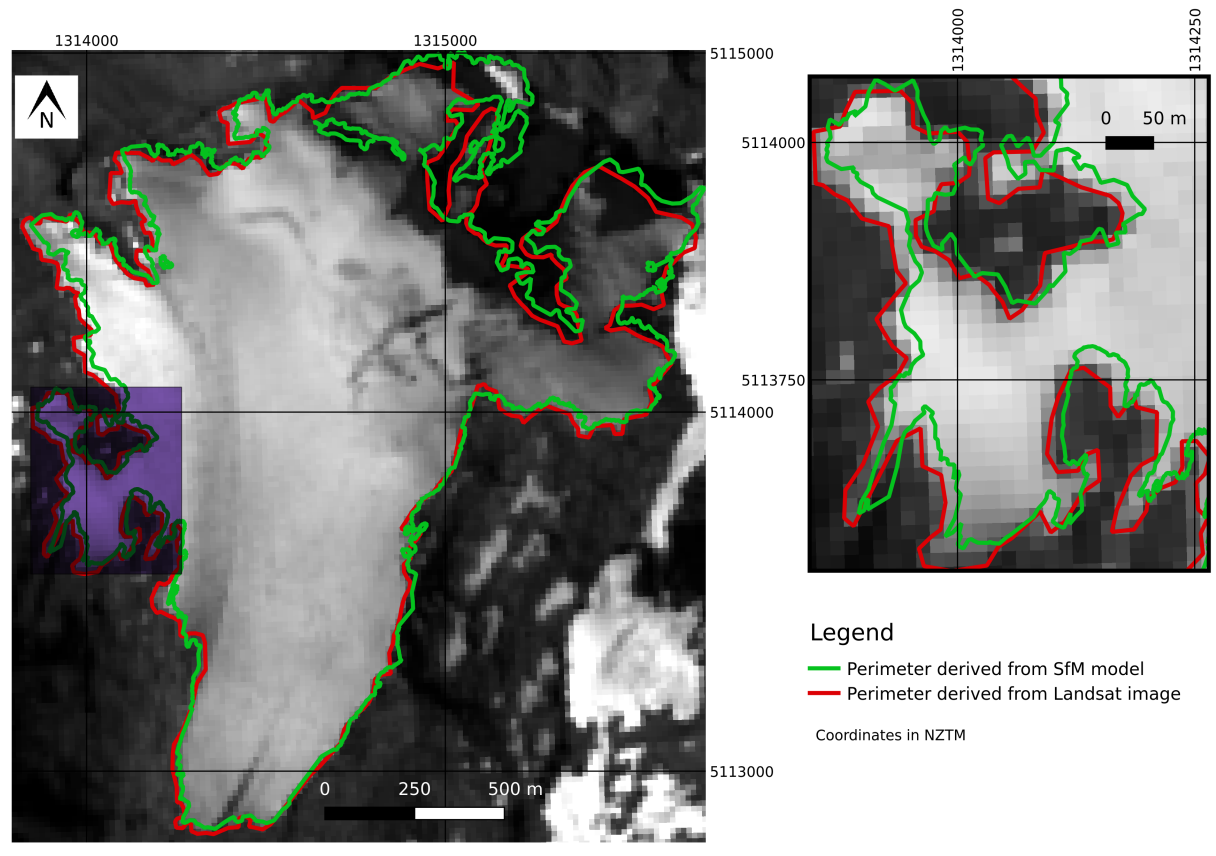

(a)

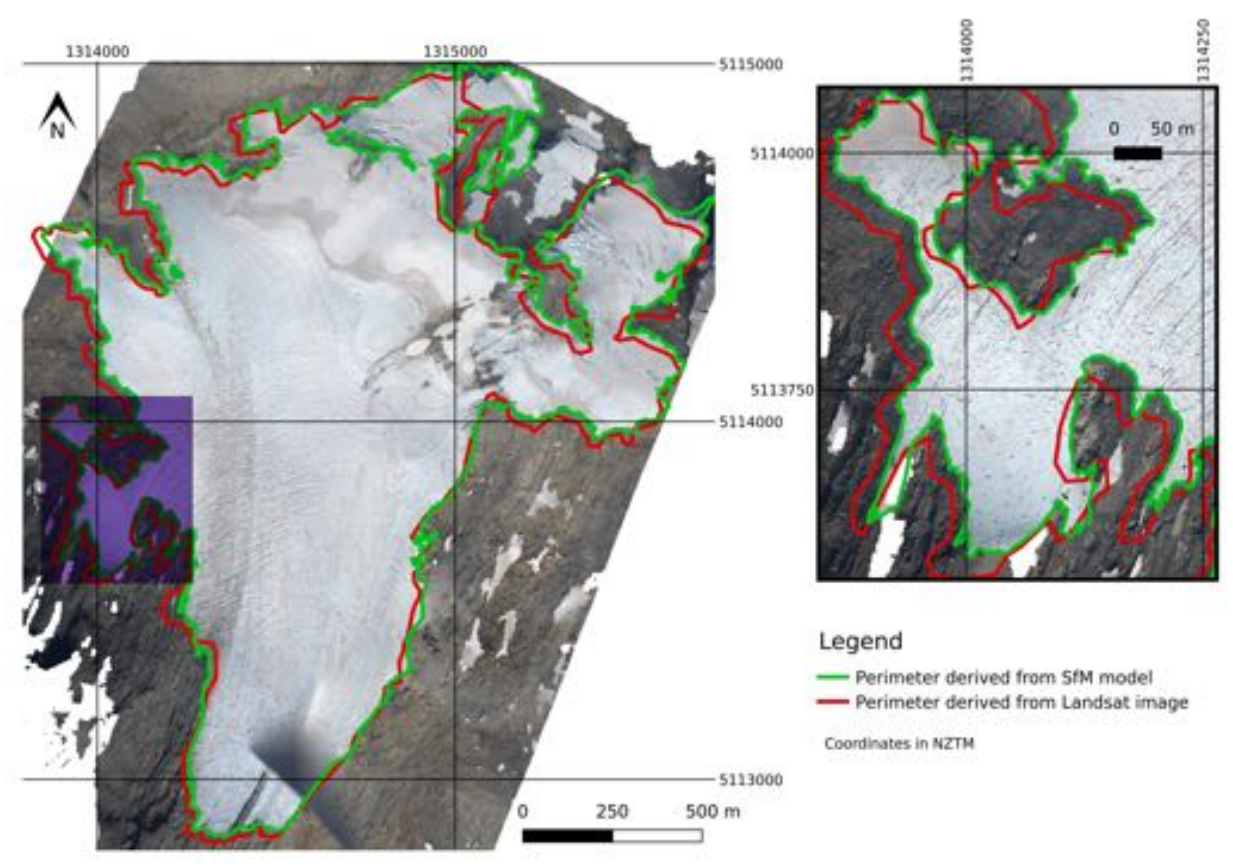

(b)

Figure 2.12: Digitised perimeters derived from Landsat (red), and Structure from Motion model (green) for March 2016. Background image is Landsat (a), and SfM (b).

\subsubsection{Topographic map perimeter digitisation}

For NZTopo maps, $90 \%$ of well defined points are $\pm 10 \mathrm{~m}$ vertically or half the contour interval for NZTopo maps, and $90 \%$ of well defined points are $\pm 22 \mathrm{~m}$ horizontally. Extrapolating these confidence intervals to the NZMS, the vertical accuracy is here 
defined as $\pm 15.24 \mathrm{~m}$ (half the contour interval of 100 feet) and $33.5 \mathrm{~m}$ horizontally. The area errors are therefore $0.52 \mathrm{~km}^{2}$ (NZMS) and $0.5 \mathrm{~km}^{2}$ (NZTopo). The reason why the area error is similar for the two maps, even though the horizontal accuracy of NZMS is $65 \%$ lower than that of NZTopo, is because of the detail of the two perimeters. The length of the NZMS perimeter is $8.2 \mathrm{~km}$ and the length of the NZTopo perimeter is $13.1 \mathrm{~km}$.

\subsubsection{Area calculation}

Planimetric area is the 2D area of a surface whereas surface area is the 3D area (Rashid, 2010). The 3D surface area will always be greater or equal to the $2 \mathrm{D}$ planimetric area as explained by Equation 2.6.

$$
3 \mathrm{D} \text { area }=2 \mathrm{D} \text { area } / \text { cosine(slope in degrees) }
$$

The planimetric area was calculated within the perimeter polyline. In order to explore the effect of perimeter errors (as a function of point errors) on Landsat planimetric area estimates, a number of perimeter buffers were created of varying thickness for the years where both a SfM and Landsat derived perimeters were available. The buffer which encompassed $68 \%$ of the SfM nodes is considered the $68 \%$ planimetric area error. The area was split into two parts; area on the south west face of Mt Brewster, which incorporates glacier surface area dipping greater than $20^{\circ}$, and the remaining glacier surface area. Planimetric area errors for the two parts are therefore defined as \pm half the area of the buffer which contains $68 \%$ of the SfM nodes. Area errors for a given year are a combination of the bipartite area buffers, weighted proportionally to their sizes. These area errors are $\pm 0.30,0.14$, and $0.16 \mathrm{~km}^{2}$ for the years $2015(22.7 \mathrm{~m}$ and $31 \mathrm{~m}$ buffers), 2016 (26 m and $27.5 \mathrm{~m}$ buffers), and 2017 (20 m and $18 \mathrm{~m}$ buffers) respectively. $68 \%$ confidence intervals for all Landsat derived area estimates prior to 2015 are therefore defined to be $\pm 0.30 \mathrm{~km}^{2}$, the largest of the three errors. Using the largest error of the three comparisons is in acknowledgement of the poorer quality and fewer aerial photographs available to guide interpretation for earlier perimeters. 
Although the comparison between Landsat and SfM derived perimeters provide a good estimate of error, these datasets are not perfectly aligned in the temporal domain. As a result, small differences may be caused by spatial snow differences.

In order to calculate 3D surface area, the appropriate surface DEM must be converted to a slope DEM (Figure E.7) and clipped by the area polygon. The true area is then calculated using Equation 2.6, where the slope is the mean slope. To investigate the error that this has on area calculation, the 2016 SfM DEM was converted into a slope DEM. Using the mean slope, the true area was calculated. This resulted in an area of $1.96 \mathrm{~km}^{2}$, which is $3.9 \%$ greater than the planimetric area. A difficulty arises when using this method as a result of the difference in spatial resolution of the DEM's. A higher resolution DEM shows more topographic detail (Jenness, 2004), and thus has a greater mean slope. For reasons of consistency, the chosen way to quantify area, is planimetric area estimates. Fortunately, the majority of glacier surface is at an inclination of less than $15^{\circ}$, and this part of the glacier is where most area change occurs, meaning that the change of planimetric area should not be greatly different to true area changes. To further constrain future true area estimates, methods such as those discussed in (Jenness, 2004) should be implemented.

\subsection{Terminus position estimation}

Purdie et al. (2014), defines the terminus position as “... the furtherest, connected down-glacier point of terminus ice along the centreline of the glacier", and this is the definition adopted in this study. Terminus positions were therefore estimated by extracting a line at right angles from the centreline to the furtherest connected down glacier point (Figure 2.13).

\subsection{Volume calculation}

All surface DEMs were clipped by their respective perimeter polygons, after which the bed DEM was subtracted from the surface DEM. The resultant DEM showed dis- 


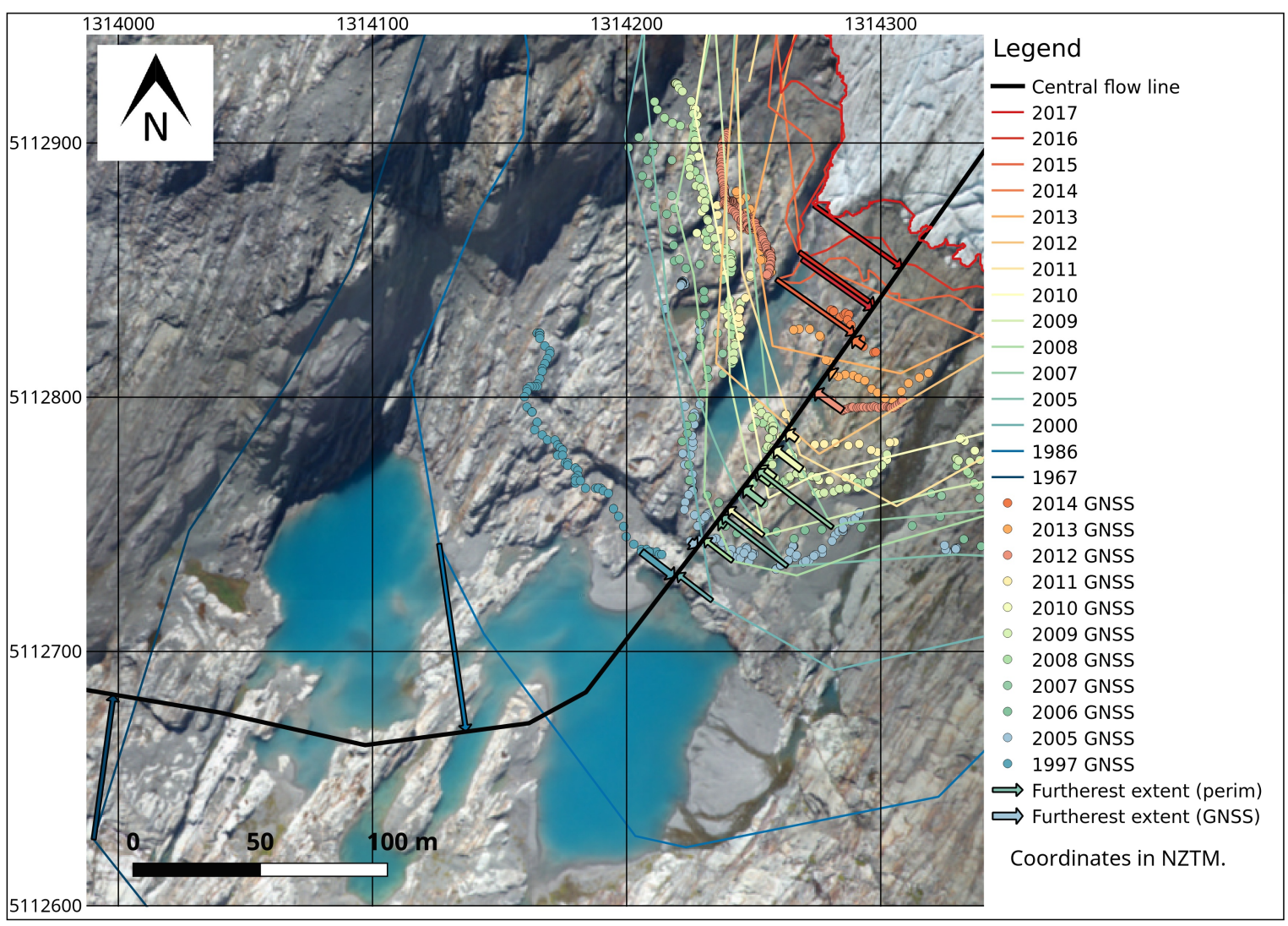

Figure 2.13: Method for determining the terminus position.

tributed thickness across the glacier. Around certain parts of the glacier perimeter (mainly in the vicinity of the SE face of Mt Brewster), surface elevation was slightly lower than bed elevation as a result of measurement and interpolation errors. This contributed small volume errors in comparison to total volume. This could have been accounted for by converting the thickness DEM into a DEM separating 'positive thickness' from 'negative thickness', however this would lead to a non-normal error distribution. The volume is calculated as the mean thickness of the thickness raster multiplied by the area of the raster (the area of the glacier surface). 


\section{Results}

This chapter summarises the results for surface elevation change, describes the bed topography estimated by the bed DEM, and presents time-series for the terminus position, area, and volume.

\subsection{Surface elevation}

A total of 25 surfaces were processed for use in this study. Each surface has its own error, as shown in Table 3.1. The most accurate surfaces are the SfM surfaces, with an average mean standard error of $1.1 \mathrm{~m}$. Of the 19 cokriged surfaces used in this study, the average mean standard error is $2.15 \mathrm{~m}$. Most surfaces show a similar topographic pattern, as evidenced by the similarity of contour patterns (Figure 3.1). The contour pattern of the NZMS surface (1967) differs in places, in that it crosses other DEM contours at high angles.

The surface elevation record of Brewster Glacier can be split into three time periods which summarise surface elevation change. These periods are; a period of overall surface lowering from 1967 to 1986, a period of surface rise from 1986 to 1997 (with lowering continuing at the terminus), and another period of overall surface lowering from 1997 to 2017 (Figure 3.2).

- During the period of $\mathbf{1 9 6 7}$ to $\mathbf{1 9 8 6 , 6 7 . 7 \%}$ of the surface experienced a change in surface elevation at a rate of $-1.08 \mathrm{~m} \mathrm{a}^{-1}$, and $32.3 \%$ of the surface experienced a surface rise at a mean rate of $0.58 \mathrm{~m} \mathrm{a}^{-1}$. The majority of surface lowering was at the terminus, while most of the surface elevation gain is near the periphery. The overall mean rate of elevation change is $-0.67 \mathrm{~m} \mathrm{a}^{-1}$, corresponding to a mean elevation change of $-12.73 \mathrm{~m}$ during the entire period. 


\begin{tabular}{|c|c|l|}
\hline Dataset & Surface type & Mean standard error (m) \\
1967 & NZMS & 27.6 \\
1986 & NZDEM_SoS_v1.0 & 9.16 \\
January 1997 & Cokriged GPS & 0.68 \\
February 2000 & SRTM & 7.59 \\
February 2005 & Cokriged GPS & 1.23 \\
November 2007 & Cokriged GPS & 2.06 \\
January 2008 & Cokriged GPS & 2.14 \\
April 2008 & Cokriged GPS & 2.62 \\
November 2008 & Cokriged GPS & 2.54 \\
March 2009 & Cokriged GPS & 6.19 \\
November 2009 & Cokriged GPS & 1.67 \\
March 2010 & Cokriged GPS & 5.18 \\
October 2010 & Cokriged GPS & 1.19 \\
March 2011 & Cokriged GPS & 1.24 \\
November 2011 & Cokriged GPS & 1.4 \\
March 2012 & Cokriged GPS & 1.25 \\
October 2012 & Cokriged GPS & 0.69 \\
March 2013 & Cokriged GPS & 3.35 \\
November 2013 & Cokriged GPS & 1.49 \\
April 2014 & Cokriged GPS & 2.14 \\
December 2014 & Cokriged GPS & 2.59 \\
March 2015 & SfM & 2.59 \\
March 2016 & SfM & 0.42 \\
November 2016 & Cokriged GPS & 1.24 \\
March 2017 & SfM & 0.28 \\
\hline
\end{tabular}

Table 3.1: Mean standard errors of surfaces used in this study.

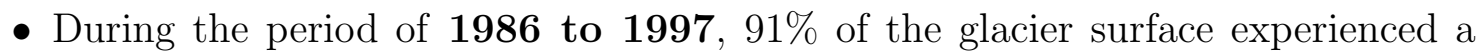
positive gain in surface elevation at a mean rate of $0.53 \mathrm{~m} \mathrm{a}^{-1}$ while $9 \%$ of the glacier experienced a change in surface elevation at a mean rate of $-0.30 \mathrm{~m} \mathrm{a}^{-1}$. The surface lowering was mainly confined to the terminus with a maximum rate of $1.81 \mathrm{~m} \mathrm{a}^{-1}$. The maximum rate of surface rise was $1.55 \mathrm{~m} \mathrm{a}^{-1}$ occurring on the upper accumulation area. The mean rate of elevation change is $+0.47 \mathrm{~m} \mathrm{a}^{-1}$, corresponding to an average change in elevation of $+14.57 \mathrm{~m}$ during the entire period.

- During the period of $\mathbf{1 9 9 7}$ to $\mathbf{2 0 1 7}, 97.9 \%$ of the glacier experienced a surface elevation change at a rate of $-1.22 \mathrm{~m} \mathrm{a}^{-1} \cdot 2.1 \%$ of the glacier experienced an elevation gain at an average rate of $0.15 \mathrm{~m} \mathrm{a}^{-1}$, and this was confined to areas 


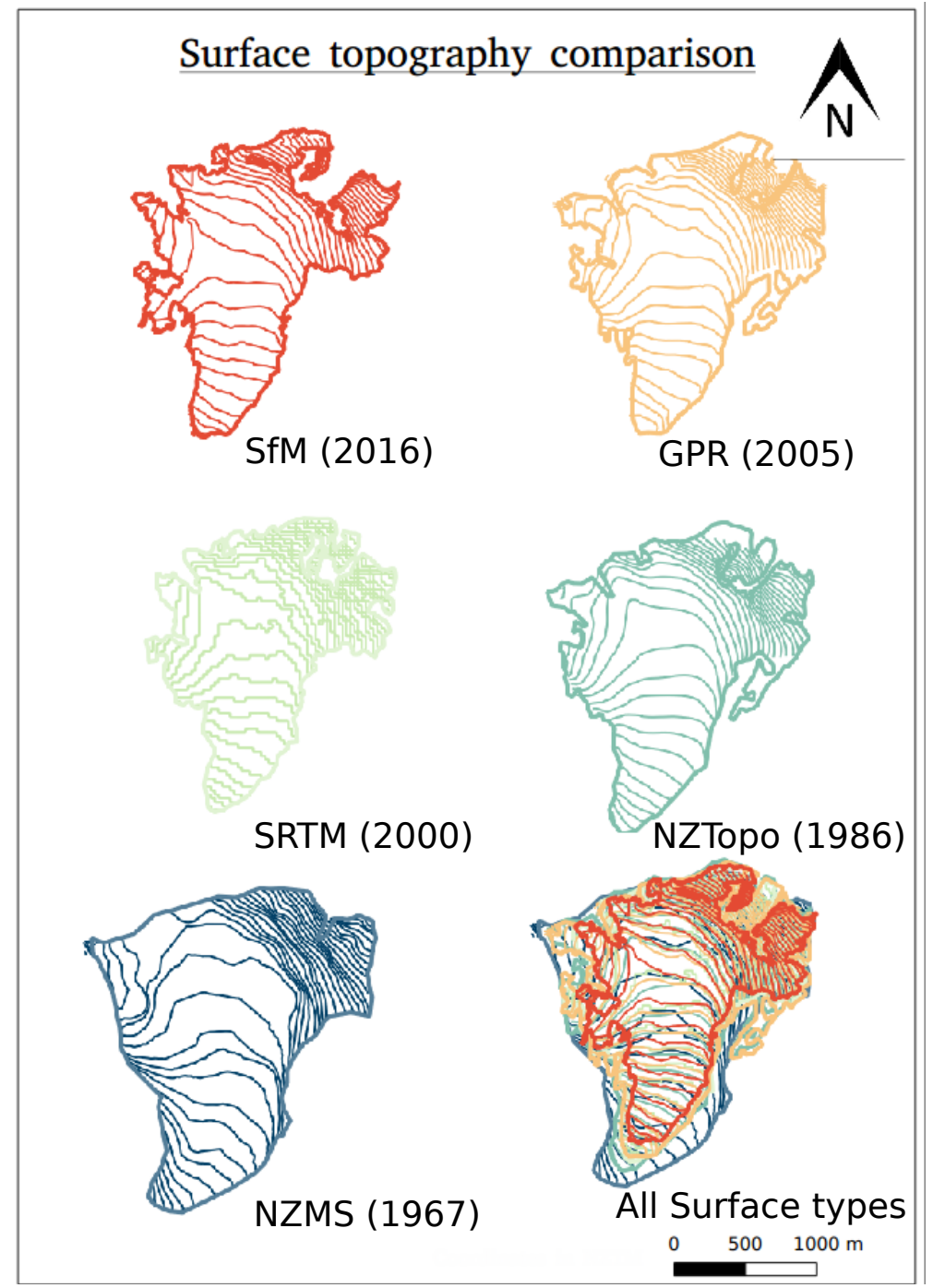

Figure 3.1: Surface contours derived from all 5 DEM types used in this study. All surfaces show a similar topographic pattern with the possible exception of the NZMS surface.

of high elevation ${ }^{1}$. The maximum rate of surface lowering occurred near the terminus at a rate of $3.11 \mathrm{~m} \mathrm{a}^{-1}$, and the maximum rate of surface elevation gain is $0.65 \mathrm{~m} \mathrm{a}^{-1}$. The mean rate of elevation change is $-1.19 \mathrm{~m} \mathrm{a}^{-1}$, corresponding to an average surface elevation change of $-23.8 \mathrm{~m}$ during the entire period. Figure 3.3 shows average surface elevation change for all surfaces clipped to the 2017 glacier extent.

\footnotetext{
${ }^{1}$ Areas of high elevation also correspond to areas of large surface interpolation errors in the 1997 co-kriged DEM as a result of sparse elevation data points.
} 


\section{Rate of surface elevation change}

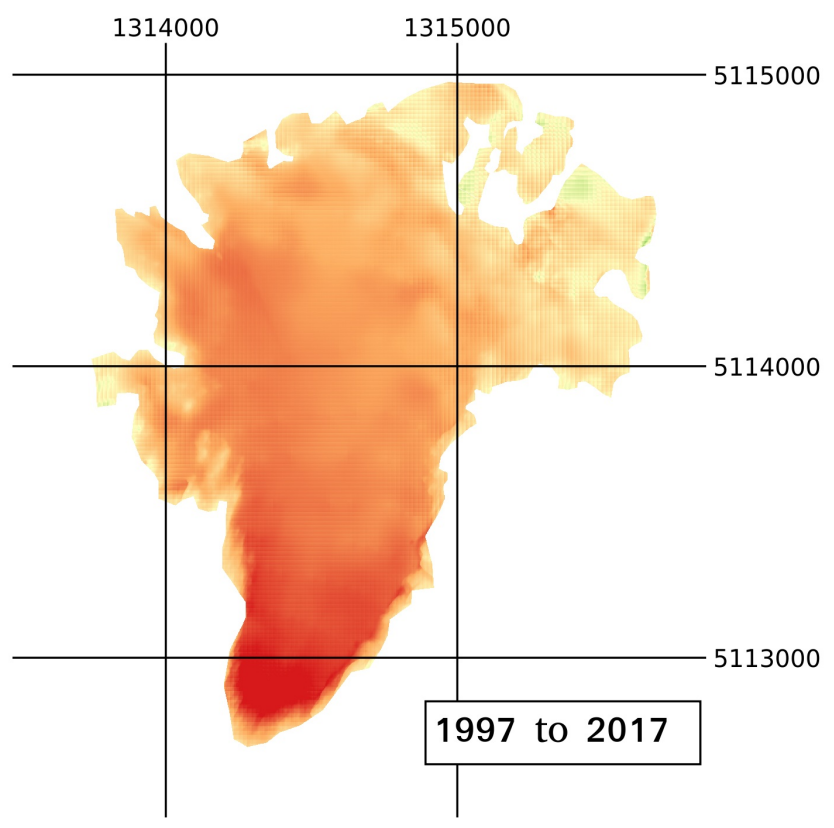

Legend

Rate of change (m/year)

$-2.5$

$\square-1.25$

$\square 0$

1.25

2.5

Coordinates in NZTM
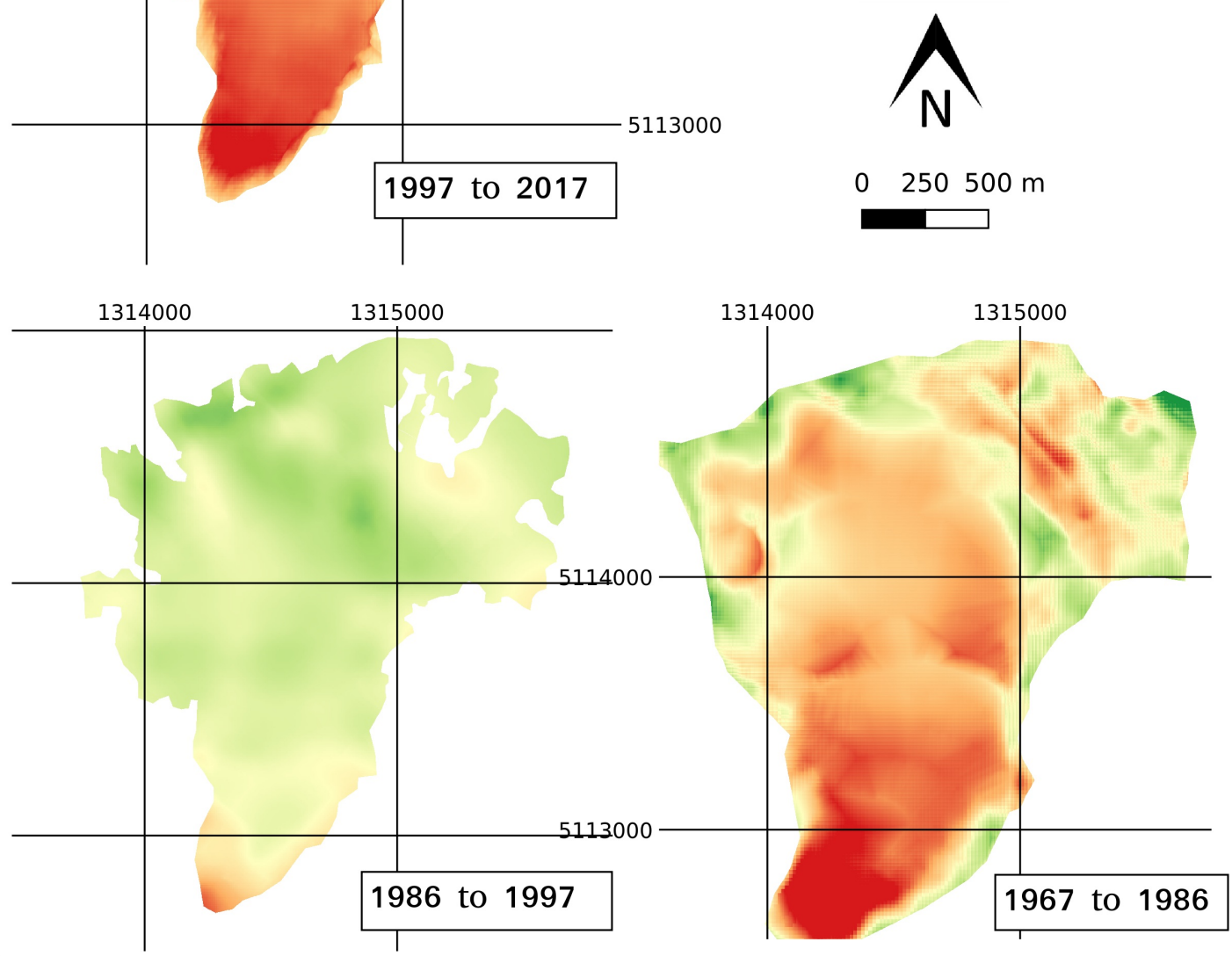

Figure 3.2: Rate of surface elevation change for the 1967 to 1986, a period of surface lowering, 1986 to 1997, a period of surface elevation increase, and 1997 to 2017, a period of surface lowering.

From the period 2005 to 2017, increased surface elevation sampling reveals seasonal 


\section{Mean surface elevation through time}

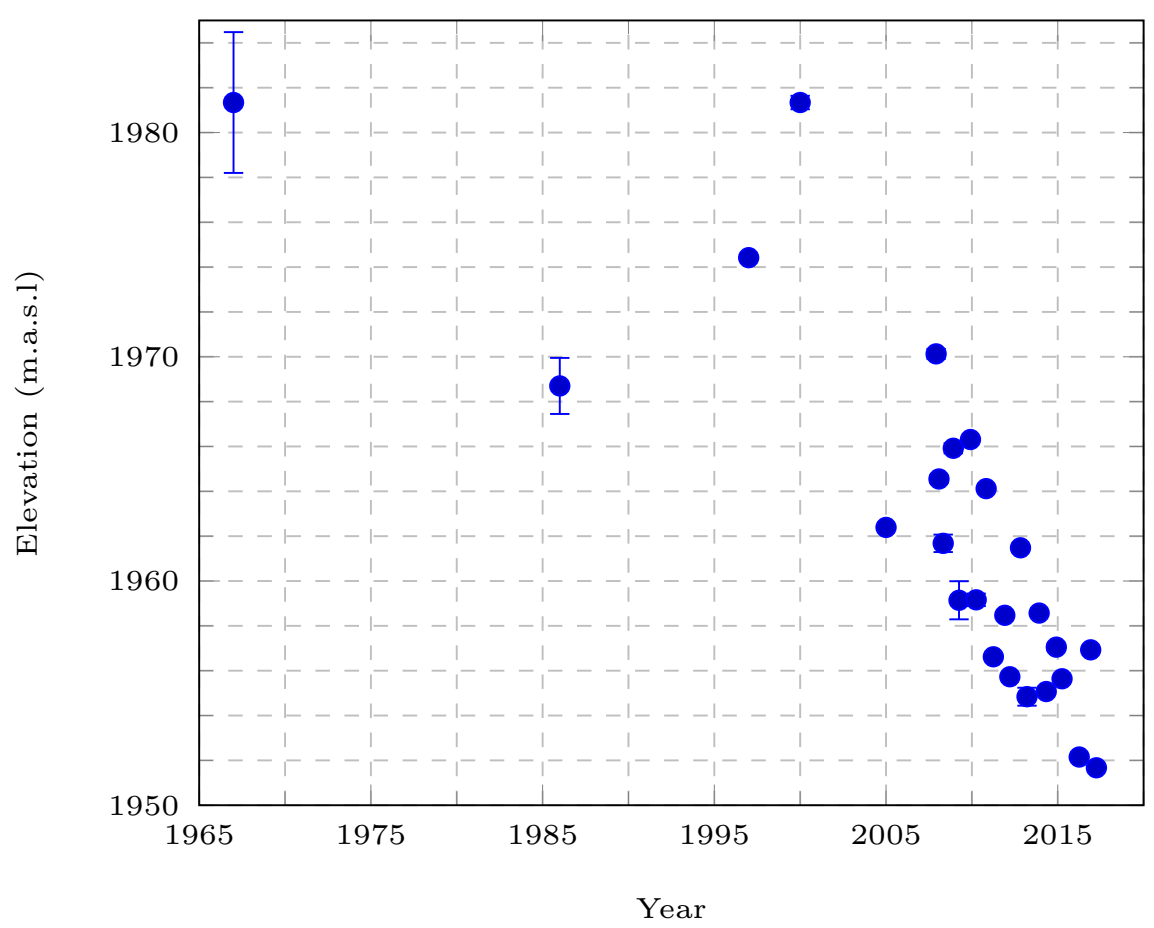

Figure 3.3: Mean surface elevation of all surfaces, clipped to the 2017 glacier extent. Error bars represent 95\% confidence intervals in the mean. Confidence intervals for the 1967, 1986, and 2000 DEMs were calculated assuming 300, 250, and 2500 points respectively.

surface elevation change (Tables 3.2 and 3.3). Greatest (minimum) summer elevation change occurred during the 2007/08 (2011/12) summer when a surface elevation change of $-7.74 \mathrm{~m}(-4.69 \mathrm{~m})$ occurred. Winter volume change is more variable than summer volume change. Greatest (minimum) summer elevation change occurred in the 2009 (2011) winter when a surface elevation change of $+7.95 \mathrm{~m}(+3.16 \mathrm{~m})$ occurred.

Results obtained from the 1967 and 1986 surfaces must be treated with caution. The underlying technique for creating topographic maps (stereoscopic photogrammetry) relies on the matching of features from two overlapping aerial photographs (Blachut, 1971). This is a problem in areas where featureless snow is present. As a result, elevation from these DEMs may be inaccurate, particularly in areas of higher elevation, where snow is more likely to be present (Blachut, 1971). Furthermore, the information section of the NZMS map, states; "Contours through bush, forest, and ice may be of lesser reliability". This is evident in the undulating surface pattern near the terminus 


\begin{tabular}{|c|c|c|}
\hline \multicolumn{3}{|c|}{ Summer ablation } \\
\hline Year & mean elevation change $(\mathrm{m})$ & EoSS elevation (m.a.s.l) \\
\hline $2007 / 08$ & -7.74 & 2270 \\
\hline $2008 / 09$ & -6.92 & 1990 \\
\hline $2009 / 10$ & -6.21 & 1930 \\
\hline $2010 / 11$ & -7.49 & 2285 \\
\hline $2011 / 12$ & -4.69 & 2270 \\
\hline $2012 / 13$ & -6.24 & 1918 \\
\hline $2013 / 14$ & -4.91 & 1950 \\
\hline $2014 / 15$ & -5.71 & 2010 \\
\hline $2016 / 17$ & -6.07 & 1833 \\
\hline
\end{tabular}

Table 3.2: Mean surface elevation change resulting from ablation between 2007-2017.

\begin{tabular}{|c|c|}
\hline \multicolumn{2}{|c|}{ Winter accumulation } \\
\hline Year & mean elevation change $(\mathrm{m})$ \\
\hline 2008 & 3.58 \\
\hline 2009 & 7.95 \\
\hline 2010 & 4.02 \\
\hline 2011 & 3.16 \\
\hline 2012 & 6.1 \\
\hline 2013 & 4.57 \\
\hline 2014 & 4.61 \\
\hline 2016 & 4.39 \\
\hline
\end{tabular}

Table 3.3: Mean surface elevation change resulting from accumulation between 20082016 .

of the glacier where incorrect contouring or glacier classification is likely (Figure C.19 in Appendix C).

Errors in the cokriged surfaces, are more prevalent around the periphery, especially the steep areas on the Southwest face of Mt Brewster. These are likely due to errors in perimeter digitisation, leading to a large vertical error in steep areas. Another cause of error could be that the detrend surface did a poor job in certain areas, leading to a violation in the assumption of stationarity. Furthermore, estimation methods may be prone to underestimate high points, and overestimate low points as a result of averaging (Bohling, 2005b). 


\subsection{The glacier bed}

Figure 3.4 shows the bed DEM. The processed GPR $(2012,2016)$ provided bed elevation to a maximum depth of approximately $80 \mathrm{~m}$, but commonly much less. Figure 3.5 shows the radargram with the deepest interpreted reflection. For all interpreted radargrams, the reader is directed to Appendix D.

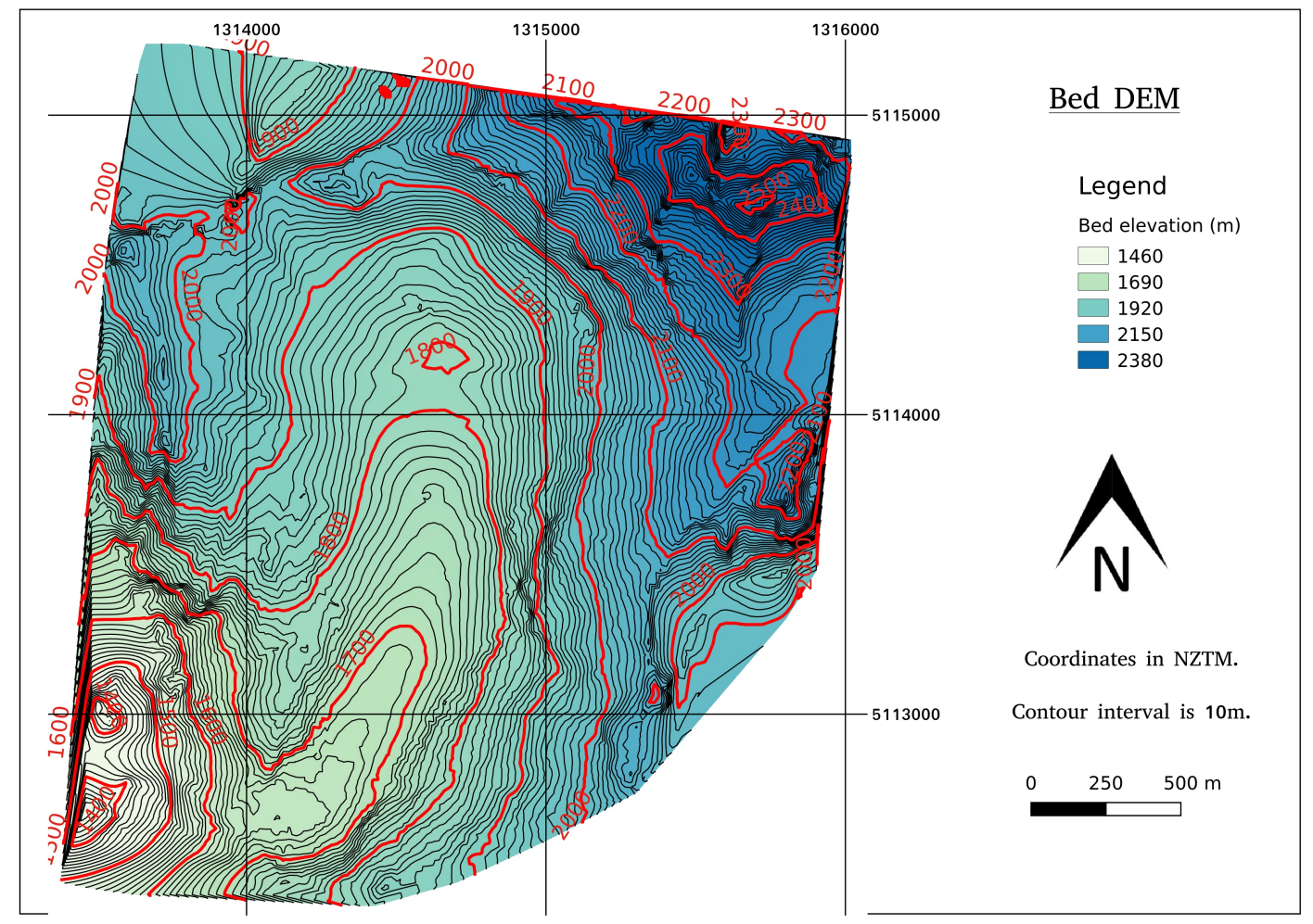

Figure 3.4: Bed DEM constructed from GPR and SFM data, and interpolated using ordinary kriging.

The interpolated bed of Brewster Glacier is in the form of a U-shaped valley (Figure 3.4). The uppermost base of the bed dips gently downslope from $\sim 1800$ m.a.s.l to $\sim 1655$ m.a.s.l at the location of the lakes, at an average inclination of $\sim 5.2^{\circ}$ along the valley bottom. The kriged portion of the bed has an associated standard error (Figure 3.6) of $3.39 \mathrm{~m}$ to $30 \mathrm{~m}$, and a mean standard error of $6.69 \mathrm{~m}$. It is noted that there is a smooth transition between the kriged part of the bed DEM and the highly accurate SfM derived portion of the DEM. 

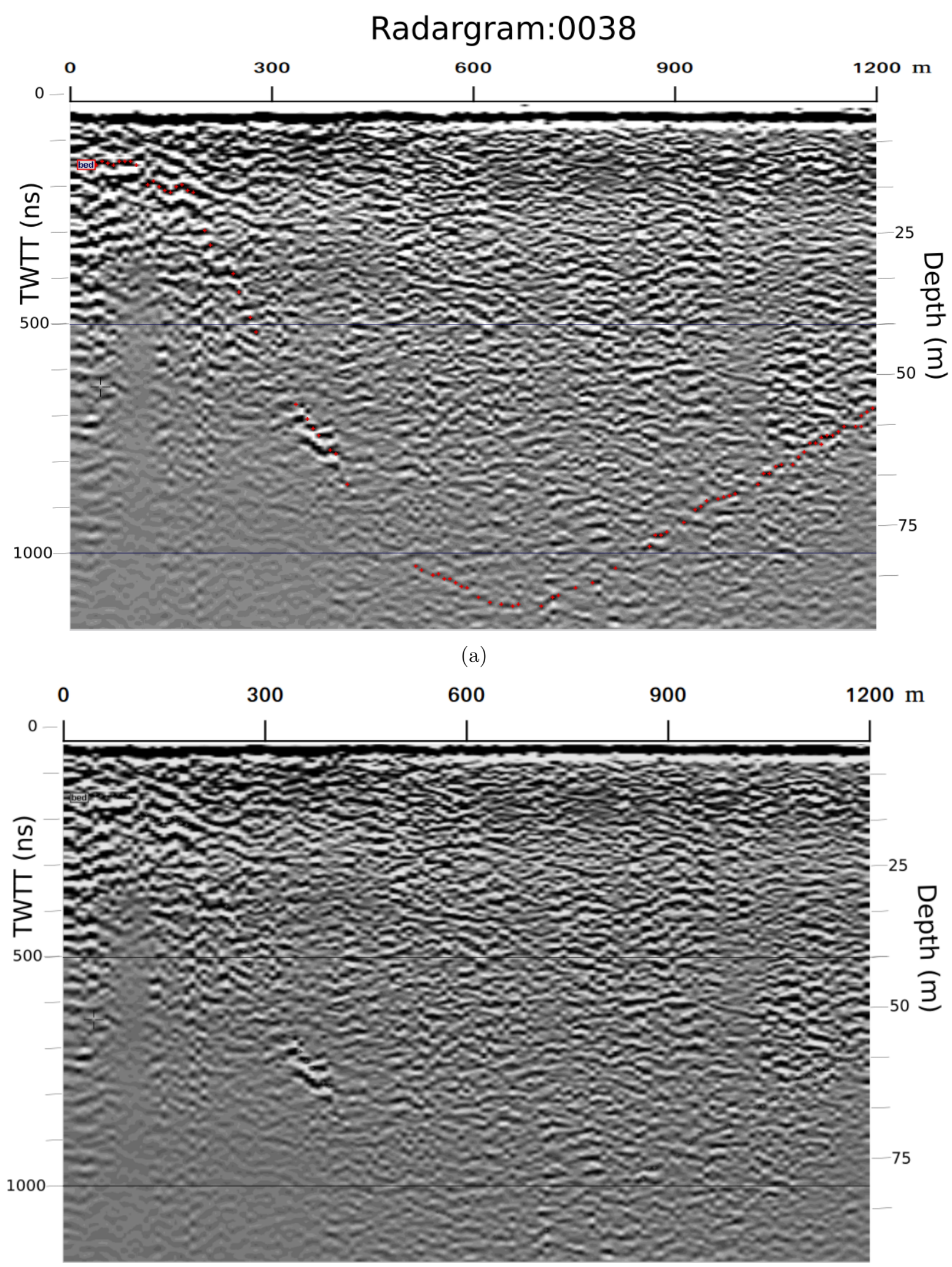

(b)

Figure 3.5: Interpreted (a), and non-interpreted (b) radargrams for profile 0038 (Figure D.3). 


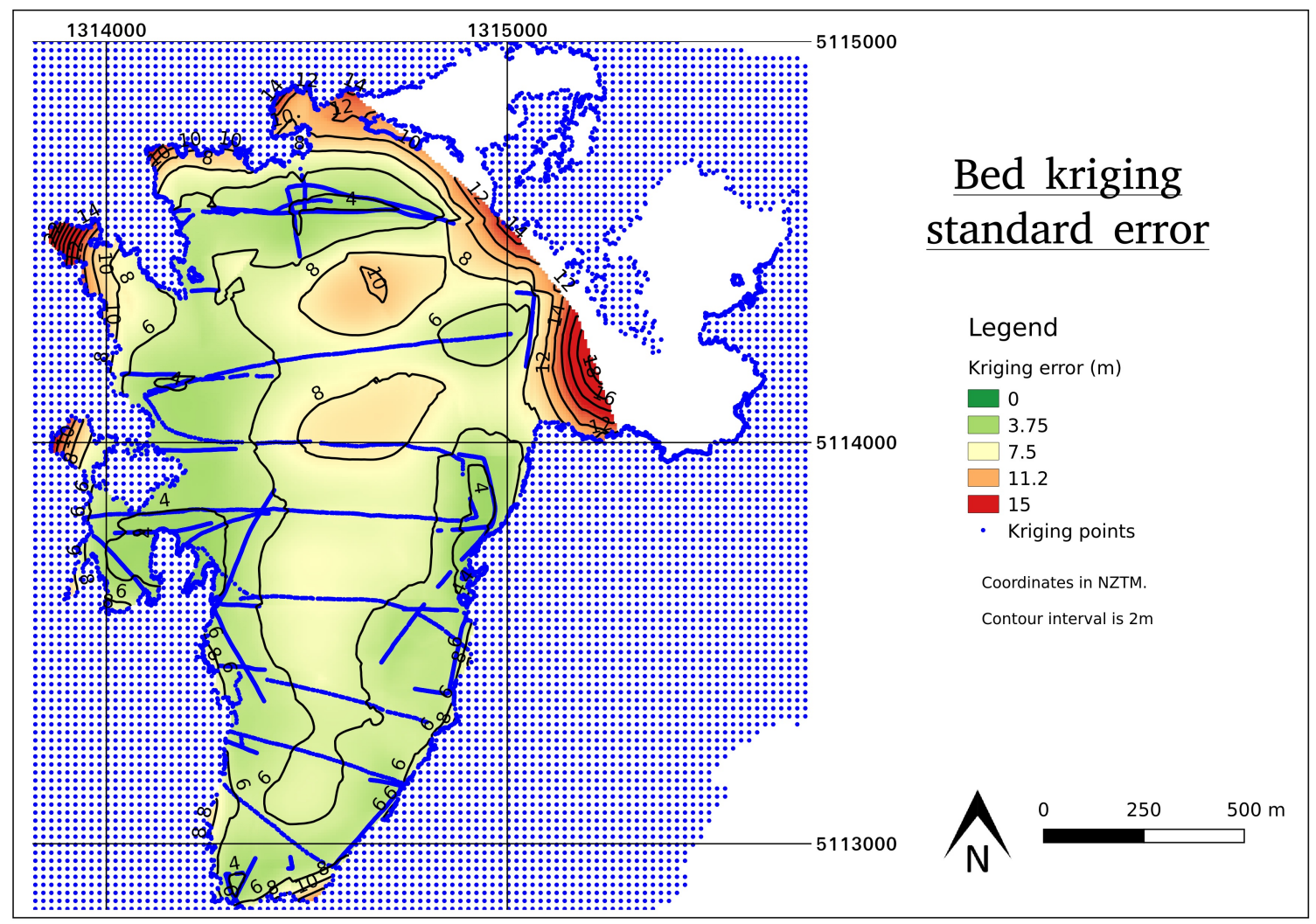

Figure 3.6: Kriging standard error for bed DEM

\subsection{Area}

The area history of Brewster Glacier (Figure 3.7) reveals overall, but not monotonic, decline (Figure 3.8). In more detail, this can be summarised as a period of area decrease from $1967\left(3.03 \mathrm{~km}^{2}\right)$ to $2000\left(2.28 \mathrm{~km}^{2}\right)$, a period of area increase from 2000 to $2005\left(2.46 \mathrm{~km}^{2}\right)$, followed by a trend of overall area decrease until $2017\left(1.90 \mathrm{~km}^{2}\right)$. The large uncertainties for Landsat derived area estimates (Figure 3.8) are due to the relatively poor resolution of Landsat images compared to other datasets, resulting in errors between $12.2 \%$ and $15.0 \%$ of the total estimated area. This compares to errors of $5.3 \%, 6.0 \%$, and $0.6 \%$ to $4.7 \%$ for NZMS, NZTopo, and SfM respectively. The overall rate of area change is $-0.02 \mathrm{~km}^{2} \mathrm{a}^{-1} \pm 0.003 \mathrm{~km}^{2} \mathrm{a}^{-1}$ (68\% confidence interval).

The temporal overlap between SfM and Landsat area calculations allows the different results of the two methods to be observed. For Landsat, the area estimates are $1.99 \mathrm{~km}^{2}, 1.91 \mathrm{~km}^{2}$, and $2.06 \mathrm{~km}^{2}$, for the years 2015, 2016, and 2017 respectively. For SfM the area estimates are $2.040 \mathrm{~km}^{2}, 1.88 \mathrm{~km}^{2}$, and $1.90 \mathrm{~km}^{2}$ for the years 2015,2016 , 


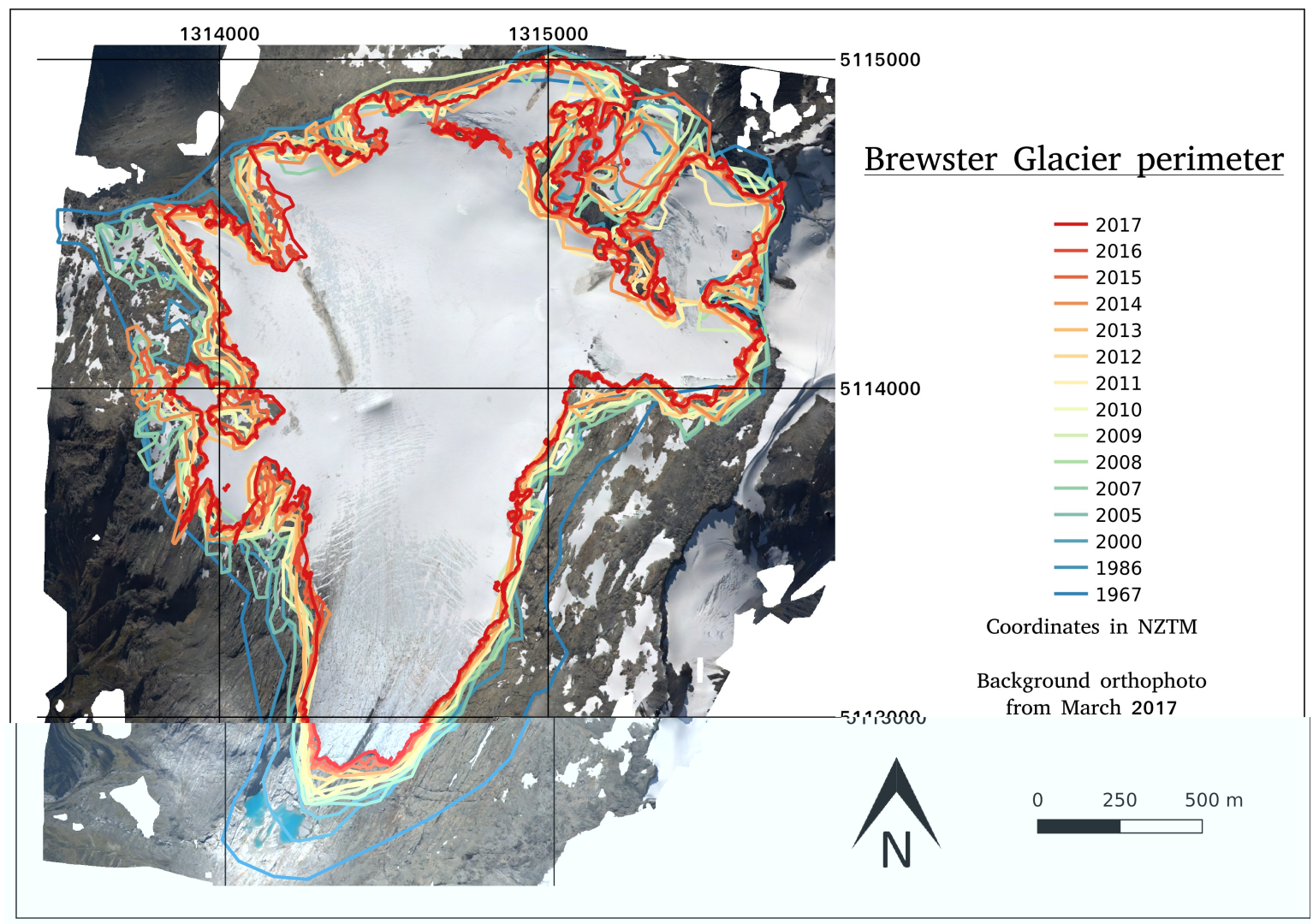

Figure 3.7: Glacier periphery topographic error for NZDEM SoS v1.0 (1986).

and 2017 respectively. This equates to a difference in area estimate of $-0.05 \mathrm{~km}^{2}, 0.03$ $\mathrm{km}^{2}$, and $0.16 \mathrm{~km}^{2}$. This compares to the area error estimates, calculated in Section 2.5.4, of $\pm 0.30 \mathrm{~km}^{2}, \pm 0.14 \mathrm{~km}^{2}$, and $\pm 0.16 \mathrm{~km}^{2}$. Further, the area history of Brewster Glacier is more variable than both the volume (excluding seasonal variations), and terminus position histories. When digitising the glacier perimeter, areas of ice no longer connected to the glacier were not included in the perimeter (See Appendix B). This results in large stepwise changes in area. This is observed by comparing perimeters for 2015 and 2016, where glacier area decreased much more than overall ice area as ice became disconnected from the glacier (on the south west face of Mt Brewster). Conversely, seasonal snow which has not fully melted may be incorporated as part of the glacier. As such, much of this area variability may be considered as noise which represents recent weather, rather than longer term climate. A comparison of EoSS ELA elevation and area returns a correlation coefficient of -0.55 . 


\section{Area of Brewster Glacier:1967-2017}

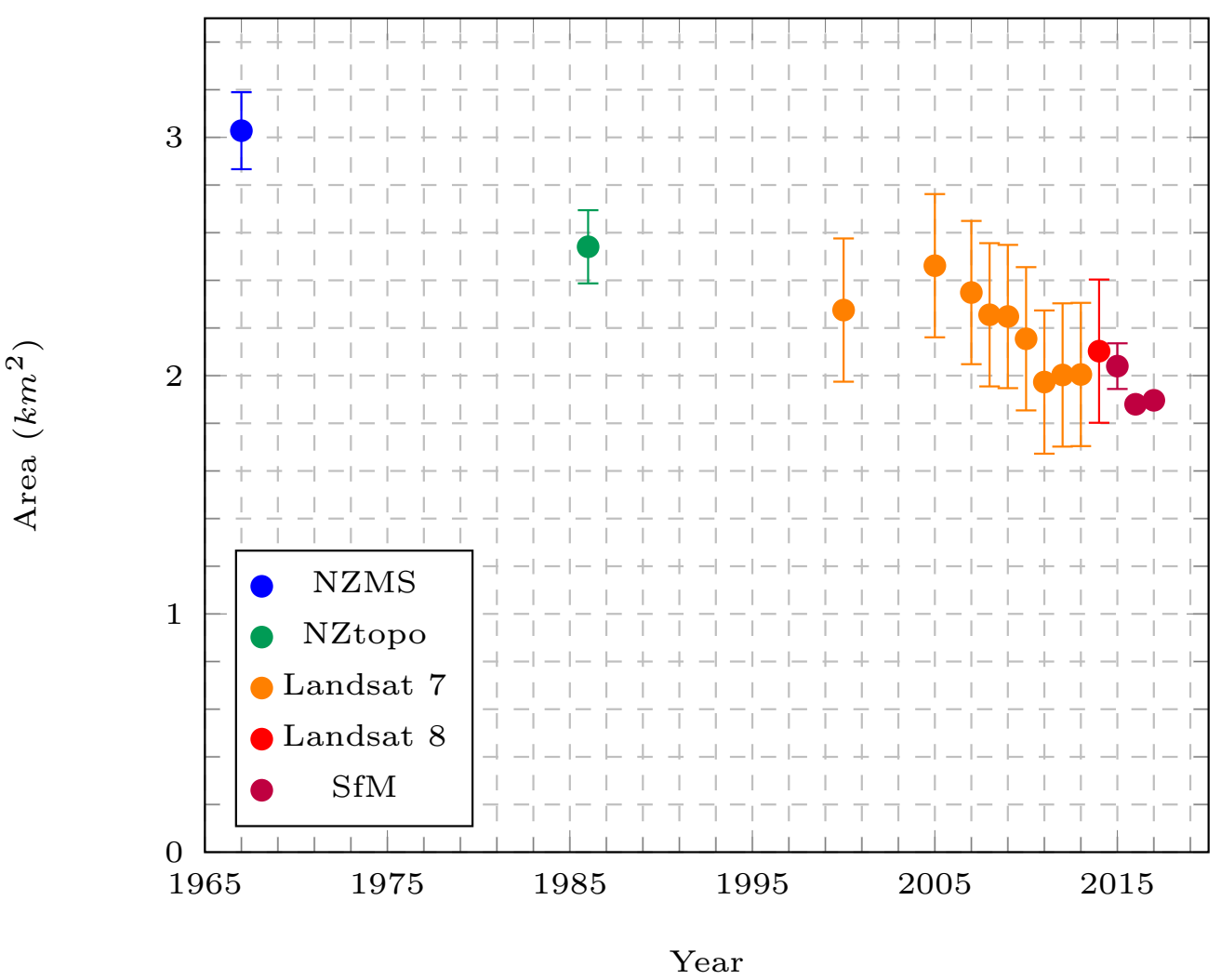

Figure 3.8: Area change history of Brewster Glacier:1967-2017. Error bars are 1 standard deviation.

\subsection{Terminus position}

Brewster Glacier retreated $390.4 \mathrm{~m}$ over the the study period. This retreat is represented graphically in Figure 3.9, which shows a steady retreat from 1967 to 2017 at an average rate of $7.8 \mathrm{~m} \mathrm{a}^{-1}$, bar a small advance from 2014 to 2015 of $8.2 \mathrm{~m}$. From the period 1967 to 1986 the terminus retreated by $141 \mathrm{~m}$ at an average rate of $7.42 \mathrm{~m} \mathrm{a}^{-1}$. This increased from 1986 to 1997 when $107 \mathrm{~m}$ of terminus retreat occurred at a rate of $9.7 \mathrm{~m} \mathrm{a}^{-1}$. This slowed slightly from the period 1997 to 2017, as $142 \mathrm{~m}$ of retreat occurred at a rate of $7.1 \mathrm{~m} \mathrm{a}^{-1}$.

The overlapping Landsat and GPS estimates allow the Landsat estimates to be scrutinised. The Landsat data shows an advance of $26 \mathrm{~m}$ between 2007 and 2008 (Figure 3.9), whereas the GPS data shows terminus retreat of $8 \mathrm{~m}$ during this time 


\section{Terminus retreat of Brewster Glacier:1967 to 2017}

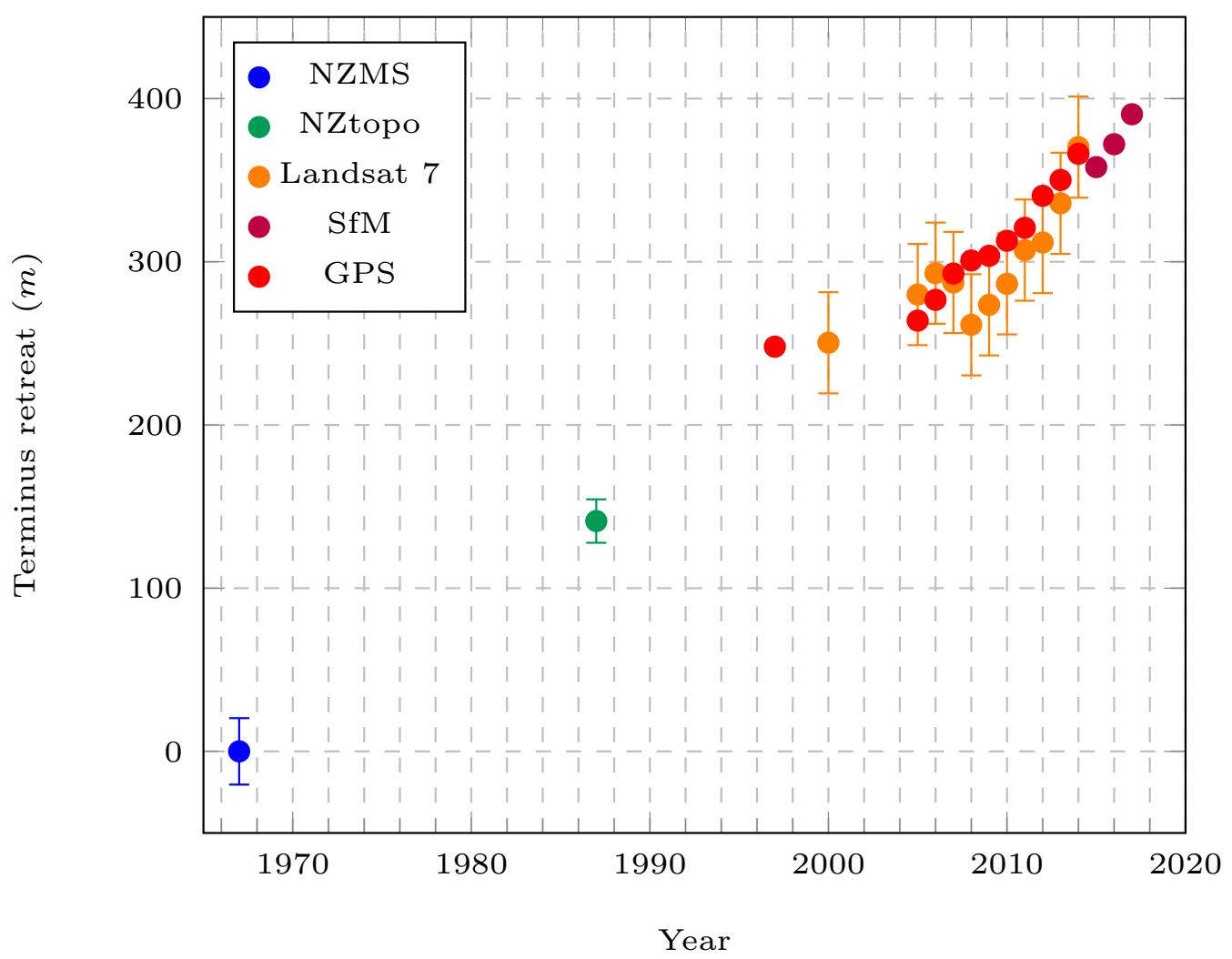

Figure 3.9: Terminus retreat of Brewster Glacier:1967-2017

2. By examining aerial photography, such an advance is not observable. Furthermore, by tracking crevasses from orthophotographs, a terminus velocity of only $7.5 \mathrm{~m} \mathrm{a}^{-1}$ is calculated rendering such an advance impossible.

\subsection{Volume}

The volume of Brewster Glacier has declined from $0.153 \mathrm{~km}^{3}$ in $1967^{3}$ to $0.064 \mathrm{~km}^{3}$ in 2017 at an average rate of $0.0018 \mathrm{~km}^{3} \mathrm{a}^{-1}$ (Figure 3.10). Within this period, there was a gain in mass between 1986 and 1997 of $0.010 \mathrm{~km}^{3}$. During the period 2005 to 2017, the improved temporal resolution shows seasonal volume fluctuation (Figure 3.11), from a low at the end of summer, to a high at the end of winter. For 1967 the

\footnotetext{
${ }^{2}$ This error is likely to be the result of the relatively low resolution of Landsat images, cloud cover/shading effects, or ground-truthing errors.

${ }^{3}$ Much of the distributed volume change relating to the 1967 surface is assumed to be error relating to incorrect geolocation of the NZMS map, land categorisation error, or incorrect contouring.
} 


\section{Volume change:1967 to 2017}

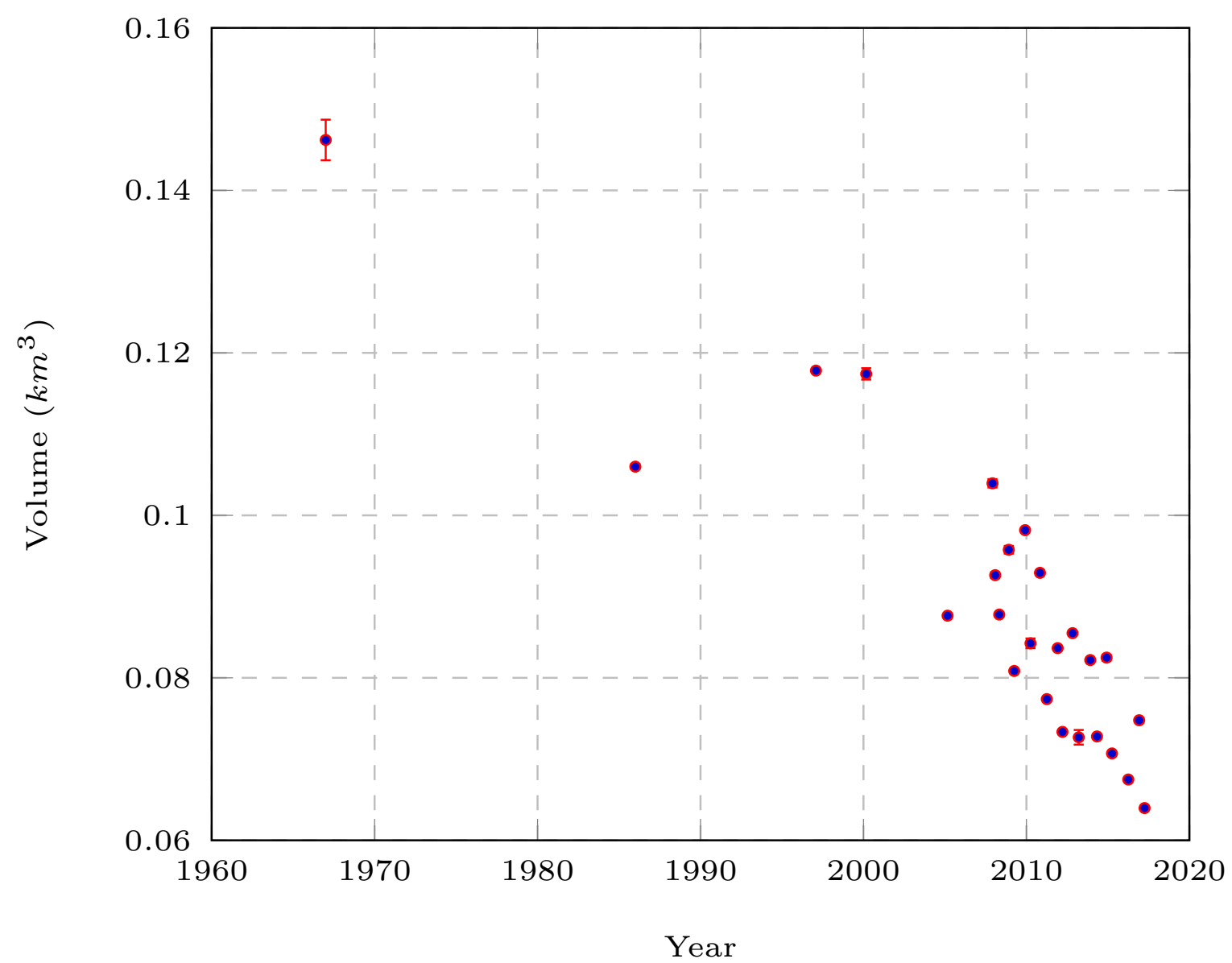

Figure 3.10: Volume change history of Brewster Glacier:1967 to 2017. Error bars represent the $95 \%$ confidence interval as a function of surface elevation only.

volume uncertainty is $\pm 0.013 \mathrm{~km}^{3}$ at the $68 \%$ confidence interval, of which \pm 0.003 $\mathrm{km}^{3}$ is attributed to surface elevation uncertainty and $\pm 0.010 \mathrm{~km}^{3}$ is attributed to bed elevation uncertainty. 1967 contains the highest uncertainty value. For March, 2017 the volume uncertainty is $\pm 0.0101 \mathrm{~km}^{3}$ at the $68 \%$ confidence interval, of which \pm $0.0001 \mathrm{~km}^{3}$ is attributed to surface elevation uncertainty, and $\pm 0.010 \mathrm{~km}^{3}$ is attributed to bed elevation uncertainty. 


\section{Volume change:2005 to 2017}

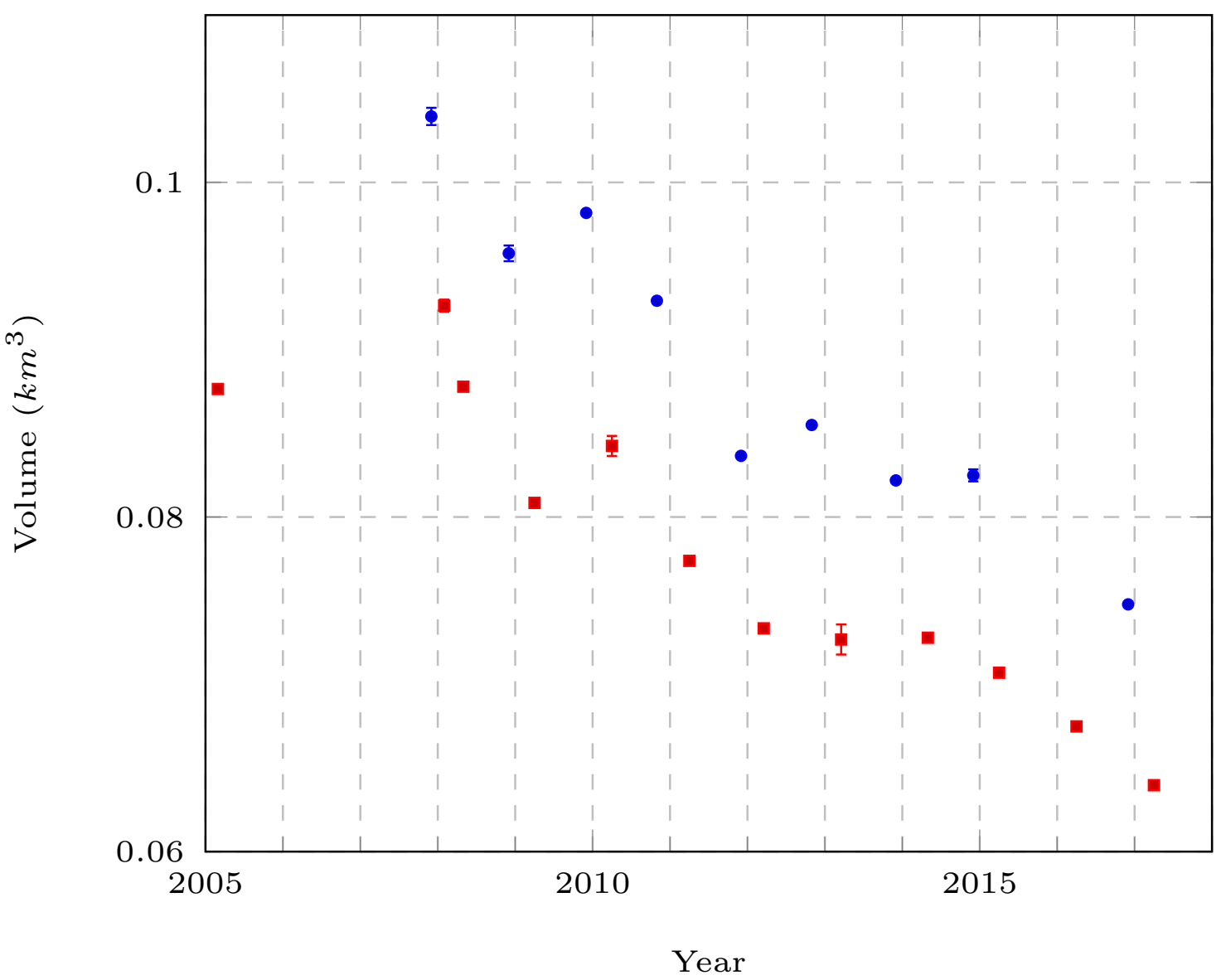

Figure 3.11: Volume change history of Brewster Glacier:2005 to 2017. Blue circles show winter volume. Red squares show summer volume. Error bars represent the $95 \%$ confidence interval as a function of surface elevation only. 


\section{Discussion}

In this section I will discuss the relationship between the geodetic and direct mass balance estimates, the relationship between the geodetic mass balance record and climate, and the timing and magnitude of glacier responses to climate in relation to Franz Josef and Fox Glaciers, New Zealand glaciers, both of which have detailed records.

\subsection{Relationship between geodetic and direct mass balance estimates}

Cullen et al. (2016) developed a high temporal and spatial resolution glaciological mass balance record for Brewster Glacier over the period 2004 to 2016. In order to convert the volume record of my study to a mass balance record such as that of Cullen et al. (2016), some assumptions on the density model must be made. The density of ice is commonly assumed to be $900 \mathrm{kgm}^{-3}$, however this does not take into account, the density of the firn layer, and the changes in firn thickness over time (Huss, 2013). Following the recommendations of Huss (2013), a density of $750 \mathrm{~kg} \mathrm{~m}^{-3}$ is adopted for the time period of one year. The resulting plot is shown in Figure 4.1, and shows that the geodetic mass balance change closely follows but underestimates the direct mass balance change. Particularly high disagreement is shown for years 2009 and 2010, where GPS points used for the 2008 and 2009 surfaces are sparse. It is therefore likely that geodetic surface interpolation error is largely responsible for this disagreement. Other errors may have arisen due to the density assumption used to convert elevation change to $\mathrm{m}$ w.e. Properly, the firn density must be calculated with knowledge of the accumulation rate, the firn temperature, as well as some known constants and 


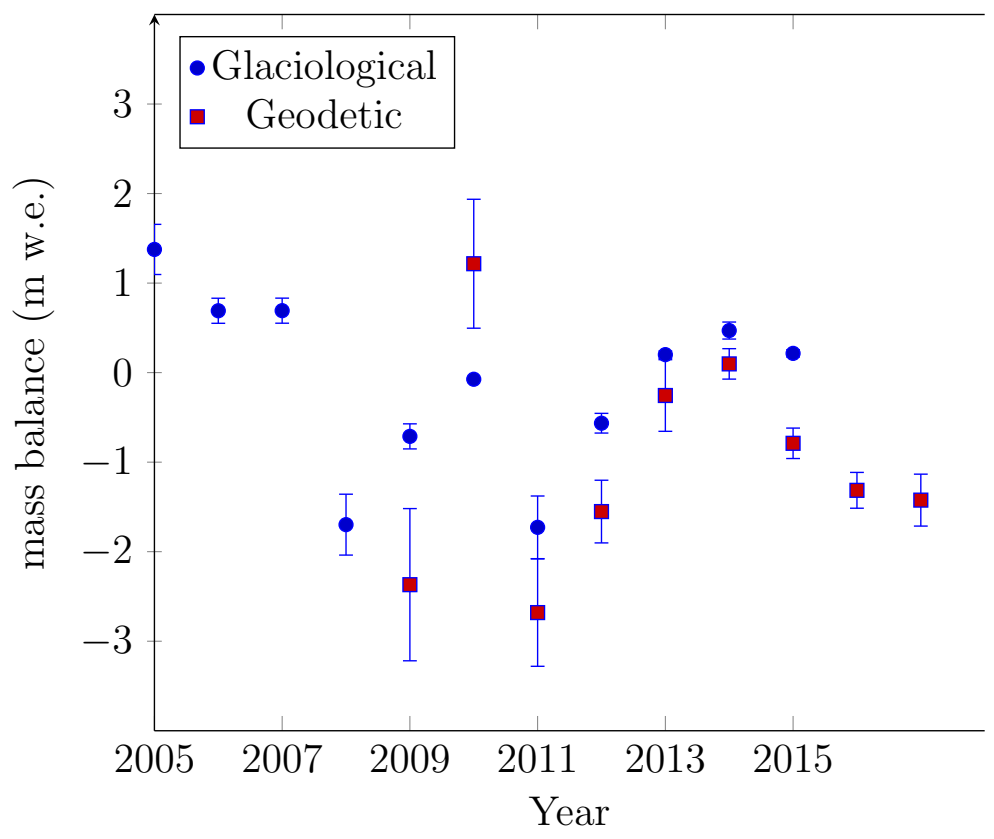

Figure 4.1: The glaciological mass balance record of Brewster Glacier derived by Cullen et al. (2016) (red crosses) compared to the volume record derived in this study (blue circles). Error bars for the geodetic method relate to the uncertainty in the mean elevation (95\% confidence interval), and the uncertainty of density, assumed to be \pm $75 \mathrm{~kg} \mathrm{~m}^{-3}$ as given by Huss (2013) (Figure 4.2).

empirically derived constants (Herron and Langway, 1980). In extreme cases, the volume to mass conversion factor $(f \Delta v)$ may range from a negative value to a value greater than that of water. Such extreme values of $f \Delta v$ typically occur over short observation periods (less than five years), as is evidenced by Figure 4.2 (Huss, 2013). An example of a negative $f \Delta v$ is when a large amount of ablation has occurred, and a similarly large amount of accumulation. In this case, the volume of the glacier may have increased, yet the mass of the glacier has decreased. Subsequently, changes of mass balance must be treated with caution over short time intervals. In order to obtain the same mass balance values as Cullen et al. (2016) for the 7 years when the geodetic record overlaps the glaciological record, $f \Delta v$ values ranging from $-600 \mathrm{~kg} \mathrm{~m}^{-3}$ (for 2013 ) to $3600 \mathrm{~kg} \mathrm{~m}^{-3}$ (for 2014) would need to be applied to the geodetic volume change. The two most extreme required $f \Delta v$ values occur when both the geodetic and glaciological mass balances are close to zero.

Examples in the literature of similar comparisons of the two methods also show a negative bias towards the geodetic method. In a study of an Alaskan glacier from 
the period 1974 to 1999, Cox and March (2004) found that geodetic values were more negative by $0.2 \mathrm{~m}$ w.e. and $0.4 \mathrm{~m}$ w.e. over the periods 1974 to 1993 and 1974 to 1999 respectively. In another, 2-part study, Koblet et al. (2010) reanalysed aerial photographs for the construction of high accuracy topographic maps and subsequent geodetic mass balance record from 1969 to 1999, while Zemp et al. (2010) compared this geodetic mass balance record to that of the glaciological record of the same time period. They found that the glaciological record produced mass balance values which were up to $0.8 \mathrm{~m}$ w.e. higher per decade and that the glaciological method underestimated mass loss in three of the four decades. Conversely, Basantes-Serrano et al. (2016) reported an underestimation of mass loss from geodetic records by $4.66 \mathrm{~m}$ w.e. during the period 1997 to 2009 on glacier 15a, a South American tropical glacier. They attributed this to an underestimation of precipitation in the upper reaches of the glacier due to a lack of measurement stakes in the accumulation area. On a global scale, the more negative mass balance values of the geodetic record, is concordant with the findings of Cogley (2009), where geodetic mass balance measurements were found to be more negative than direct measurements. This meant that the contribution of glacial ice loss to sea level was under-estimated by 0.3 to $0.4 \mathrm{~mm} \mathrm{a}^{-1}$. Cogley (2009), however, attributed

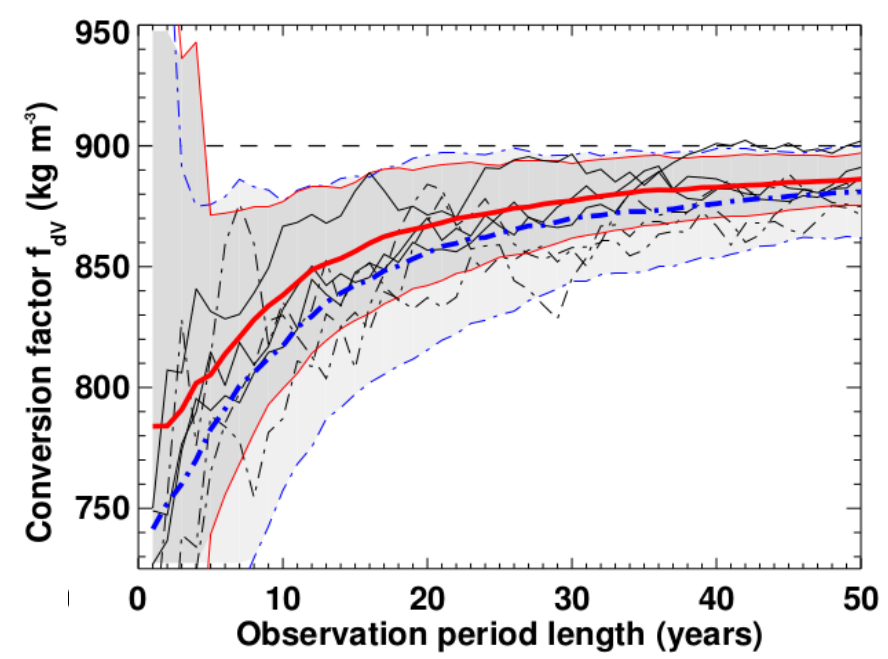

Figure 4.2: Modeled density conversion factors. Solid lines show conversion factors for an increase in mass balance, and dotted lines show the conversion factor for a decrease in mass balance. The shaded area represents \pm 2 standard deviations. Note the high density conversion factor variation for short observational periods. Figure taken from Huss (2013), p.882. 
this to the overall under-representation of tidewater glaciers in the glaciological mass balance record. Other reasons for this discrepancy may be due to the overestimation of density when using the geodetic method, or interpolation errors when using the glaciological method.

\subsection{Volume change and response time}

The volume change history of Brewster Glacier (Figure 3.10, 4.3) can be summarised as a decrease in volume from $1967\left(0.131 \mathrm{~km}^{3}\right)$ to $1986\left(0.086 \mathrm{~km}^{3}\right)$, an increase in volume until $1997\left(0.128 \mathrm{~km}^{3}\right)$, and a subsequent decrease in volume until 2017 (0.064 $\mathrm{km}^{3}$ ). The period from 2005 to 2017 corresponds to an increase in temporal resolution, and thus shows seasonal variations (Figure 3.11), an example of which can be seen in Figure 4.4.

Surface profile and terminus position are interdependent (Cuffey and Paterson, 2010). Before an advance, it is expected that a change in surface elevation will occur which increases from the head of the glacier, to the terminus. This is no different for

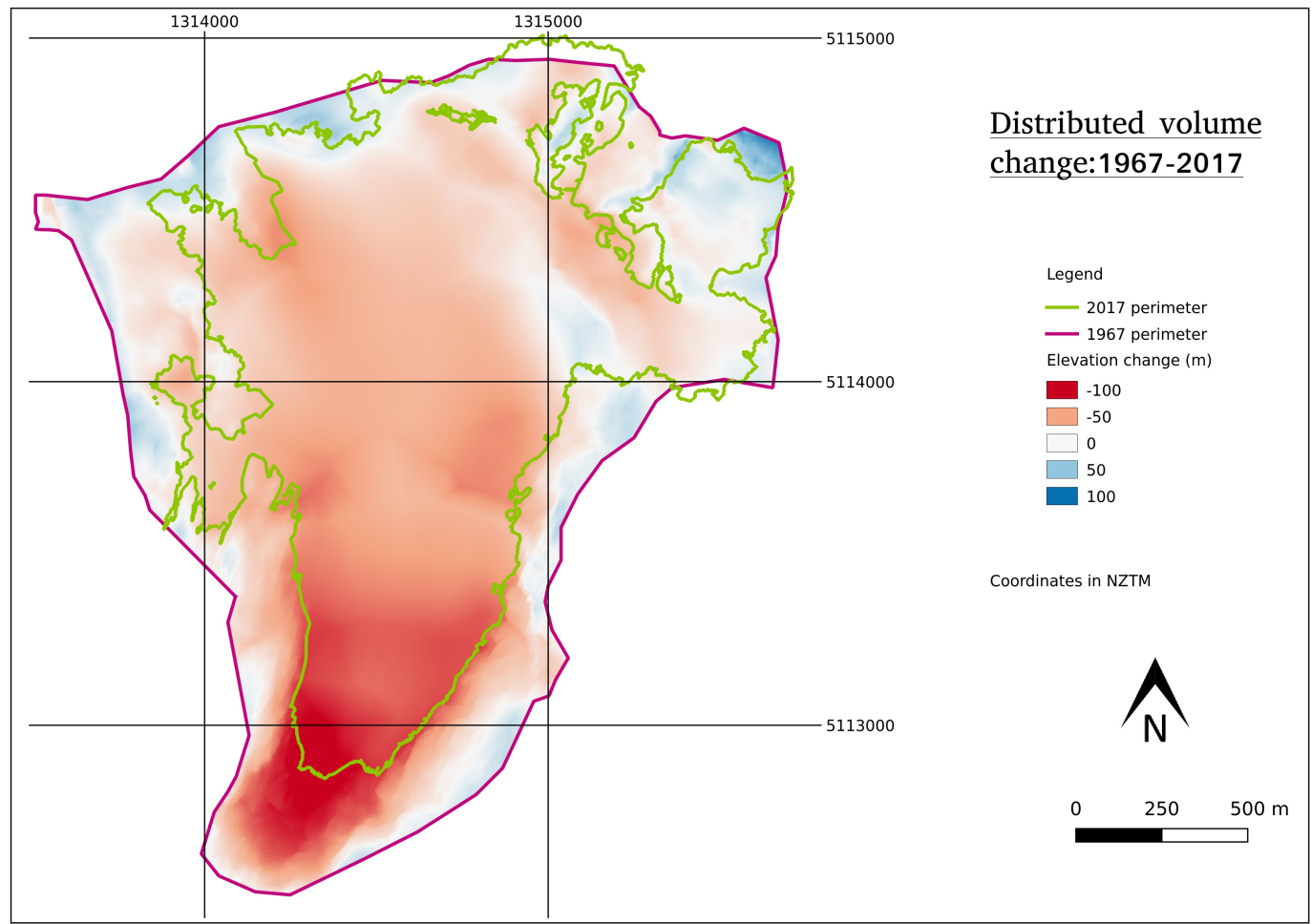

Figure 4.3: Distributed volume change of Brewster Glacier: 1967 to 2017. 


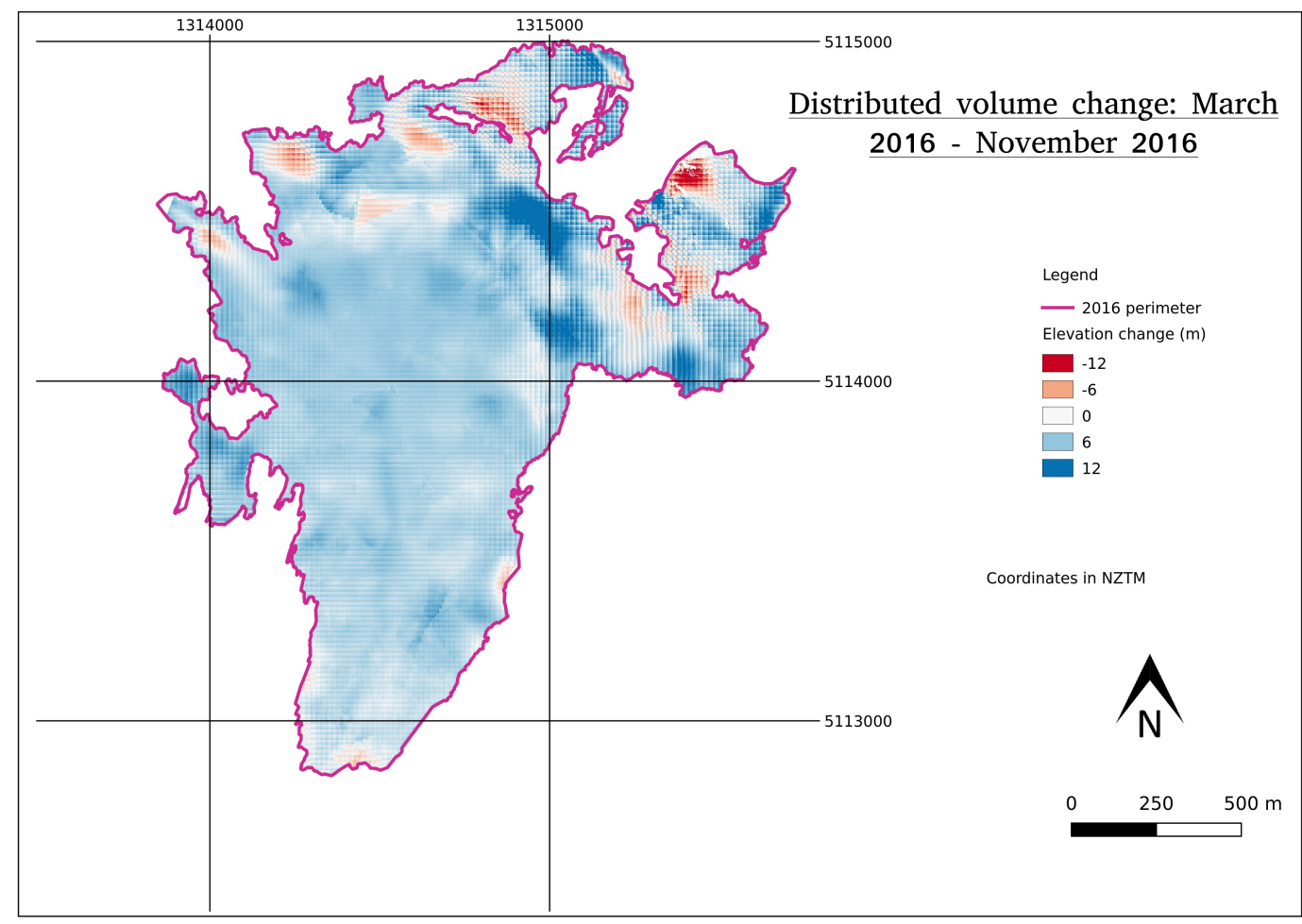

(a)

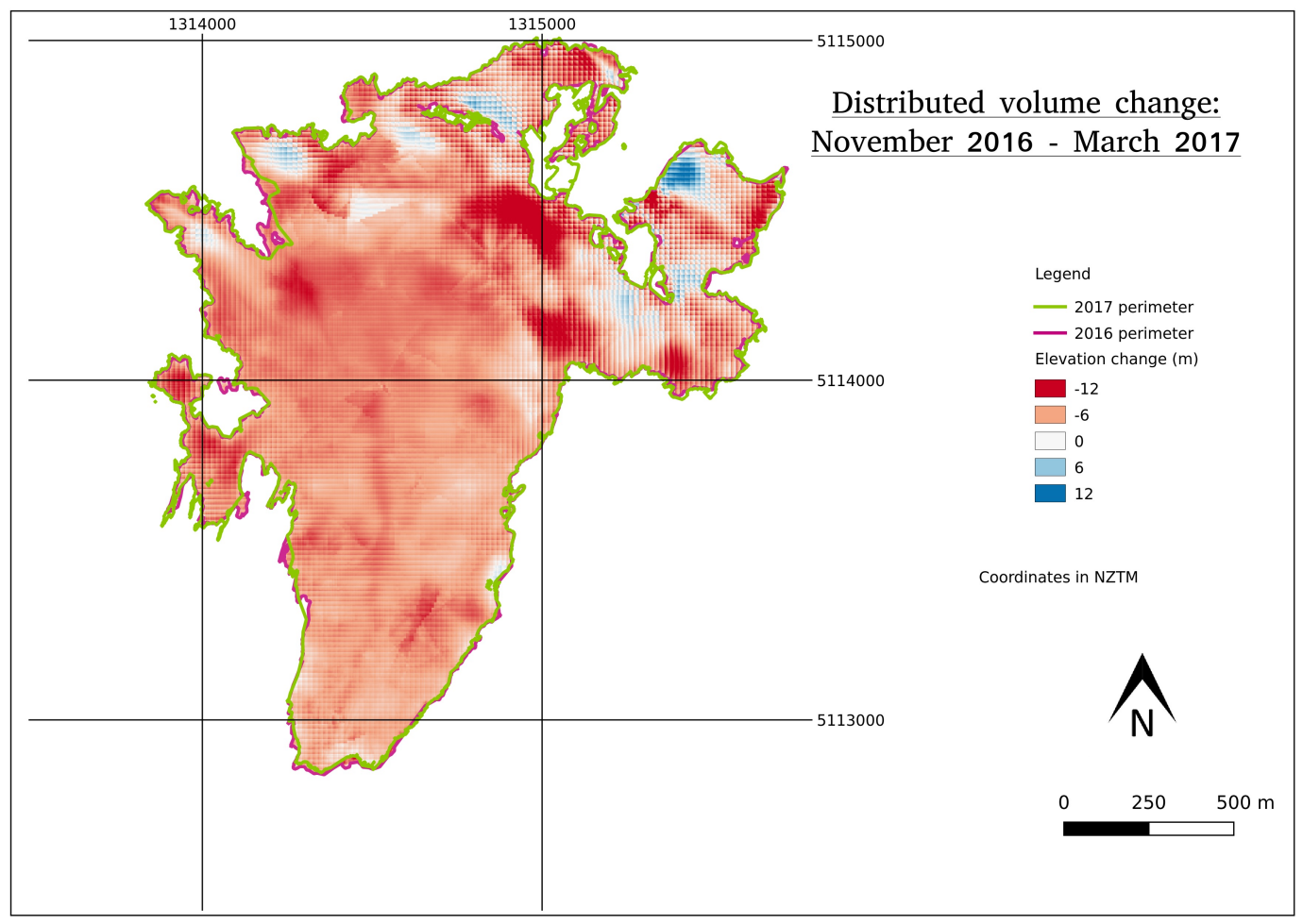

(b)

Figure 4.4: Distributed volume change of Brewster Glacier: March 2016 to November 2016 (a) and November, 2016 to March, 2017 (b).

Brewster Glacier (Figure 4.6, 4.7, Figure 4.5 for orientation), where positive changes in surface elevation, are most pronounced in the accumulation area (Figure 4.8), and 


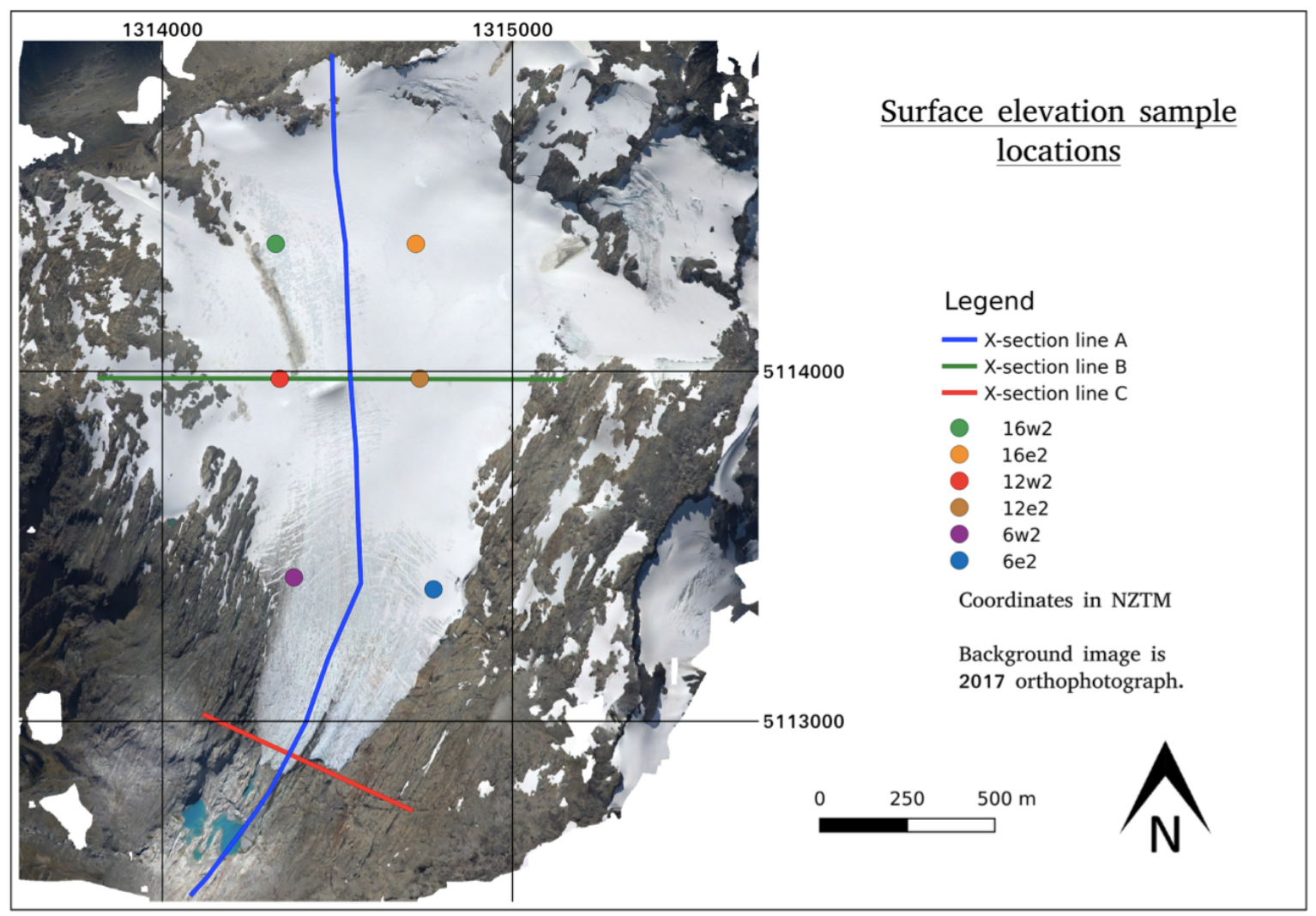

Figure 4.5: Map showing location of lines and points along which the surface is sampled, shown in subsequent Figures, 4.7, 4.8,4.9,4.6.

negative changes, most pronounced near the terminus (Figure 4.9). Figures 3.2 and 3.9, show that after times of negative (positive) mass balance, there is a corresponding period of relatively rapid (slow) retreat which occurs some time later. Of particular interest is the period of glacier thickening between 1986 to 1997 (Figures 3.2, and 4.7). During this period, the terminus continued to retreat at an increased rate of $9.7 \mathrm{~m} \mathrm{a}^{-1}$ (compared to the previous rate of $7.8 \mathrm{~m} \mathrm{a}^{-1}$ ). This is partly due to the difference in response times for volume, and length, whereby length typically takes around 1/3 longer to respond than volume (Oerlemans, 2001). Furthermore, mass balance gradients are typically nonlinear, with higher gradients correlating with lower elevations (Oerlemans and Hoogendoorn, 1989). Thus, for a glacier with slow mass transfer such as Brewster Glacier (calculated to be $7.5 \mathrm{~m} \mathrm{a}^{-1}$ at the terminus by tracking crevasses from orthophotographs), relatively high ablation rates at the tongue 
may inhibit thickening and advance of the terminus. Therefore, the period of glacier thickening never led to a significant advance (Figure 4.7),

\section{Point surface elevation change}
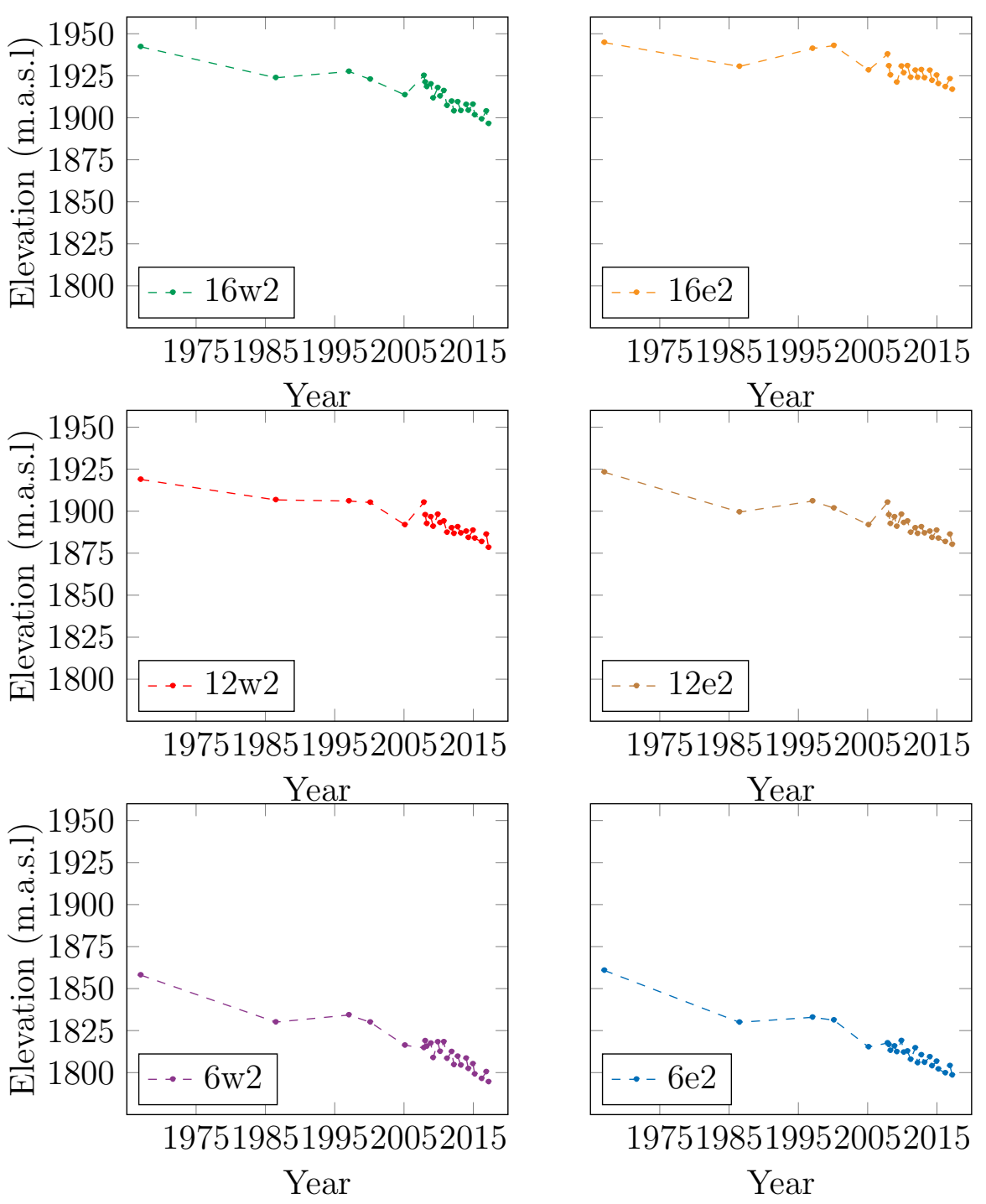

Figure 4.6: Surface elevation change for point locations shown in Figure 4.5

and instead, during the following period of 1997 to 2017, retreat occurred at a decreased rate, while the majority of the glacier experienced a rapid decrease in surface elevation. Although terminus retreat continued during this period, the rate of retreat slowed to $7.1 \mathrm{~m} \mathrm{a}^{-1}$ (Figure 3.9), and to $\sim 2 \mathrm{~m} \mathrm{a}^{-1}$ during 1997 to 2005. Nevertheless, it is possible to use the change of terminus retreat rate to calculate a reaction time.

The reaction time is the time taken for the first noticeable terminus response to a change in climate (Oerlemans, 2001; Adhikari et al., 2009). The response time $\left(t_{r}\right)$ is the 


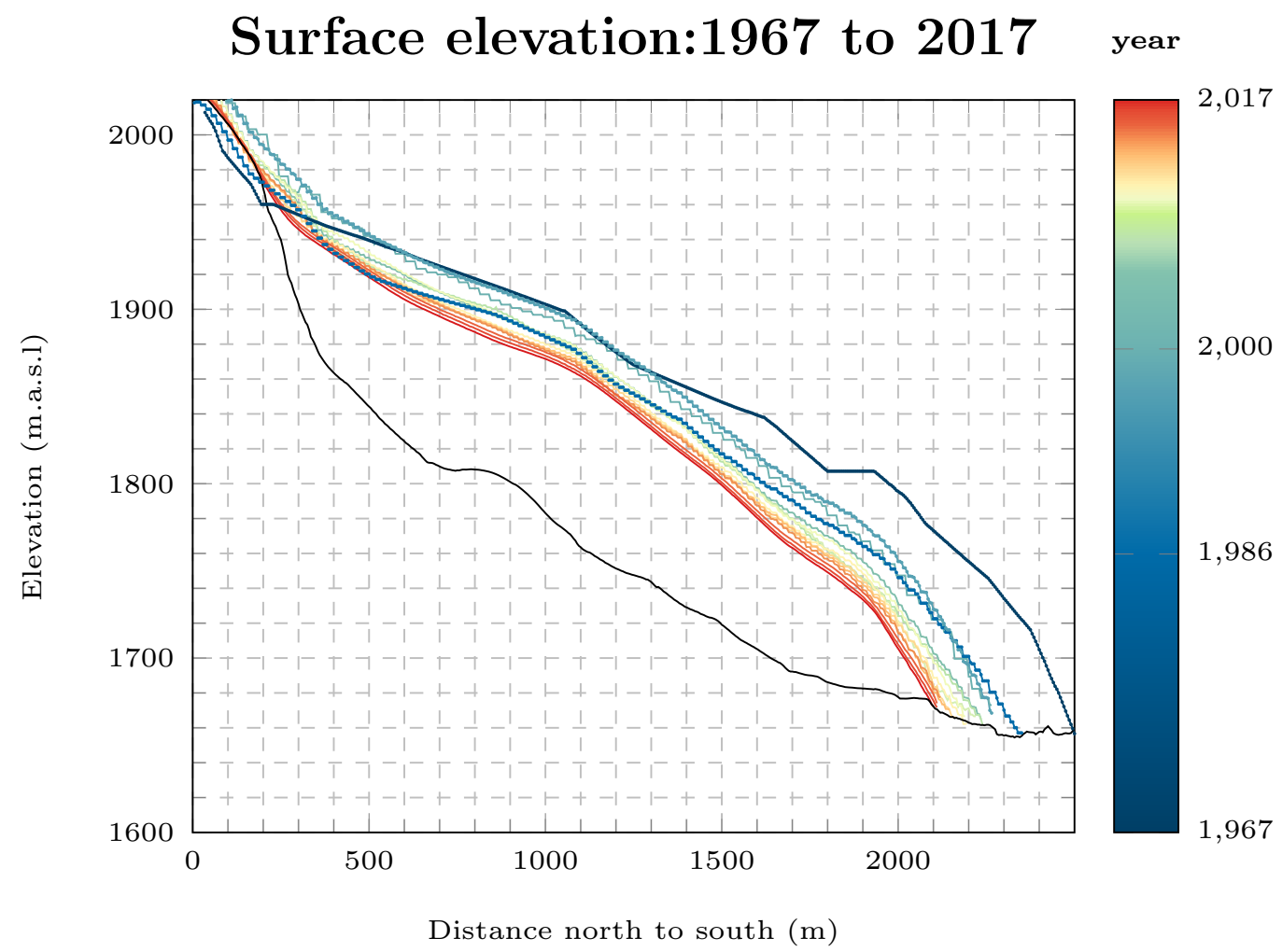

Figure 4.7: Surface elevation change history of Brewster Glacier along cross-section line A in Figure 4.5 from 1967 to 2017. Where there is more than one surface for a given year, only the surface representing the end of summer is shown. Figure E.1 shows all surfaces.

time it takes for a glacier to reach equilibrium after a change in climate, a process that is theoretically infinitely long (Adhikari et al., 2009). The transient nature of both climate and glaciers renders the response time difficult to test from climate data. As such, the response time is determined from simple numerical models. As a glacier approaches a new equilibrium asymptotically (Oerlemans, 2001), here we use the definition of response time from Cuffey and Paterson (2010); "the time a glacier takes to complete most of it's adjustment to a change in mass balance", where 'most' means $1-e^{-1}(\sim$ $2 / 3$ ) of the glacier's adjustment. Nye (1960), developed a simple model to estimate the response time based on kinematic wave theory. Essentially, the main model inputs are the flow velocity at the terminus, and the length of the glacier. The main criticism of this approach is that it renders response times which are much longer than the climate and glacier records suggest (by an order of magnitude). Indeed, this yields a very large response time for Brewster Glacier of $\sim 340$ years. Another simple approach is that 


\section{Surface elevation:1967 to 2017 year}

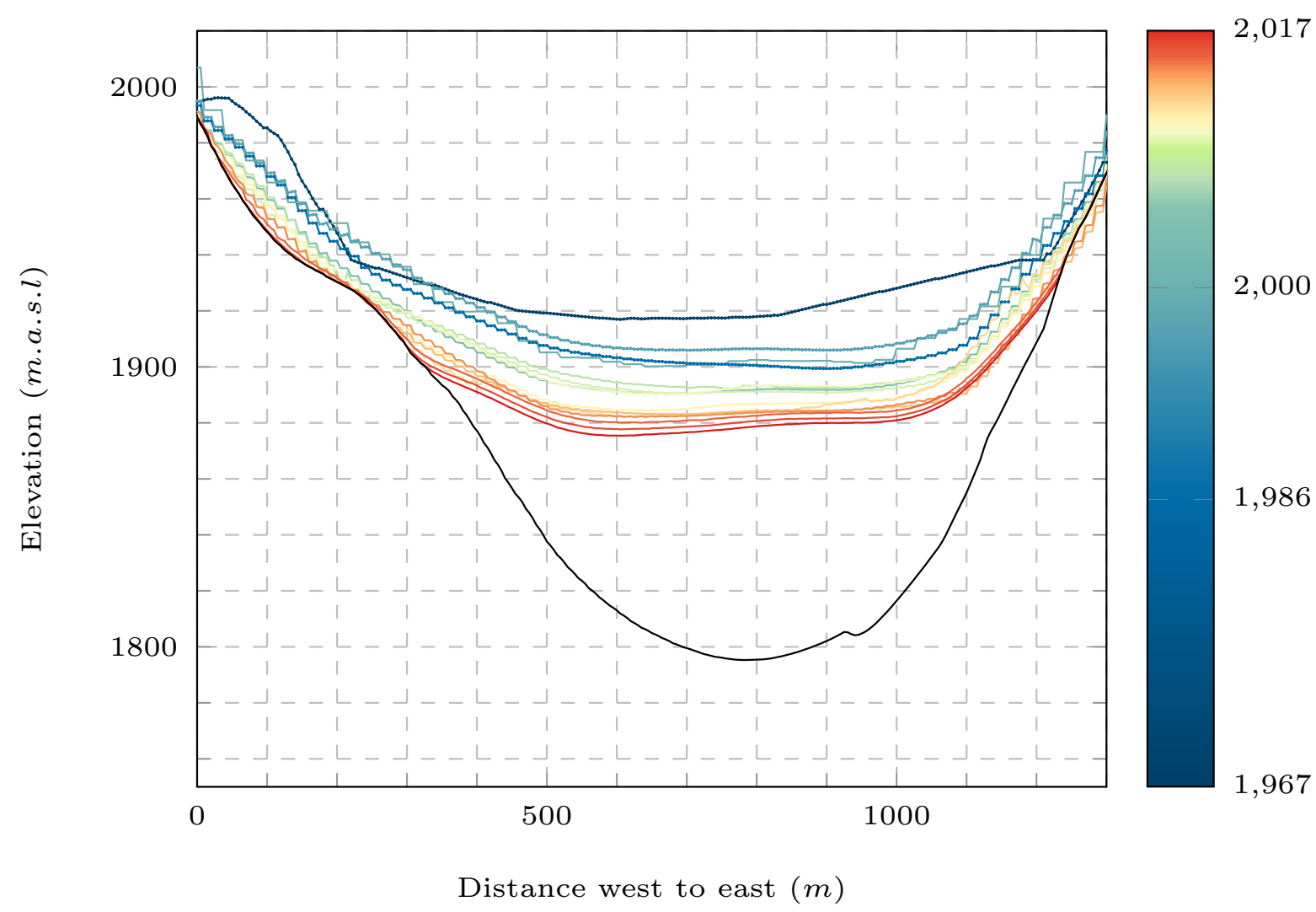

Figure 4.8: Surface elevation change history of Brewster Glacier along cross-section line B in Figure 4.5 from 1967 to 2017. Where there is more than one surface for a given year, only the surface representing the end of summer is shown. Figure E.3 shows all surfaces.

given by Jóhannesson et al. (1989a) and shown in Equation 4.1.

$$
t_{r}=H_{\max } / \dot{a}_{0}
$$

Based on a terminus ablation rate $\left(\dot{a}_{0}\right)$ of $3.5 \mathrm{~m}$ w.e $\mathrm{a}^{-1}$ (the mean ablation rate from 2015 to 2017$)$, and maximum thicknesses of $\left(H_{\max }\right) 105$ to $151 \mathrm{~m}$, Equation 4.1 gives a response time of between 33 and 43 years $^{1}$. The reaction time cannot be confidently calculated directly from climate-glacier observations, as no stepwise changes in climate occur in nature (Adhikari et al., 2009). However, one empirical method to calculate the reaction of a glacier to climate is to correlate the glacier length record with a climate

\footnotetext{
${ }^{1}$ For the 2017 and 1967 glacier thickness respectively, and assuming no change in terminus ablation rate.
} 


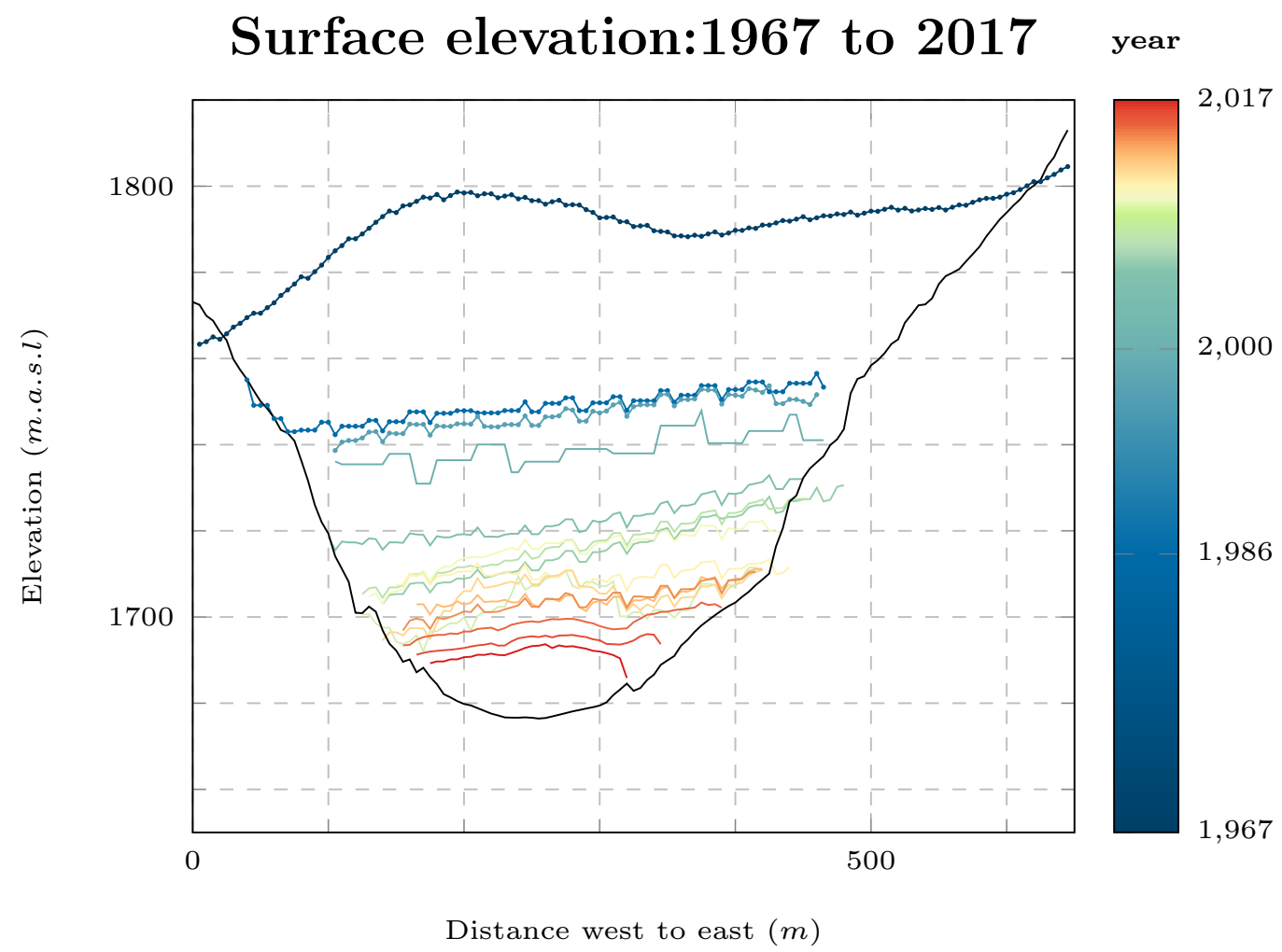

Figure 4.9: Surface elevation change history of Brewster Glacier along cross-section line C in Figure $4.5: 1967$ to 2017. Where there is more than one surface for a given year, only the surface representing the end of summer is shown. Figure E.5 shows all surfaces. Of note is the poor alignment of the 1967, 1986, and 2000 surfaces. This is especially the case for the 1967 surface where the glacier surface crosses the bed. Also note the unusual surface topography of the 1967 surface.

proxy for a given number of lags (reaction time in years), a method used in many studies (e.g. McClung and Armstrong (1993)). It is common for studies to use the ELA as a proxy for climate (Hooker and Fitzharris, 1999; Kayastha and Harrison, 2008; Clare et al., 2002), and fortunately, Brewster Glacier has an ELA record dating back to 1978 (Chinn et al., 2005b). The small terminus response magnitudes and large response times compared to the ELA record, render it difficult to correlate Brewster's terminus position history with the ELA record with confidence. Furthermore, the lack of ELA estimates before 1978 means that only a small number of measurements can be cross correlated, especially at larger lag times. Nevertheless, correlations were calculated for a number of lags (Figure 4.10).

The highest negative correlation coefficient is -0.55 for a lag of 17 years, estimated by cross correlating 12 overlapping points (high ELA negatively correlates with a short 


\section{ELA vs terminus position correlation}

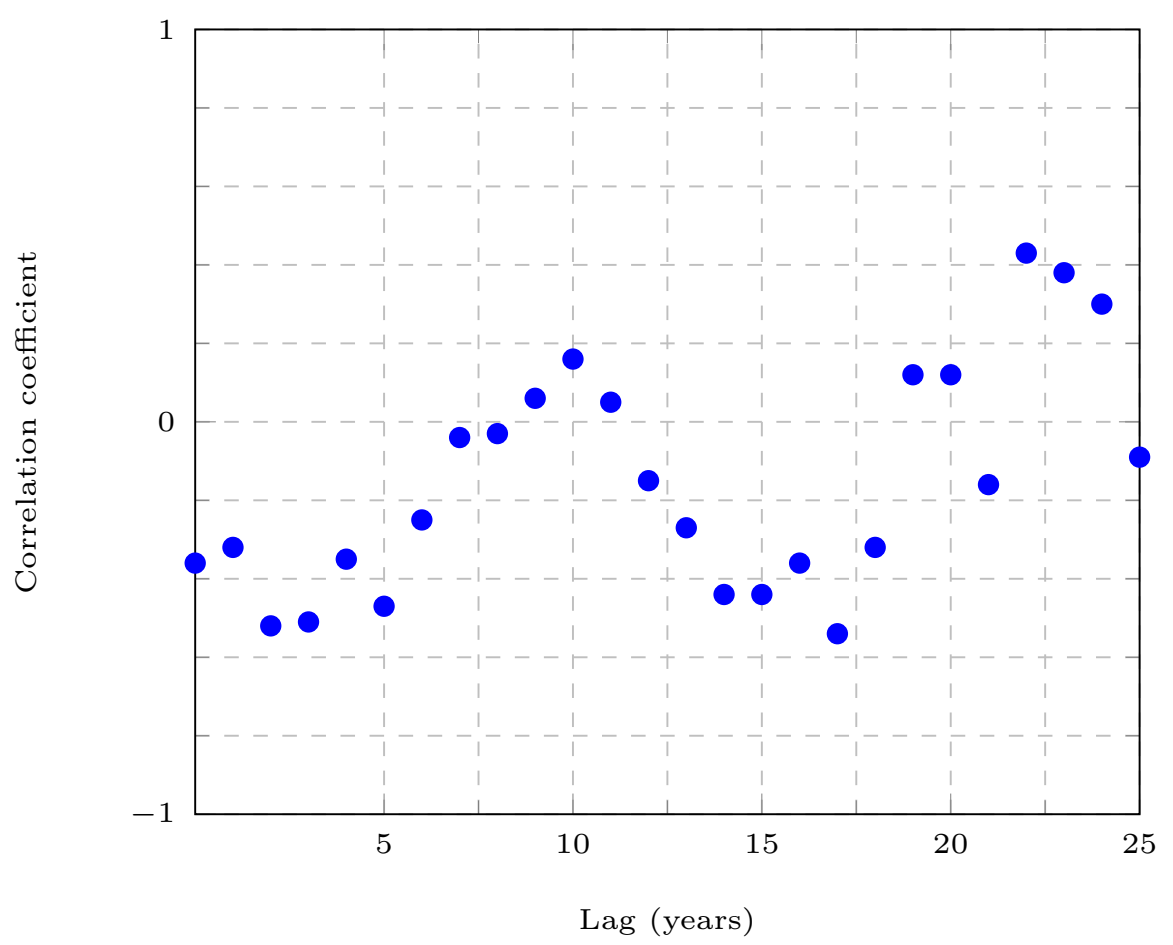

Figure 4.10: The strongest negative correlation coefficients are for a lag of $\sim 17$ years.

glacier length). The resulting standard error for the correlation coefficient is 0.36 . This reaction time falls within the range of 17 to 21 years, estimated by Chinn (1999) (but discussed therein using the term response time). It is noted that the response time calculated in this way may not be statistically significant due to insufficient overlapping points for cross correlation. By examining Figure 4.10, it can be seen that a similar correlation coefficient is obtained for a lag of 2 to 3 years. Such a short response time is highly unlikely and would suggest a thickness of only $\sim 7$ to $10.5 \mathrm{~m}$ using Equation 4.1.

\subsection{Brewster Glacier in the context of local climate}

In this subsection, I correlate rainfall and temperature data with the terminus position record to identify the main driver of glacier change. Previous studies have found strong positive correlations between glacier sensitivity to both temperature, and precipitation (Oerlemans, 2001; Anderson and Mackintosh, 2006). Within New Zealand, there has 
been long standing debate on the relative importance of temperature and precipitation on glacier-climate sensitivity (e.g. Salinger et al. (1983); Hessell (1983); Hooker and Fitzharris (1999); Chinn et al. (2005a); Mackintosh et al. (2017)). Across the Southern Alps, there is a strong decreasing precipitation gradient with distance eastward from up to $\sim 14 \mathrm{~m} \mathrm{a}^{-1}$ (Henderson and Thompson, 1999) to $\sim 1 \mathrm{~m} \mathrm{a}^{-1}$ Sinclair et al. (1997). In comparison, Brewster Glacier receives 5-6 m.w.e. $\mathrm{a}^{-1}$ (Conway et al., 2015; Cullen and Conway, 2015). The higher the precipitation, the higher the sensitivity to temperature, as this controls how the precipitation is partitioned between snow and rain, and thus the magnitude of accumulation difference (Anderson et al., 2010). In addition to this, glaciers in wet environments, tend to extend to lower, warmer altitudes and thus, the temperature change is effective over a longer ablation season, which can lead to a greater positive feedback effect on the change in albedo (Oerlemans, 2001). Furthermore, precipitation that falls as rain contributes to melt, the rate of which it does so is dependent on the temperature (Anderson et al., 2010).

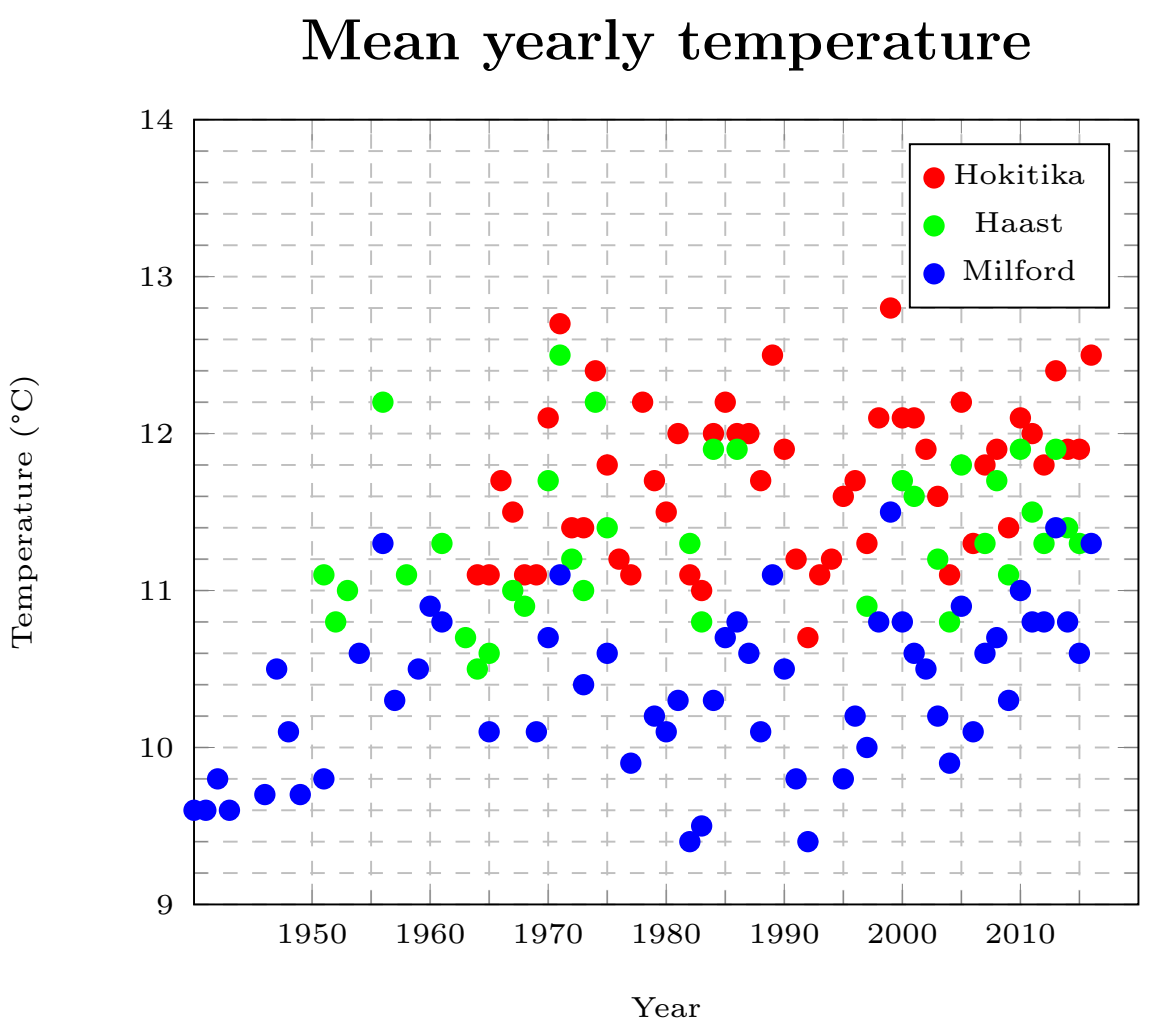

Figure 4.11: Temperature records of three stations located on the West Coast of the South Island. 
Figure 4.11 shows the temperature record for Hokitika, Haast, and Milford Sound. For both the Hokitika and Haast stations, the highest correlation coefficient was obtained for a 17 year lag (-0.40 and -0.71 respectively). The highest correlation coefficient for Milford Sound, however, was for an 18 year lag (-0.38, (17 year lag is -0.34)), and this record was the only one which extended far enough back in time to utilise the 1967 terminus position. The number of points used to calculate the highest correlation coefficients were 16 (Hokitika), 3 (Haast), and 14 (Milford Sound). The sparsity of overlapping (temperature and glacier length) points limits the confidence in these correlation coefficients. If changes in precipitation were the main driver of glacier-climate sensitivity, one would expect to have positive correlation coefficients when comparing precipitation to glacier length (high precipitation, long glacier), for lag periods similar to that of the reaction time.

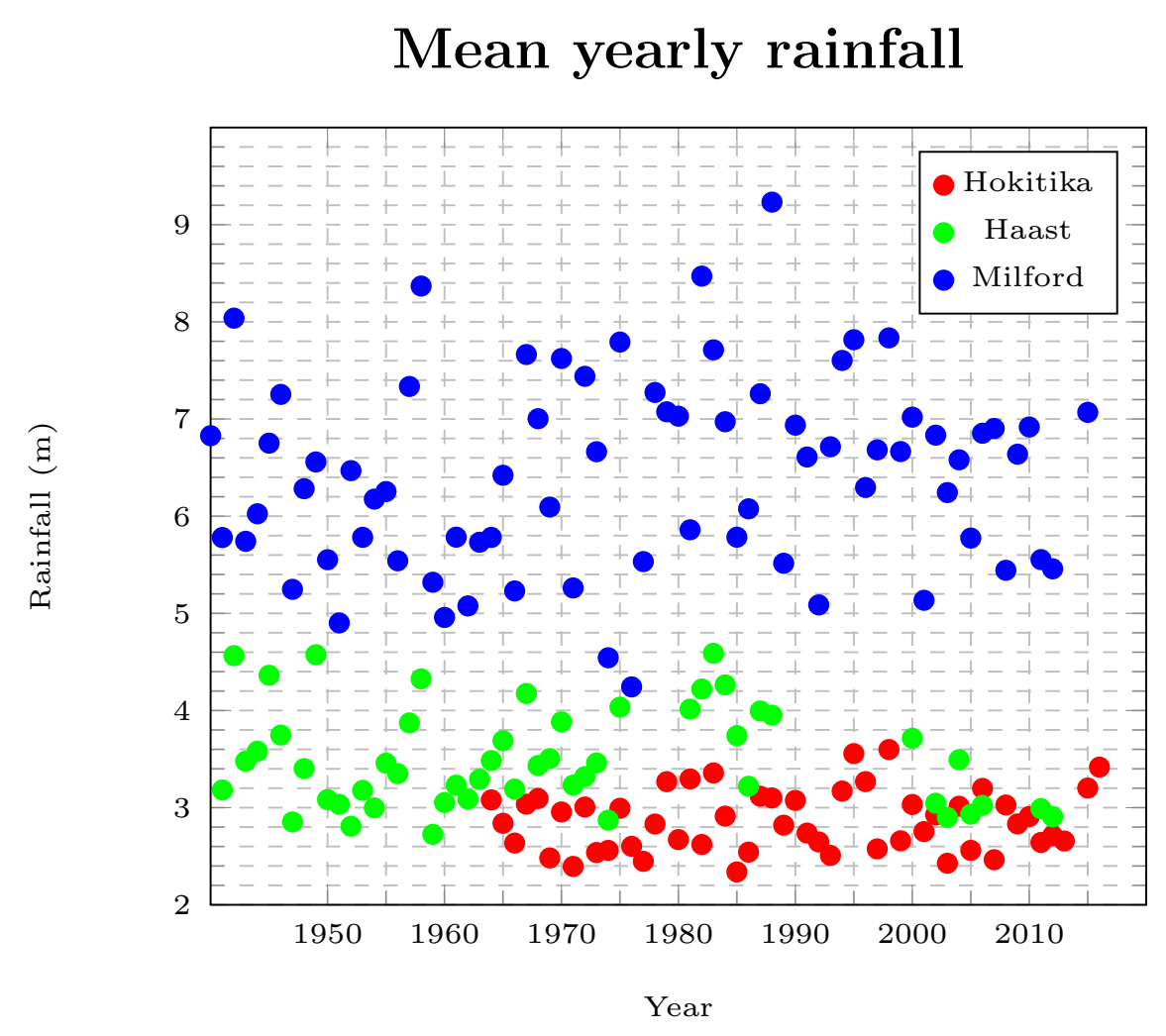

Figure 4.12: Rainfall records of three stations located on the West Coast of the South Island.

In the case of length vs precipitation, all correlations returned negative values for all stations, and for lags of 15 to 20 years, bar a correlation coefficient of 0.36 for 
a lag of 18 years for the Haast station. These results suggest that Brewster Glacier is more sensitive to changes in temperature than precipitation. This is in line with previous work by Anderson et al. (2010), who used an energy balance model to study the climate sensitivity of Brewster Glacier. They found that turbulent heat fluxes, which comprise sensible and latent heat fluxes, accounted for 50 to $54 \%$ of the energy used for summer melt over the study period, 2004-2008. The remaining energy used for melt is net radiation (43 to $48 \%$ ), and heat transfer from precipitation (2-4\%). This differs from many other studies, where radiation flux is the most prevalent source of melt energy (Ohmura, 2001), especially in continental regions where cloud cover is not as prevalent (Willis et al., 2002). In contrast, this result is not as extreme as that of Franz Josef Glacier, $90 \mathrm{~km}$ to the North, where sensible heat flux provided up to $80 \%$ of available energy for melt for the period of February (Ishikawa et al., 1992). By adjusting the roughness length for wind (which effects the turbulent heat flux) in the model, Anderson et al. (2010) found that the mean temperature sensitivity of Brewster Glacier over the period 2005-2008 is $2.0 \mathrm{~m}$ w.e. ${ }^{\circ} \mathrm{C}^{-1}$, one of the highest reported values on Earth. This high sensitivity was explained as a result of the limited altitudinal range, as well as positive surface feedbacks. Higher temperatures lead to less snow cover, and therefore more exposed ice. More exposed ice, in turn, allows greater absorption of radiation and increases the surface roughness, and thus turbulent heat fluxes (Anderson et al., 2010). Their modeling shows a change in the snow-rain partitioning temperature of $1^{\circ} \mathrm{C}$ accounts for $60 \%$ of the temperature sensitivity.

Anderson et al. (2010) found that, between 2004 to 2008, winter mass balances ranged between 2.3 to $2.8 \mathrm{~m}$ w.e., and summer balances ranged from -1.4 to $-4.5 \mathrm{~m}$ w.e. From this they concluded that during that period, annual balance variability was driven by summer balances primarily, a conclusion also made by (Cullen et al., 2016). The data from this study allows the volume variability from 2007 to 2017 to be studied in detail. It is found that winter volume balance varies between 3.16 to 7.95 $\mathrm{m}$, and summer volume balance varies between -7.74 to $-4.69 \mathrm{~m}$ (Figure 4.13). From this, neither winter nor summer volume balance appears to dominate volume balance variability, however, it is important to note that the geodetic method does not take 
into account density variability. It is noted that over the period studied by Anderson et al. (2010), the ELA was relatively inconsistent between 1780, and 2270 m.a,s.l (490 m range), whereas over the longer period of 2007 to 2017, the ELA ranged from 1815 to 2285 (470 $\mathrm{m}$ range), which may explain the increased summer variability during the period 2004 to 2008. Figure 4.13 shows a general relationship between ablation and

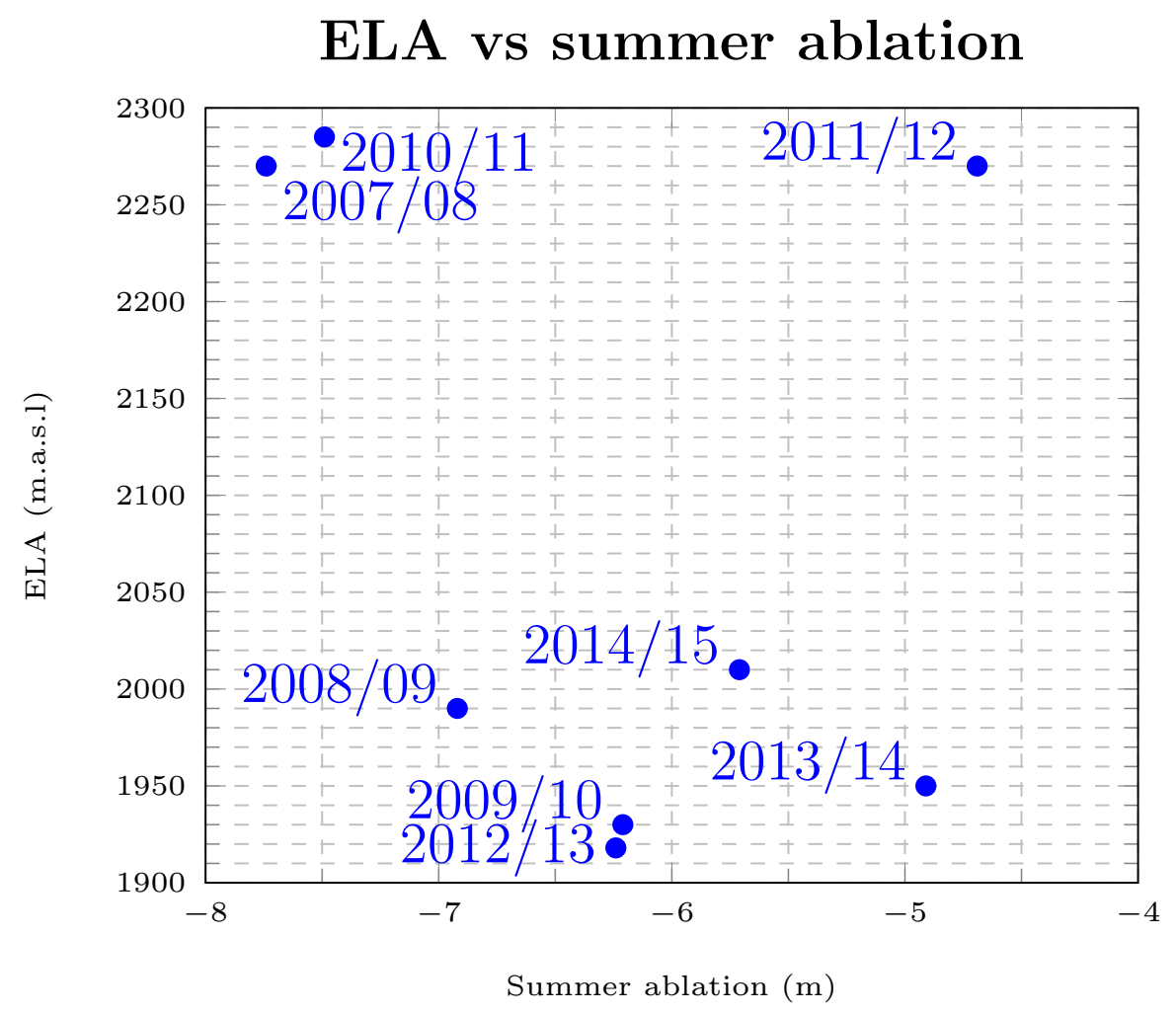

Figure 4.13: Summer ablation plotted against ELA. With the exception of the 2011/12 season (top right), there is a strong correlation of ELA and summer ablation.

ELA value, with the notable exception of 2011/12. The correlation coefficient between ELA elevation and summer surface elevation change is -0.3 , however this increases to -0.75 with the omission of the $2011 / 12$ season. For the $2011 / 12$ season, the ELA elevation is comparable to those of the $2007 / 08$ and 2010/11 seasons, however the estimated ablation is much less. This may be due to spatial interpolation error (Table 3.1) or intense snow melt just prior to EoSS image capture. Observation of the 2012 EoSS image suggests the latter is likely the case, where small patches of snow are visible far below the snow line.

Within the study area, it is possible to see evidence of variable climatic conditions. 
From examination of Figure 4.6, it can be seen that at location 16e2, balance is either more positive, or less negative over the study period than all other locations. This is due to the shading experienced in this area, and therefore the smaller amount of incoming shortwave radiation. This phenomena may be further exacerbated from avalanching from the south west face of Mount Brewster. A similar observation was made by Anderson et al. (2010) based on ablation stake measurements on the glacier tongue. By examining Figures 4.3 and 4.7, it is clear that there is a strong elevation control on distributed volume change. This is primarily caused by the temperature lapse rate, which typically ranges from $-1{ }^{\circ} \mathrm{C} \mathrm{km}^{-1}-7{ }^{\circ} \mathrm{C} \mathrm{km} \mathrm{km}^{-1}$ for alpine environments (Blandford et al., 2008), and the typically nonlinear nature of the mass balance curve (Oerlemans and Hoogendoorn, 1989). Temperature effects volume change in a number of ways because long wave radiation, shortwave radiation, and sensible heat fluxes are all correlated with air temperature (Ohmura, 2001). Furthermore, the partitioning of precipitation into rain and snow is predominantly determined by temperature, the transition usually occurring at $1.2^{\circ} \mathrm{C}$ (Dai, 2008).

Other factors effecting distributed volume change are wind redistribution of snow and avalanching (Paterson, 1994b). Avalanches are prevalent below the southwest slope of Mount Brewster.

\subsection{Comparison to other New Zealand glacier records}

Glaciers of the Southern Alps have garnered worldwide interest as a result of an advance period from 1983 to 2008 (Figure 4.14). In contrast, the history of Brewster Glacier is one of near constant retreat. The differences in the response of Brewster Glacier can be accounted for in a quantitative manner, as glacial advances and retreats are determined by local climate, distribution of surface area with altitude, size, steepness, and substrate characteristics (Cuffey and Paterson, 2010).

As discussed in Section 4.2, terminus position can be considered a weighted average of past climate (Jóhannesson et al., 1989b), the period of which is termed the memory, or response time (Oerlemans, 2001). Assuming an ablation rate near the terminus $\left(\dot{a}_{0}\right)$ 


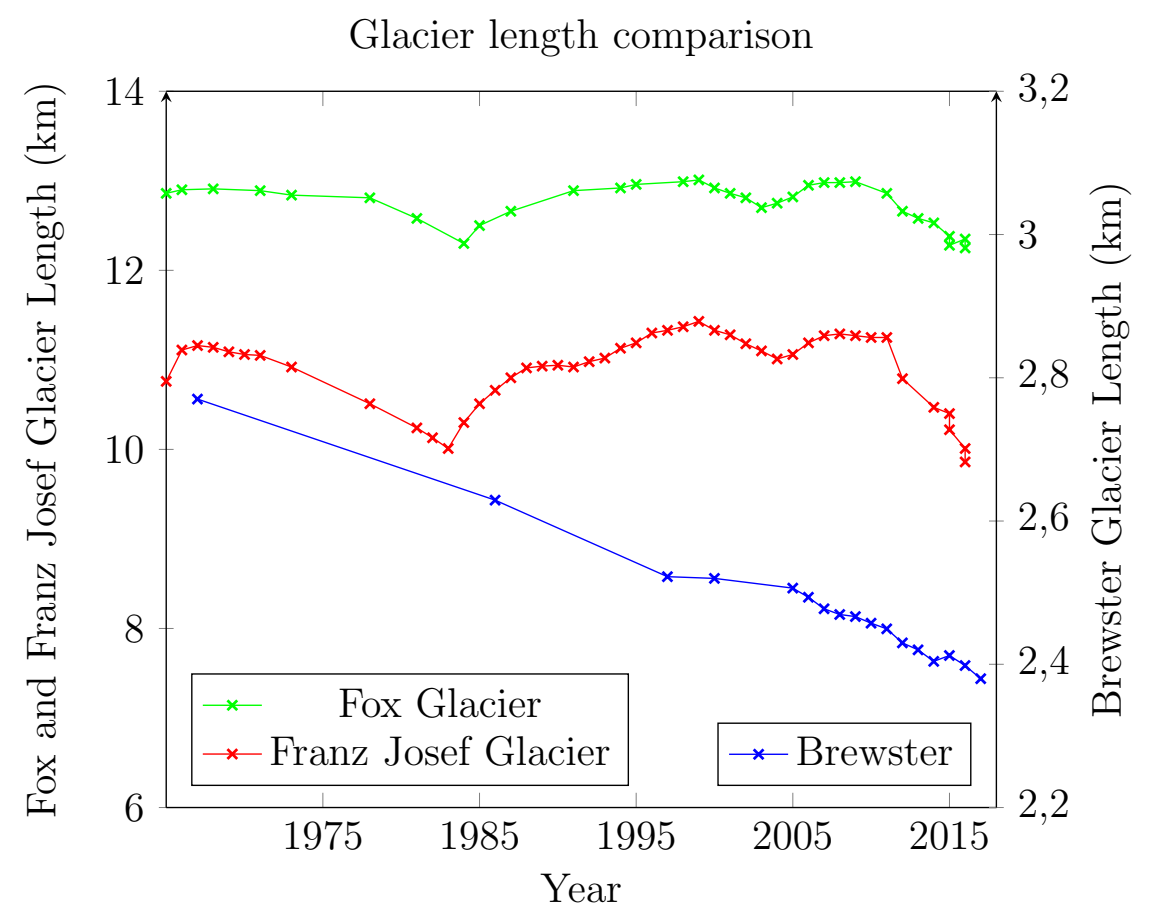

Figure 4.14: Comparison of New Zealand Glacier length records.

of $3.5 \mathrm{~m}$ w.e $a_{-1}$ (average terminus ablation rate between 2015 to 2017), and a maximum thickness of $115 \mathrm{~m}$ (the maximum estimated thickness in 2017), the response time for Brewster Glacier is $\sim 33$ years. This compares with a response time of $\sim 15-25$ years for Franz Josef (Anderson et al., 2008) and 9 years for Fox Glaciers (Purdie et al., 2008). As the response time is dependent on glacier thickness and ablation rate, factors which are transient through time, the response time will also be transient through time (Purdie et al., 2014). In reality, response times are more difficult to determine than Equation 4.1 would suggest. This is because there are other factors to consider. For example, in a study conducted by Haeberli and Hölzle (1995), using data of 1763 glaciers over the period 1850 1970, response times decreased exponentially with an increase in surface slope. This is a factor not considered in this study ${ }^{2}$. The main reason for the difference in ablation rates between Brewster Glacier and Fox and Franz Josef Glaciers, is that Brewster Glacier is confined to a relatively high altitude, extending down to a present day elevation of 1670 m.a.s.l, with a mean annual temperature of $1.2^{\circ}$ (Conway et al., 2015), whereas Fox and Franz Josef Glaciers extend down to a present day elevation of $\sim 300$ m.a.s.l where mean annual temperatures are $\sim 11^{\circ}$. This

\footnotetext{
${ }^{2}$ However this may be accounted for indirectly by the ablation rate.
} 
has large implications for ablation rates with rates of $\sim 20$ m.w.e.a ${ }^{-1}$ reported on the terminus of Franz Josef Glacier (Anderson and Mackintosh, 2006).

The steepness, as well as the size of a glacier has a big impact on sensitivity (Haeberli and Hölzle, 1995). For a glacier like Brewster Glacier, where $\sim 90 \%$ of the glacier has an elevation of within $300 \mathrm{~m}$ that of the terminus (Anderson et al., 2010), a sudden temperature rise of $\sim 0.7^{\circ} \mathrm{C}$ (the amount of warming during the 20th century (Riebeek, 2010)) can change the accumulation area ratio (AAR) from 0.38 to 0.19, while a sudden temperature drop of the same magnitude can change the AAR to 0.71 (assuming no immediate change in surface elevation and a change in ELA altitude of $130 \mathrm{~m}^{\circ} \mathrm{K}^{-1}$, concordant with Oerlemans and Hoogendoorn (1989)). The same temperature changes for a bigger, steeper glacier such as Fox Glacier, produce AARs ranging from 0.74 to 0.84 (as determined from the NZTopo DEM). Additionally, the area-altitude distribution can have a large effect on the response of a glacier to changes in mass balance. For example, a glacier that is on average very wide, but has a narrow terminus, will have relatively large terminus fluctuations compared to a glacier with the opposite area-altitude distribution (Cuffey and Paterson, 2010). This can be represented by Equation 4.2,

$$
L_{1}=L_{0} \times\left\langle\dot{b_{1}}\right\rangle / \dot{a_{0}} \times \bar{Y} / Y_{t}(\text { Cuffey and Paterson, 2010) }
$$

where a glacier at a steady state, known as the datum state, will have a spatially averaged net balance of 0 , at $\mathrm{t}=0\left(\dot{b_{0}}\right)$, and a length of $L_{0}$. With a change of net balance $\left(\dot{b_{0}}+\dot{b_{1}}\right)$, and enough time to adjust, the glacier will attain a different surface profile with a length of $L_{0}+L_{1}$, where $\left\langle\dot{b_{1}}\right\rangle$, is the new spatially averaged specific balance, $\dot{a}_{0}$ is the ablation rate near the terminus, $\bar{Y}$ is the average width of the glacier, and $Y_{t}$ is the terminus width (Cuffey and Paterson, 2010). If the ratio of mean width to terminus width $\left(\bar{Y} / Y_{t}\right)$ is large, it is expected that the terminus will be more sensitive to changes in specific balance. By examining Figure 4.15, it can be seen that both Fox and Franz Josef Glaciers have a high $\bar{Y} / Y_{t}$ ratio, as well as a larger $L_{0}$ compared to Brewster Glacier, both of which are conducive to higher levels of terminus 
fluctuation (Cuffey and Paterson, 2010). This effect would be partially offset by the

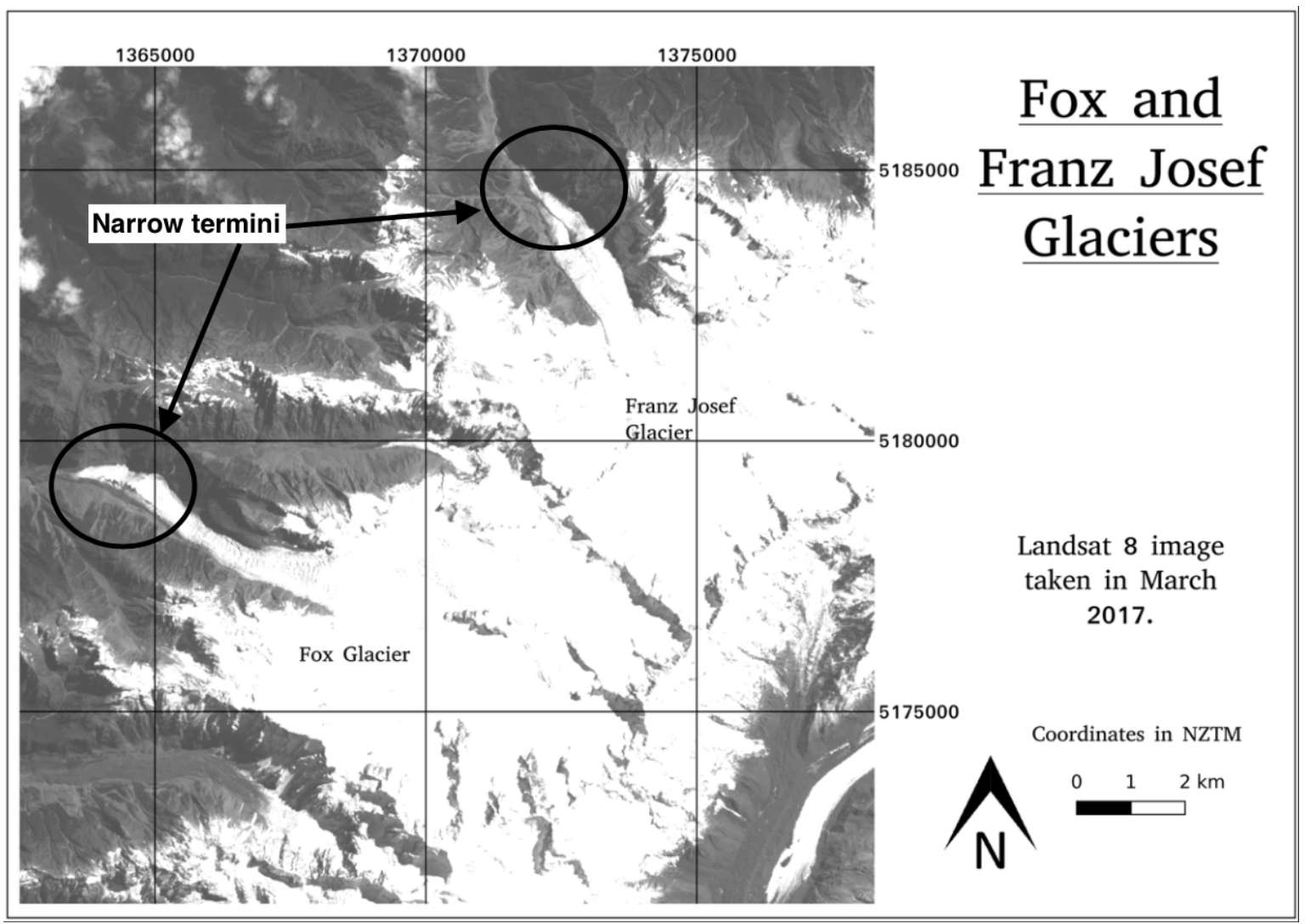

Figure 4.15: Landsat 8 image of Fox and Franz Josef glaciers, March 2017. These glaciers lie $\sim 90 \mathrm{~km}$ to the north of Brewster Glacier.

higher ablation rates of Fox and Franz Josef glaciers resulting from their lower terminus elevations ( $\sim 280$ m.a.s.l compared to Brewster's terminus elevation of $\sim 1670$ m.a.s.l). By using Equation 4.2, a change in the spatially averaged mass balance of $0.5 \mathrm{~m}$ w.e. would produce a change in glacier length of 2940 m for Franz Josef Glacier, while only producing a change in length of $963 \mathrm{~m}$ for Brewster Glacier (given enough time for the glacier to adjust to the new conditions). Furthermore, the amplitude of the terminus fluctuation is dependent on the period of the mass balance perturbation $t$ in relation to the response time (Cuffey and Paterson, 2010). This means that a change in mass balance of equal period will result in a larger terminus perturbation for a glacier with a smaller response time. Thus, Equation 4.2 can be expressed as Equation 4.3 for the more realistic case when the period of the mass balance perturbation is greater than 
zero $(t>0)$ (Cuffey and Paterson, 2010).

$$
L_{1}(t)=L_{0} \times \dot{b}_{1} / \dot{a}_{0} \times \bar{Y} / Y_{t} \times\left[1-\exp \left(-t / t_{r}\right)\right]
$$

In this case, if the change in mass balance lasted 25 (50) years, Brewster Glacier would have only obtained $53 \%$ (78\%) of the advance calculated in Equation 4.2, while Franz Josef would have attained $71 \%(91 \%)$ of it's respective advance.

\subsection{Further considerations}

The temporal resolution of this study, especially in the earlier temporal range, is sparse. Therefore, it is highly probable that some of the peaks and troughs of the distributed volume may not be captured by the data as a result of sample aliasing. For example, for the period 1967-1997, the volume time series suggests that minimum volume of 0.011 $\mathrm{km}^{3}$ is attained in 1986. In reality, the minimum value occurring on this date is unlikely to be true. For the cokriged surfaces, this study assumed that the spatial pattern of surfaces is the same for each year as that of the 2017 SfM surface. This assumption has, to some extent, the possibility of being violated as a result of a change of climate or accumulation processes. For example, further investigation must be carried out on the effects of El Niño/La Niña climate trends on surface pattern, and the effects of avalanche and wind deposition. 


\section{Conclusions}

Comparison between the geodetic mass balance record generated by this thesis, and direct measurements show that the pattern of the geodetic mass balance record is similar to that of the glaciological record. This validates our methodology, which has incorporated all available geodetic data. A difference between the magnitude of mass balance change exists between the geodetic record of this study, and the glaciological record. This may be due to density assumptions for converting volume to mass, and the choice of interpolation method (as well as the number of points used for interpolation), and co-kriging parameters, and these errors are difficult to quantify. The highest confidence DEMs are the SfM DEMs, as these surfaces have the lowest mean standard error. The lowest confidence DEM is that of the NZMS DEM, as this DEM has the highest mean standard error. The geodetic volume record documents the overall decline of Brewster Glacier from $0.146 \mathrm{~km}^{3}$ in 1967 to $0.064 \mathrm{~km}^{3}$ in 2017 . Superimposed on the long-term volume decline is a volume increase from 1986 to $1997(+0.012 \pm 0.0003$ $\mathrm{km}^{3}$ ), and seasonal variations visible from 2005 to 2017. Figure 5.1 summarises the changes in volume $\left(-0.082 \pm 0.003 \mathrm{~km}^{3}\right)$, length $(-390 \pm 20 \mathrm{~m})$, and area $(-1.13 \pm 0.52$ $\mathrm{km}^{2}$ ) which occurred over the study period. 


\section{Brewster Glacier volume, length, and area}

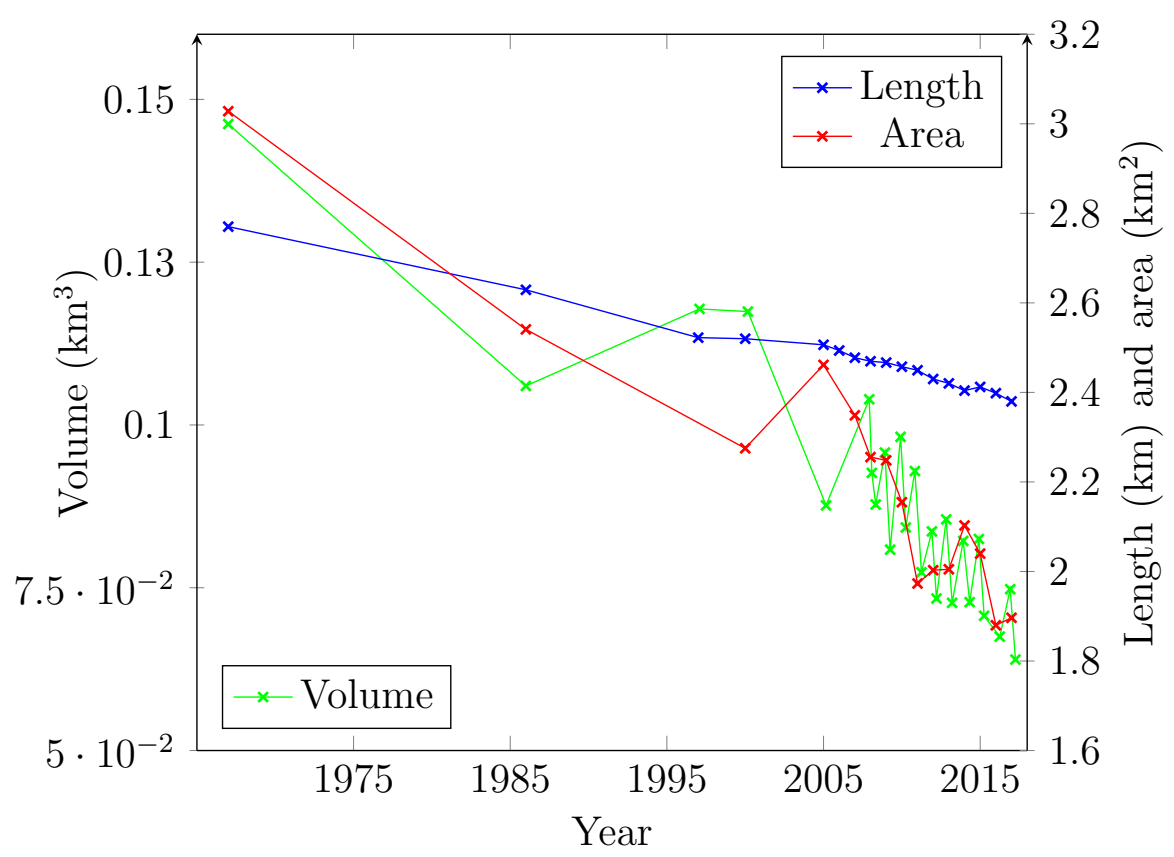

Figure 5.1: This study created a time-series of volume, length and area from 1967, to 2017.

This study has extended the glaciological mass balance record. As such, this is the most detailed and longest volume record for a New Zealand Glacier. Further acquisition and processing of GPR data, along with error analysis of previously acquired GPR data, has increased the detail and accuracy of the bed DEM. Furthermore the use of a SfM DEM to represent stable terrain that was previously ice-covered has allowed higher accuracy glacier volume change results than would previously be possible. The use of co-kriging has produced surface DEMs from GNSS data of a level of accuracy that would not be possible by using other currently available interpolation methods. The terminus position record compiled in this study, coupled with precipitation, temperature, and ELA records, has allowed the drivers of glacier change, as well as the response times to be identified with greater confidence than was previously possible. 


\section{$5.1 \quad$ Completed study objectives}

\subsubsection{Data objectives}

A surface elevation time series was created which incorporated all available surface elevation data. This included two topographic maps (NZTopo and NZMS), satellite data (GNSS and SRTM), and aerial orthophotography (SfM orthophotographs). Stable terrain represented in the highly accurate SfM DEMs was used to apply a stable terrain correction for the topographic maps, and the SRTM DEM. GNSS data was interpolated by cokriging against the 2017 SfM DEM. The acquisition of GPR data to supplement previous GPR datasets further contributed to the knowledge of bed elevation. Construction of a bed DEM was accomplished by kriging of the GPR data, and incorporating stable terrain from the 2017 SfM DEM. A terminus position and area time series was created using Landsat and GNSS data, topographic maps, and SfM othophotographs. The terminus position was interpreted as the furtherest down glacier connected ice, perpendicular to the flow line. The terminus position time series shows a history of varying retreat (bar a small advance between 2014 and 2015 of 8 $\mathrm{m})$. The glacier area time-series shows a decline in area with superimposed variation which is believed to be, at least partly, due to variations in snow cover at the time of image capture.

\subsubsection{Research investigations}

Based on the completed research objectives above, the following research investigations were made:

\section{How does the volume change record from Brewster Glacier compare with the direct mass balance record?}

Where the geodetic volume record and glaciological mass balance record coincide, they both follow a similar pattern overall. When converting volume change to mass 
change, however, it is clear that either the geodetic method overestimates mass change in comparison to the direct method, or that the density used to convert volume change to mass change $\left(750 \mathrm{~kg} \mathrm{~m}^{-3}\right)$ is too great. In order to obtain the same mass balance results as Cullen et al. (2016), the required density conversion factor would need to vary from $-600 \mathrm{~kg} \mathrm{~m}^{-3}$ to $3600 \mathrm{~kg} \mathrm{~m}^{-3}$ as a result of the short time intervals, and surface elevation uncertainties.

\section{What is the relationship between glacier volume, and length change?}

Following the increase in volume of Brewster Glacier from 1986 to 1997, it would be expected that Brewster Glacier would begin to advance some time later, corresponding to its reaction time. However, due to Brewster Glacier's long reaction time, the terminus record shows a retreat for almost the entire study period, and the volume increase of 1986-1997 only results in a later reduction in retreat rate (and possible small advance between 2014 and 2015). This indicates that the glacier terminus is indeed responding to changes in mass but the duration and magnitude of the volume change is not sufficient to generate a significant advance. This underscores the limitation of using terminus positions as climate indicators, especially when considering a small selection of glaciers. The highest correlation coefficient between the ELA and terminus position is for a lag of 17 years.

\section{What can the Brewster Glacier length record tell us about climate?}

Globally, the two main climatic factors which influence glacier change are temperature, and precipitation. By using climate records from three weather stations on the West Coast of the South Island, Brewster Glacier had the strongest correlation coefficients for temperature at a 17 year lag for Hokitika, and Haast, and at an 18 year lag for Milford Sound. This is similar to the reaction time of the glacier to changes in the ELA. There were no convincing correlation coefficients for precipitation and terminus position, indicating that Brewster Glacier's terminus is not sensitive to the changes in precipitation that have occurred during the observation period. 


\section{How does Brewster Glacier's length record compare with other New Zealand glaciers?}

While many glaciers experienced a period of advance during the 1980s and 1990s, Brewster Glacier's length record over the past 5 decades is one of predominantly different rates of retreat. This difference is likely to be due to the slower mass transfer of Brewster Glacier, the relatively lower mass turnover rates of Brewster Glacier, the varying area-altitude distribution of New Zealand glaciers (where Brewster Glacier has a relatively low area centred around the ELA compared to other more responsive New Zealand glaciers), and the varying local climates (where more precipitation correlates with a more climate-sensitive glacier). Glaciers that advanced during this period, such as Fox Glacier and Franz Josef Glacier, had very narrow termini compared to their average width, as well as a higher mass turnover than Brewster Glacier.

\section{$5.2 \quad$ Future work}

This detailed volume record is unique to New Zealand, because of the long observation period, and high temporal resolution during the past decade. As such, continued surface elevation measurements would be extremely valuable in the future. The construction of SfM DEMs would provide a relatively cheap and high precision way to monitor a larger number of glaciers. Furthermore, future space based geodesy from satellites will provide high precision DEMs to document volume change of glaciers over a large area.

For more accurate estimations of absolute volume, higher resolution GPR should be acquired. This can be achieved by using a lower resolution source signal to counter high attenuation rates, particularly in wet areas of the glacier. Furthermore, if the current diminishing trend of glacier volume continues, information regarding bed elevation will become clearer as a result of an increase in stable terrain around the periphery of the glacier, and a decrease in ice thickness. 
Appendices 



\section{A Spatial interpolation techniques}

Appendix A is largely adapted from material by Isaaks and Srivastava (1989); Webster and Oliver (2007); Goovaerts (1997); Bohling (2005a,b); McKillup and Dyar (2010); Hock and Jensen (1999).

This appendix aims to provide a background on various spatial interpolation techniques, as well as the theory of spatial continuity. Covariance-function parameters used for the cokriging of GNSS data are listed at the end of the appendix. An explanation of some common spatial interpolation methods are listed below:

\section{Deterministic methods}

\section{Polygons:}

Also known as the nearest neighbour method. The estimated value is taken from the nearest sample point. Therefore, all weighting $(\lambda)$, is given to the sampled point which is closest to the estimated point, such that the estimated point attains the same value as the nearest sample point (Li and Heap, 2008). This method, which creates polygons of equal value, is generally not desirable as it creates the unrealistic artifact of sharp discontinuities between polygons (Isaaks and Srivastava, 1989).

\section{Triangulation:}

Also known as triangular irregular network (TIN). All sample points make up vertices of triangles, such that no sample points are contained within these triangles. The surface is therefore represented by a triangular plane which can be linearly or cubicly interpolated based on the values of the points which define the triangle (Isaaks and 
Srivastava, 1989; Li and Heap, 2008). A variation of this method uses an equation to apply weight based on proximity to the sample point within the triangle (Isaaks and Srivastava, 1989). One disadvantage to this method is that, as it is only using three of the nearest sample points, It ignores much of the other nearby samples ( $\mathrm{Lu}$ and Wong, 2008).

\section{Inverse Distance Methods:}

This method applies a greater weighting to near samples than distant samples in order to satisfy Tobler's first law of geography: "everything is related to everything else, but near things are more related than distant things" (Tobler, 1970). This method does this by making the weight for a sample inversely proportional to the distance to the point at which one wishes to estimate (Isaaks and Srivastava, 1989).

$$
\lambda_{i}=1 / d_{i}^{p} / \sum_{i=1}^{n} 1 / d_{i}^{p}
$$

(Li and Heap, 2008)

Equation A.1 shows how weighting is applied. The numerator represents the weighting for the $i$ th point to estimate. This is then standardised by the denominator part of the equation so that all weightings sum to one (Isaaks and Srivastava, 1989). The exponent $p$ is used to make the weights inversely proportional to the power of the distance. This is an important factor which can have a large influence on the accuracy of the inverse distance method. A smaller $p$ means less variance on the weights of the samples and the further samples increase in weight compared to the closer samples (Isaaks and Srivastava, 1989).Conversely, as $p$ approaches $\infty$, the estimated value approaches that of the polygonal estimate. Inverse distance methods work best when the data is evenly spaced, unlike the GPS glacier surface traverse data.

\section{Probabilistic methods}

Probabilist methods, such as kriging, rely on the spatial dependency of the surface. 


\section{Scatter plot of variable $Z$. Lag distance $(h): 1$ unit}

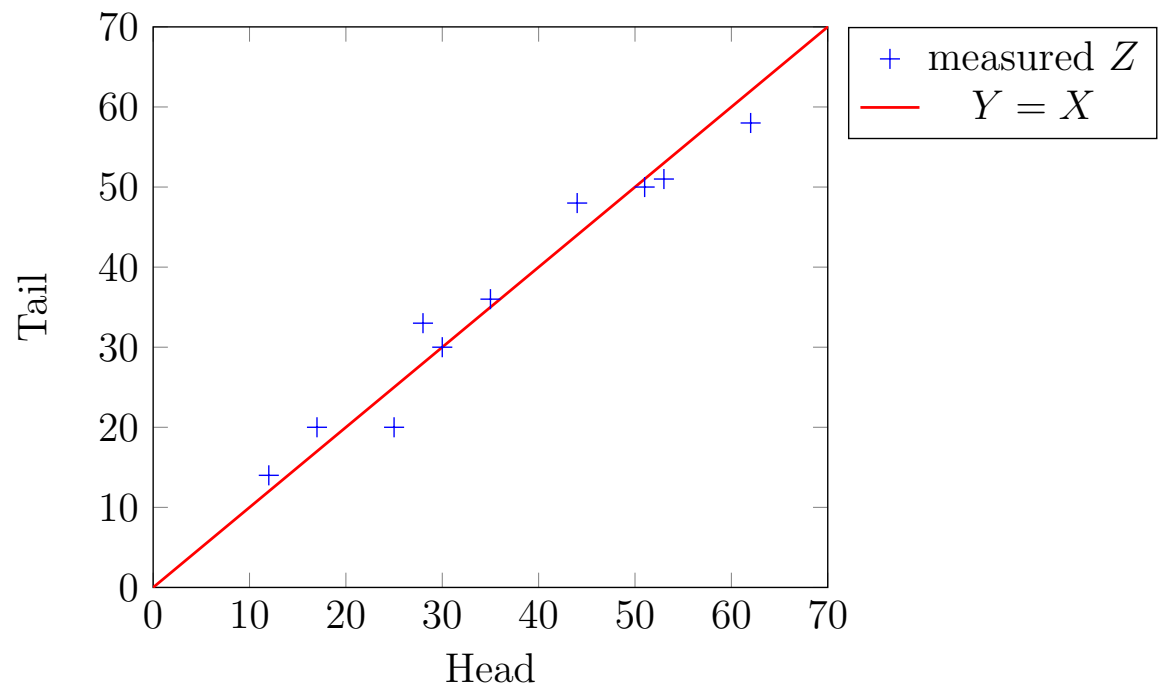

Scatter plot of variable $Z$. Lag distance $(h): 2$ units

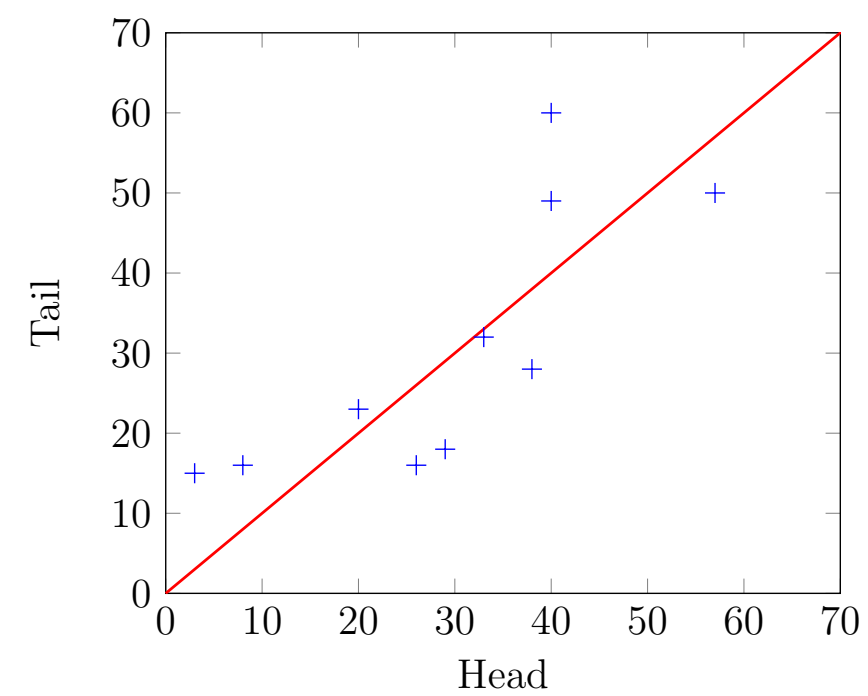

Figure A.1: Synthetic scatter plot of a measured variable $(Z)$ at a head and tail for lag $=1$ (top) and lag $=2$ (bottom). The spatial autocorrelation between the head and tail can be described by the correlation coefficient ( 0.98 for $\operatorname{Lag}=1,0.78$ for lag $=2$ )

Spatial dependencies are described with reference to a lag $(h)$, which is a (separation) vector of both a distance and direction (Webster and Oliver, 2007). Figure A.1 shows a variable separated by two separation vectors of different distances. The correlation between the values at the head and tail of this separation vector can be described by the (auto)covariance $(C(h))$ (Equation A.2) where $Z$ is the variable of interest at both the tail $Z_{i}$ and head $Z_{i+h}$, and $\mu$ is the mean) or autocorrelation $(\rho(h))$ (Equation A.3 where $\sigma$ is the standard deviation) (Bohling, 2005a) (the covariance normalised by the 
variance $\left(\sigma^{2}\right)$ at lag 0$)$.

$$
\begin{gathered}
C(h)=n^{-1} \sum_{i=1}^{n}\left\{\left(Z_{i}-\mu\right)\left(Z_{i+h}-\mu\right)\right\} \text { (Webster and Oliver, 2007) } \\
\left.\rho(h)=\sum_{i}^{n}\left(Z_{i}\right)\left(Z_{i+h}-\mu\right)\right) / \sqrt{\sigma_{i} \sigma_{i+h}}=C(h) / C(0)=C(h) / \sigma^{2}(0) \text { (Bohling, 2005a) }
\end{gathered}
$$

The correlation is expected to be much stronger for shorter lags. On the other hand, the difference between the head and tail can be described as the semi-variance $(\gamma(h))$, or the moment of inertia (distance) of all points about the $Y=X$ line in Figure A.1 (Equation A.4) (Isaaks and Srivastava, 1989).

$$
\gamma(h)=1 /(2 n) \sum_{i=1}^{n}\left(Z_{i}-Z_{i+h}\right)^{2}(\text { Isaaks and Srivastava, 1989) }
$$

For the top (bottom) scatter graph in Figure A.1, the difference between values at the head of the separation vector, and the tail of the separation vector are small (big), and thus, the moment of inertia about the $\mathrm{Y}=\mathrm{X}$ line for each pair of points is small (big), and the semi-variance is small (big). The spatial dependency of a dataset is commonly described by either the covariance function, correlogram, or semi-variogram (Bohling, 2005a). These are plots of the covariance, autocorrelation and the semi-variance (as a function of lag distance (and lag direction in the case of anisotropic data (Webster and Oliver, 2007))) respectively (Bohling, 2005a). The semi-variogram $(\gamma(h))$ is a plot of half the mean squared difference between the head and tail (Equation A.4) for a number (n) of pairs with different lags Isaaks and Srivastava (1989). In layman's terms, spatial dependency describes the similarity of two points with increasing separation (Hock and Jensen, 1999). There are a number of models which do this, but essentially they do the same thing. For example, the semi-variogram is a mirror-image of the covariance function (Webster and Oliver, 2007; Bohling, 2005a)(Equation A.5).

$$
\gamma(h)=C(0)-C(h) \text { (Webster and Oliver, 2007; Bohling, 2005b) }
$$


In the context of this study, the semi-variogram would very quickly taper of towards the surface elevation variance for reasonably small lags (small distance between head and tail values) for a glacier surface which has little spatial continuity. Conversely the semi-variogram would show small (semi)variance up until very large lag distances for a surface which has a high degree of spatial continuity. Glacier surfaces typically exhibit high spatial continuity

For spatially autocorrelated data, the correlation will typically equal 1 at a lag distance of 0 , and taper away towards a correlation of 0 at greater lag distances (Isaaks and Srivastava, 1989). Conversely, the semi-variogram will typically equal 0 at a lag distance of 0 , and taper off towards the glacier surface elevation semi-variance. The value of semi-variance at which the semi-variogram tapers off to a constant is called the sill Bohling (2005a), and represents the global variance (Isaaks and Srivastava, 1989). The lag distance that this occurs at is called the range (Figure A.2). For areas of high regional dependence, the sill, also known as the outer limit of regional dependence, will be reached at a high lag distance (range) (McKillup and Dyar, 2010). It is important to note that a sill and range are only reached with certain theoretical semi-variogram models (e.g. spherical). For information on the different model types, the reader is referred to Chiles and Delfiner (2009). Often a semi-variogram model will not equal 0 at 0 lag, in order to satisfy the measurement error (e.g. vertical GNSS error), or any variance at very small lags (Hock and Jensen, 1999). This is termed the nugget effect (Matheron, 1963) (Figure A.2). As distance is generally continuous, it is impossible to estimate a useful mean semi-variance for a given lag. Therefore, theoretical semi-variograms or correlogram functions must be estimated, as no function may pass through all points due to noise (McKillup and Dyar, 2010). This is especially the case at large lag distances (McKillup and Dyar, 2010). To overcome this, lag points must be binned. Estimating covariance functions and semi-variograms is therefore open to a large degree of subjective judgment (Bohling, 2005a), and in practice, trial and error. The number of defining points of a function are dictated by the number of bins used. More bins allow a greater number of lag distances to be represented, but at the cost of the semi-variogram/correlogram detail (Bohling, 2005a). 


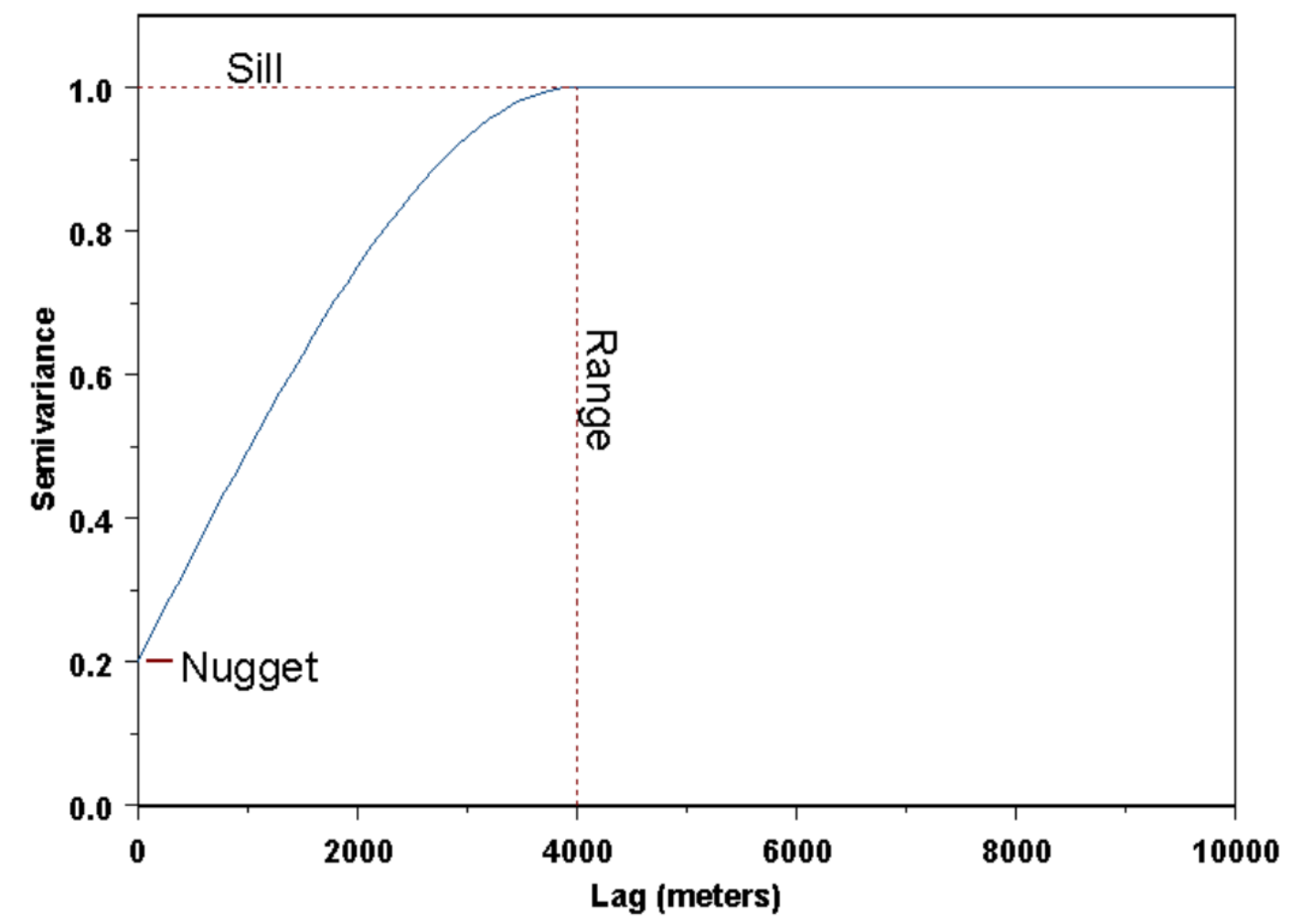

Figure A.2: Main parts of a theoretical semi-variogram. If no spatial coorelation exists, the variance would be represented by a horizontal line. In practice, the theoretical semivariogram is the line of best fit around which the experimental semi-variogram points are scattered. Figure taken from Bohling (2005a).

\section{Kriging:}

Kriging incorporates a variety of spatial estimation methods, which aim to minimise variance, and to have a mean error of 0 , by using the constraint $E\{\hat{Z}(x)-Z(x)=0\}$, where $\hat{Z}(x)$ is the estimated value of $Z$ at location $x$, and $Z$ is the actual value $(E$ denotes expected) (Isaaks and Srivastava, 1989; Goovaerts, 1997). Kriging is a probabilistic approach to estimating an unknown value where the available data is treated as a result of a large scale component (the mean), and small scale error components. In its simplest form, this can be represented by Equation A.6,

$$
Z(x)=\mu(x)+\epsilon(x)(\text { Goovaerts, 1997) }
$$

where $Z$ is the point to be estimated at location $x, \mu$, the mean at location $\mathrm{x}$ represents the large scale variation, and $\epsilon$ is the small scale autocorrelation at $x$, often termed the 
error (Goovaerts, 1997). The error component is modeled by random variables (Isaaks and Srivastava, 1989). These random variables are defined by a cumulative distribution function, where surrounding points are weighted in accordance to a spatial covariance model (e.g. semi-variogram) (Bohling, 2005b)).

To estimate unknown values, a random function model is used. This model assumes stationarity. This means (Isaaks and Srivastava, 1989; Hock and Jensen, 1999; Webster and Oliver, 2007):

- There is no trend in the mean of the random variable to be estimated (e.g. the glacier surface does not increase/decrease in elevation in a certain direction).

- There is no trend in the variance of the random variable (e.g. the elevation variance does not increase/decrease in a certain direction).

- There is no trend in the difference between head and tail values for a given lag. e.g, the covariance is only a function of $h$ (e.g. The difference in elevation between a given lag is not dependent on location such as a steep or shallowly dipping portion of the glacier surface).

In other words, the cumulative distribution function (cdf) of the random variable $Z$ at point $x(Z(x))$ (which is used to define the probability distribution function(pdf)), does not vary with location, as is also the case for the joint cdf of $Z(x)$ and $Z(X+h)$ (Webster and Oliver, 2007). If one or more of these requirements are violated, the data must be detrended. The error component, $\epsilon$ is treated as the random component and when working with detrended, or constant mean data, is estimated using Equation A.7,

$$
\hat{\epsilon}(x)=\sum_{i}^{n} \lambda_{i}\left(\epsilon_{i}\right) \text { (Goovaerts, 1997) }
$$

where $\lambda_{i}$ is the weighting assigned for the $i t h$ data point. To ensure unbiaseness, the weights, $\lambda_{i}$ must sum to 1 (Isaaks and Srivastava, 1989). The key is to determine the values of $\lambda_{i}$. The error variance at location $x_{0}, \sigma_{E}^{2}\left(x_{0}\right)$, of a linear combination of 
random variables is expressed by Equation A.8 (Isaaks and Srivastava, 1989).

$$
\begin{gathered}
\sigma_{E}^{2}\left(x_{0}\right)=\operatorname{Var}\left\{\hat{\epsilon}\left(x_{0}\right\}+\operatorname{Var}\left\{\epsilon\left(x_{0}\right)\right\}-2 \operatorname{Cov}\left\{\hat{\epsilon}\left(x_{0}\right), \epsilon\left(x_{0}\right)\right\}\right. \\
=\sigma_{\epsilon}^{2}+\sum_{i=1}^{n} \sum_{j=1}^{n} \lambda_{i}\left(x_{0}\right) \lambda_{j}\left(x_{0}\right) C_{\epsilon}\left(x_{0 i}, x_{0 j}\right)-2 \sum_{i=1}^{n} \lambda_{i}\left(x_{0}\right) C_{\epsilon}\left(x_{i}, x_{0}\right) \text { (Goovaerts, 1997) }
\end{gathered}
$$

From this, we can minimise error variance by taking the derivative of Equation A.8 for all kriging weights, and setting all derivatives to 0, leading to Equation A.9,

$$
\sum_{j=1}^{n} \lambda_{j}\left(x_{0}\right) C_{\epsilon}\left(x_{i}, x_{j}\right)=C_{\epsilon}\left(x_{i}, x_{0}\right) \text { (Isaaks and Srivastava, 1989) }
$$

which can be represented in matrix form by Equation A.10,

$$
\begin{gathered}
\mathrm{C} \\
{\left[\begin{array}{cccc}
C_{\epsilon 11} & \ldots & C_{\epsilon 1 n} & 1 \\
\vdots & \ddots & \vdots & \vdots \\
C_{\epsilon n 1} & \ldots & C_{\epsilon n n} & 1 \\
1 & \ldots & 1 & 0
\end{array}\right] \cdot\left[\begin{array}{c}
\lambda_{1} \\
\vdots \\
\lambda_{n} \\
\mu
\end{array}\right]=\left[\begin{array}{c}
C_{10} \\
\vdots \\
C_{n 0} \\
1
\end{array}\right] \text { (Isaaks and Srivastava, 1989) }}
\end{gathered}
$$

where the $C$ matrix represents the covariance between 1 to $n$ points in the area surrounding the point to be estimated (e.g. covariance of GNSS points), $W$ is the weighting assigned to each of the $n$ points, and $D$ is the covariance matrix of the $n$ points with the location to be estimated. From Equation A.10, it is possible to solve for the $W$ matrix, by rearranging the matrices to the form $W=C^{-1} \cdot D$.

\section{Cokriging:}

Cokriging exploits the cross-correlation between two or more variables, in order to further minimise estimation error variance of the primary variable (Isaaks and Srivastava, 1989). This is especially useful in the case where the primary variable is under sampled. If the data is sufficiently detrended, and we can assume a constant mean, 
simple cokriging can be used as represented by Equation A.11,

$$
\hat{u}\left(x_{0}\right)=\sum_{i=1}^{n} \lambda_{a i} \times u_{i}+\sum_{j=1}^{m} \lambda_{b j} \times v_{j}
$$

where $\hat{u}$ is the estimate of the primary variable, $U$, at location $x_{o}, u_{i}$ are the primary nearby data from $n$ locations, $v_{j}$ are the secondary nearby data from $m$ locations, and $\lambda a_{i}$ and $\lambda b_{j}$ are their nearby weights which must be determined. Like for simple univariable kriging, the weights for the primary variable must sum to one, however for cokriging another requirement is that the weights for the secondary variable must sum to 0 (Isaaks and Srivastava, 1989). Assuming a constant mean, Equation A.11 can be represented in the simple cokriging case as Equation A.12 (Rivoirard and Cours, 2003).

$$
\hat{\epsilon}_{u}\left(x_{0}\right)=\sum_{i=1}^{n} \lambda_{a i}\left(\epsilon_{u i}\right)+\sum_{j=1}^{m} \lambda_{b j}\left(\epsilon_{v j}\right)
$$

After taking the 1st derivative of Equation A.12 and setting this to 0, we obtain Equation A.13,

$$
\begin{gathered}
\sum_{i=1}^{n} \lambda_{a i} C\left\{\epsilon_{u i}, \epsilon_{u j}\right\}+\sum_{i=1}^{m} \lambda_{b i} C\left\{\epsilon_{v i}, \epsilon_{u j}\right\}=C\left\{\epsilon_{u 0}, \epsilon_{u j}\right\} \quad \text { for } j=1 \text { to } n \\
\sum_{i=1}^{n} \lambda_{a i} C\left\{\epsilon_{u i}, \epsilon_{v j}\right\}+\sum_{i=1}^{m} \lambda_{b i} C\left\{\epsilon_{v i}, \epsilon_{v j}\right\}=C\left\{\epsilon_{u 0}, \epsilon_{v j}\right\} \quad \text { for } j=1 \text { to } m \\
\mathrm{C} \\
{\left[\begin{array}{ll}
C_{\epsilon\{u i, u j\}} & C_{\epsilon\{v i, u j\}} \\
C_{\epsilon\{u i, v j\}} & C_{\epsilon\{v i, v j\}}
\end{array}\right] \cdot\left[\begin{array}{l}
\lambda_{a i} \\
\lambda_{b i}
\end{array}\right]=\left[\begin{array}{c}
C_{\epsilon\{u 0, u j\}} \\
C_{\epsilon\{u 0, v j\}}
\end{array}\right] \text { (Rivoirard and Cours, 2003) }}
\end{gathered}
$$

which is represented in matrix form by Equation A.14. Where $C$ represents the covariance of the primary and secondary variables, the $W$ matrix represents the weighting of both the primary and secondary variables, and the $D$ matrix represents covariance between primary and secondary variables at locations $j$ to $n$ with the point to be estimated. From Equation A.14, it is possible to solve for the $W$ matrix, by rearanging the matrices to the form $W=C^{-1} \cdot D$. 


\section{Confidence interval in mean}

In order to calculate the $95 \%$ confidence interval of the mean, this study uses the Equation A.15 (Clark and Randal, 2004), where $\mu$ is the mean, $\sigma$ is the standard deviation, and $n$ is the sample size.

$$
\mu \pm 1.96 \times(\sigma / \sqrt{n}) \quad \text { (Clark and Randal, 2004) }
$$

\begin{tabular}{|c|c|c|c|c|c|c|}
\hline \multicolumn{7}{|c|}{ GNSS-GNSS } \\
\hline Year & no. lags & Lag size $(\mathrm{m})$ & Range (m) & Partial sill & Nugget & no. bins \\
\hline 1997 & 12 & 89.5 & 782.605 & 0.685 & 0.379 & 89 \\
\hline 2005 & 12 & 81.3 & 695.7 & 0.970 & 0 & 47 \\
\hline 2007 (Nov) & 12 & 113.0 & 786.82 & 0.2 & 0.92 & 18 \\
\hline 2008(Jan) & 12 & 131.1 & 881.38 & 0.58 & 0.417 & 23 \\
\hline 2008(Apr) & 12 & 131.1 & 903.53 & 0.477 & 0.522 & 22 \\
\hline 2008(Nov) & 12 & 134.53 & 929.9 & 0.496 & 0.504 & 22 \\
\hline 2009(Mar) & 12 & 156.61 & 1252.8 & 1.005 & 0.112 & 14 \\
\hline 2009(Nov) & 12 & 82.85 & 726.82 & 0.721 & 0.231 & 57 \\
\hline 2010(Mar) & 12 & 85.447 & 764.28 & 1.737 & 0 & 36 \\
\hline 2010(Nov) & 12 & 110.57 & 686.15 & 0445 & 0.526 & 75 \\
\hline 2011(Mar) & 12 & 90.47 & 758.92 & 0.846 & 0.157 & 57 \\
\hline 2011(Nov) & 12 & 93.39 & 561.03 & 0.635 & 0 & 63 \\
\hline 2012(Mar) & 12 & 113.65 & 685.69 & 0.6519 & 0.366 & 70 \\
\hline 2012 (Oct) & 12 & 108.35 & 713.08 & 0.89 & 0.080 & 82 \\
\hline 2013(Mar) & 12 & 113.43 & 953.94 & 1.204 & 0 & 15 \\
\hline 2013(Nov) & 12 & 80.53 & 689.96 & 0.776 & 0.2 & 45 \\
\hline 2014(Apr) & 12 & 82.41 & 723.25 & 0.652 & 0.31 & 39 \\
\hline 2014(Dec) & 12 & 81.66 & 722.47 & 1.07 & 0 & 32 \\
\hline 2016(Nov) & 12 & 87.86 & 758.17 & 0.814 & 0.16 & 172 \\
\hline
\end{tabular}

Table A.1: Covariance function parameters for GNSS points. 


\begin{tabular}{|c|c|c|c|c|c|}
\hline \multicolumn{6}{|c|}{ GNSS-SfM } \\
\hline Year & Lags & Lag size & Range & Sill & no. bins \\
\hline 1997 & 12 & 89.5 & 782.605 & 0.245 & 89 \\
\hline 2005 & 12 & 81.27 & 695.698 & 0.478 & 47 \\
\hline 2007 (Nov) & 12 & 113.04 & 786.82 & 0.303 & 18 \\
\hline 2008(Jan) & 12 & 131.09 & 881.38 & 0.352 & 23 \\
\hline 2008(Apr) & 12 & 131.1 & 903.53 & 0.345 & 22 \\
\hline 2008(Nov) & 12 & 134.53 & 929.90 & 0.388 & 22 \\
\hline 2009(Mar) & 12 & 156.61 & 1252.84 & 0.409 & 14 \\
\hline 2009(Nov) & 12 & 82.856 & 726.82 & 0.338 & 57 \\
\hline 2010(Mar) & 12 & 85.447 & 764.28 & 1.061 & 36 \\
\hline 2010 (Oct) & 12 & 110.57 & 686.15 & 0.48 & 75 \\
\hline 2011(Mar) & 12 & 90.47 & 758.92 & 0.166 & 57 \\
\hline 2011(Nov) & 12 & 93.39 & 561.03 & 0.540 & 63 \\
\hline 2012(Mar) & 12 & 113.65 & 685.69 & 0.003 & 70 \\
\hline 2012 (Oct) & 12 & 108.35 & 713.08 & 0.460 & 82 \\
\hline 2013(Mar) & 12 & 113.43 & 953.95 & 0.523 & 15 \\
\hline 2013(Nov) & 12 & 80.53 & 689.96 & 0.480 & 45 \\
\hline 2014(Apr) & 12 & 82.41 & 723.25 & 0.553 & 39 \\
\hline 2014(Dec) & 12 & 81.664 & 722.47 & 0.671 & 32 \\
\hline 2016(Nov) & 12 & 87.86 & 758.16 & 0.488 & 172 \\
\hline
\end{tabular}

Table A.2: Covariance function parameters used for GNSS points cross covaried with SfM points 


\begin{tabular}{|c|c|c|c|c|c|c|}
\hline \multicolumn{7}{|c|}{ SfM-SfM } \\
\hline Year & Lags & Lag size & Range & Partial sill & Nugget & no. bins \\
\hline 1997 & 12 & 89.5 & 770.907 & 0.769 & 0.265 & 89 \\
\hline 2005 & 12 & 81.27 & 695.698 & 0.866 & 0.153 & 47 \\
\hline 2007 (Nov) & 12 & 113.04 & 786.82 & 0.752 & 0.282 & 18 \\
\hline 2008(Jan) & 12 & 131.09 & 881.38 & 0.633 & 0.385 & 23 \\
\hline 2008 (Apr) & 12 & 131.09 & 903.53 & 0.345 & 0.406 & 22 \\
\hline 2008(Nov) & 12 & 134.53 & 929.9 & 0.610 & 0.424 & 22 \\
\hline 2009(Mar) & 12 & 156.601 & 1252.84 & 1.188 & 0 & 14 \\
\hline 2009(Nov) & 12 & 82.86 & 726.8 & 0.903 & 0.132 & 57 \\
\hline 2010(Mar) & 12 & 85.45 & 764.28 & 1.183 & 0 & 36 \\
\hline 2010 (Oct) & 12 & 110.5654 & 686.15 & 0.867 & 0.167 & 75 \\
\hline 2011(Mar) & 12 & 90.47 & 758.92 & 0.758 & 0.260 & 57 \\
\hline 2011(Nov) & 12 & 93.39 & 561.03 & 1.520 & 0 & 63 \\
\hline 2012(Mar) & 12 & 113.65 & 685.69 & 0.842 & 0.176 & 70 \\
\hline 2012 (Oct) & 12 & 108.35 & 713.08 & 0.834 & 0.200 & 82 \\
\hline 2013(Mar) & 12 & 113.43 & 953.95 & 0.877 & 0 & 15 \\
\hline 2013(Nov) & 12 & 80.53 & 689.96 & 0.878 & 0.156 & 45 \\
\hline 2014(Apr) & 12 & 82.41 & 723.25 & 0.854 & 0.164 & 39 \\
\hline 2014(Dec) & 12 & 81.66 & 722.47 & 1.218 & 0 & 32 \\
\hline 2016(Nov) & 12 & 87.86 & 758.17 & 0.825 & 0.210 & 172 \\
\hline
\end{tabular}

Table A.3: Covariance function parameters used for SfM points. 


\section{B Images for perimeter interpretation}

Material which helped guide perimeter interpretation are included below. 


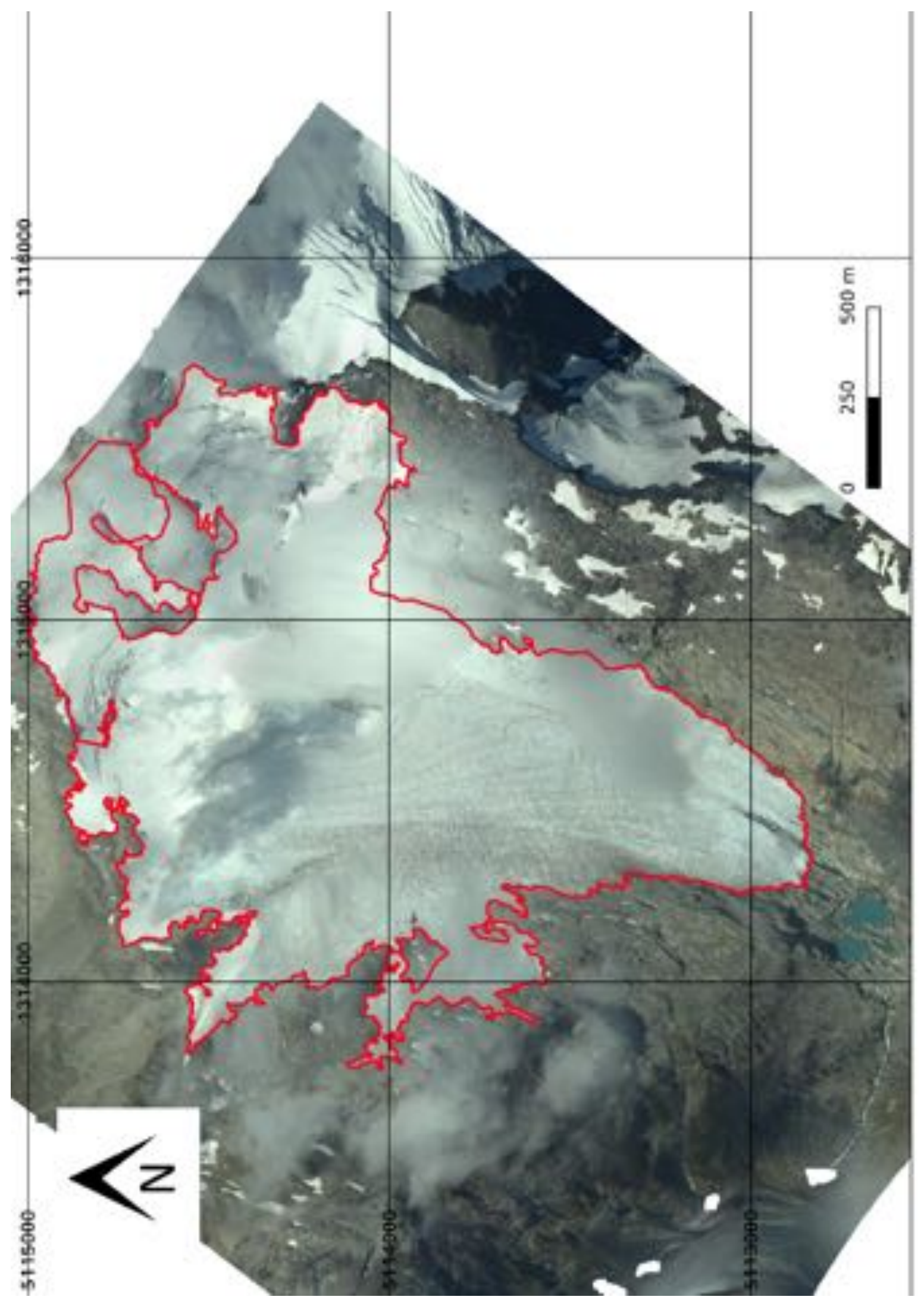

Figure B.1: 2015 perimeter (red line) digitised from sfm model developed from aerial photographs taken March, 2015. 


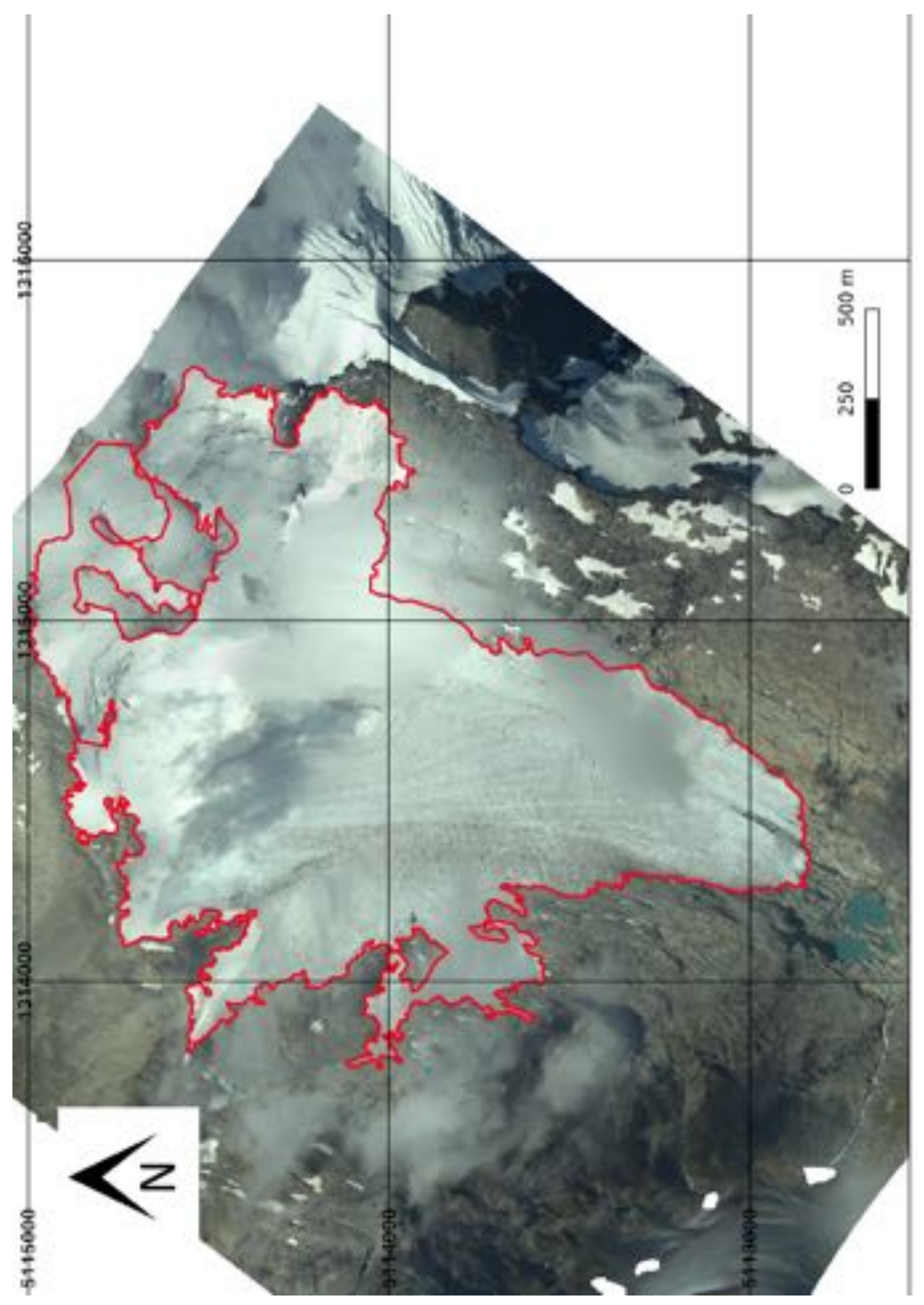

Figure B.2: 2016 perimeter (red line) digitised from sfm model developed from aerial photographs taken March, 2016. 


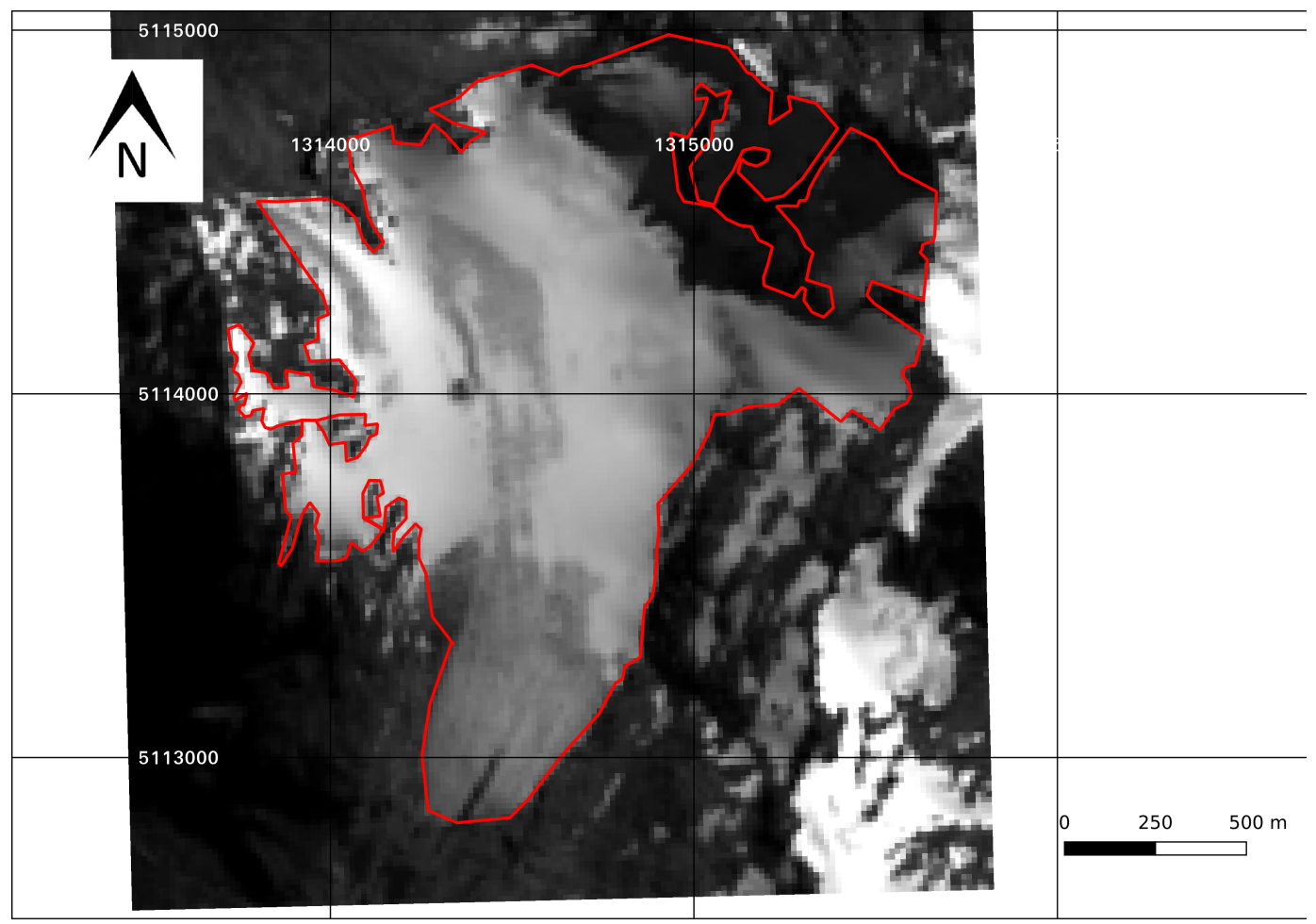

Figure B.3: 2014 perimeter (red line) digitised from Landsat 8 images with the aid of aerial photographs. Background image taken on the 12th of March, 2014.

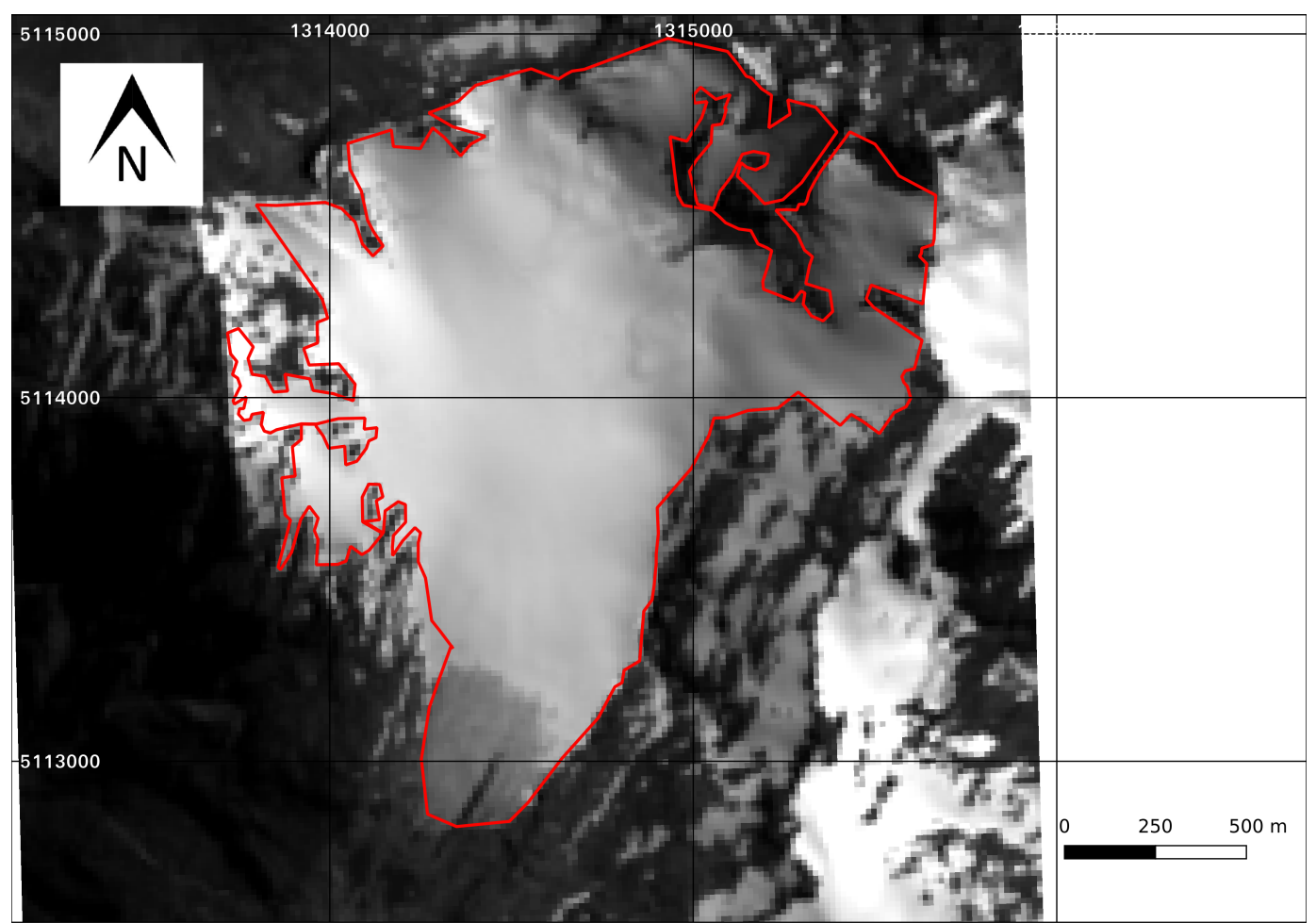

Figure B.4: 2014 perimeter (red line) digitised from Landsat 8 images with the aid of aerial photographs. Background image taken on the 7th of February, 2014. 


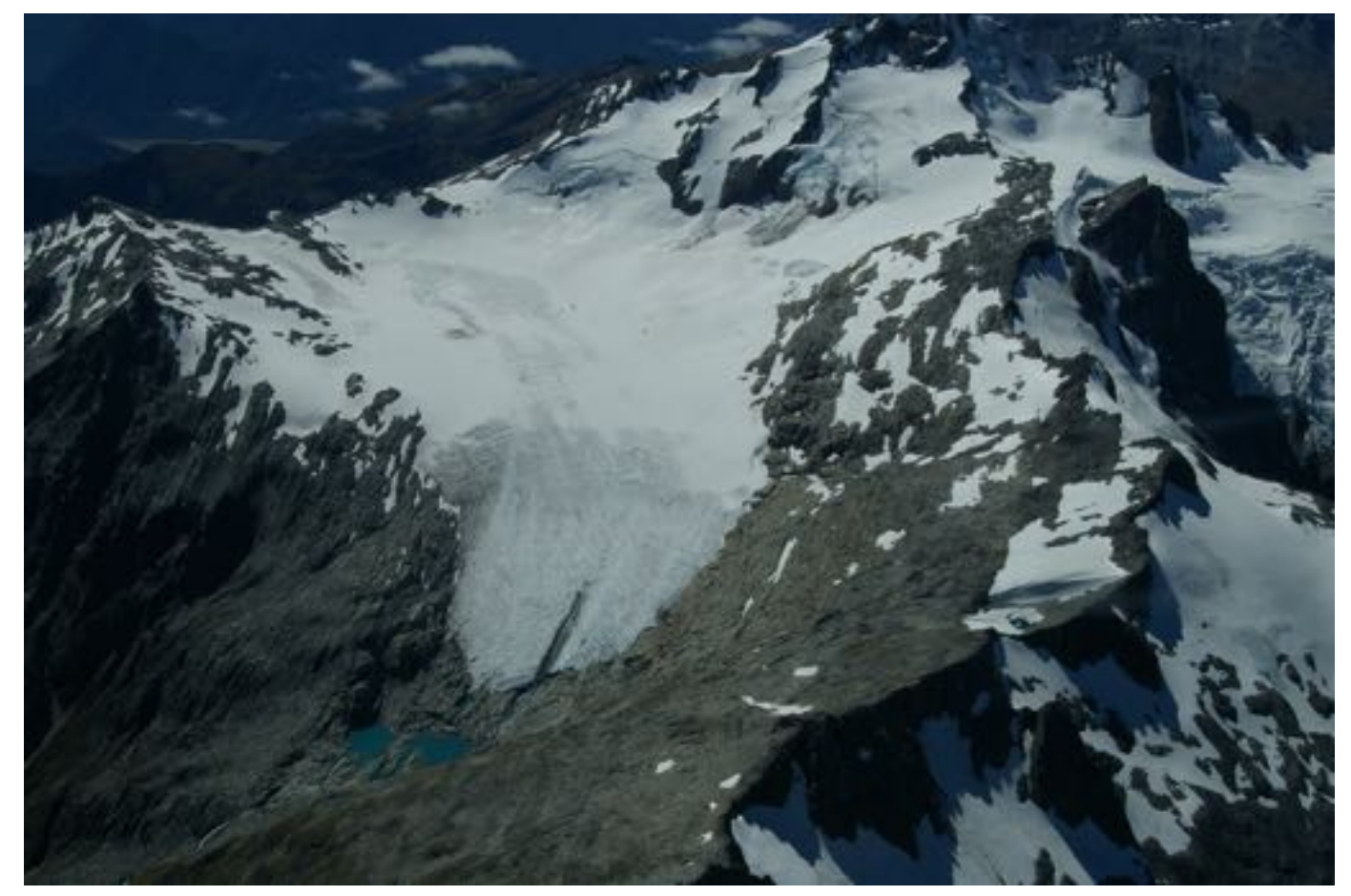

Figure B.5: Aerial photograph used to guide interpretation of perimeter. Photograph taken 11th of March, 2014.

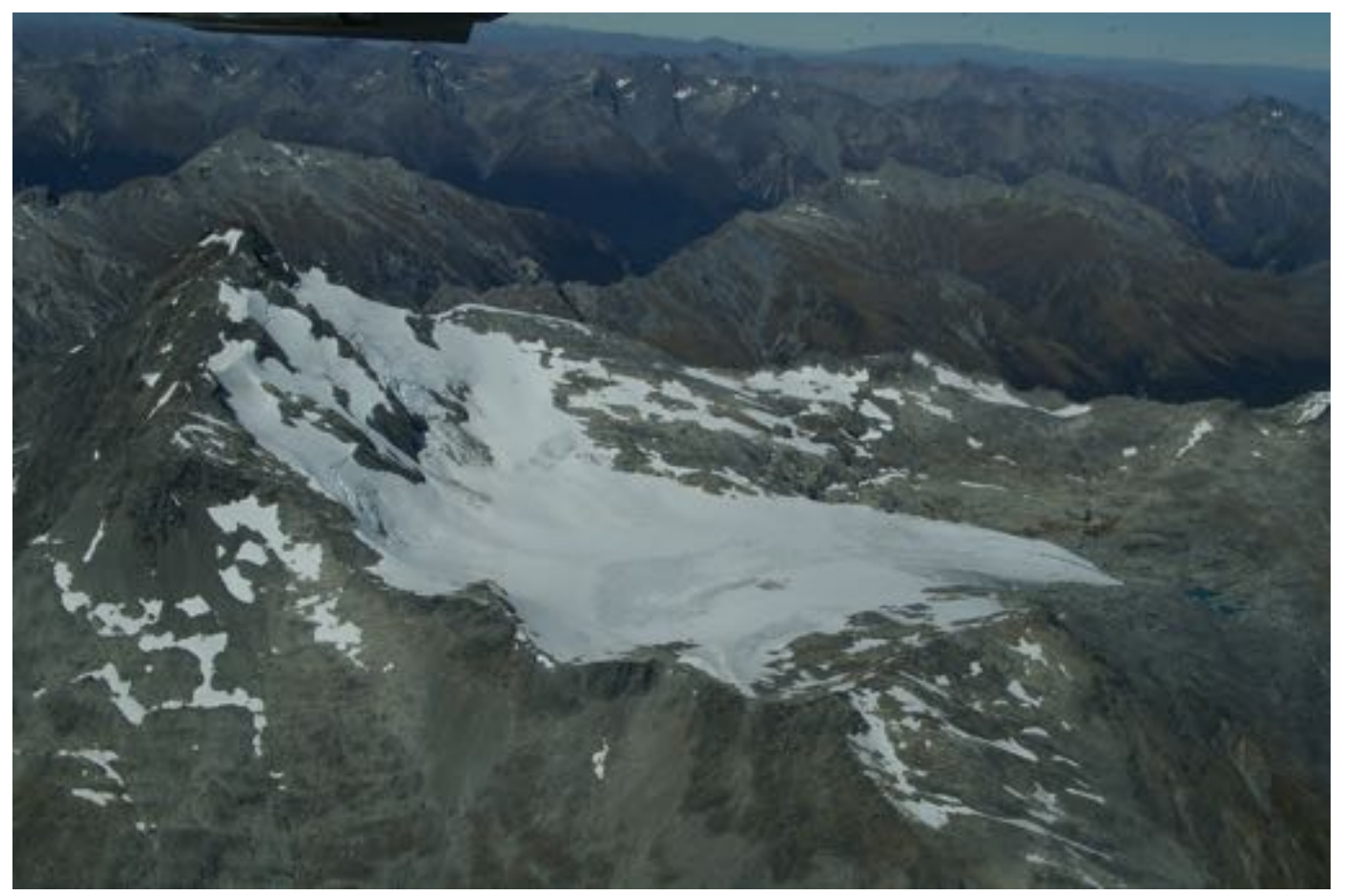

Figure B.6: Aerial photograph used to guide interpretation of perimeter. Photograph taken 11th of March, 2014. 


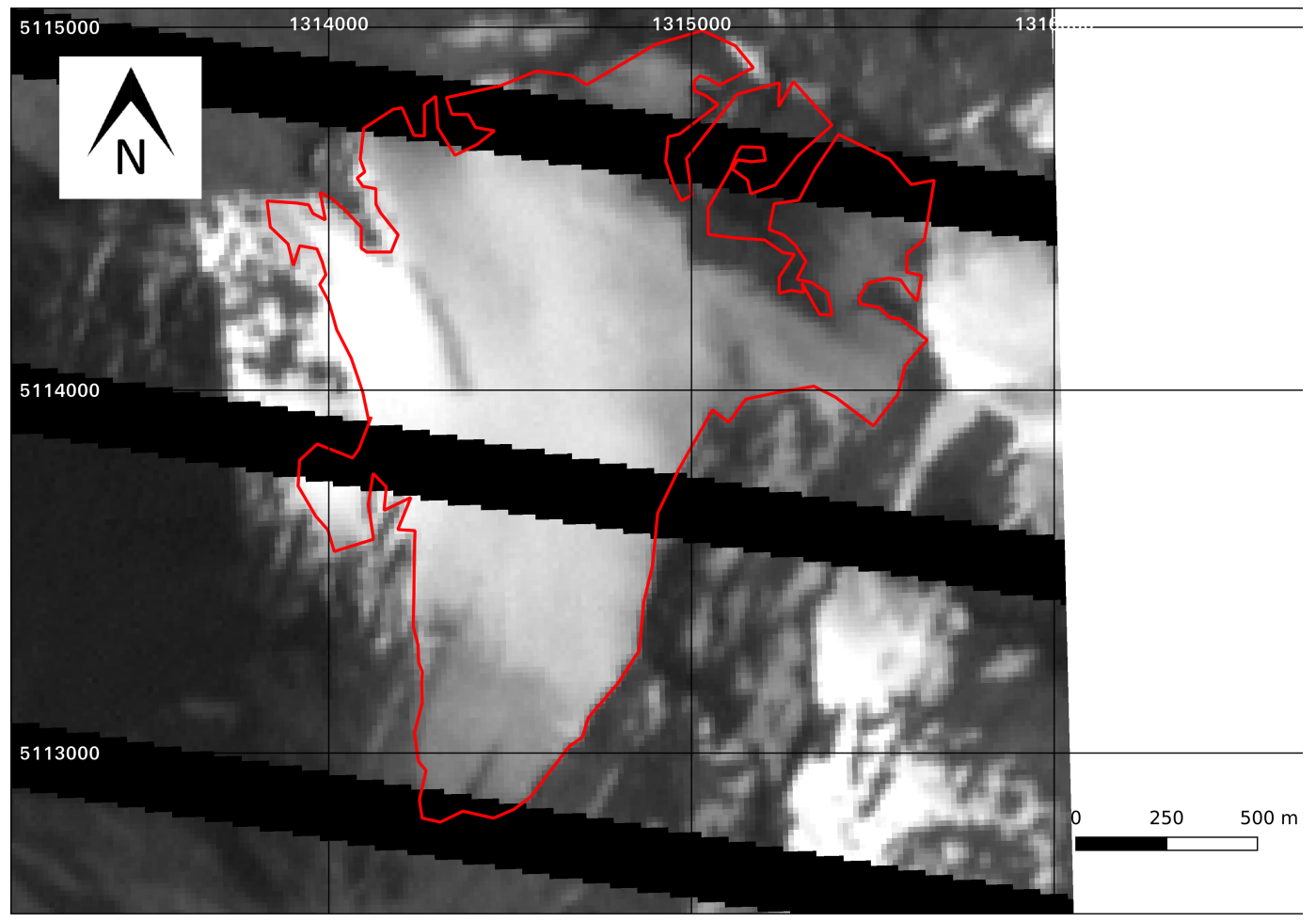

Figure B.7: 2013 perimeter (red line) digitised from Landsat 7 images with the aid of aerial photographs. Background image taken on the 28th of February, 2013.

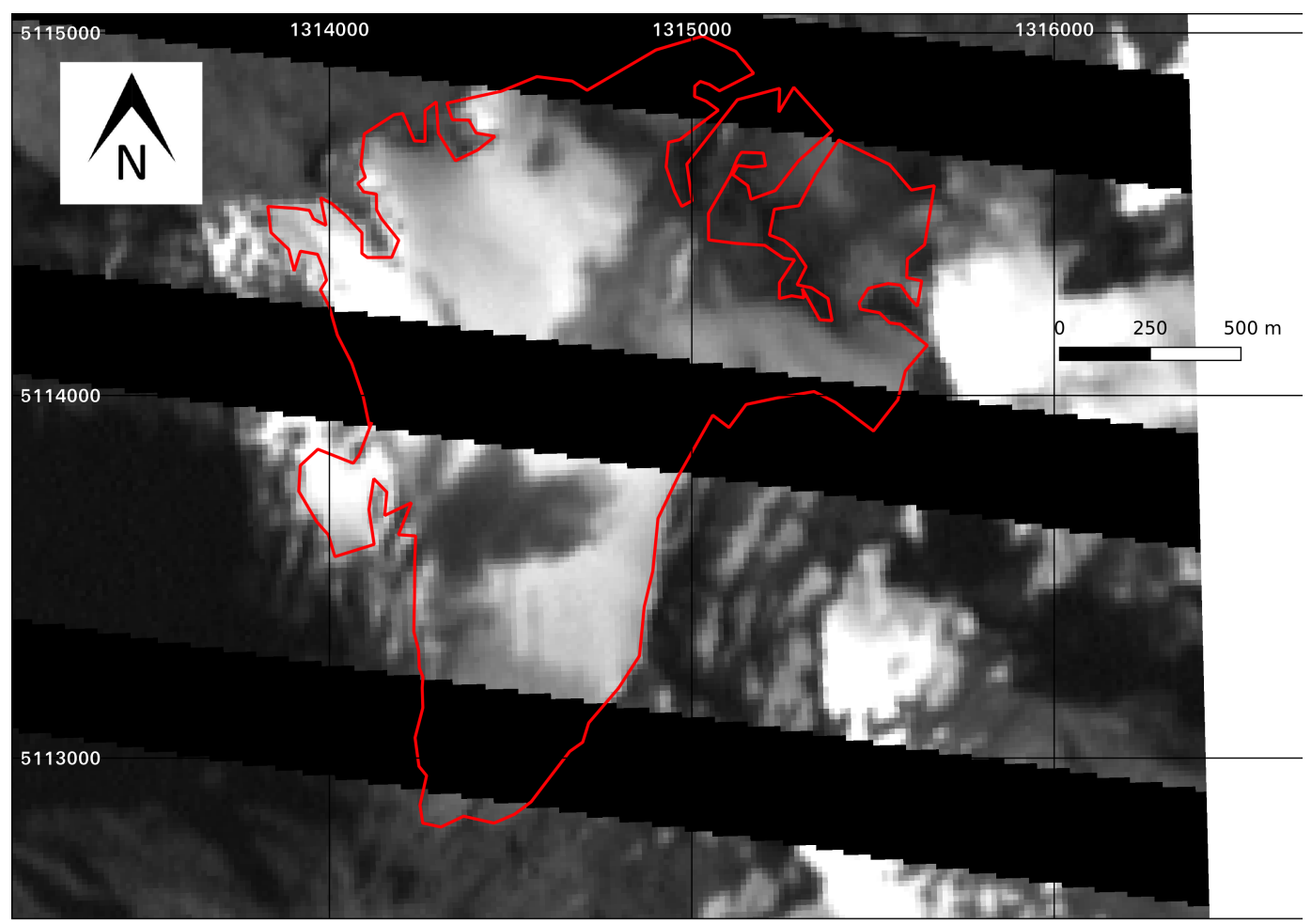

Figure B.8: 2013 perimeter (red line) digitised from Landsat 7 images with the aid of aerial photographs. Background image taken on the 7th of March, 2013. 


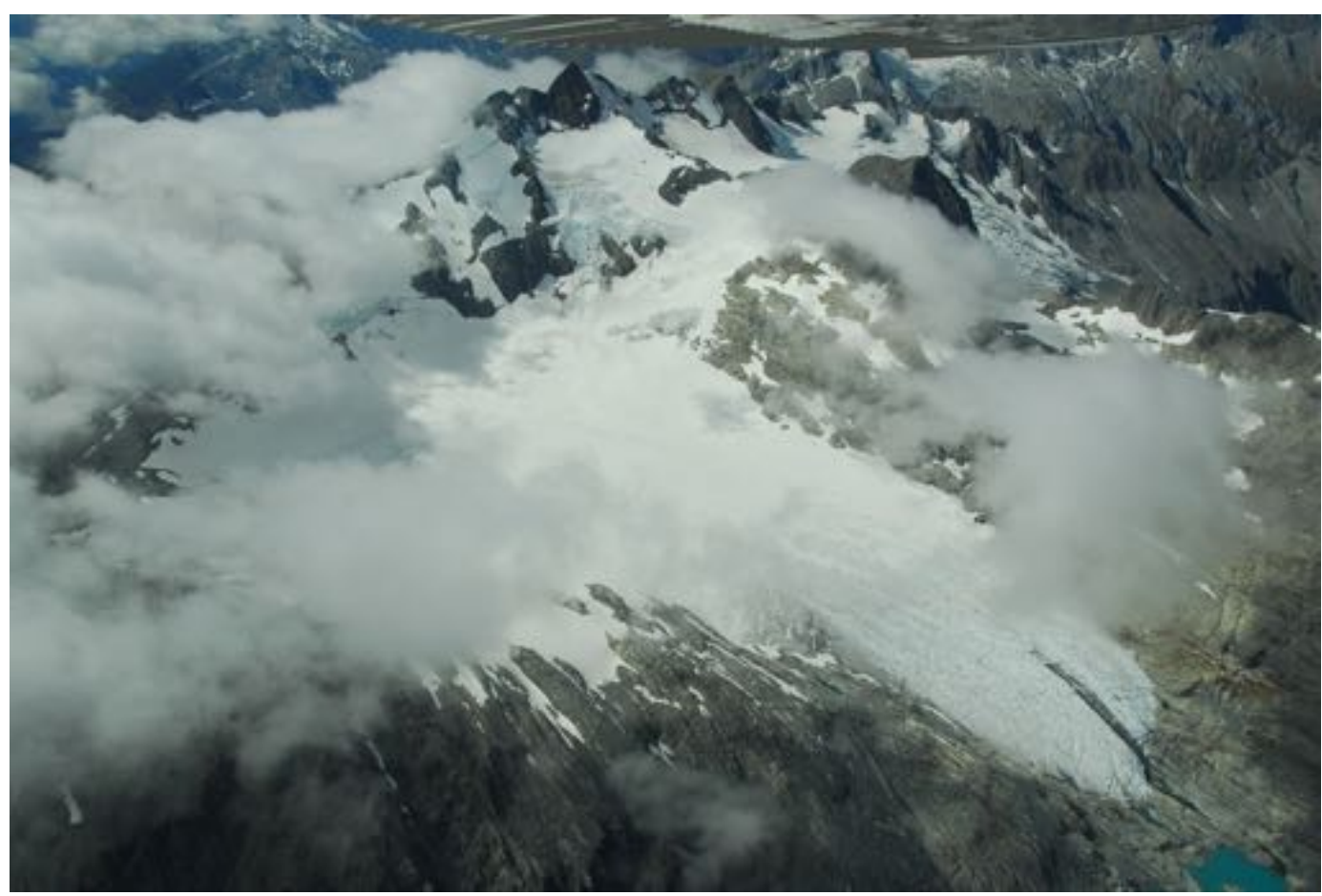

Figure B.9: Aerial photograph used to guide interpretation of perimeter. Photograph taken on the 12th of March, 2013.

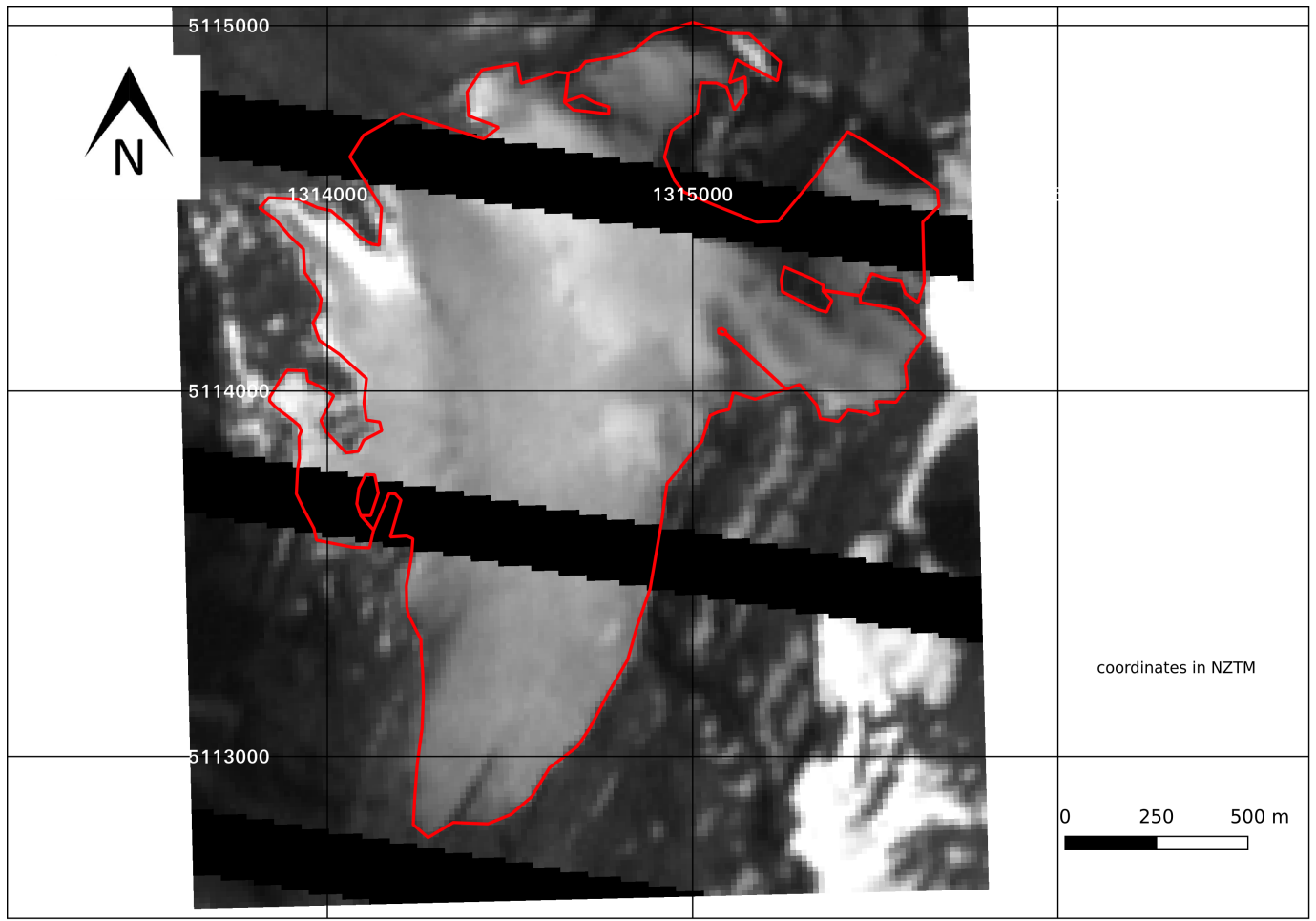

Figure B.10: 2012 perimeter (red line) digitised from Landsat 7 images with the aid of aerial photographs. Background image taken on the 10th of February, 2012. 


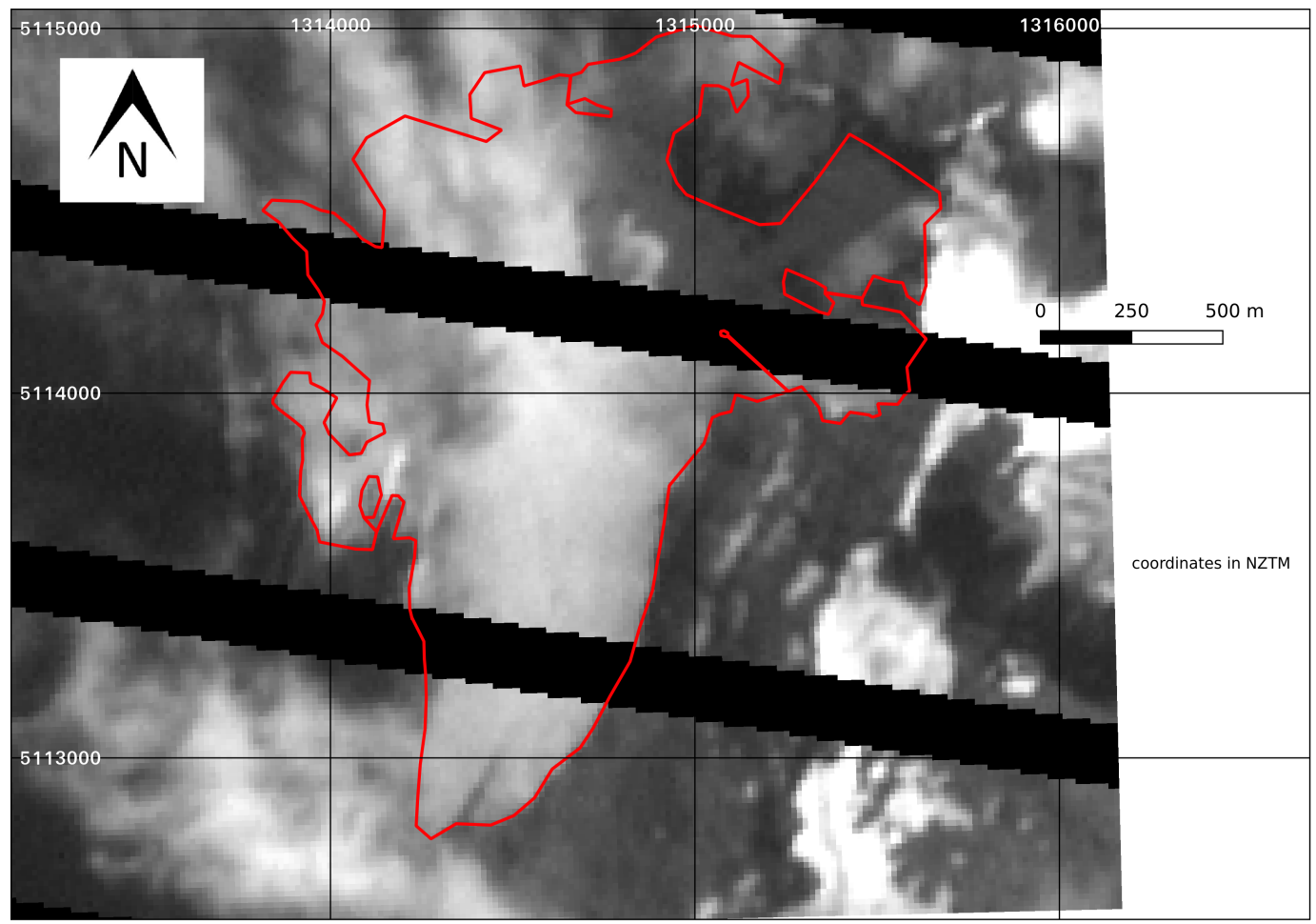

Figure B.11: 2012 perimeter (red line) digitised from Landsat 7 images with the aid of aerial photographs. Background image taken on the 13th of March, 2012.

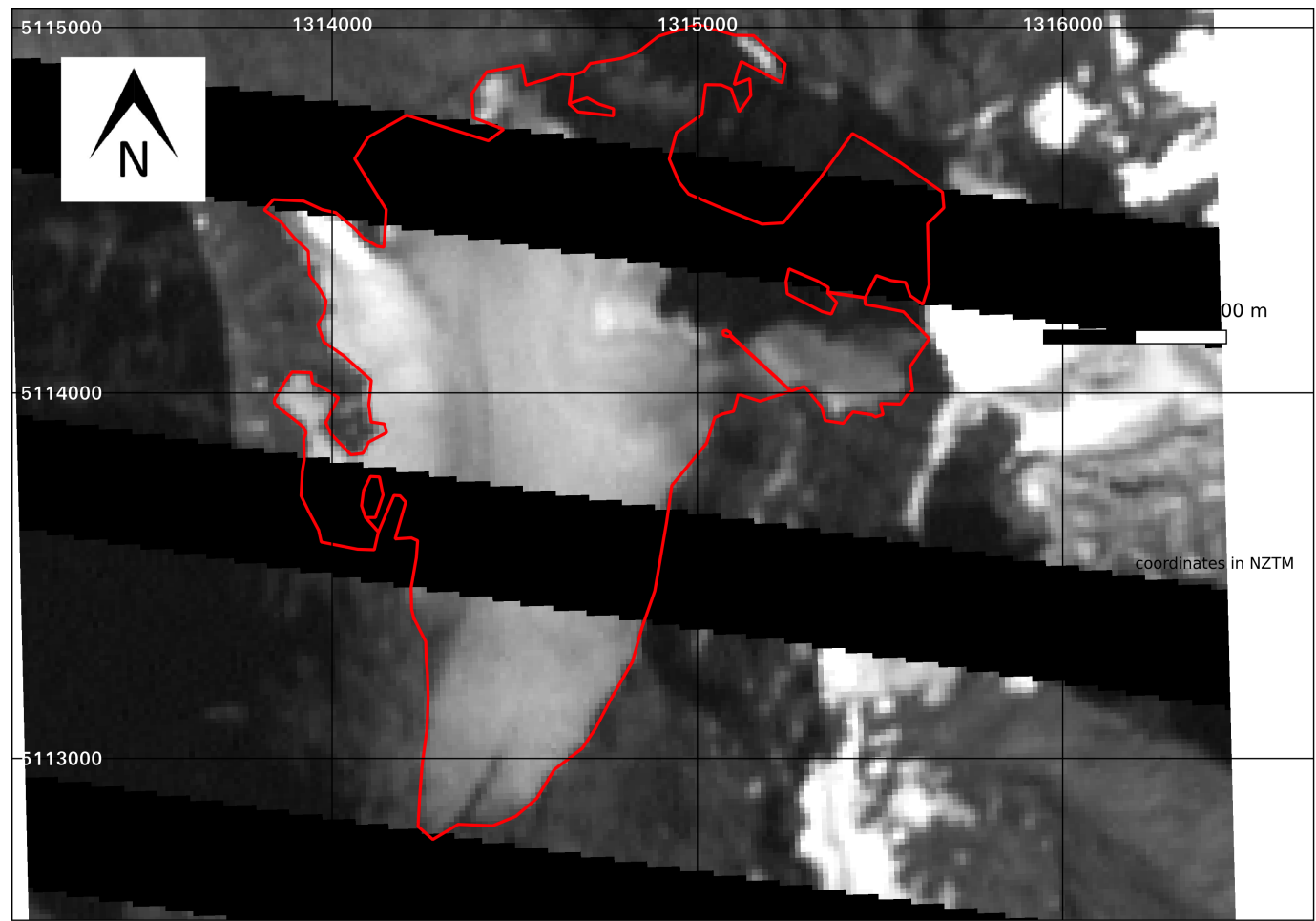

Figure B.12: 2012 perimeter (red line) digitised from Landsat 7 images with the aid of aerial photographs. Background image taken on the 20th of March, 2012. 


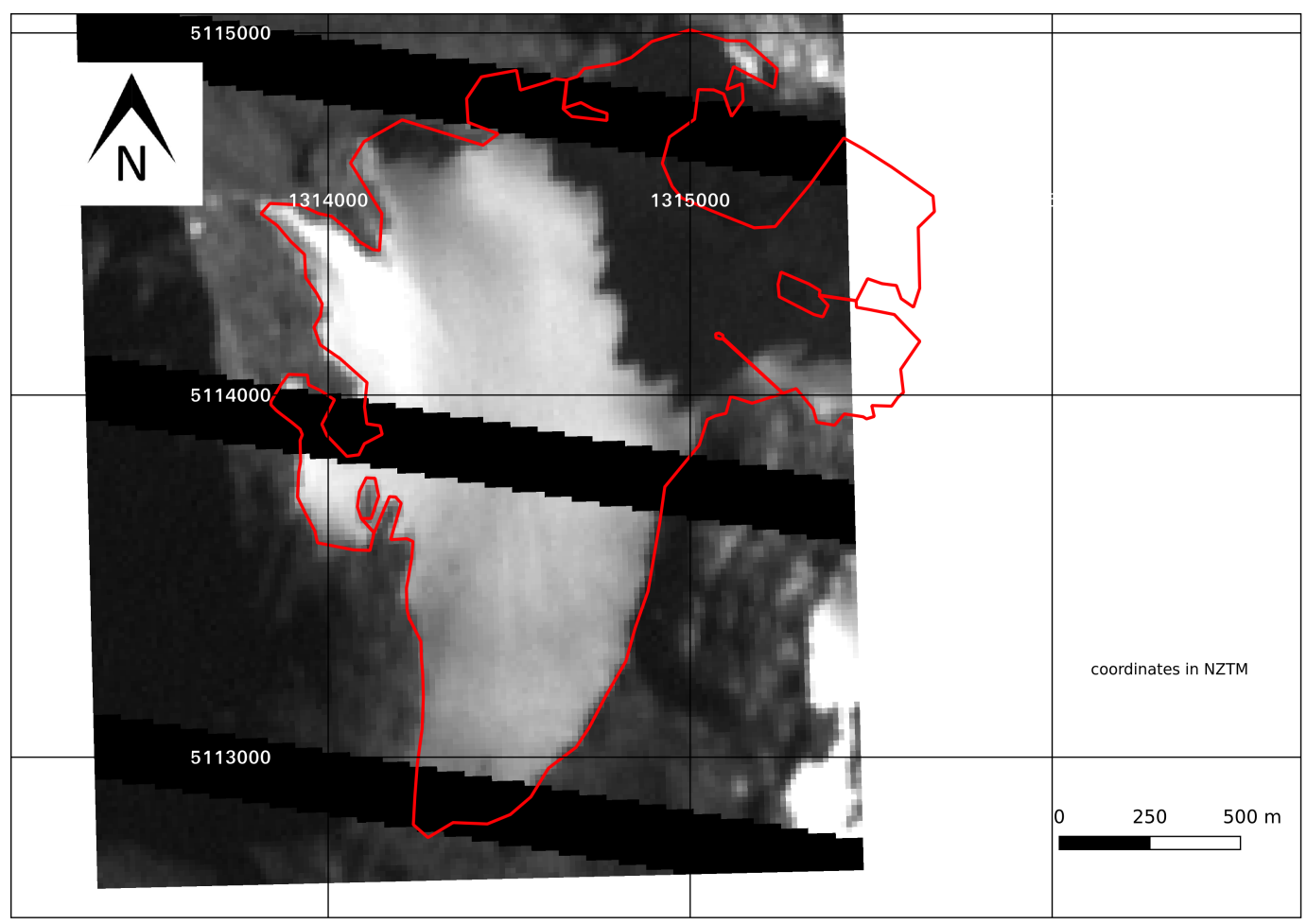

Figure B.13: 2012 perimeter (red line) digitised from Landsat 7 images with the aid of aerial photographs. Background image taken on the 29th of March, 2012.

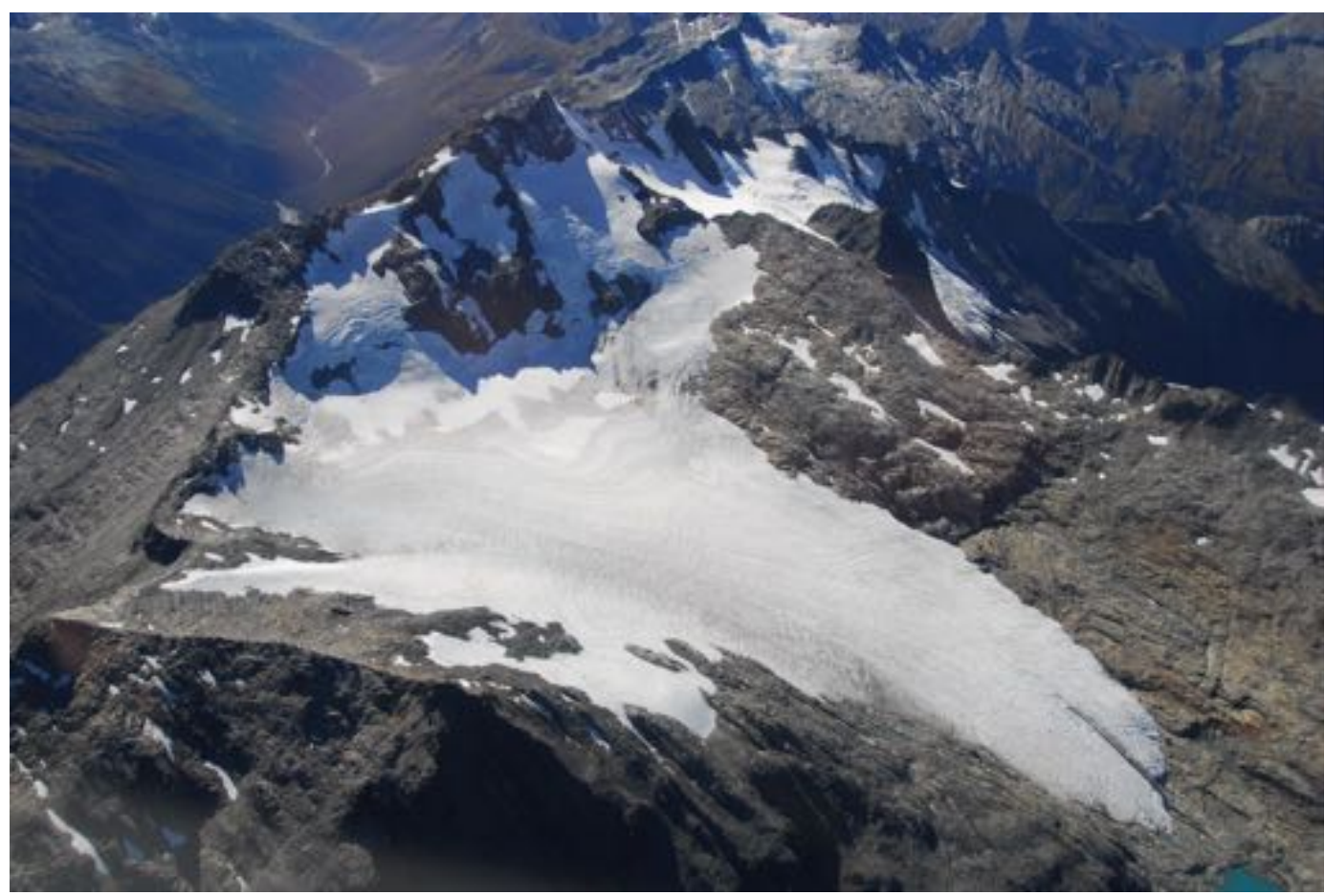

Figure B.14: Aerial photograph used to guide interpretation of perimeter. Photograph taken on the 21st of March, 2012. 


\section{Surface datasets}

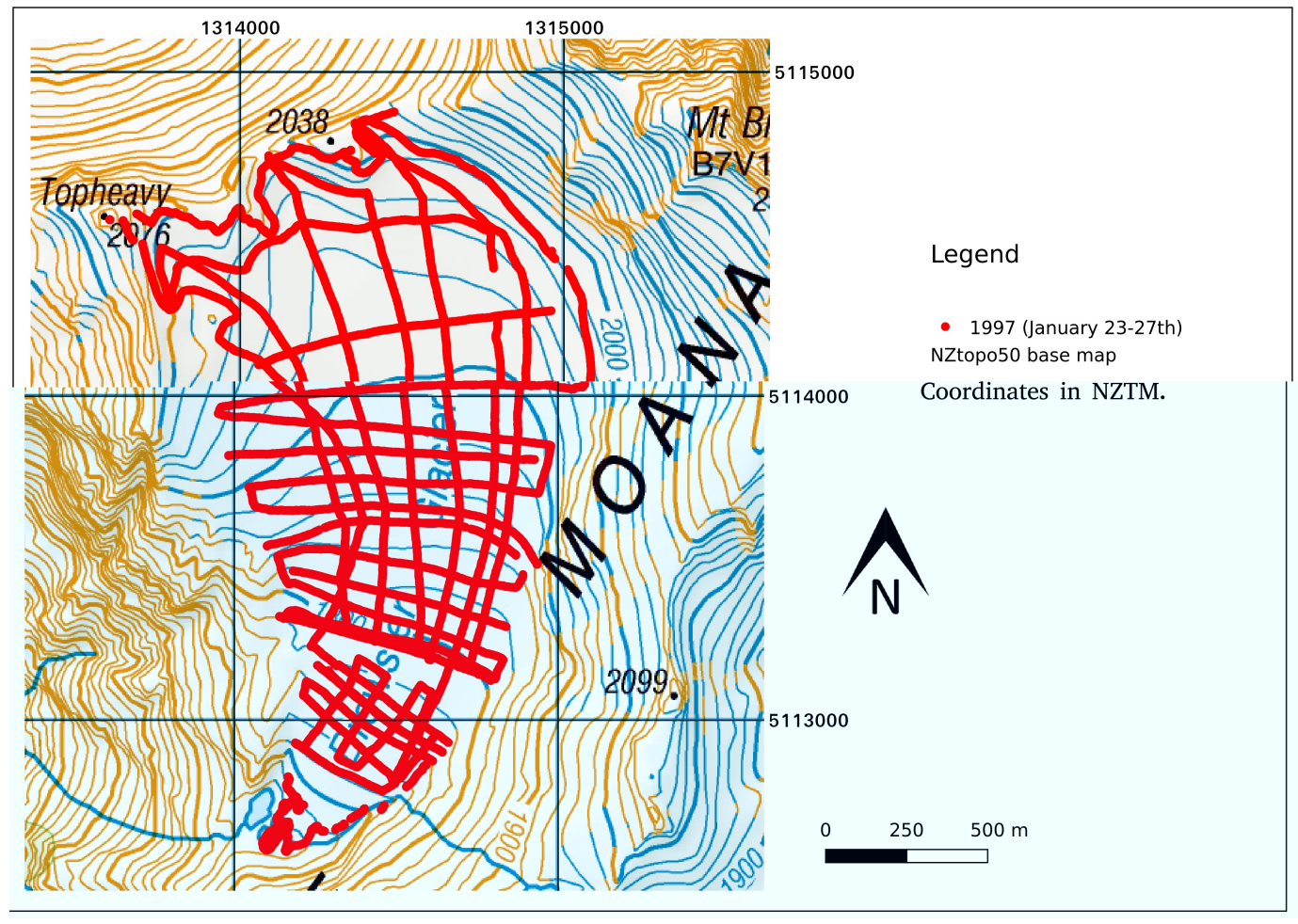

Figure C.1: January, 1997 GNSS track. 


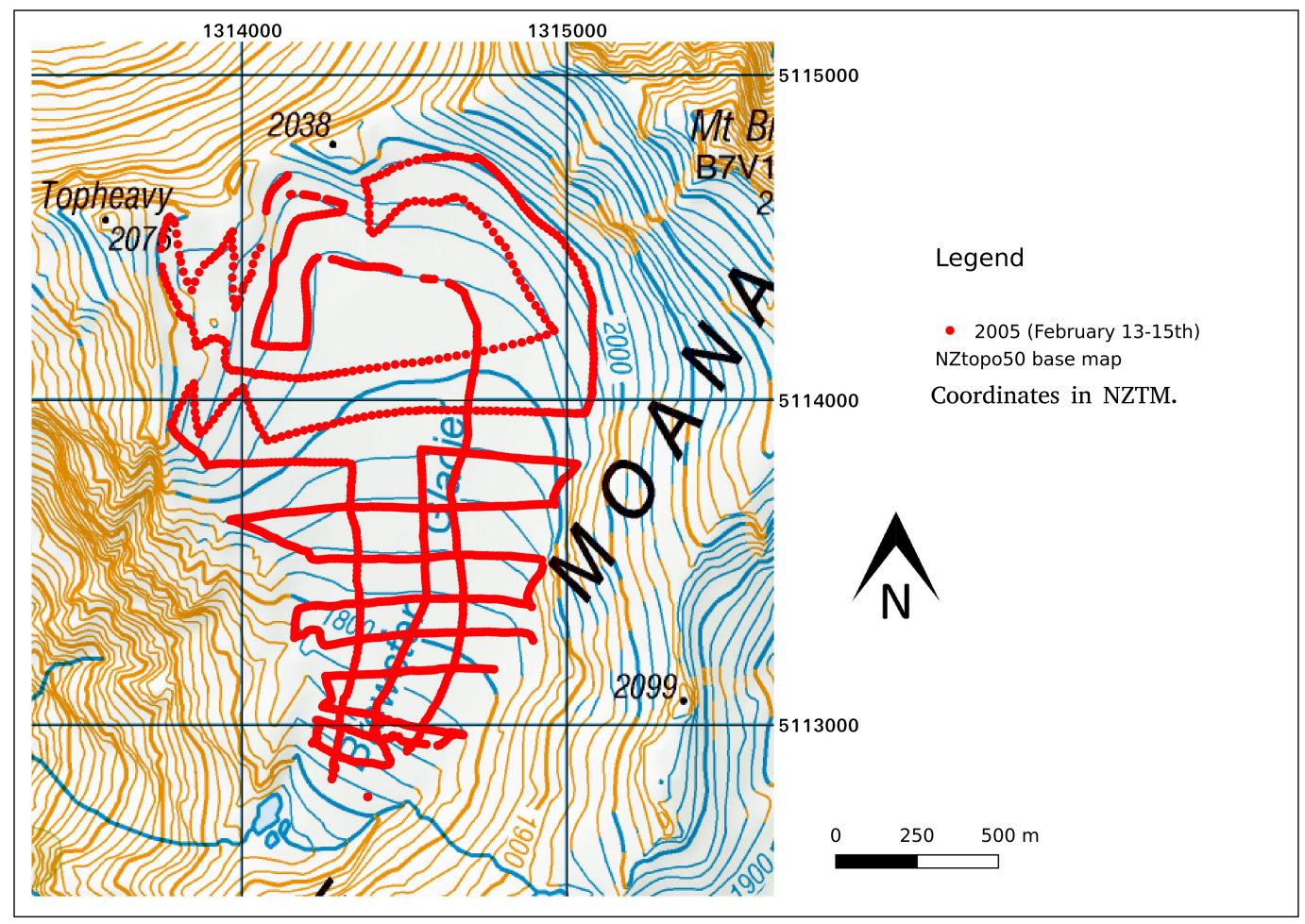

Figure C.2: February, 2005 GNSS track.

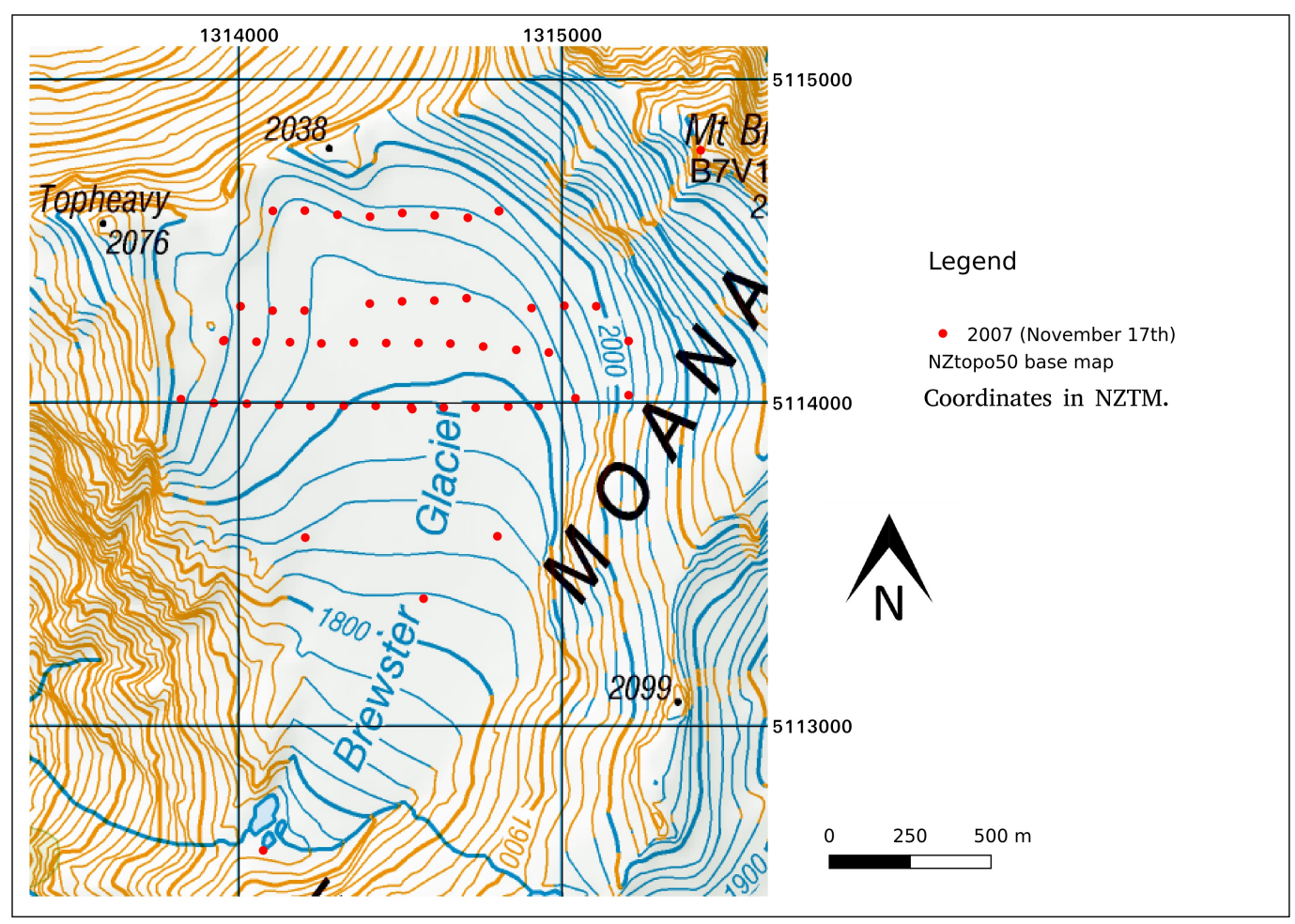

Figure C.3: November, 2007 GNSS track. 


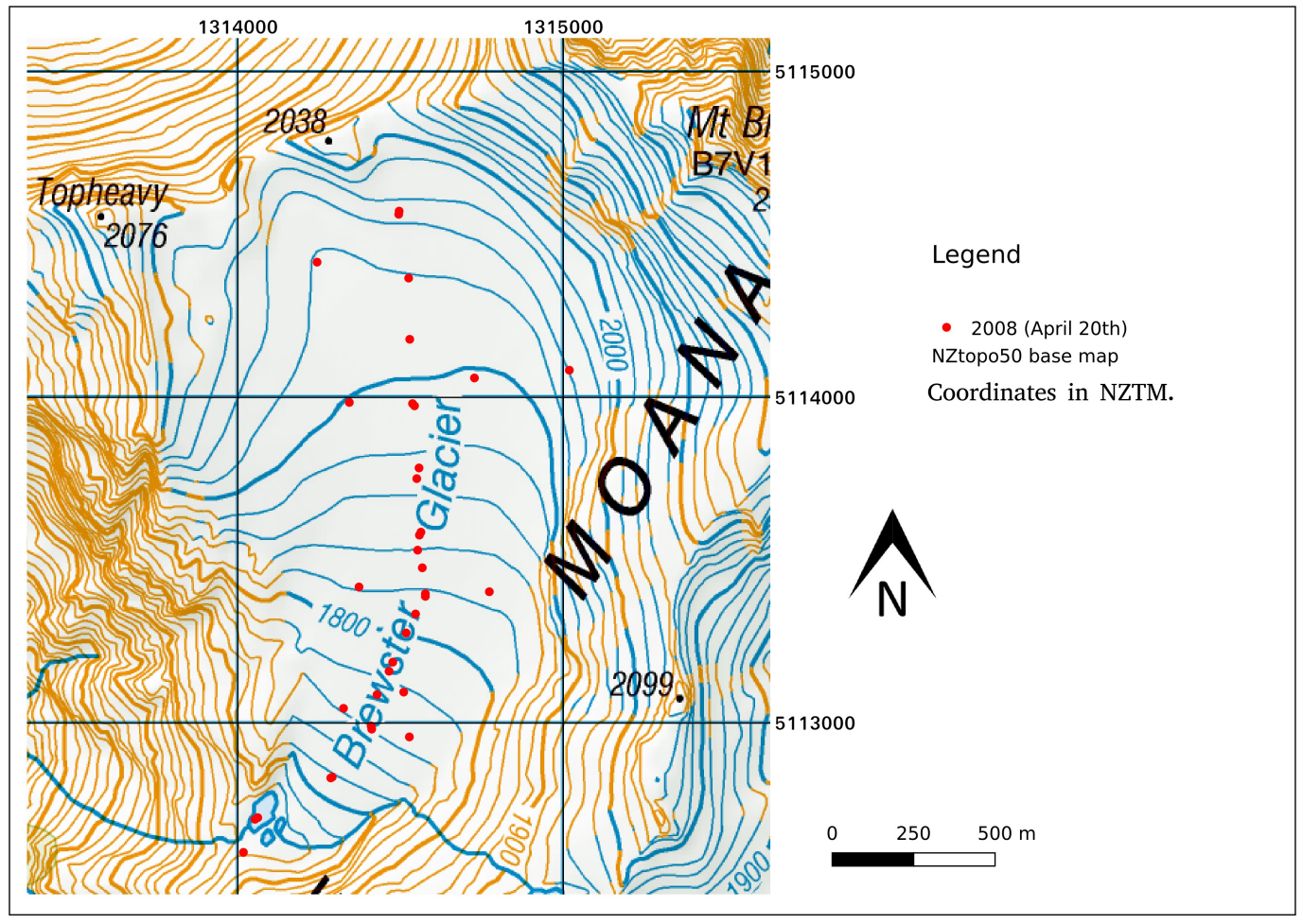

Figure C.4: April, 2008 GNSS track.

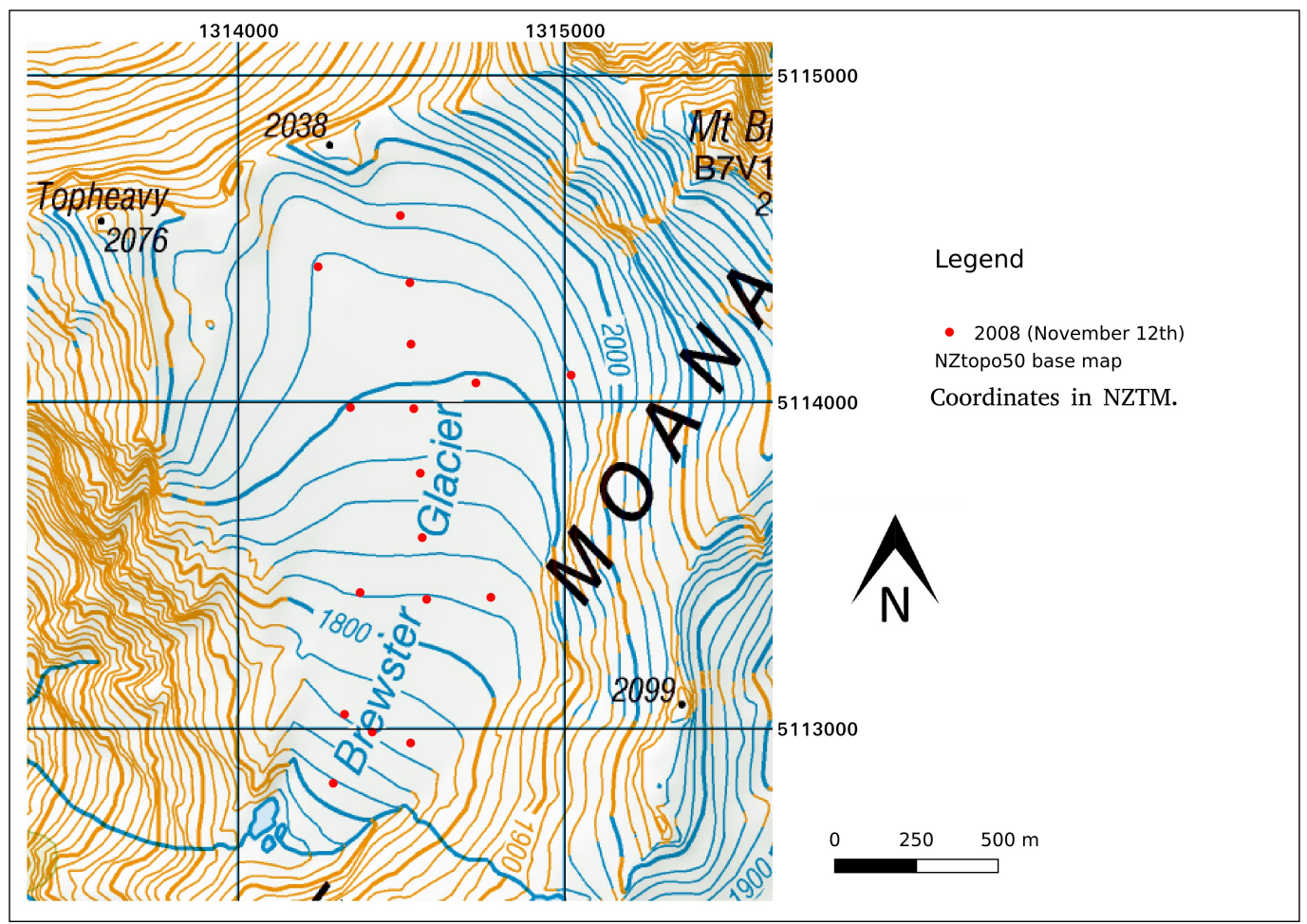

Figure C.5: November, 2008 GNSS track. 


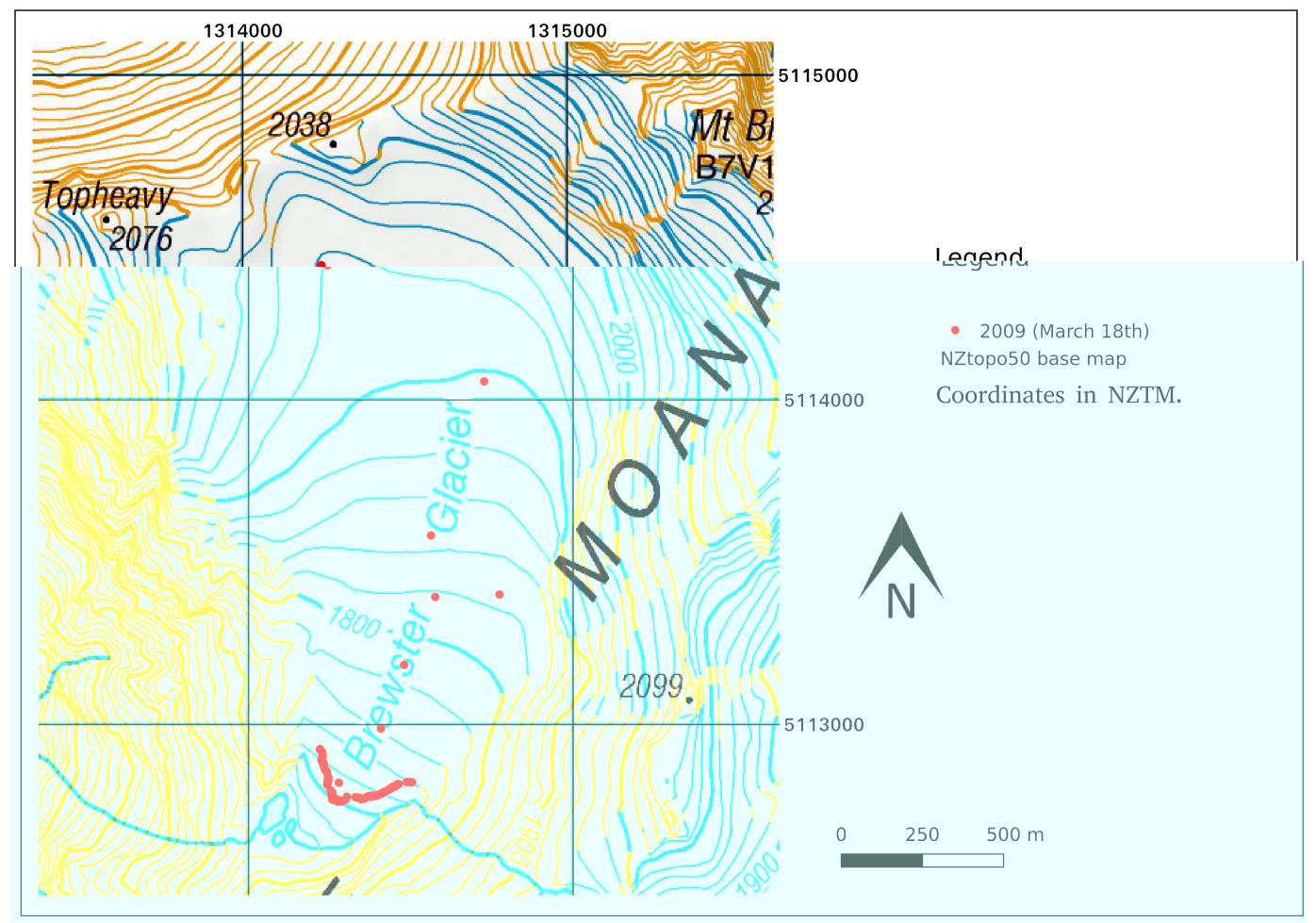

Figure C.6: March, 2009 GNSS track.

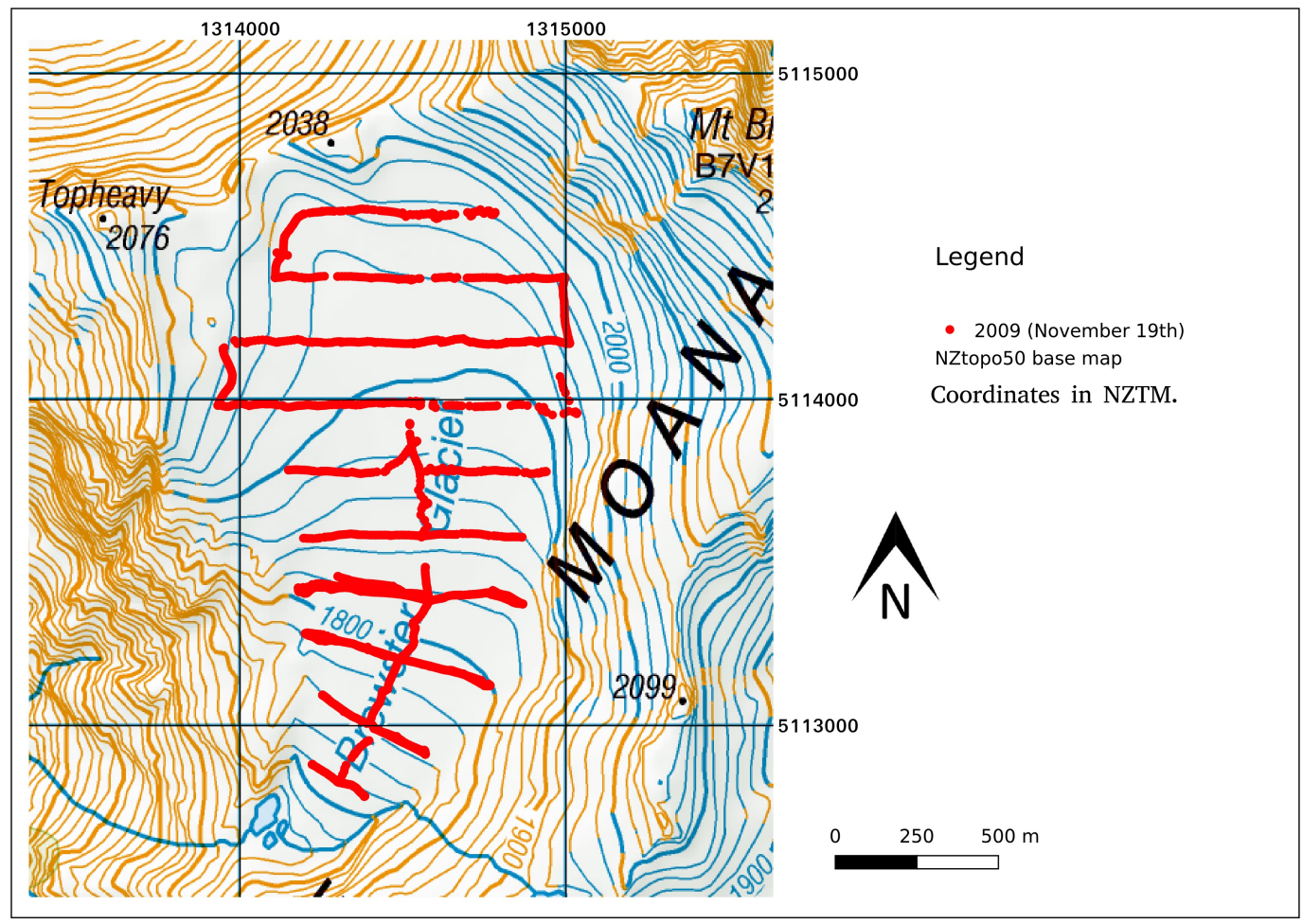

Figure C.7: November, 2009 GNSS track. 


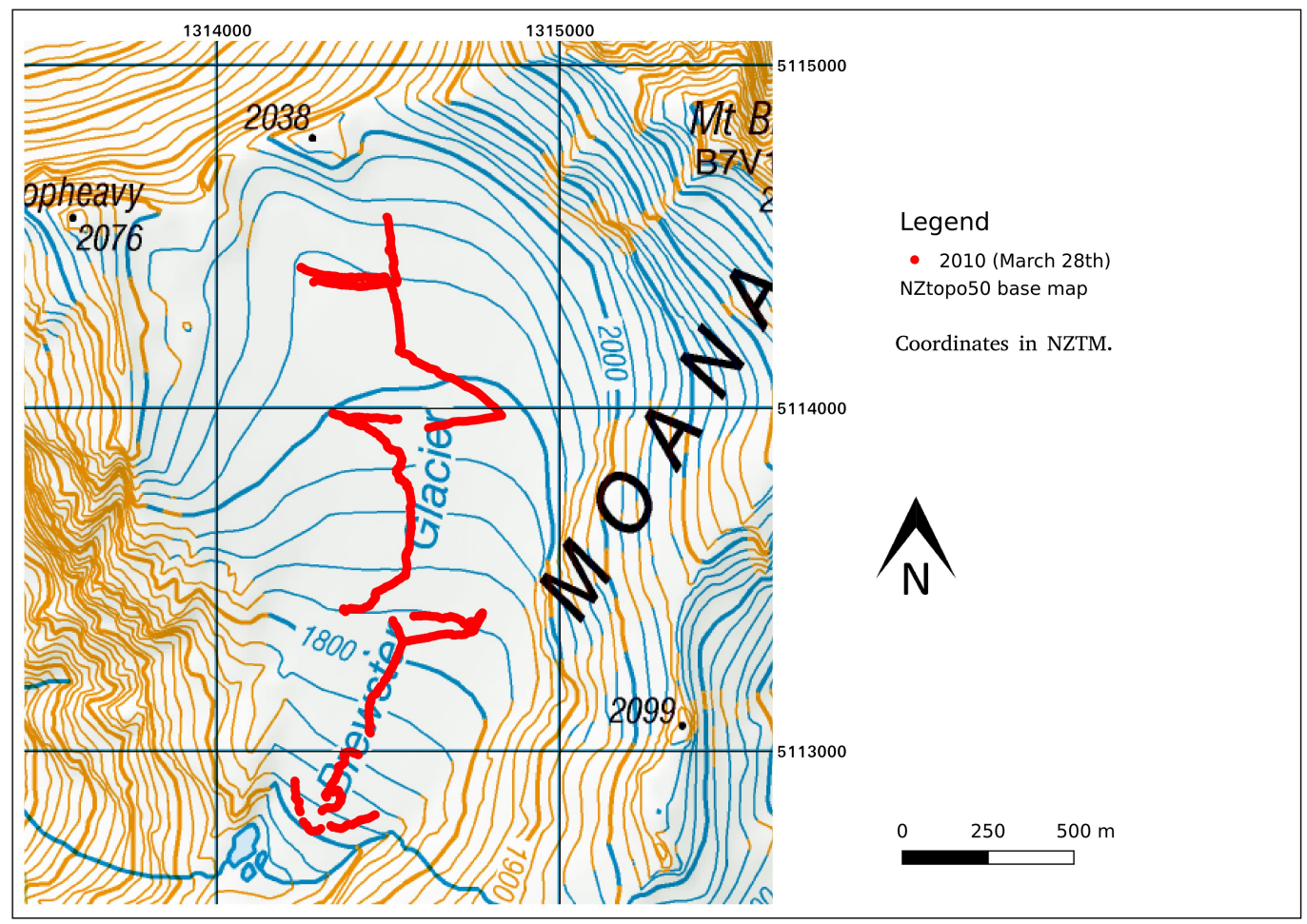

Figure C.8: March, 2010 GNSS track.

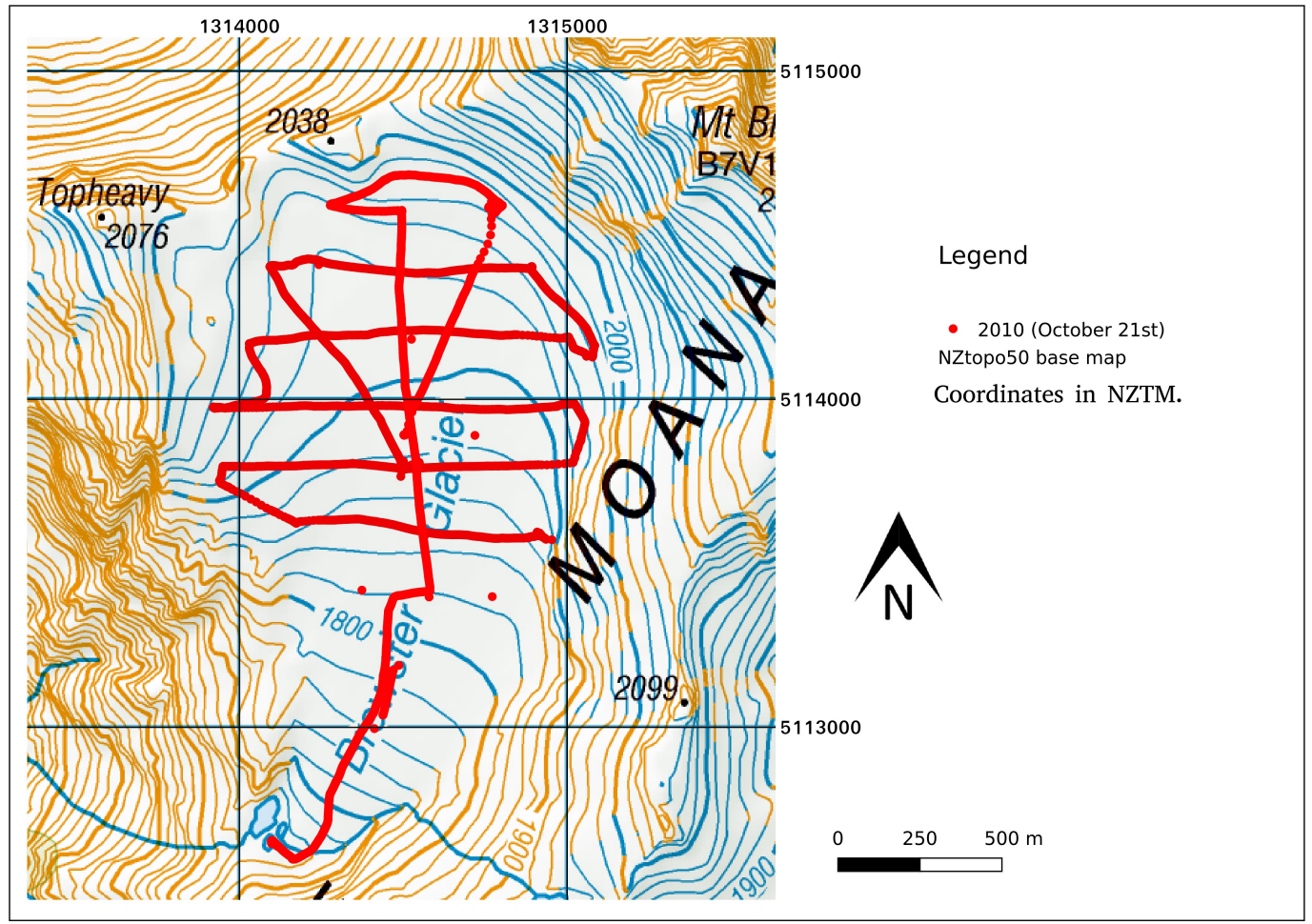

Figure C.9: October, 2010 GNSS track. 


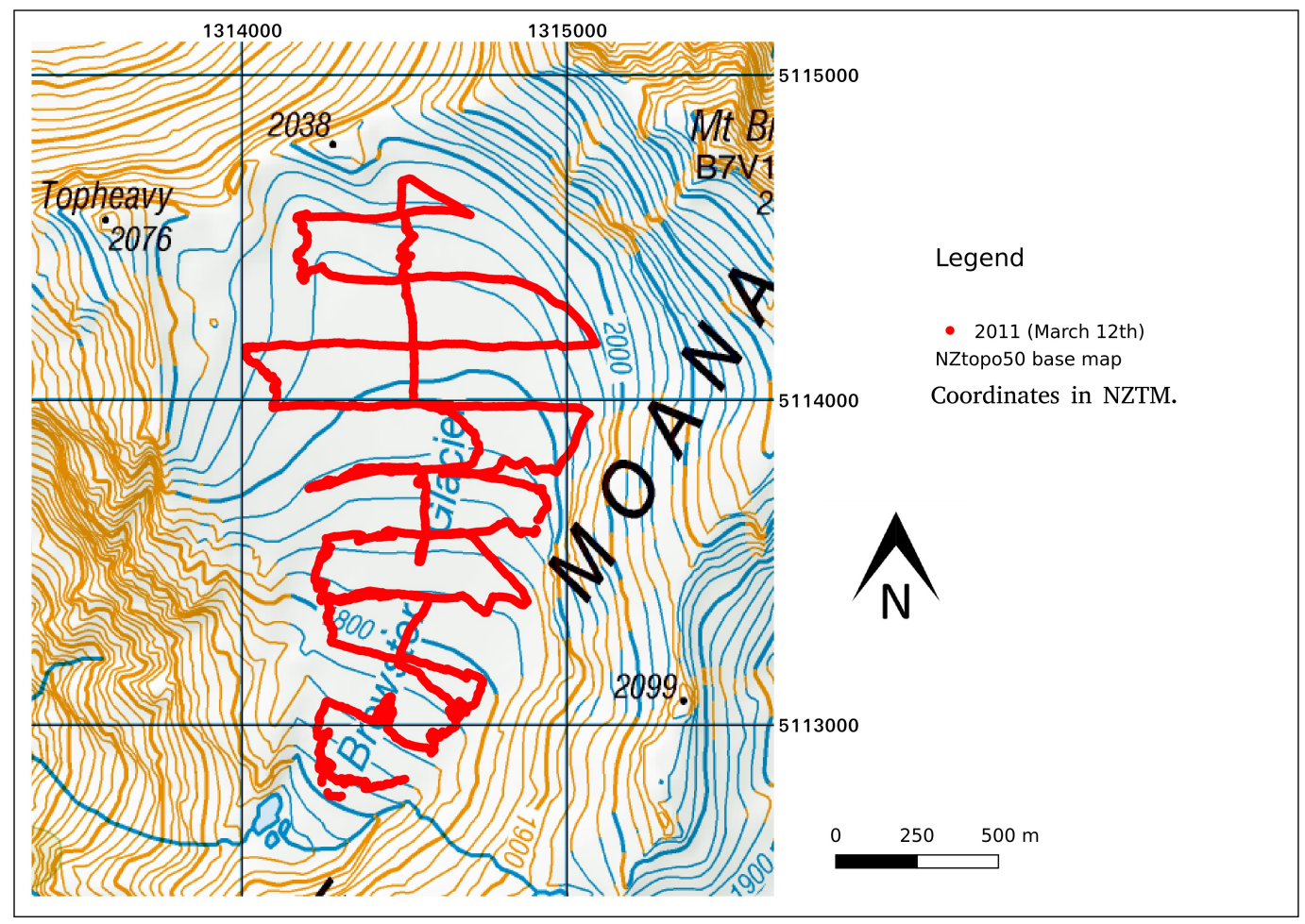

Figure C.10: March, 2011 GNSS track.

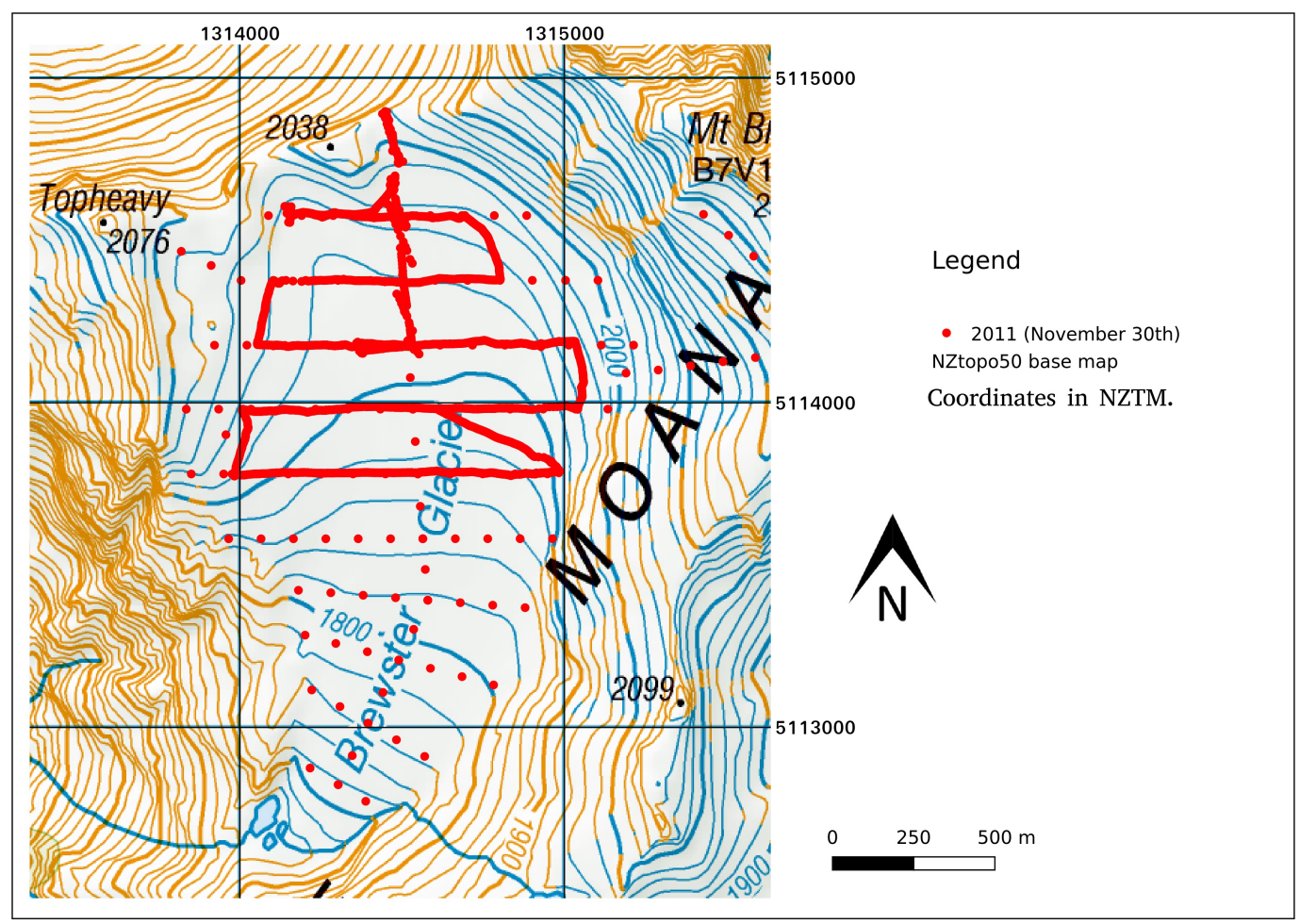

Figure C.11: November, 2011 GNSS track. 


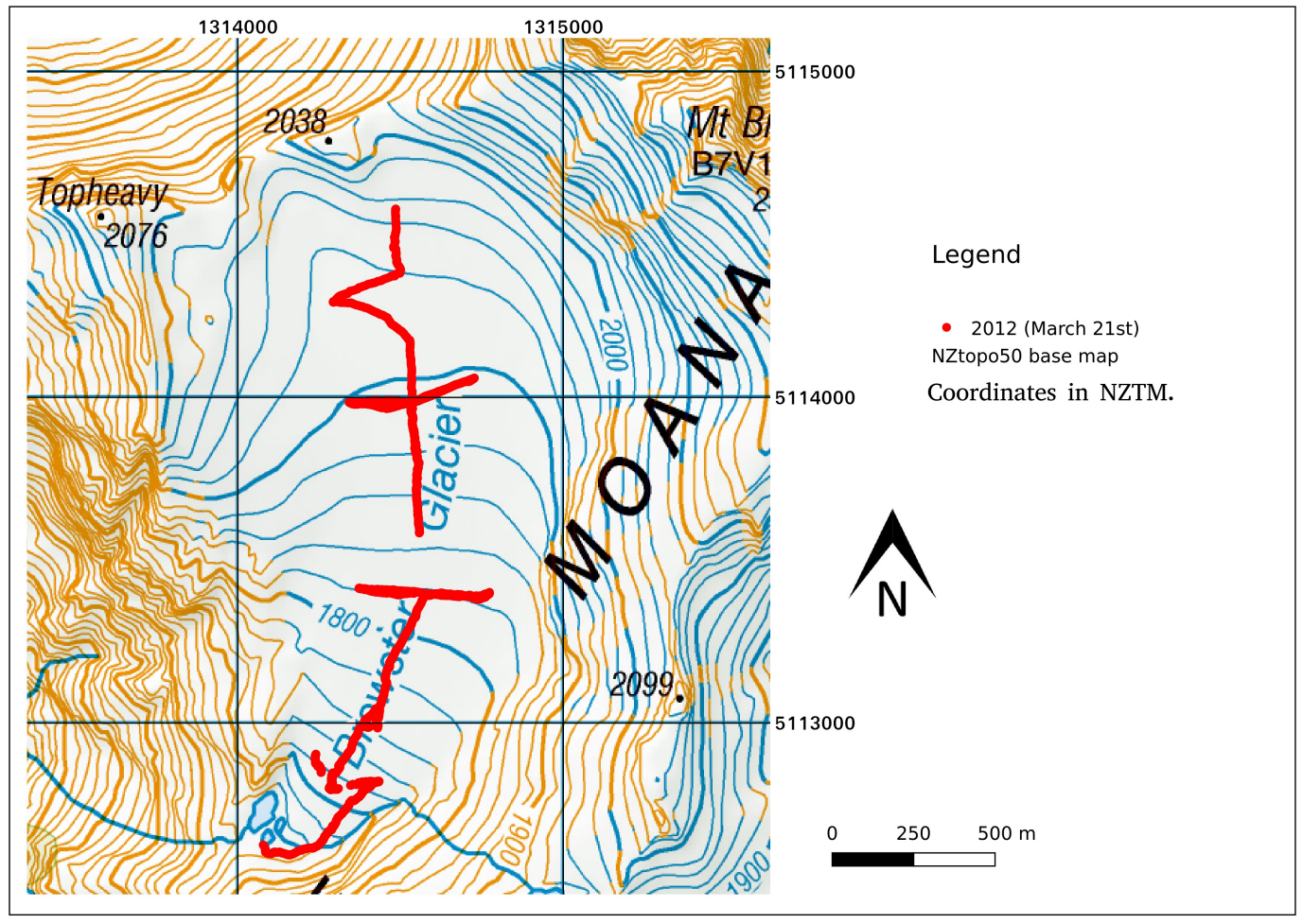

Figure C.12: March, 2012 GNSS track.

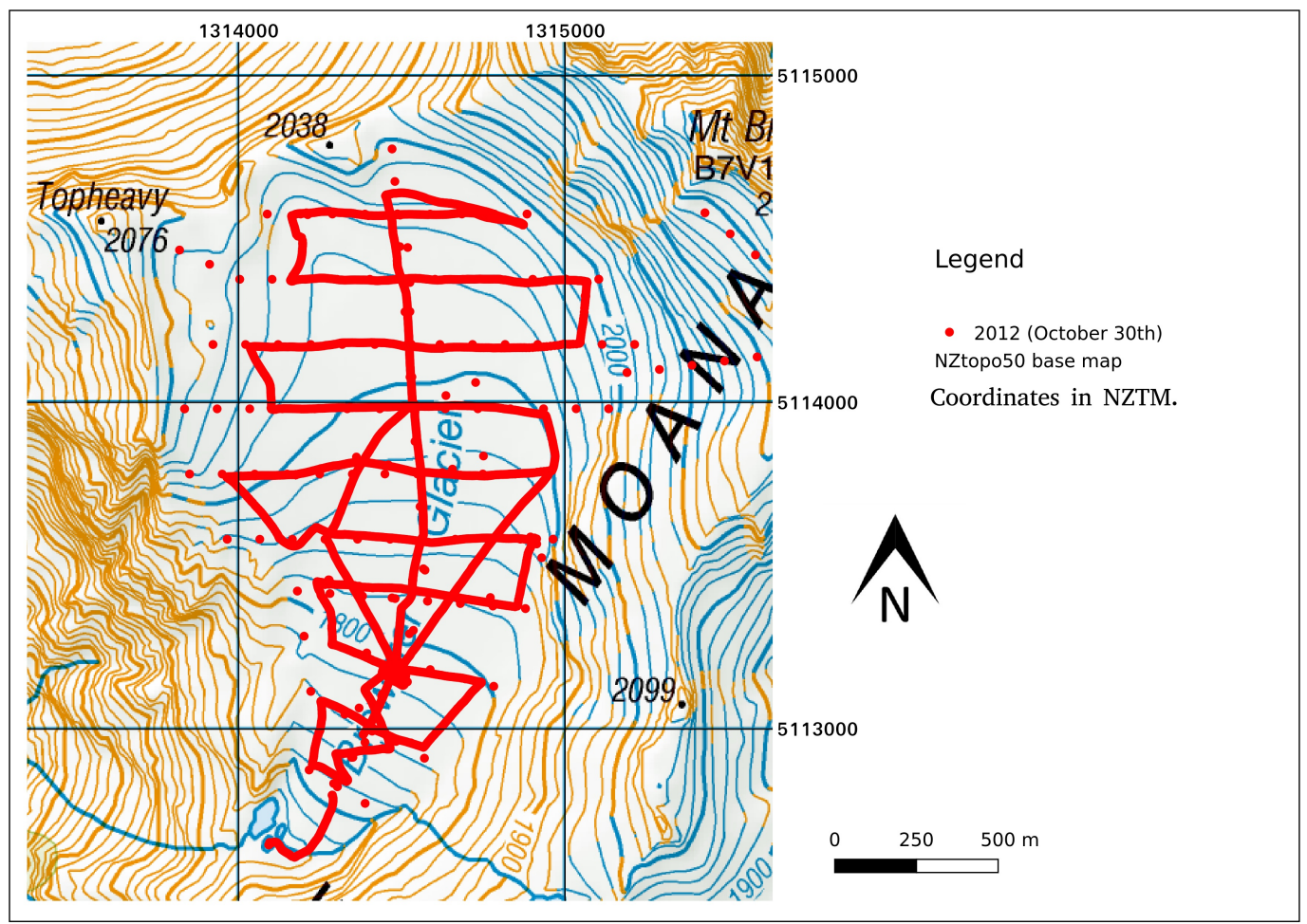

Figure C.13: October, 2010 GNSS track. 


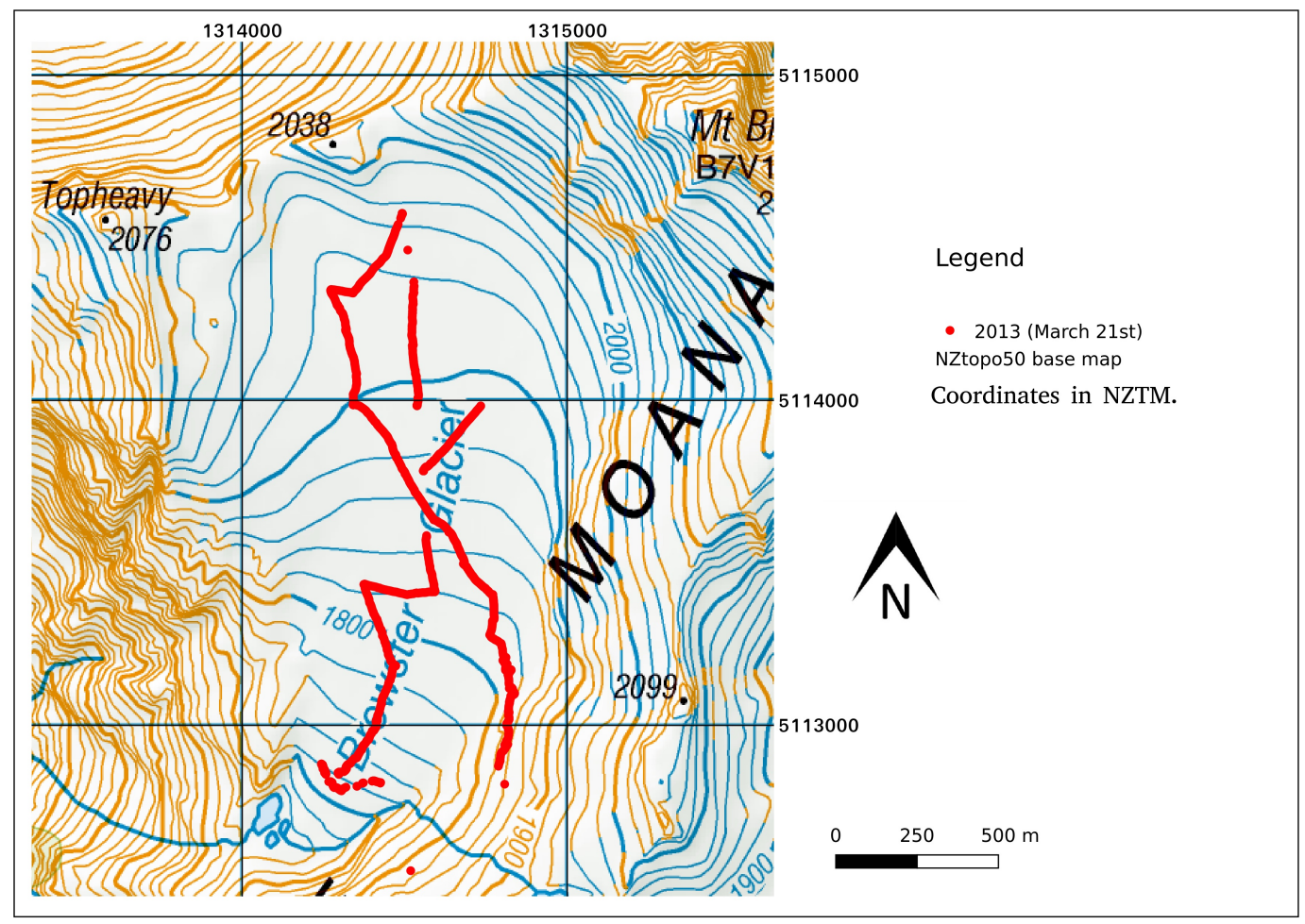

Figure C.14: February 2013 GNSS track.

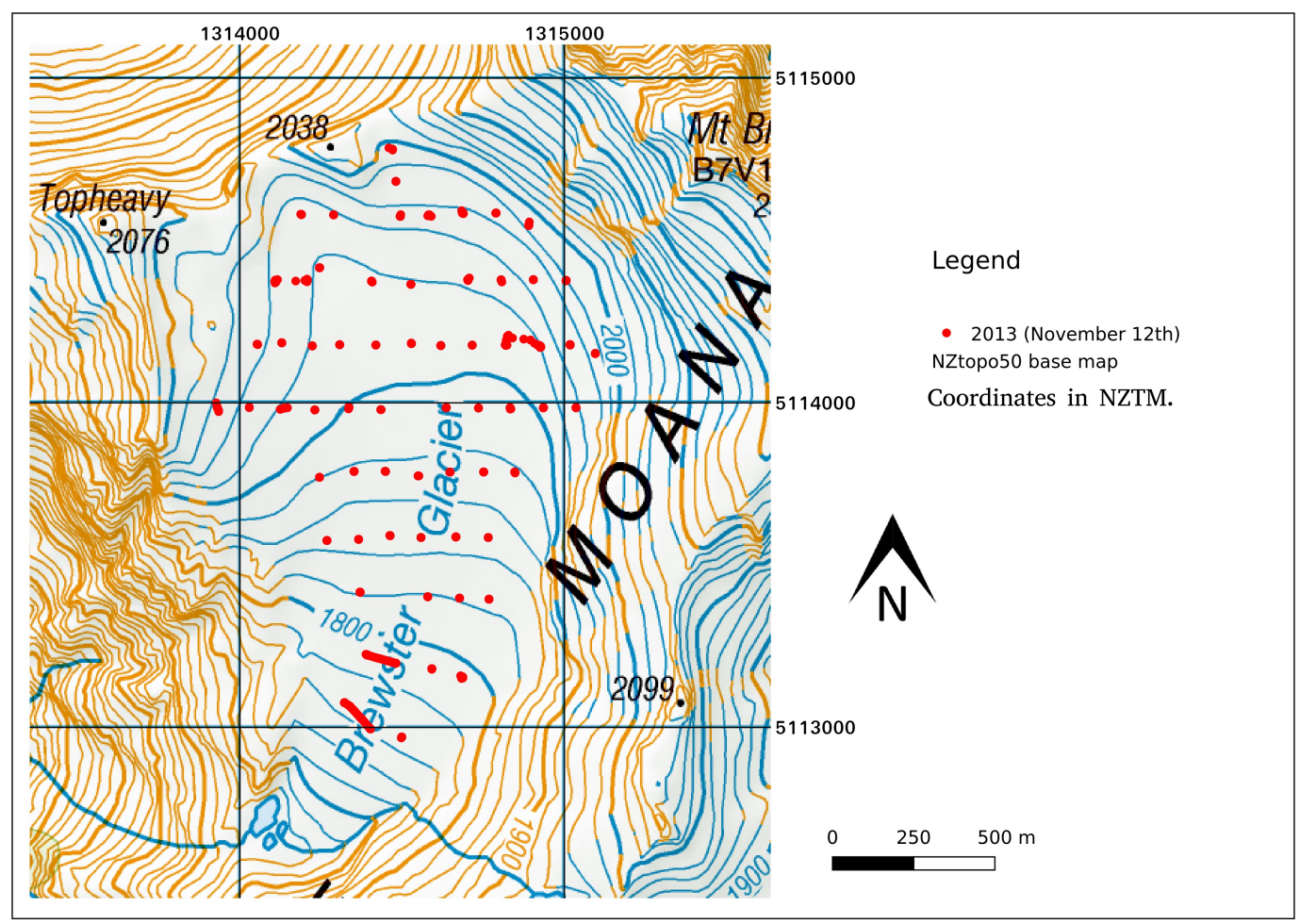

Figure C.15: November, 2013 GNSS track. 


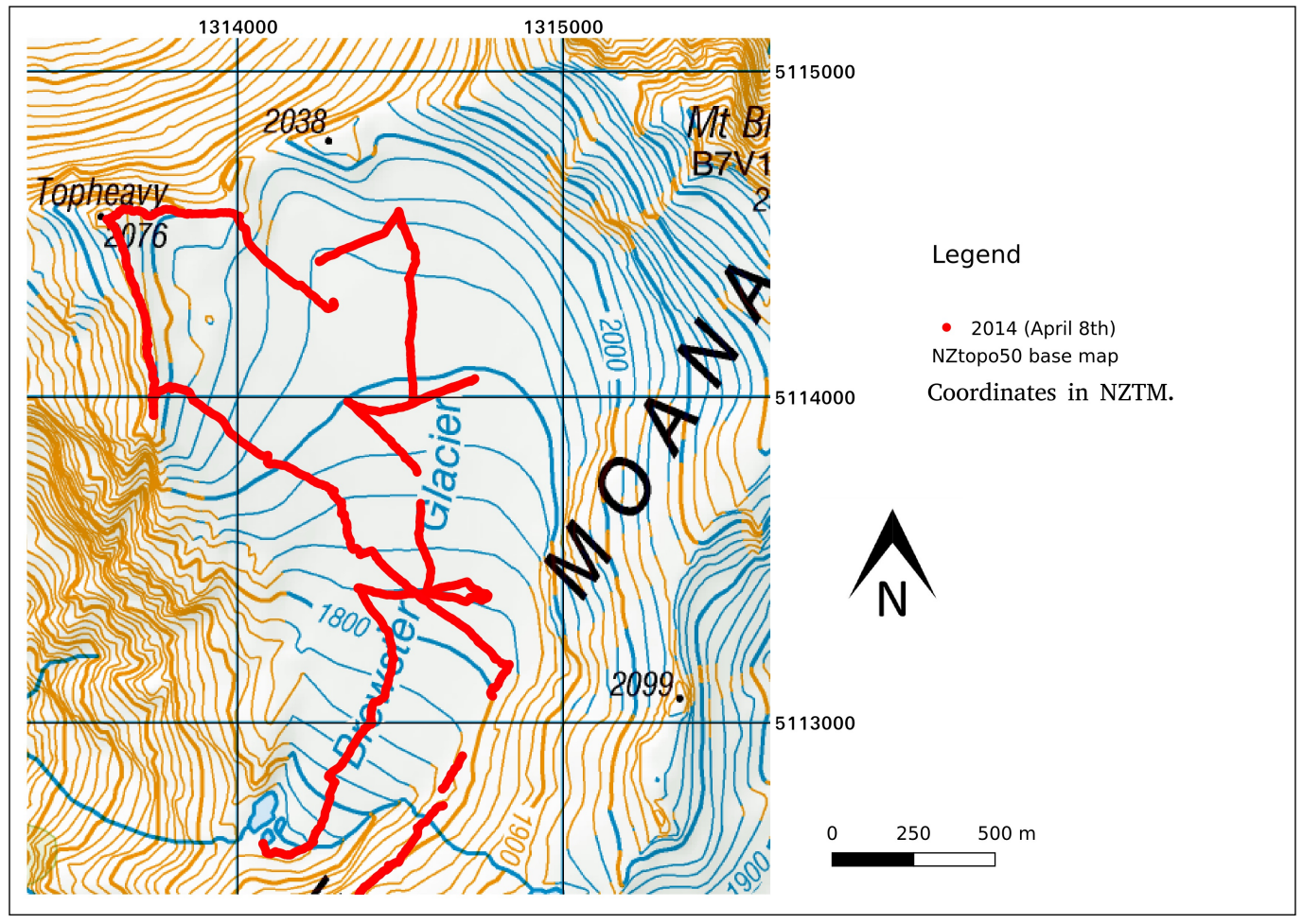

Figure C.16: April, 2014 GNSS track.

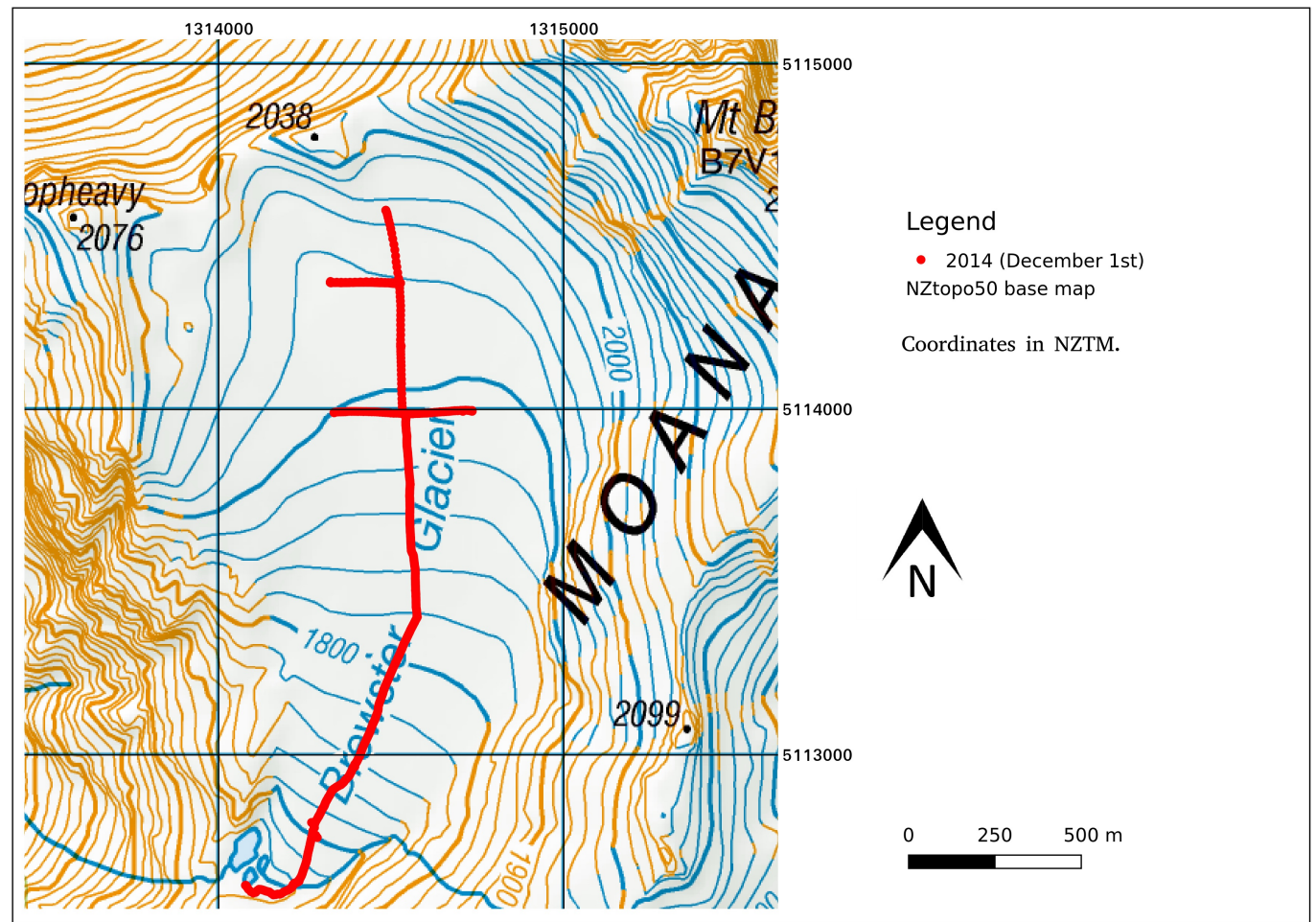

Figure C.17: December, 2014 GNSS track. 


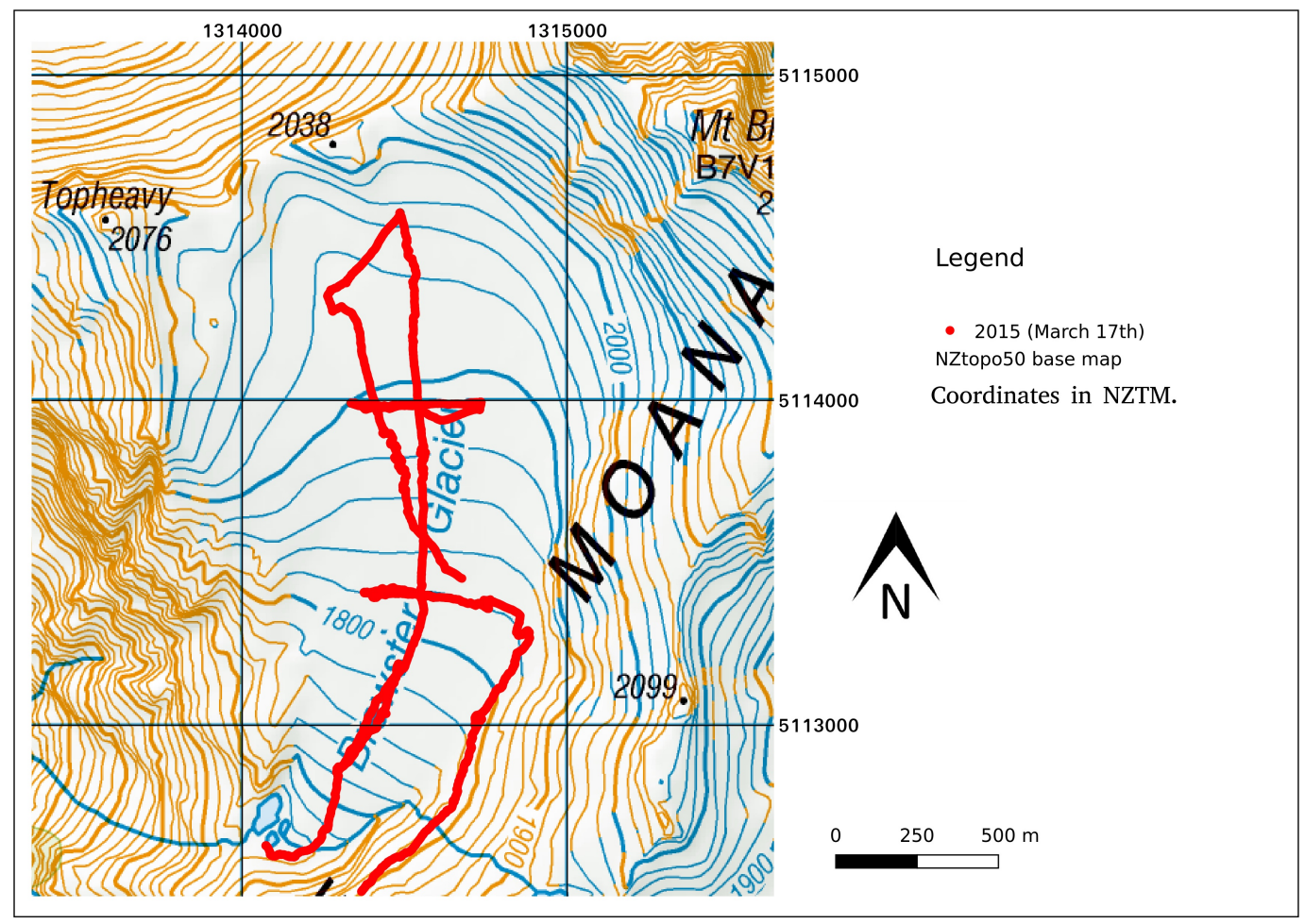

Figure C.18: March, 2015 GNSS track.

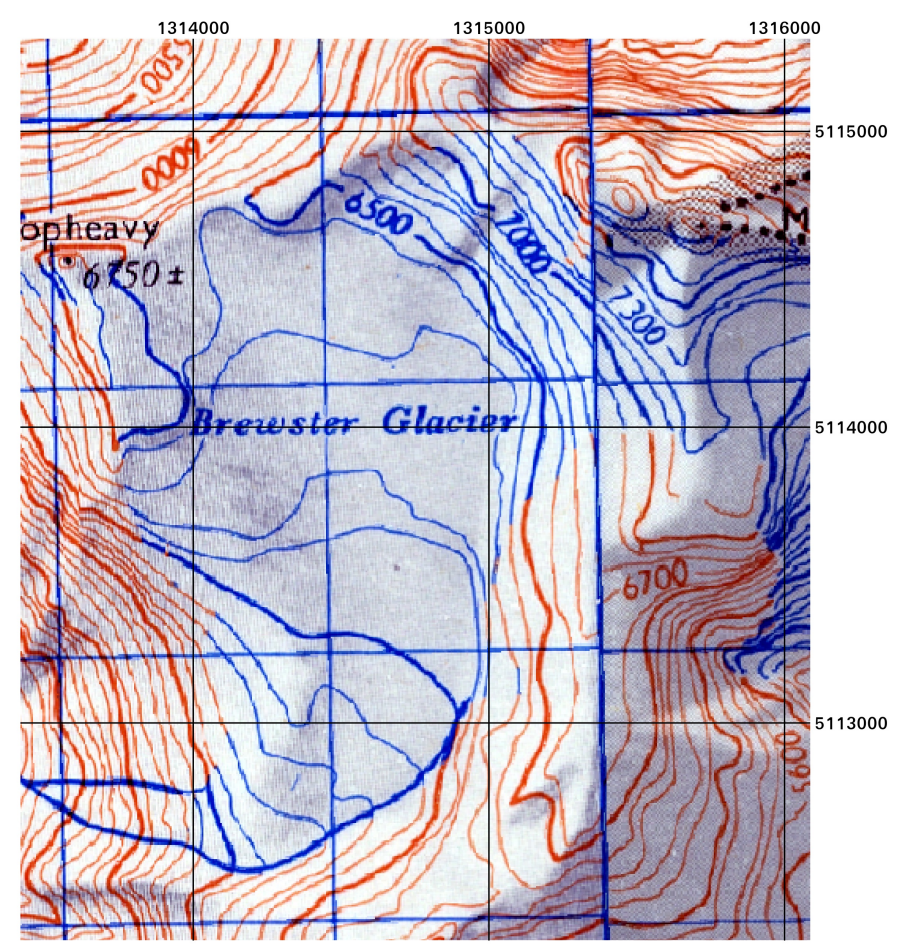

\section{NZMS}

Coordinates in NZTM

Elevation is feet above mean

sea level.

个

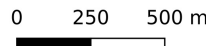

Figure C.19: New Zealand Map Series (NZMS) map. 


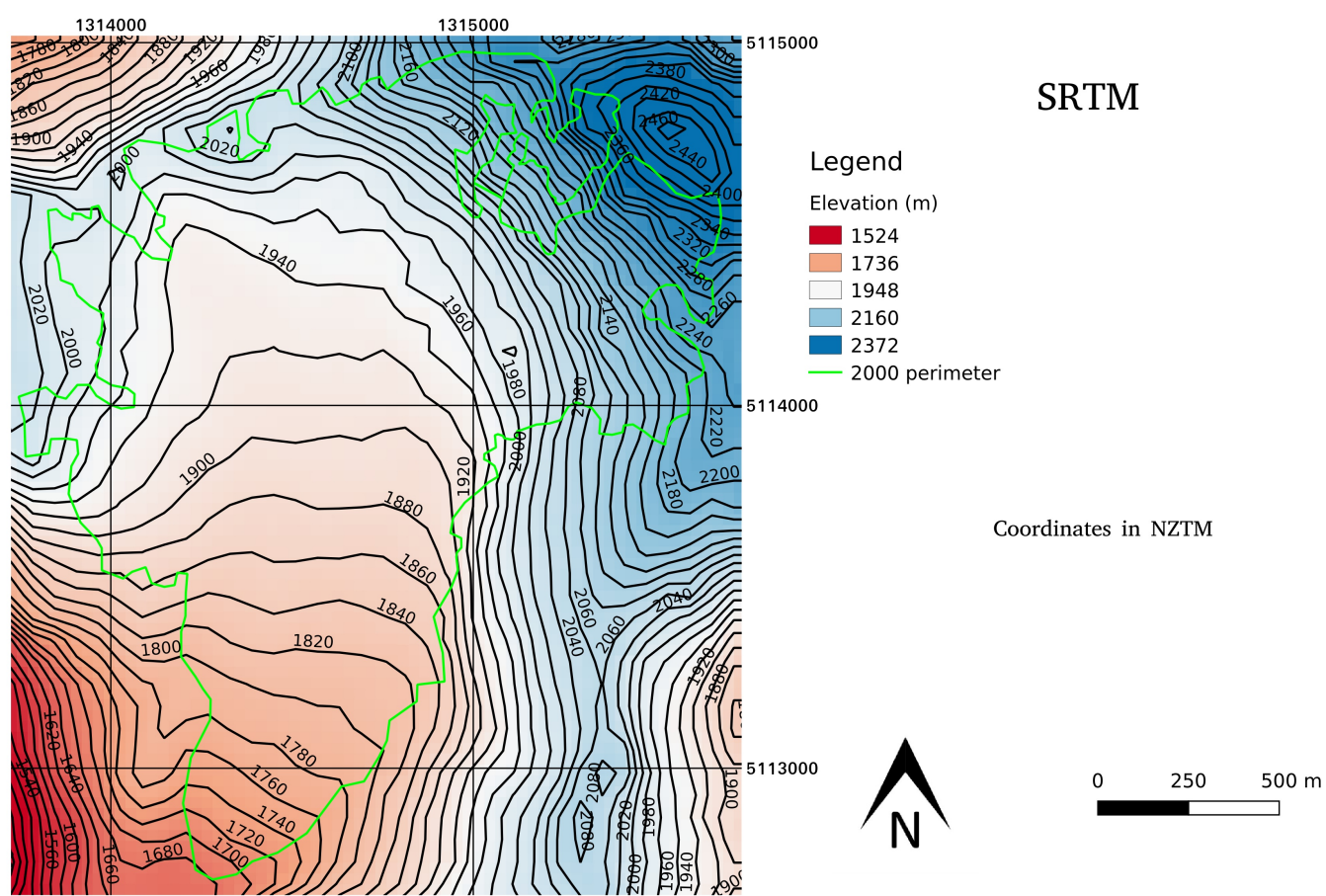

Figure C.20: Shuttle Radar Topography Mission (SRTM) DEM.

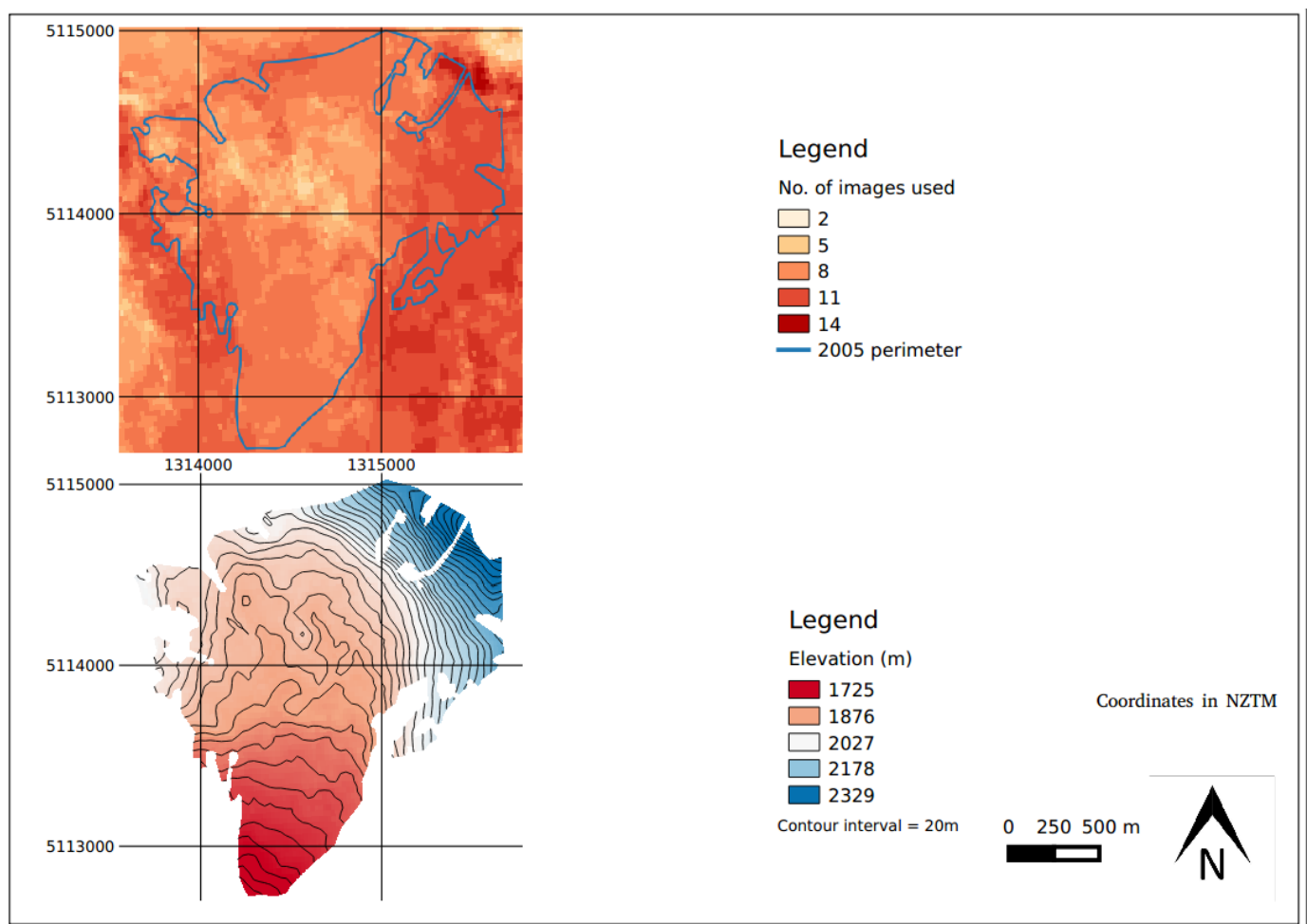

Figure C.21: Top: No. of images that were used to calculate each pixel value. Bottom: Surface topography of Brewster glacier according to ASTER GDEM V2. 


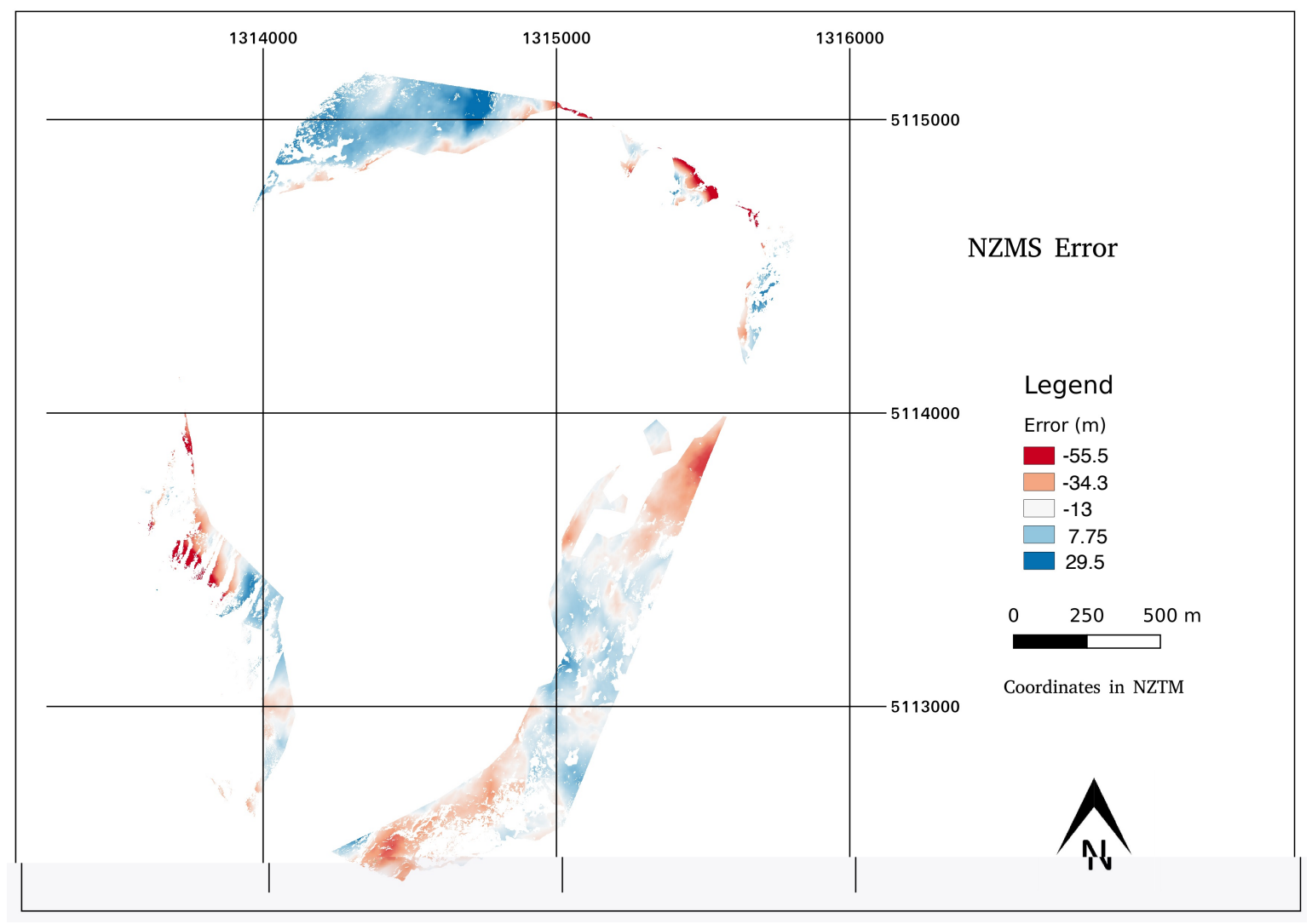

Figure C.22: Glacier periphery topographic error for NZMS (1967).

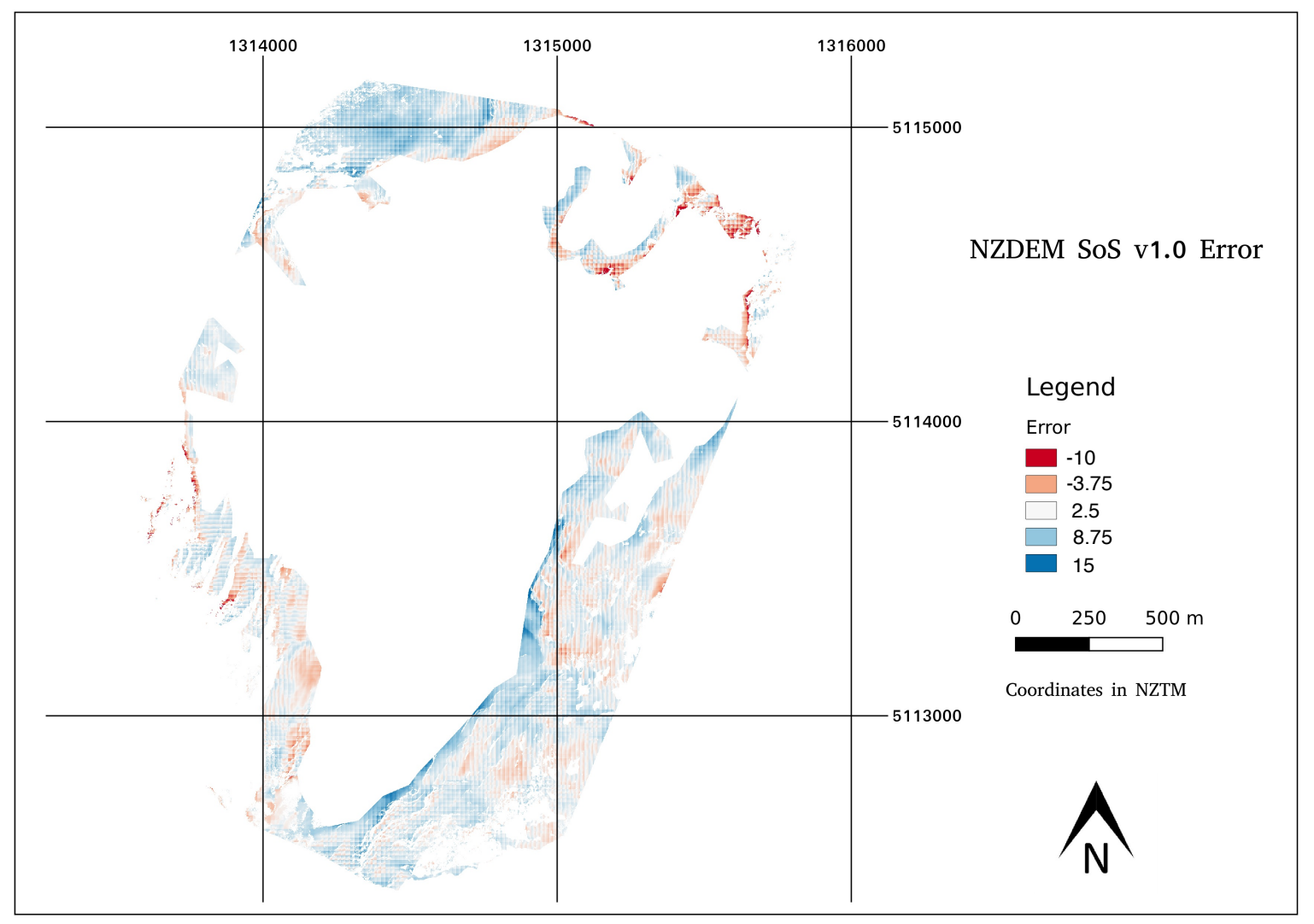

Figure C.23: Glacier periphery topographic error for NZDEM SoS v1.0 (1986). 


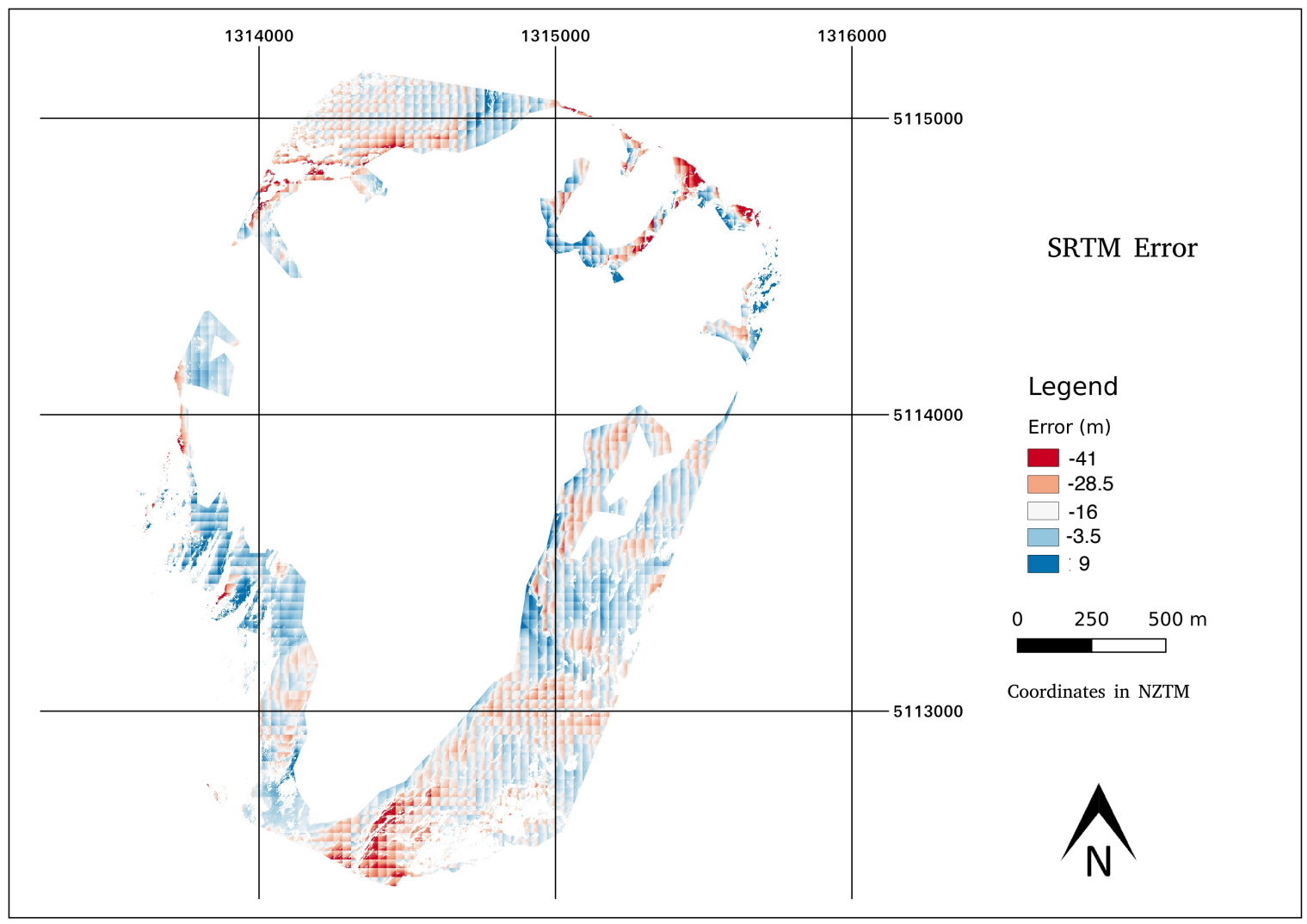

Figure C.24: Glacier periphery topographic error for SRTM (2000).

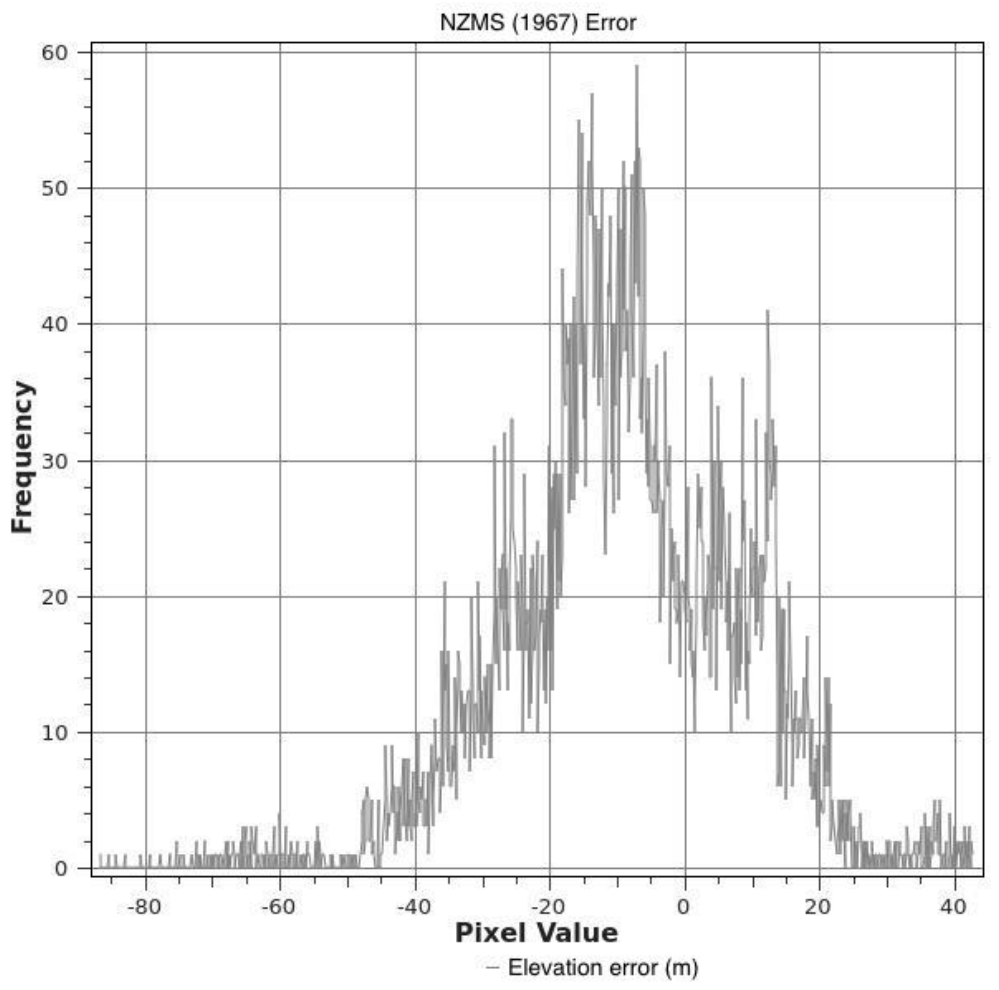

Figure C.25: NZMS error histogram. 


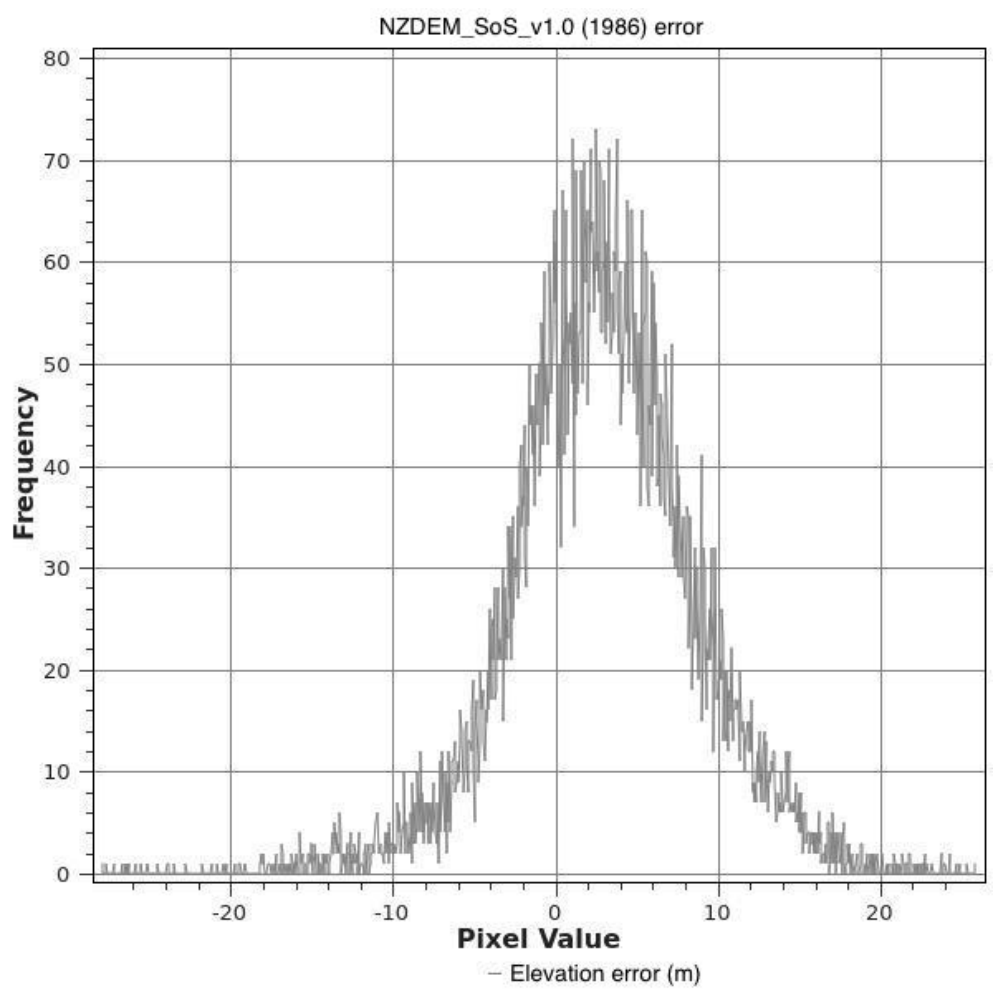

Figure C.26: NZDEM_SoS_v1.0 error histogram. 


\section{Radar profiles}

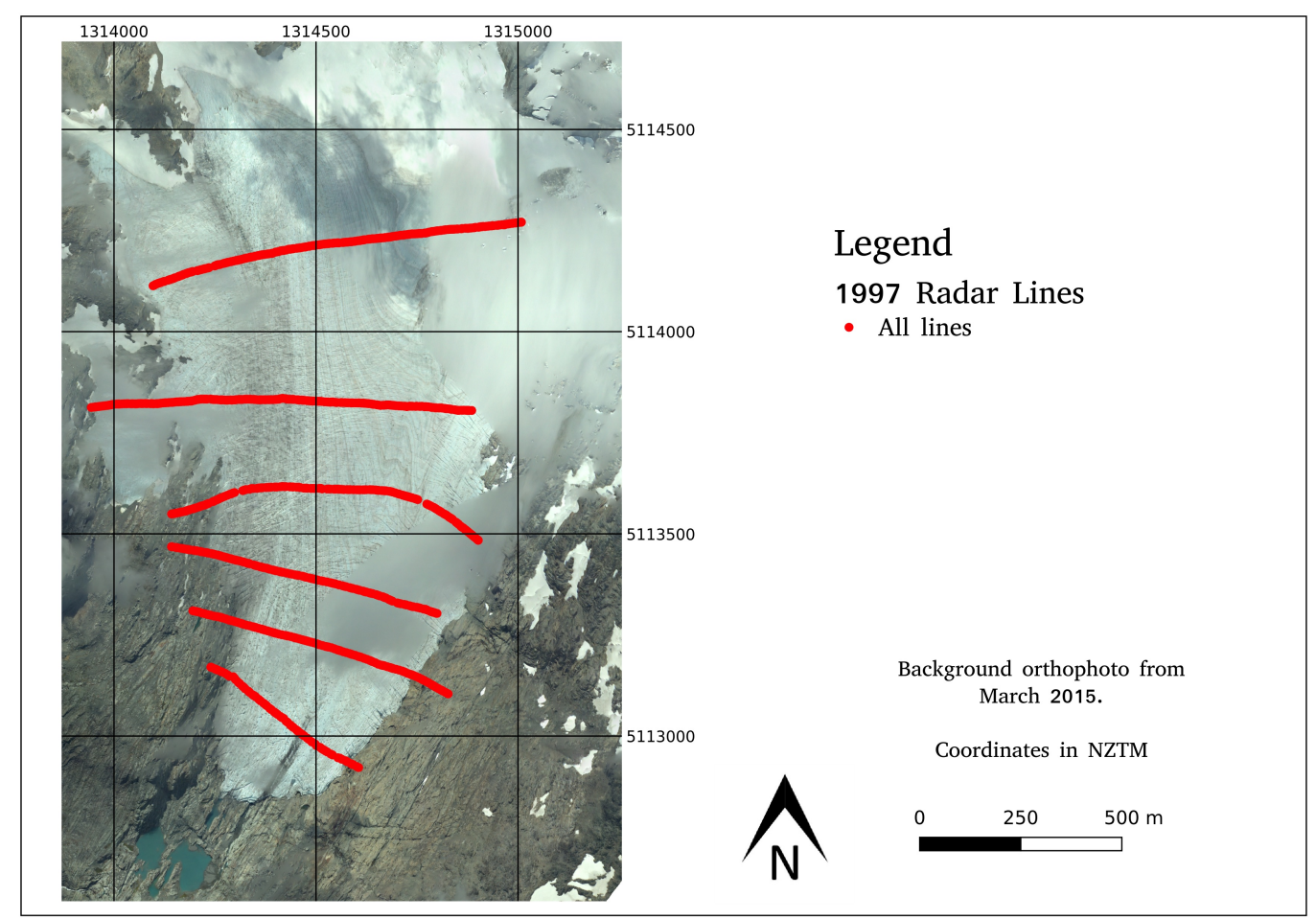

Figure D.1: 1997 GPR profiles. 


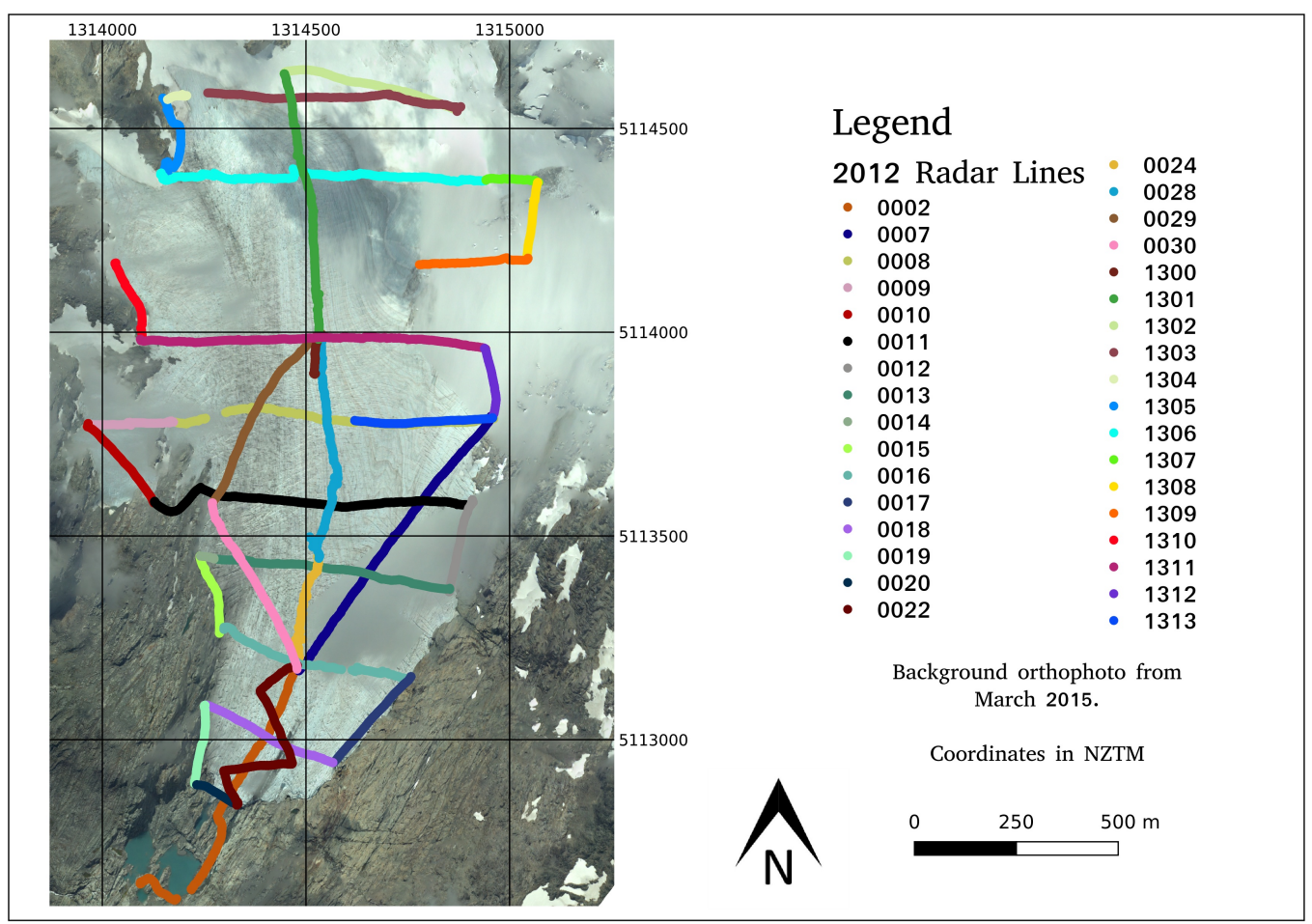

Figure D.2: 2012 GPR profiles.

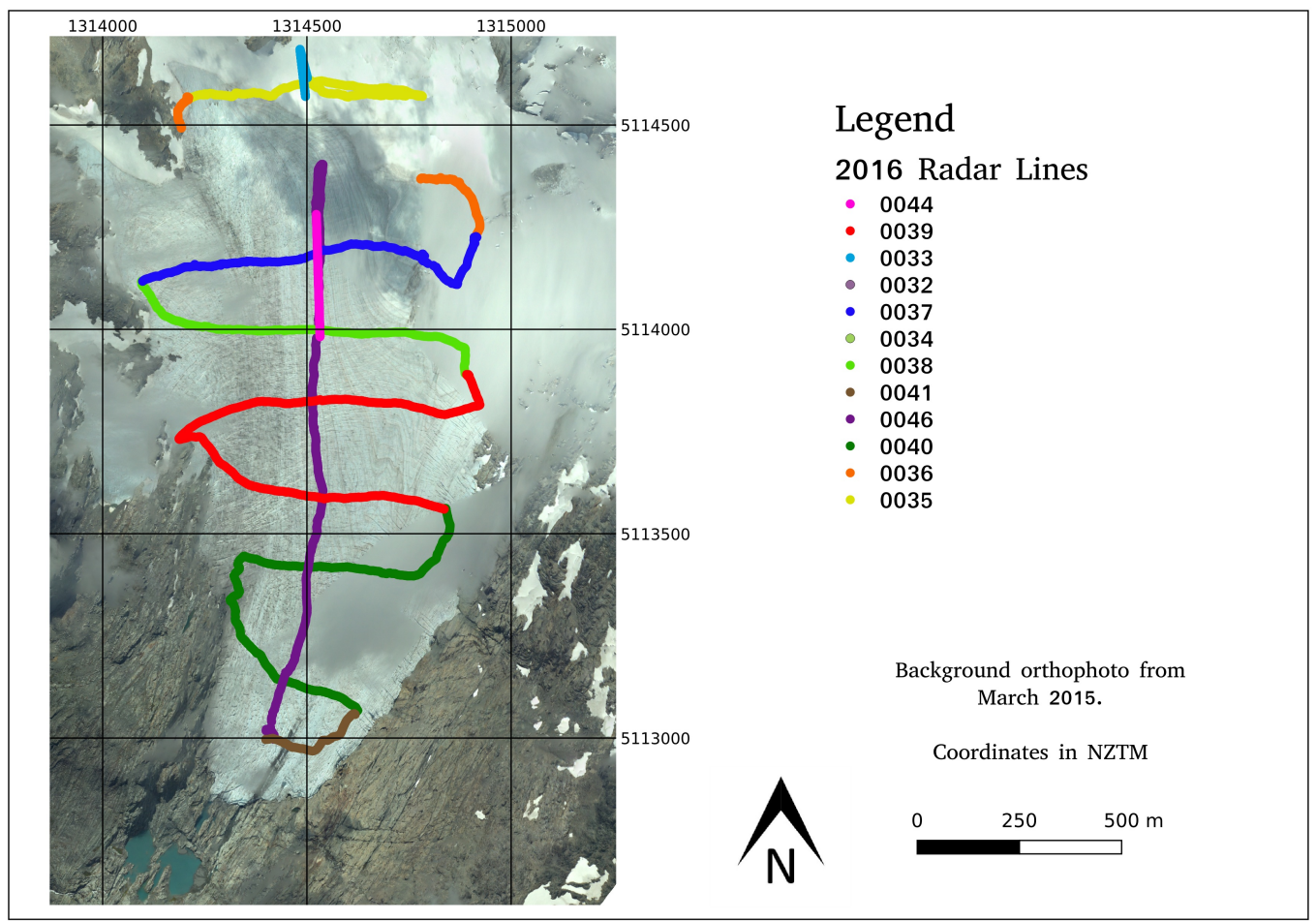

Figure D.3: 2016 GPR profiles. 


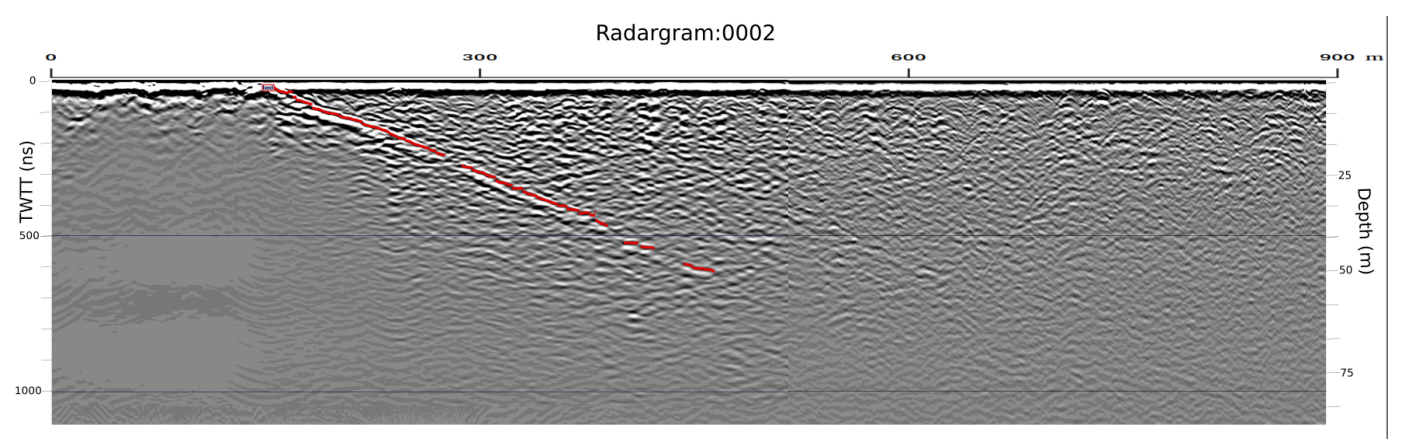

(a)

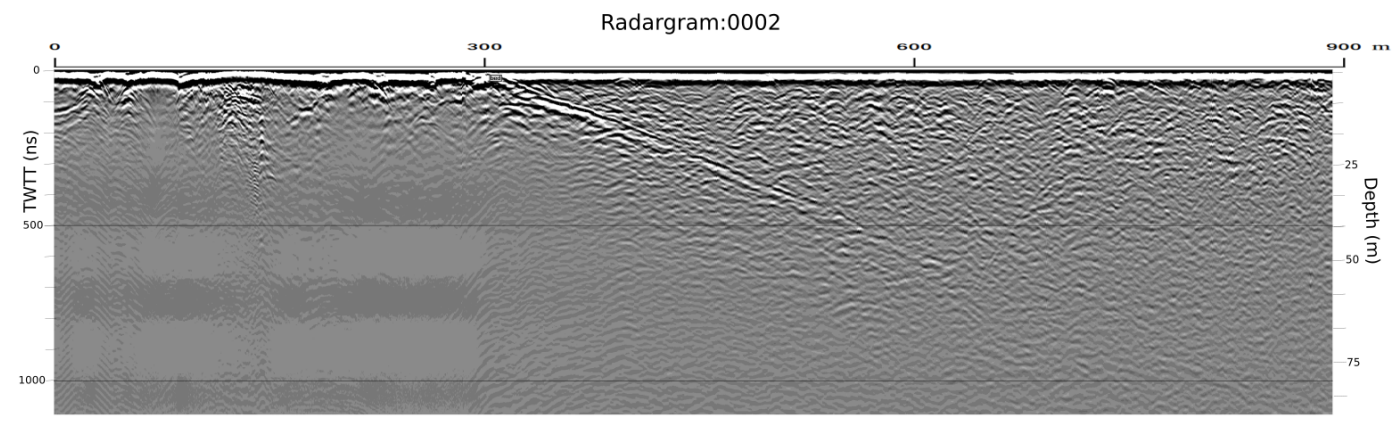

(b)

Figure D.4: Interpreted (a), and non-interpreted (b) radargrams for profile 0002 (Figure D.2).

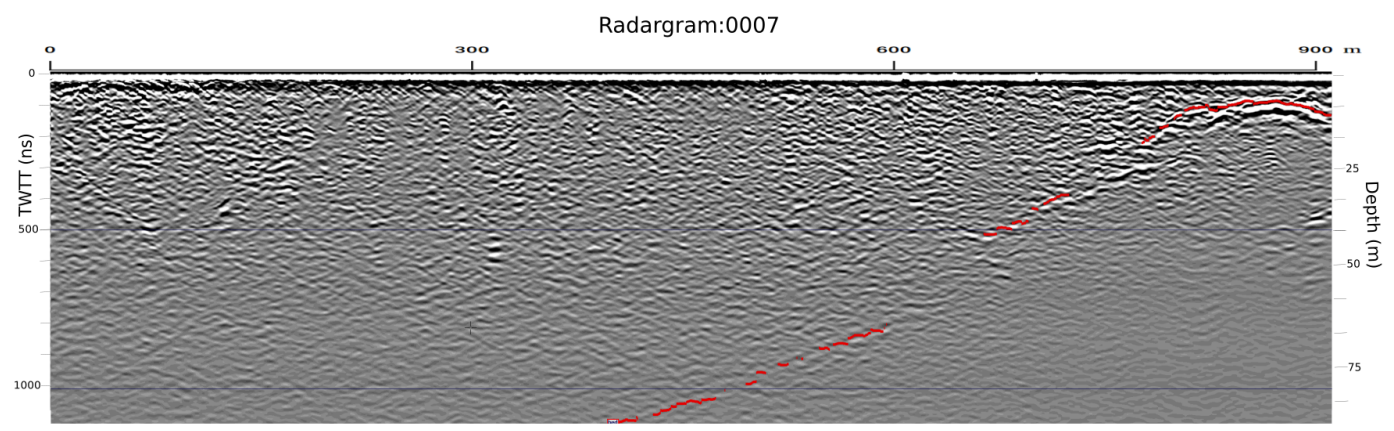

(a)

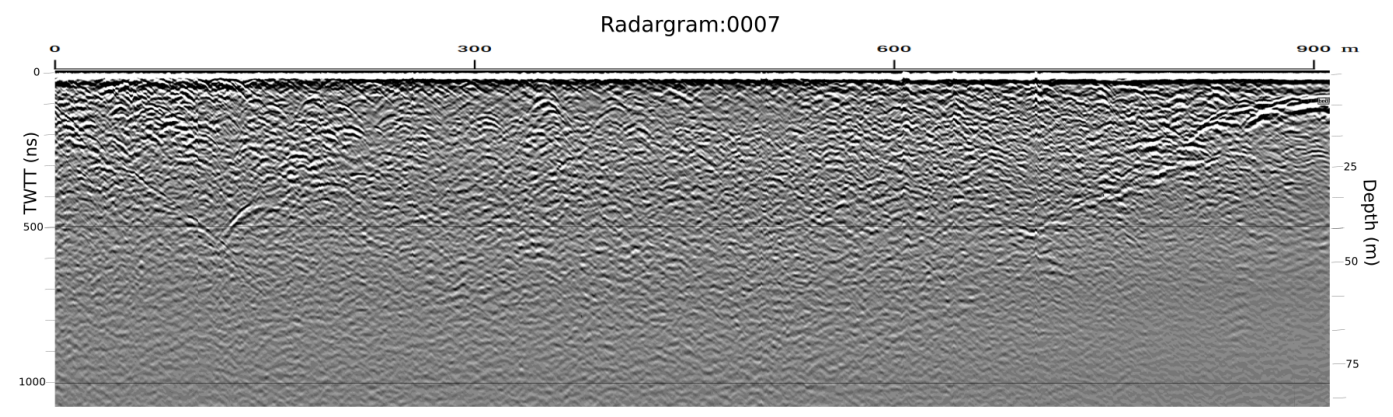

(b)

Figure D.5: Interpreted (a), and non-interpreted (b) radargrams for profile 0007 (Figure D.2). 


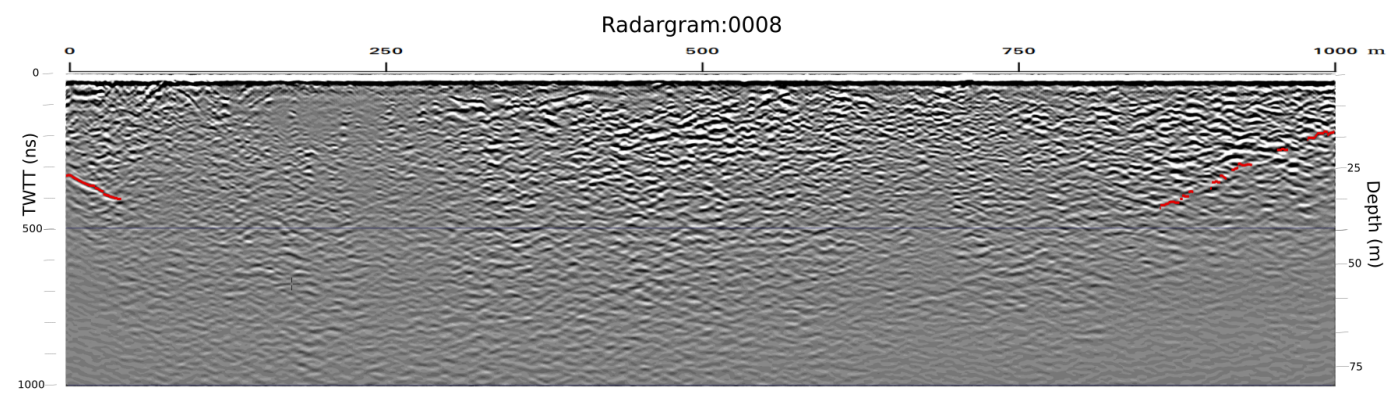

(a)

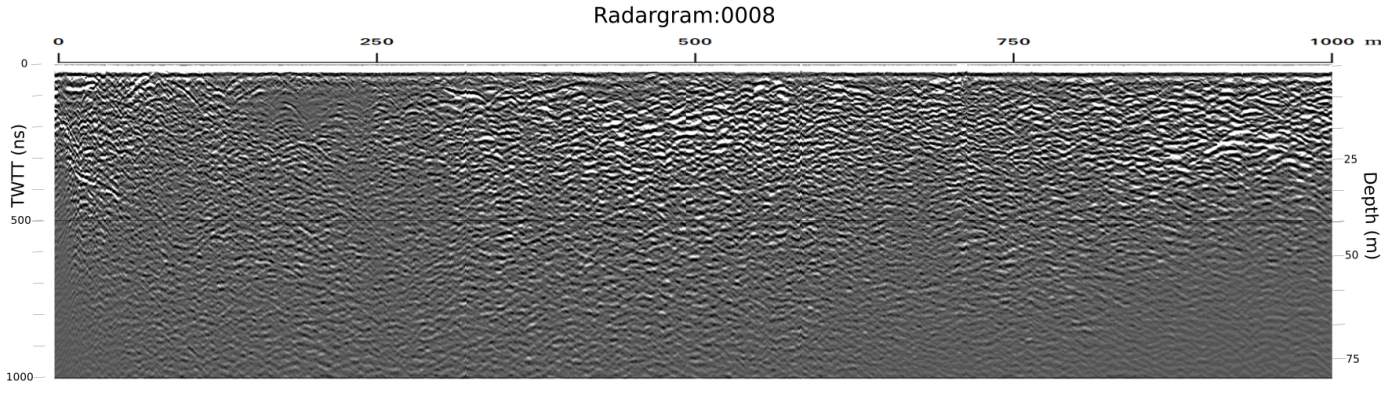

(b)

Figure D.6: Interpreted (a), and non-interpreted (b) radargrams for profile 0008 (Figure D.2). 


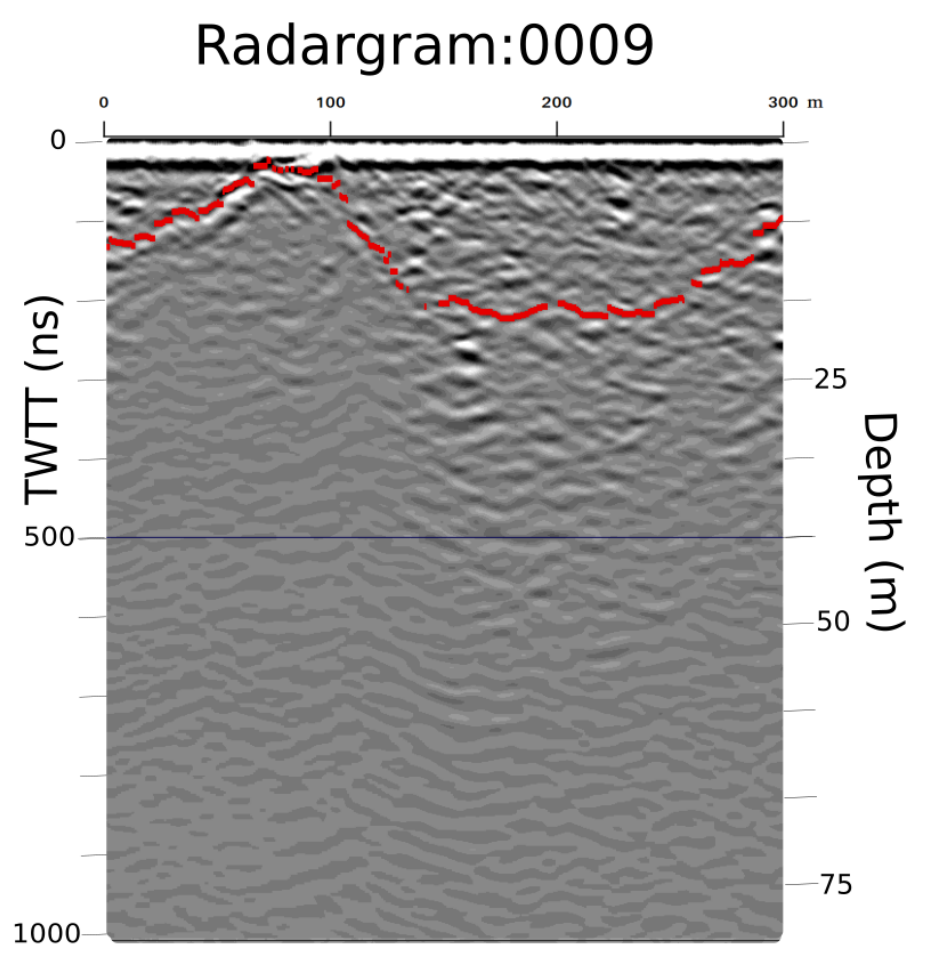

(a)

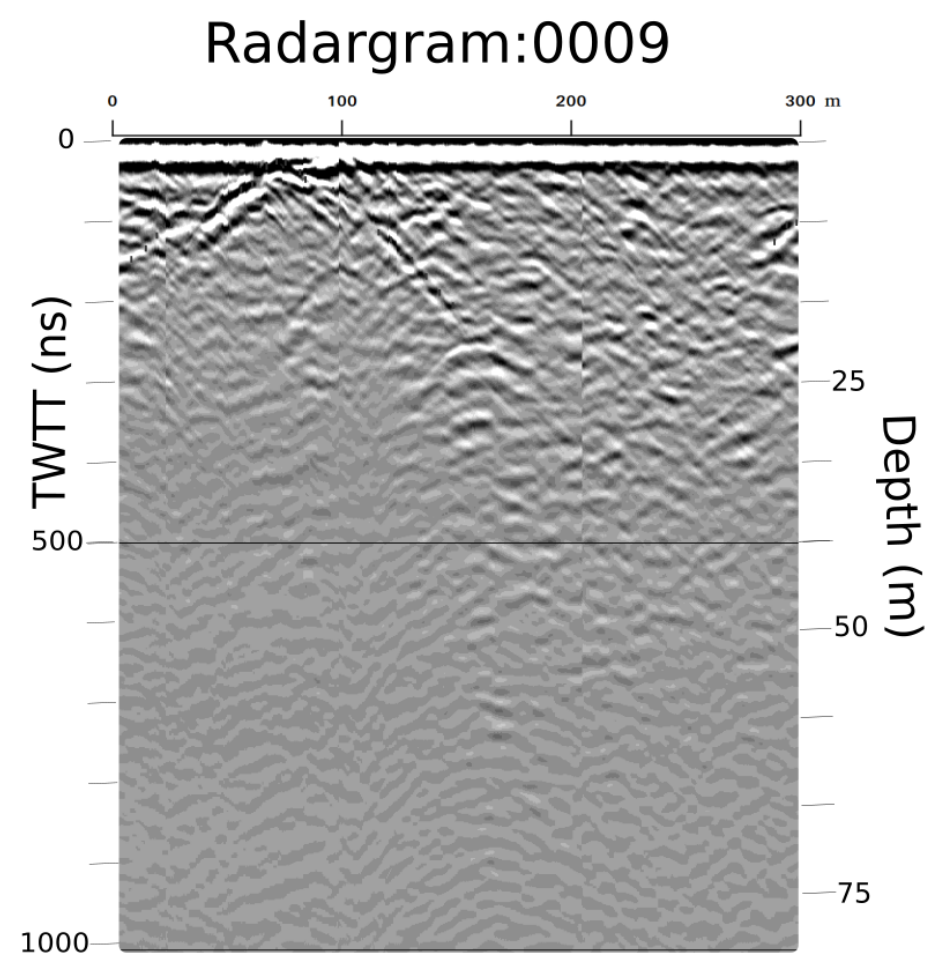

(b)

Figure D.7: Interpreted (a), and non-interpreted (b) radargrams for profile 0009 (Figure D.2). 


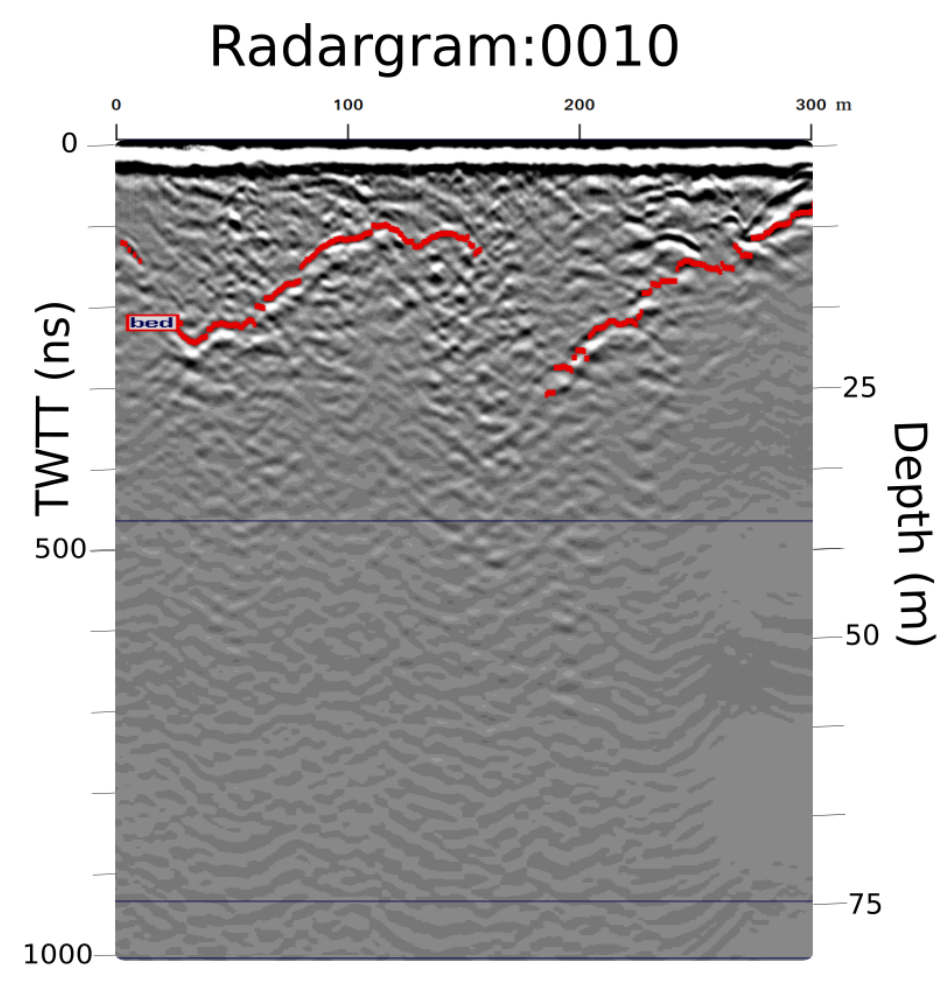

(a)

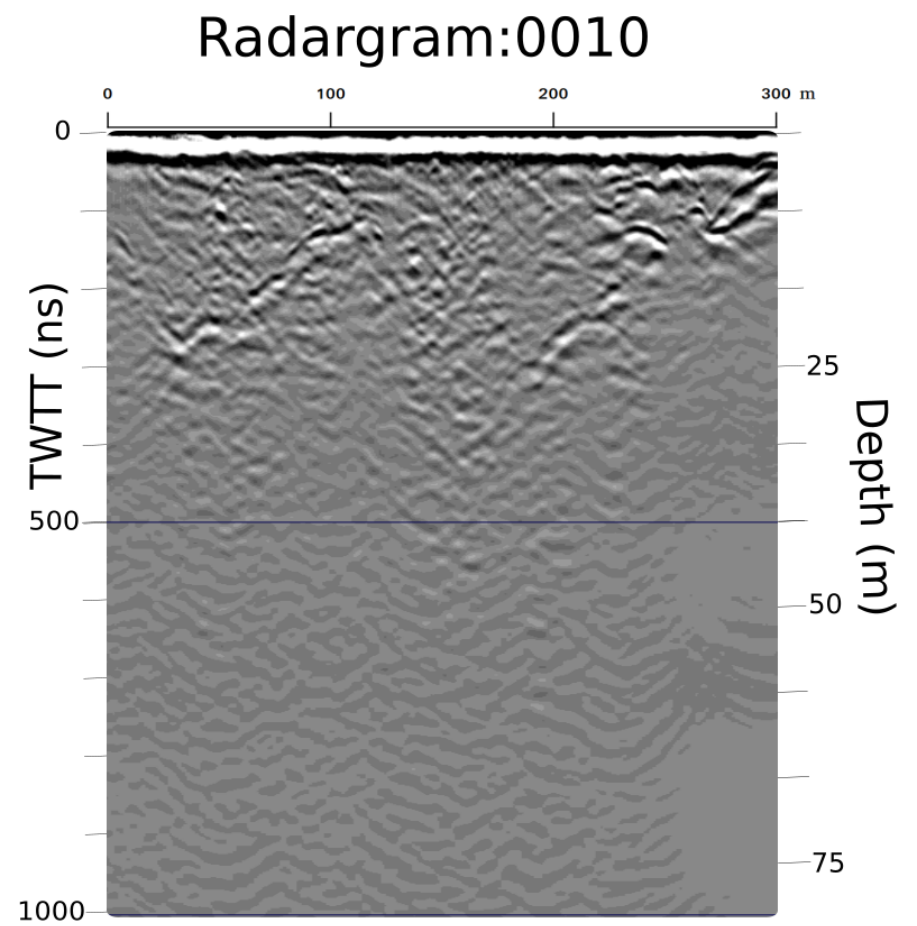

(b)

Figure D.8: Interpreted (a), and non-interpreted (b) radargrams for profile 0011. 


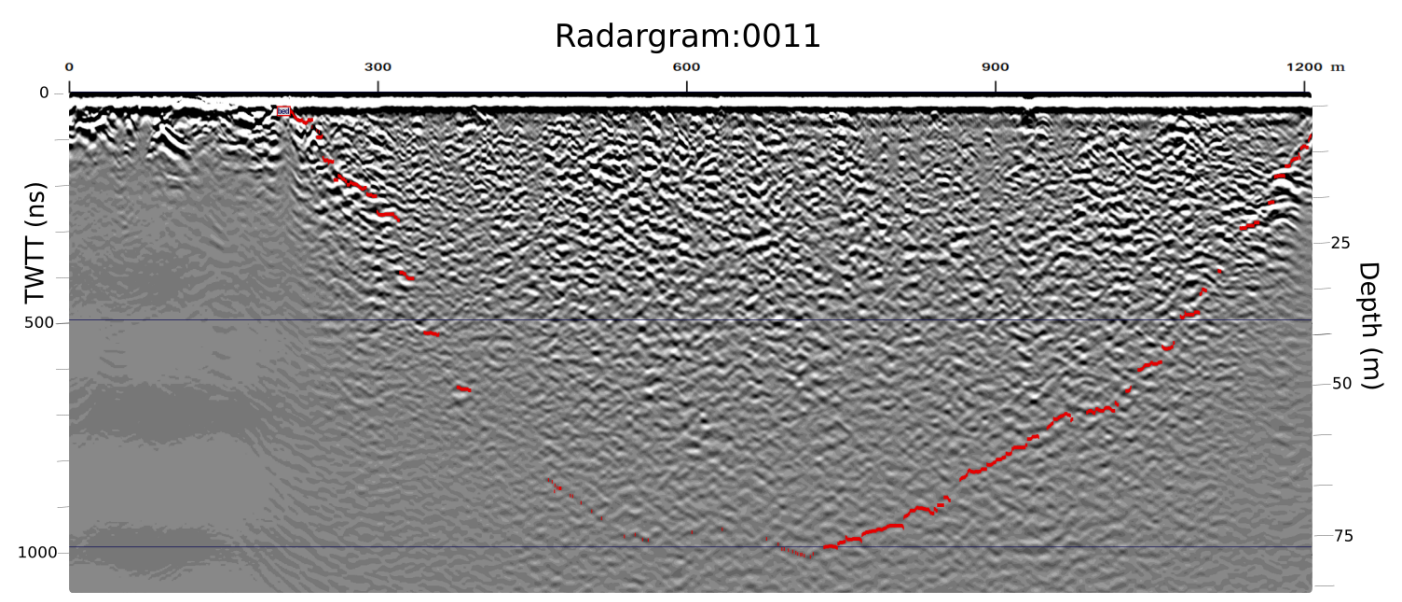

(a)

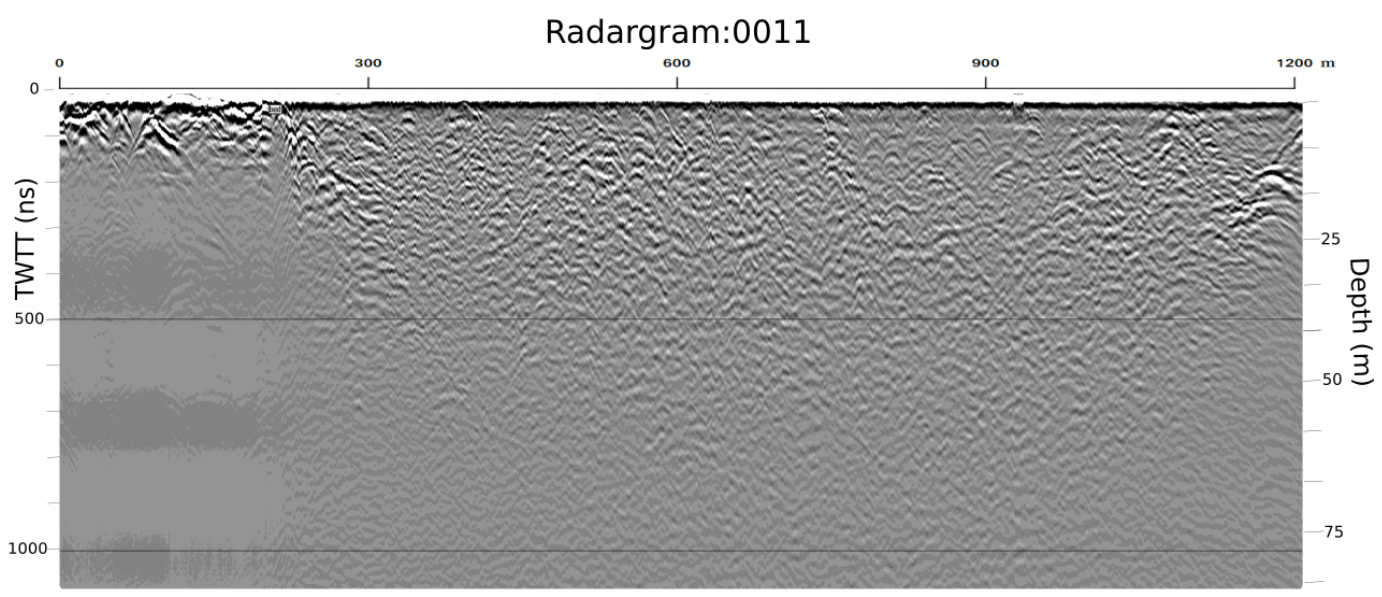

(b)

Figure D.9: Interpreted (a), and non-interpreted (b) radargrams for profile 0011. 


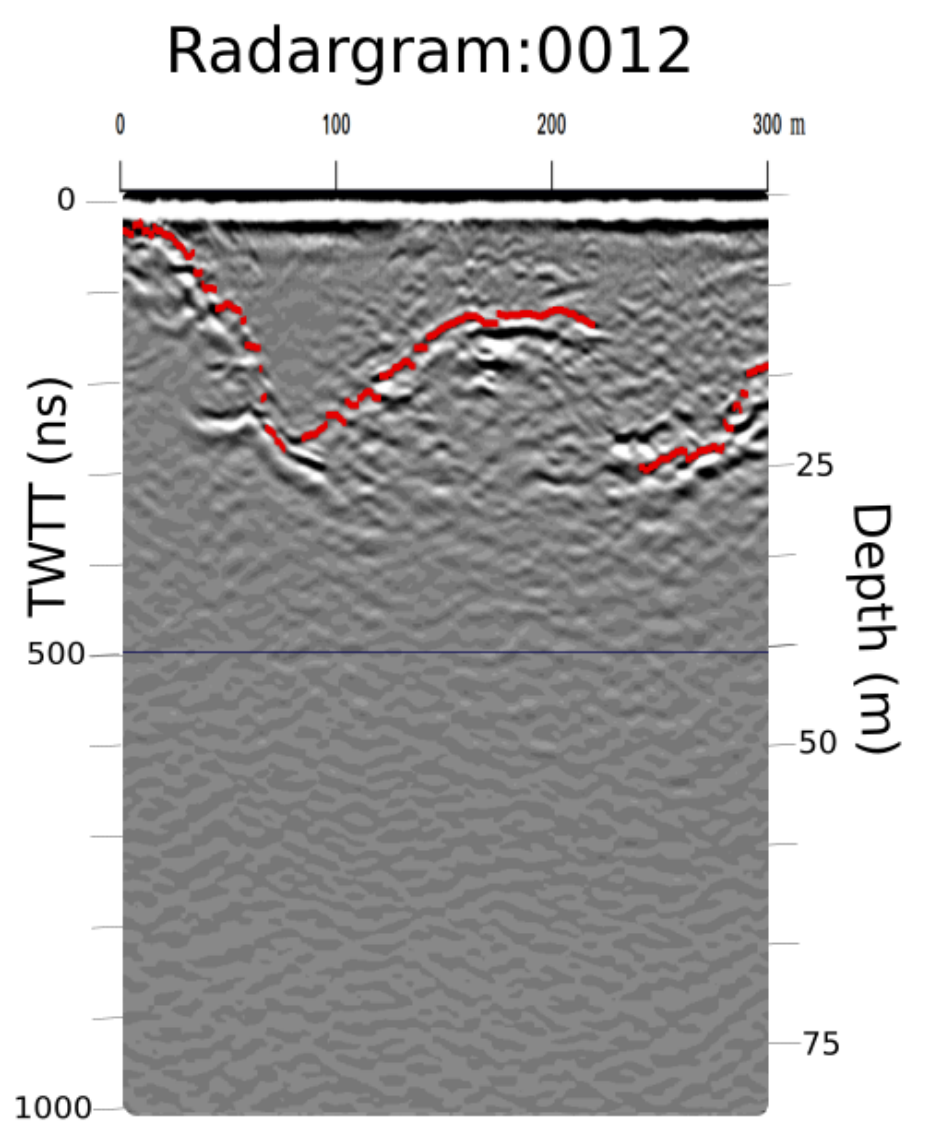

(a)

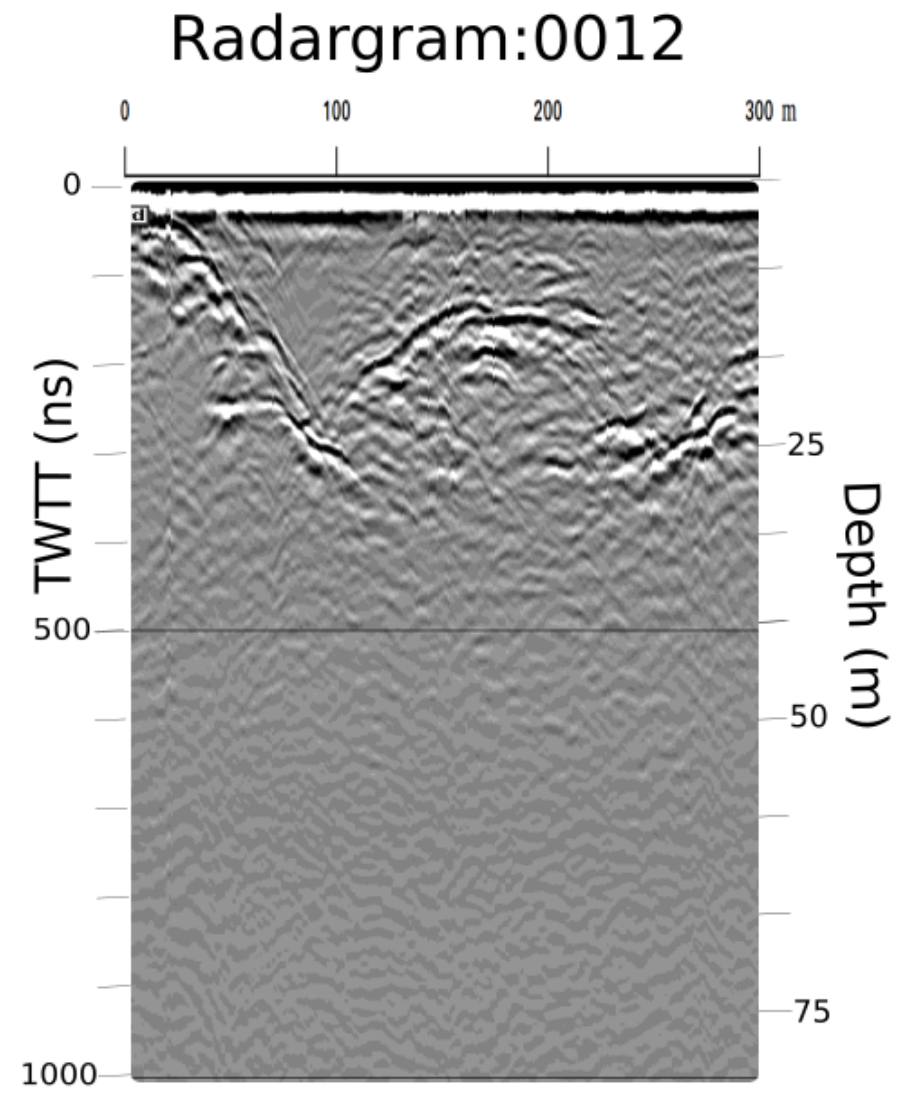

(b)

Figure D.10: Interpreted (a), and non-interpreted (b) radargrams for profile 0012. 


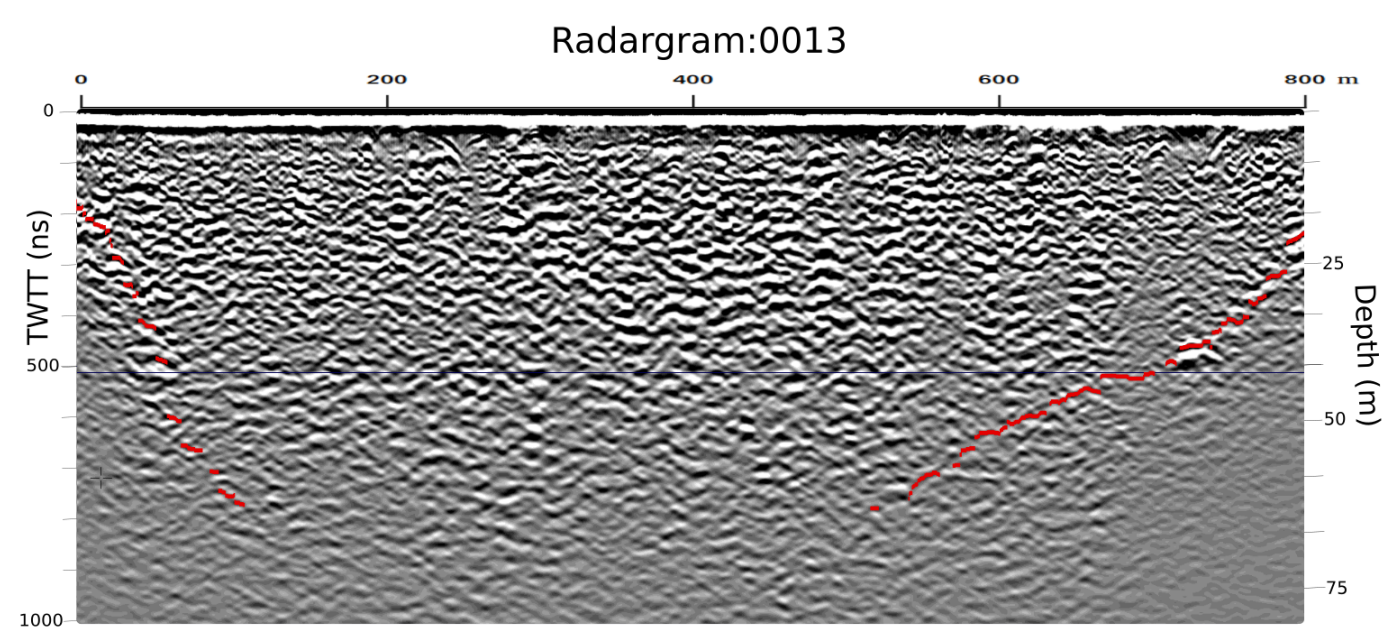

(a)

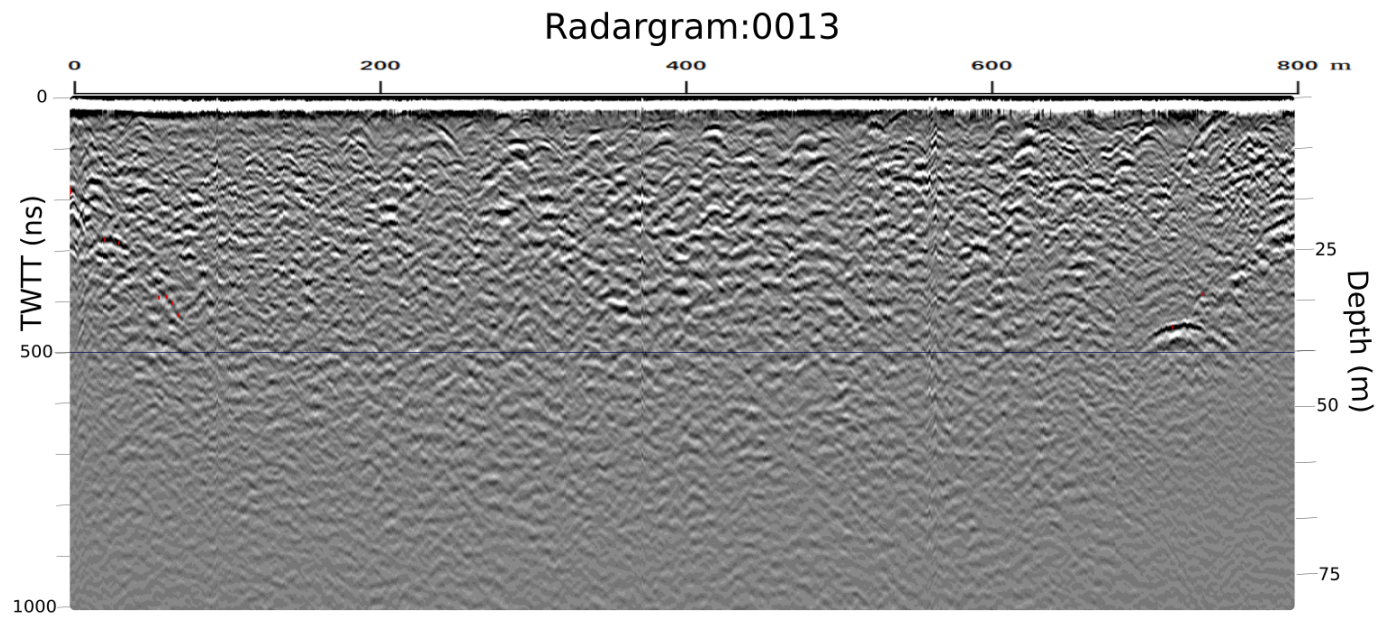

(b)

Figure D.11: Interpreted (a), and non-interpreted (b) radargrams for profile 0013. 


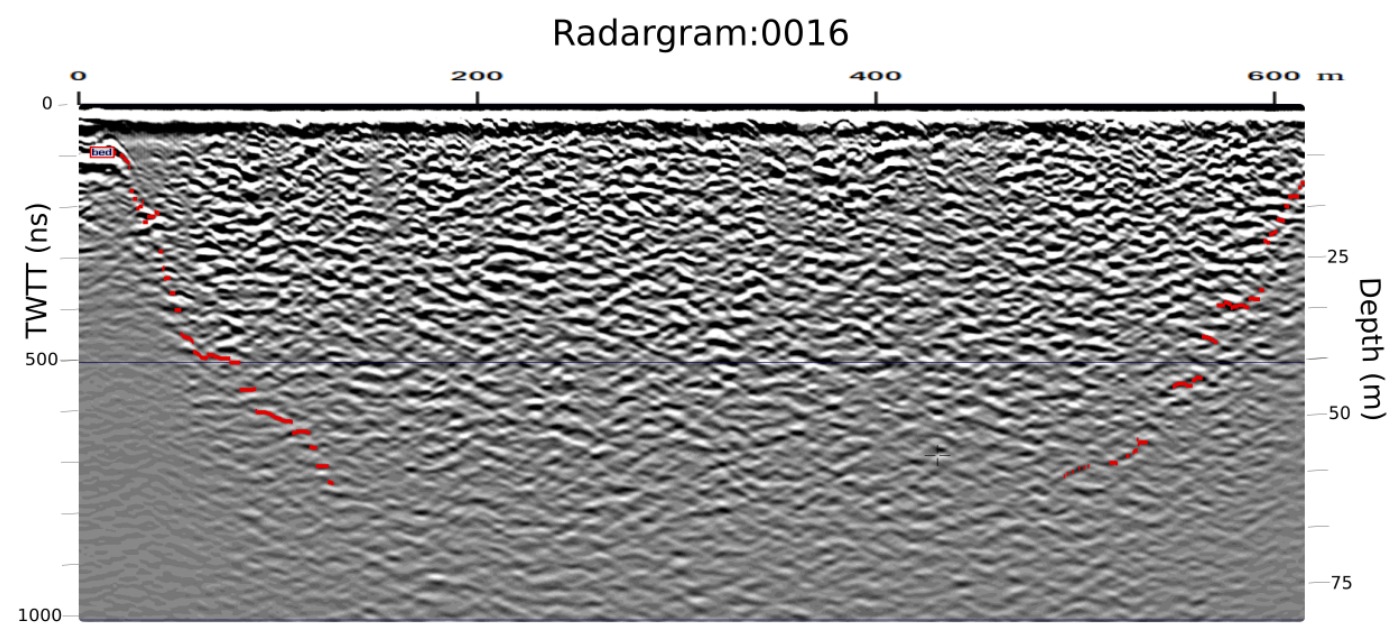

(a)

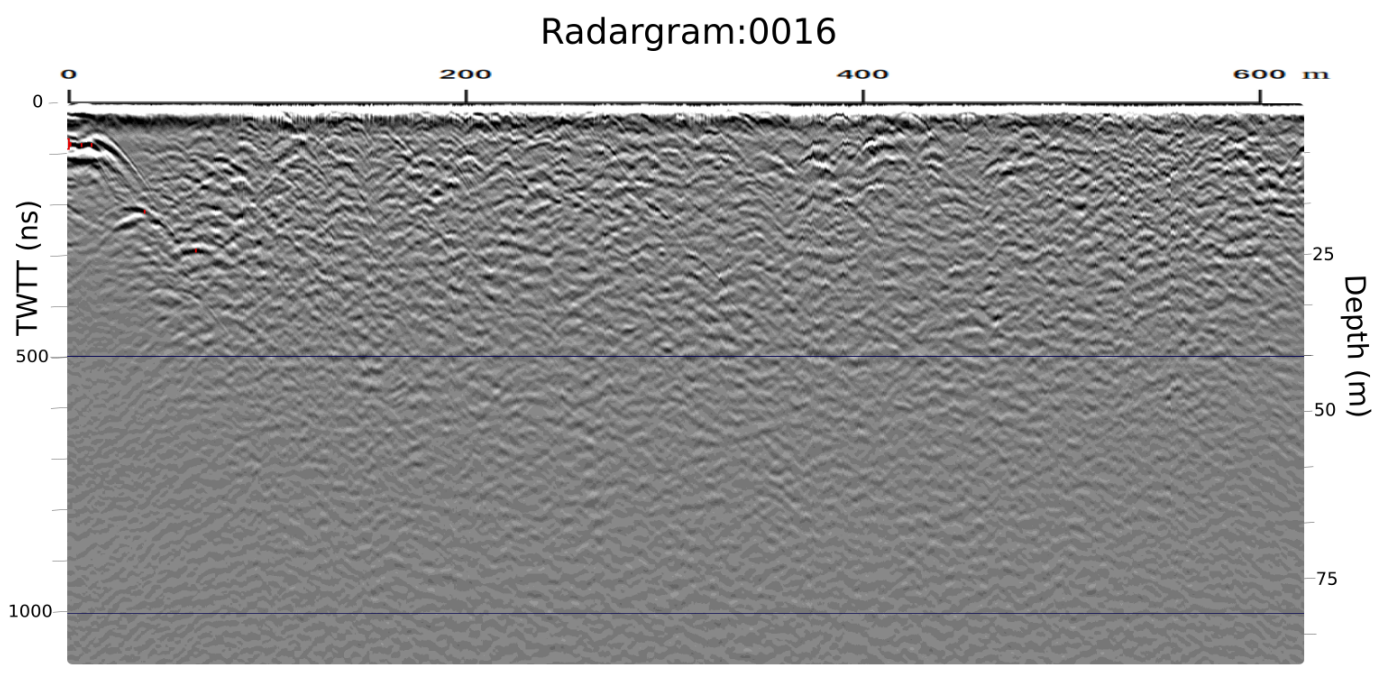

(b)

Figure D.12: Interpreted (a), and non-interpreted (b) radargrams for profile 0016. 


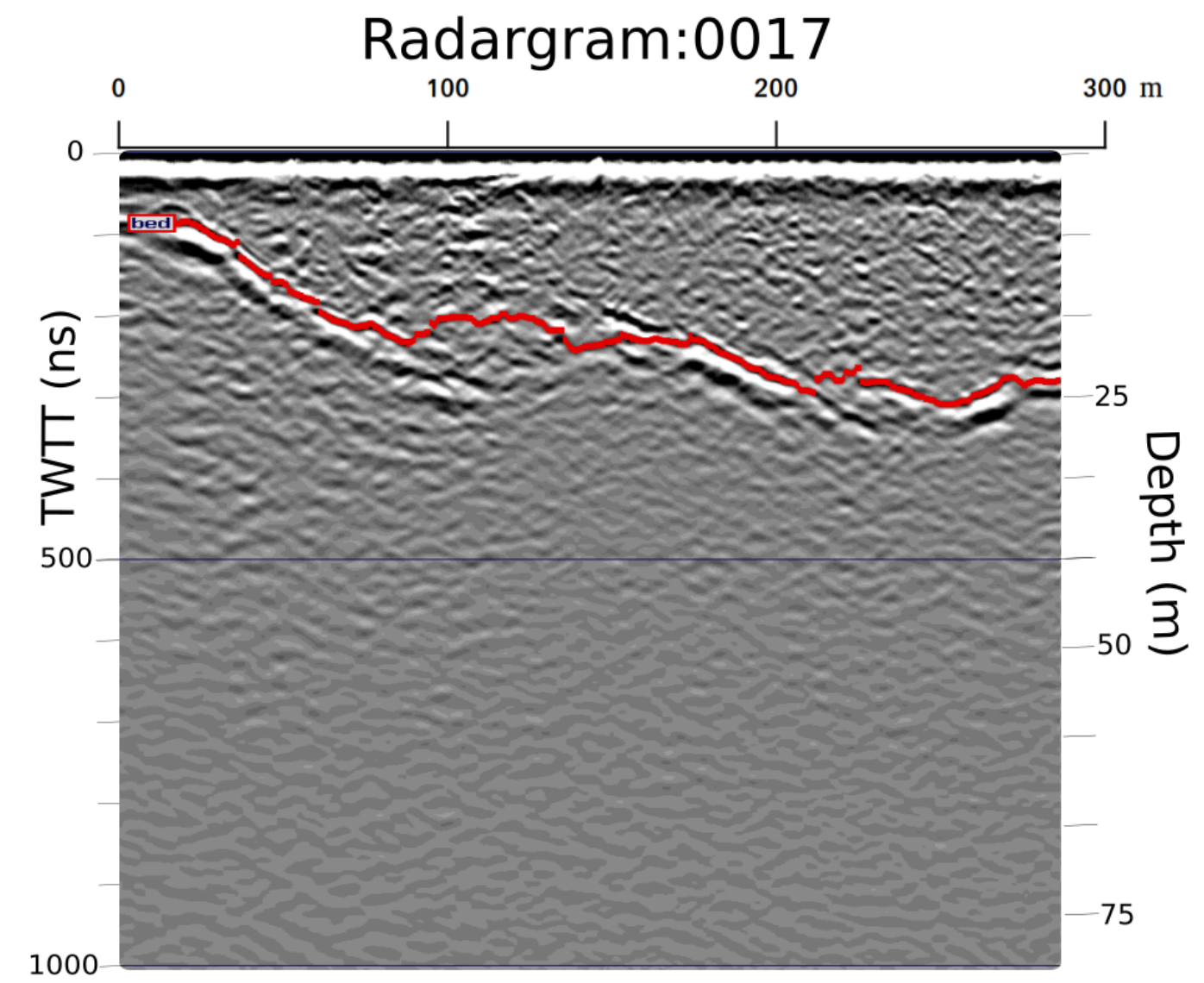

(a)

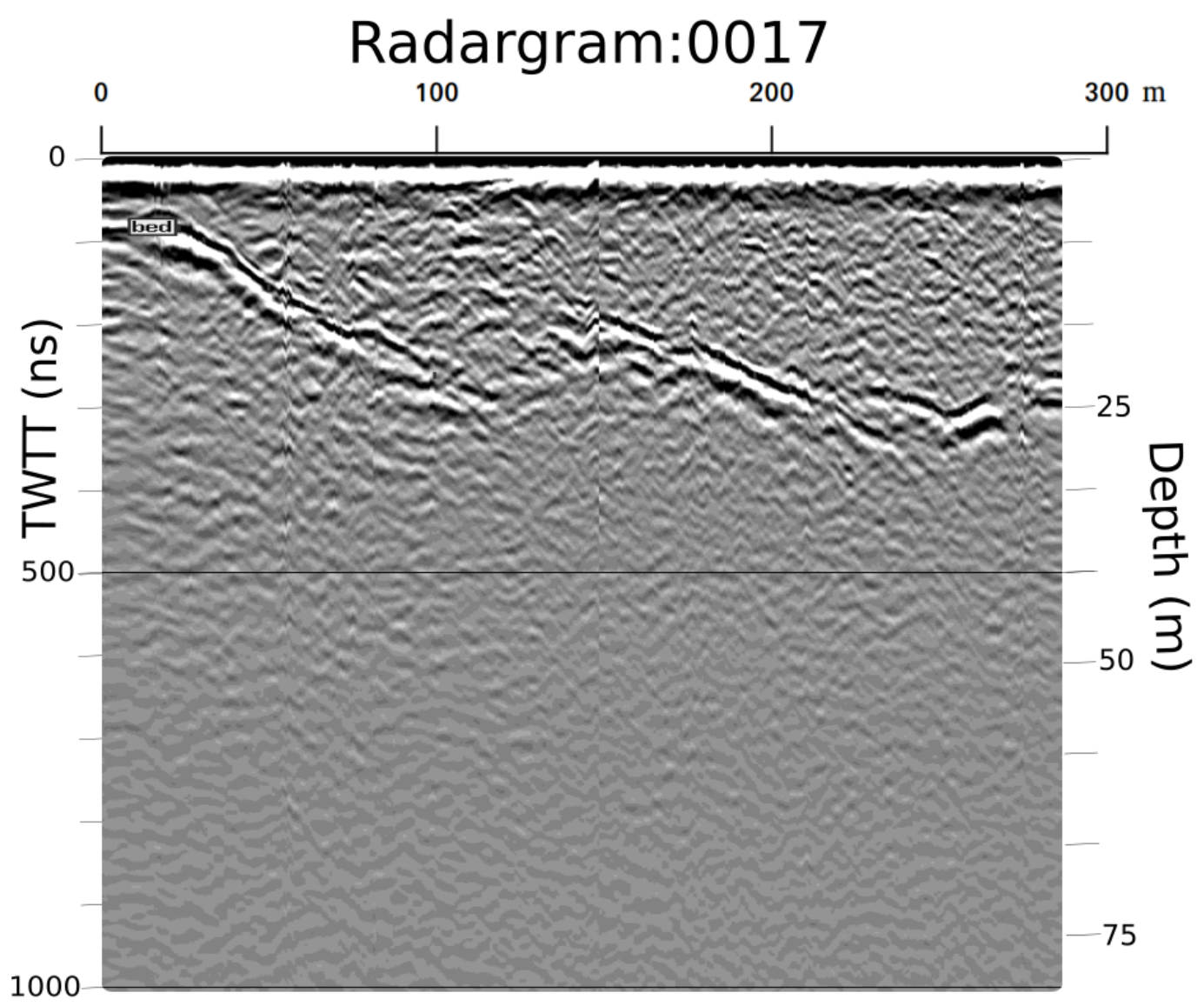

(b)

Figure D.13: Interpreted (a), and non-interpreted (b) radargrams for profile 0017. 


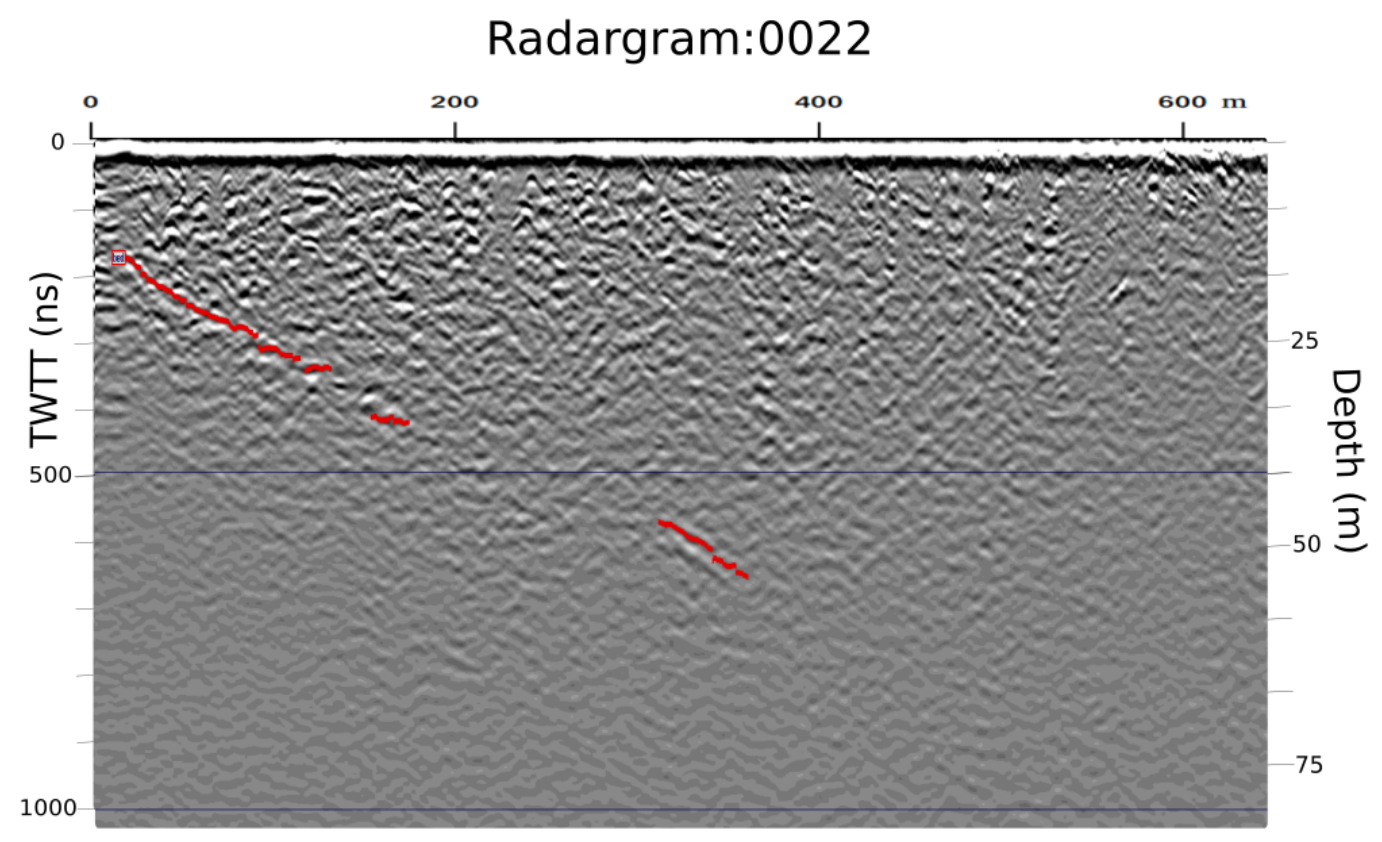

(a)

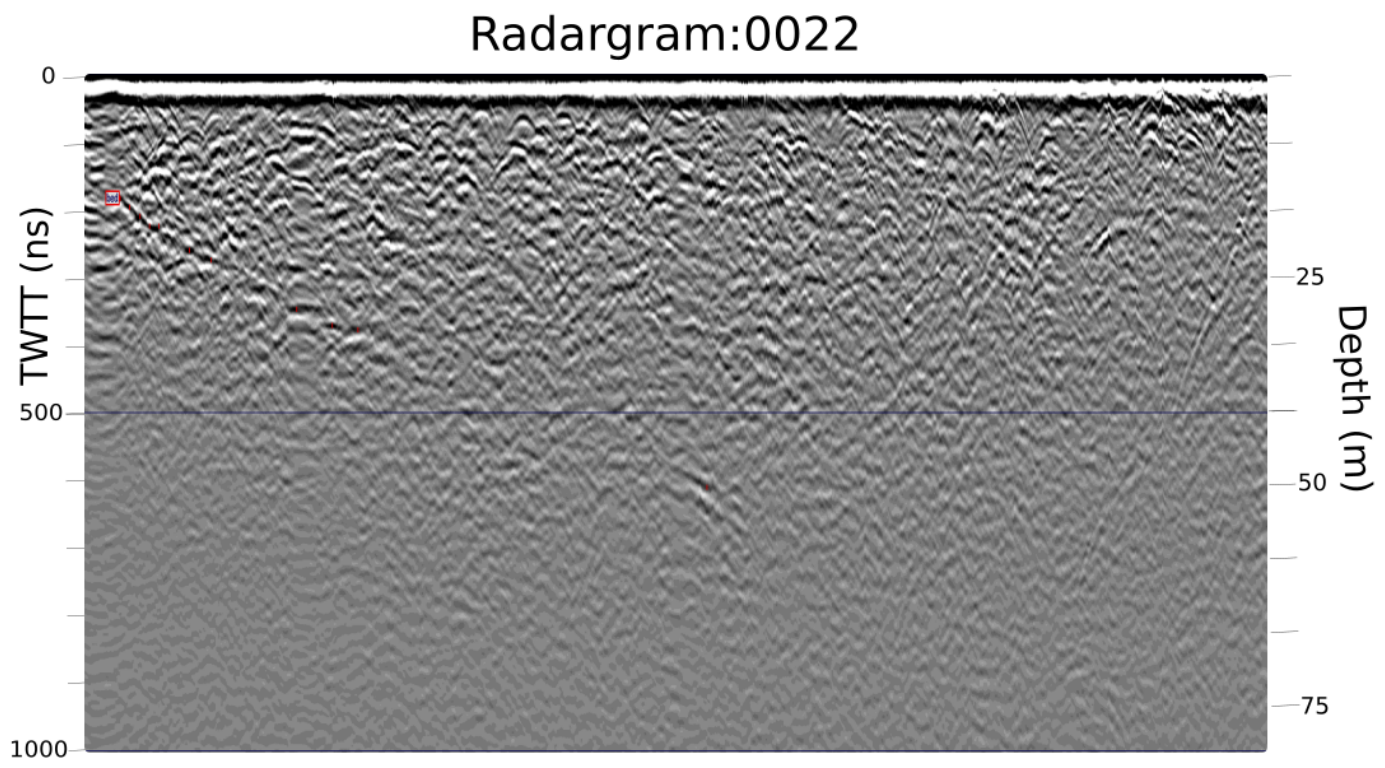

(b)

Figure D.14: Interpreted (a), and non-interpreted (b) radargrams for profile 0022. 


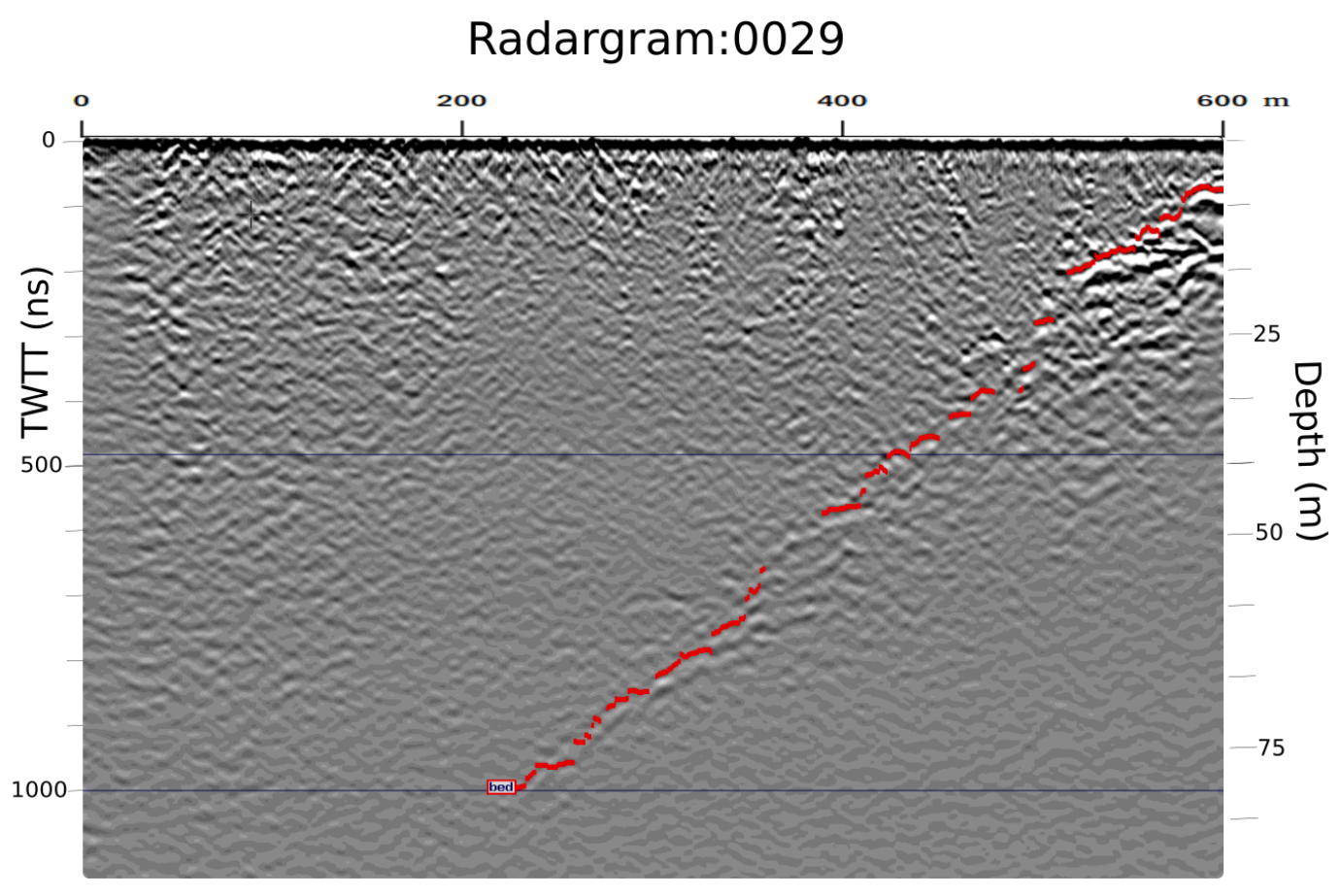

(a)

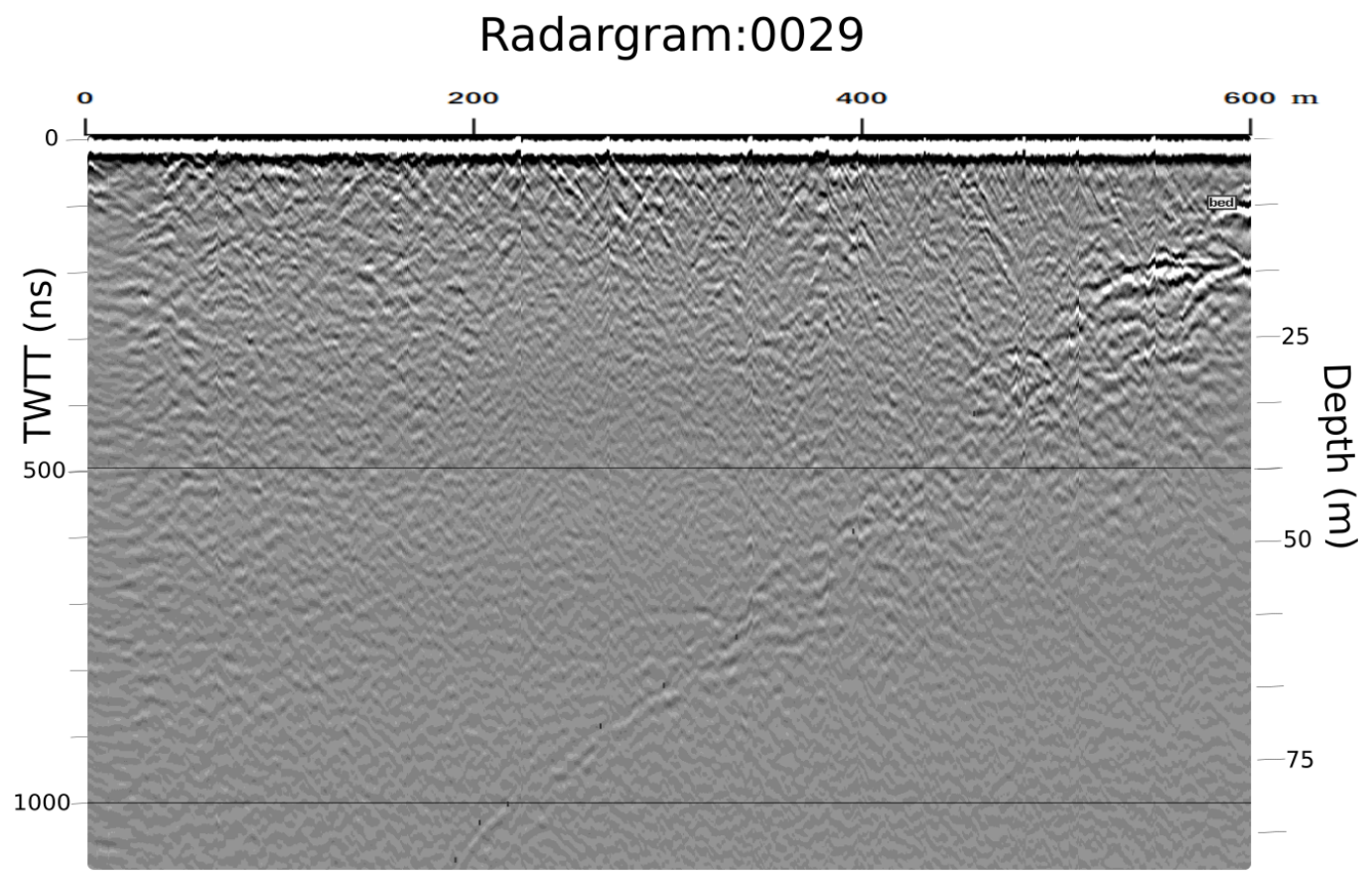

(b)

Figure D.15: Interpreted (a), and non-interpreted (b) radargrams for profile 0029. 


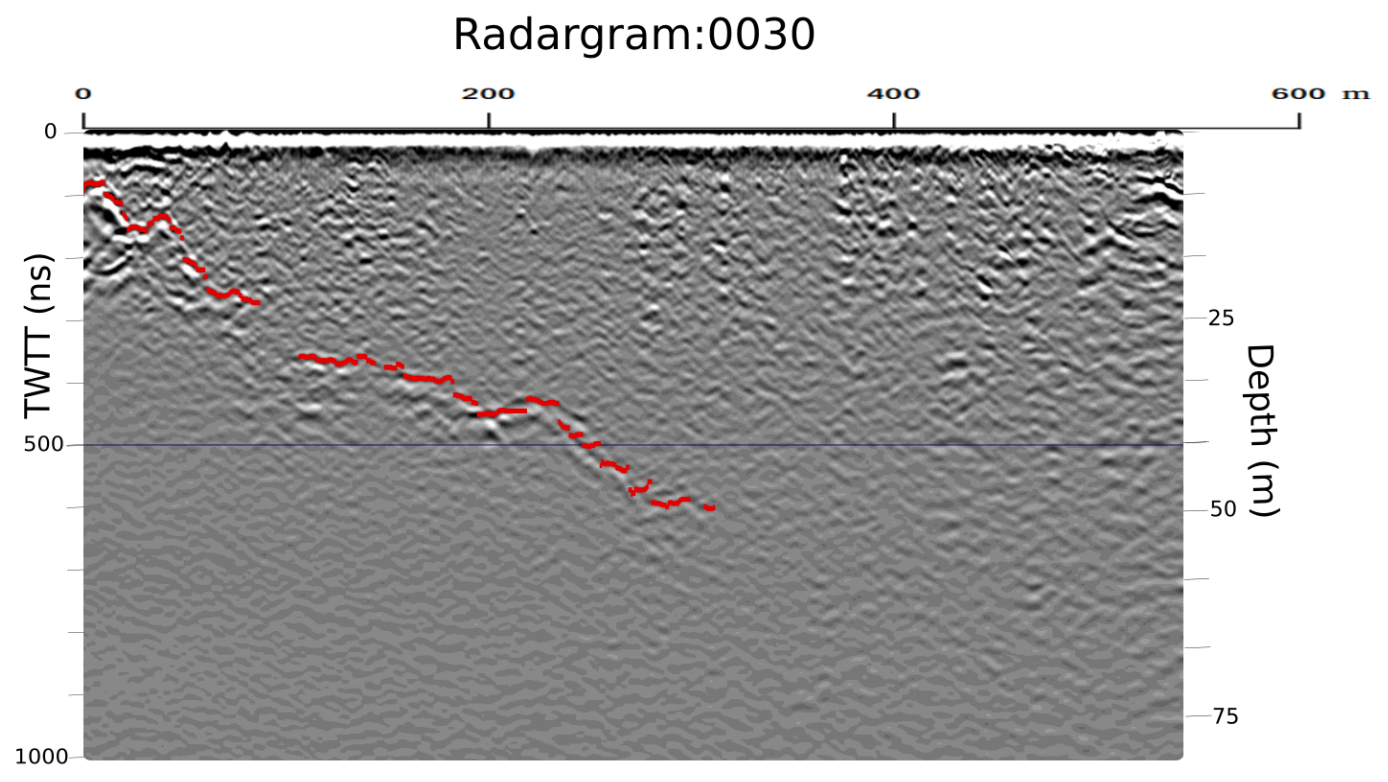

(a)

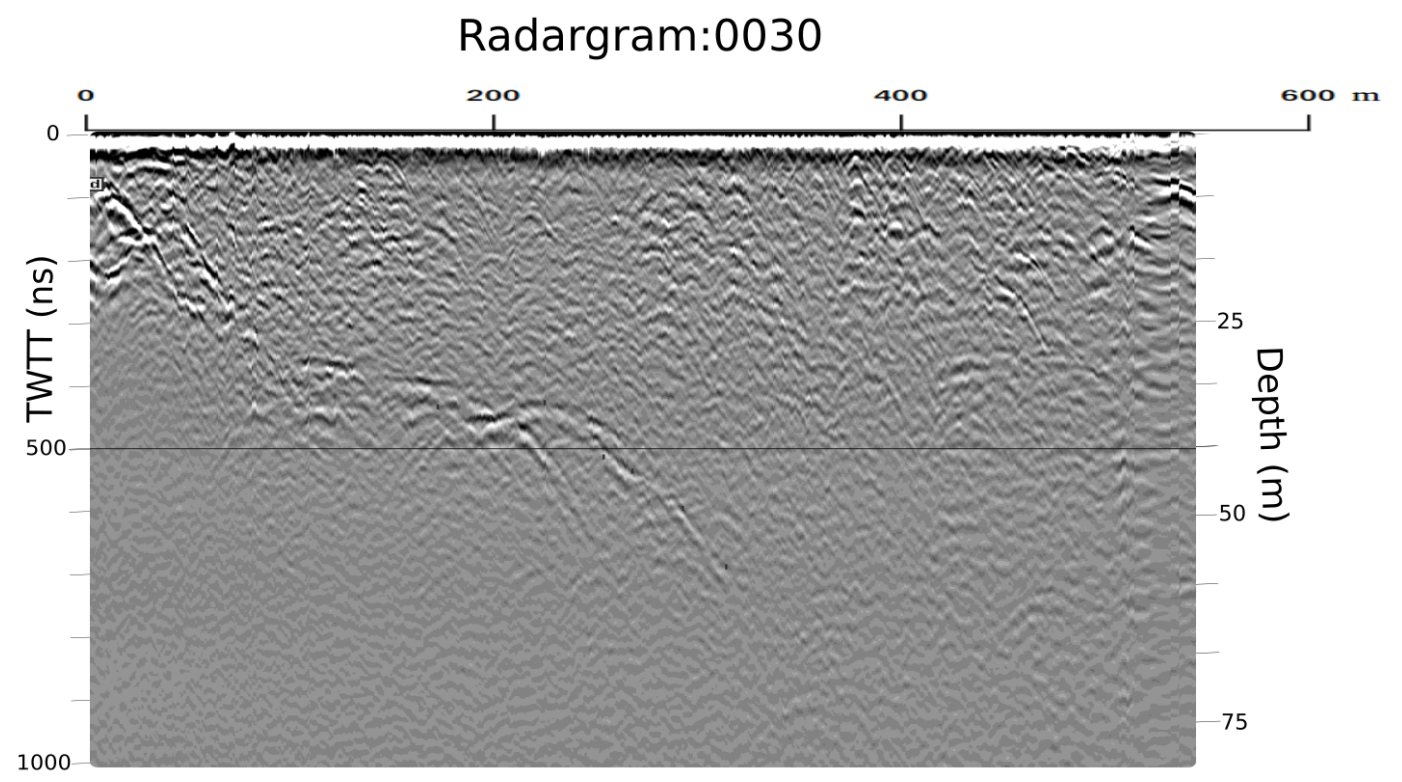

(b)

Figure D.16: Interpreted (a), and non-interpreted (b) radargrams for profile 0030. 


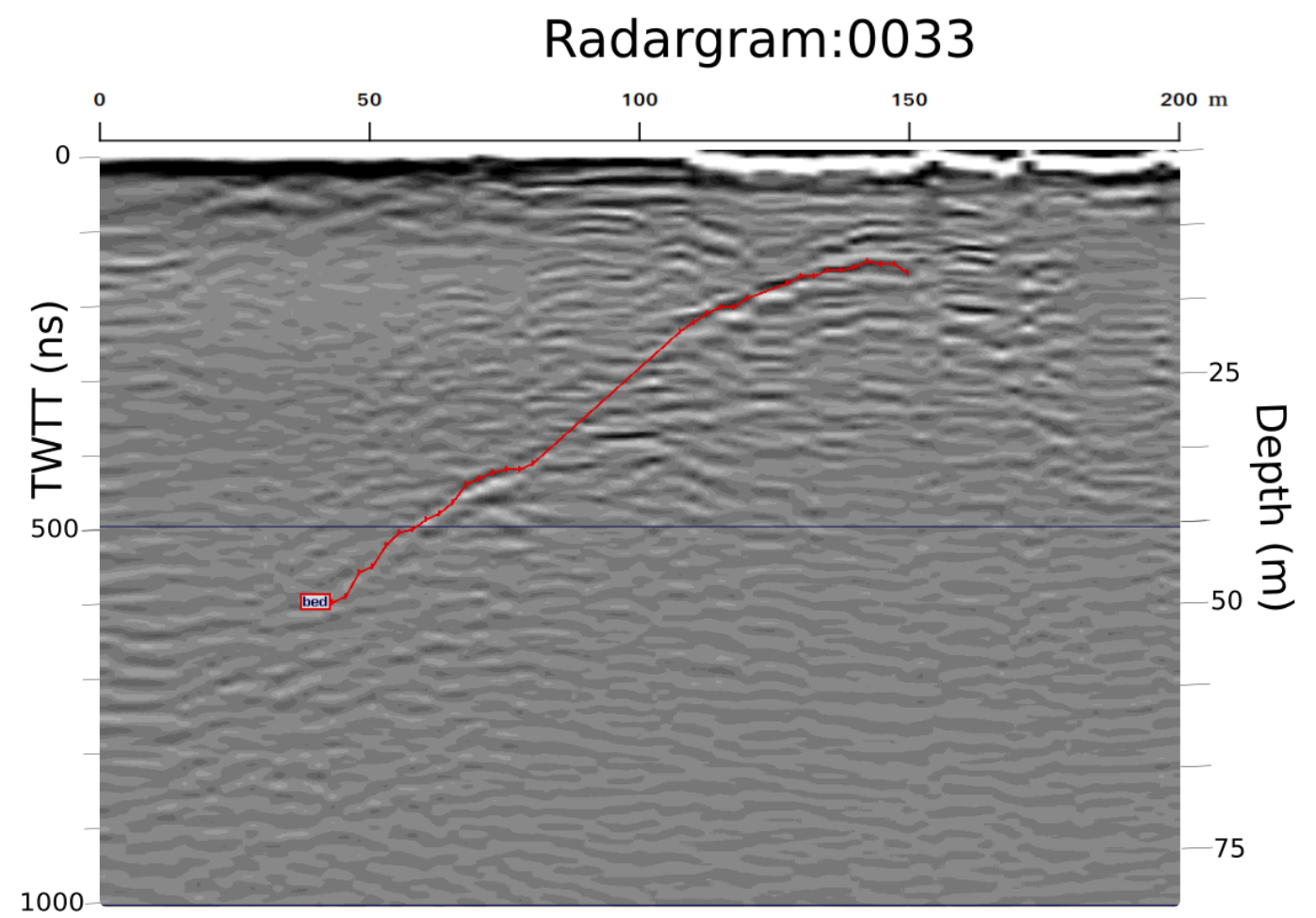

Figure D.17: Interpreted radargram for profile 0033.

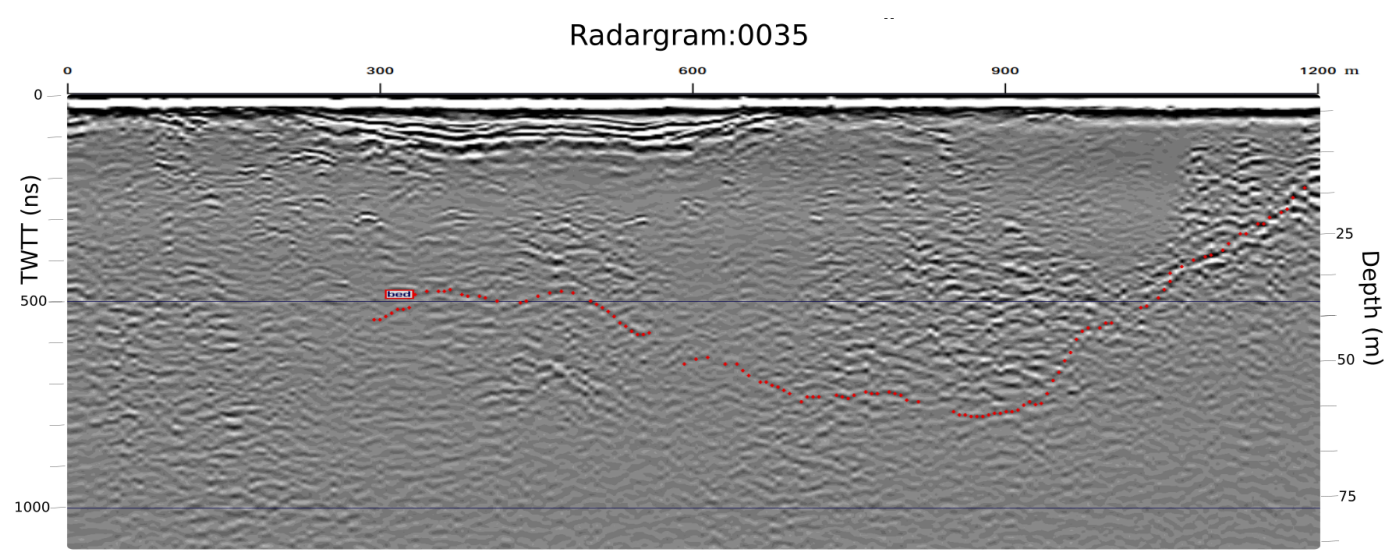

Figure D.18: Interpreted radargram for profile 0035. 


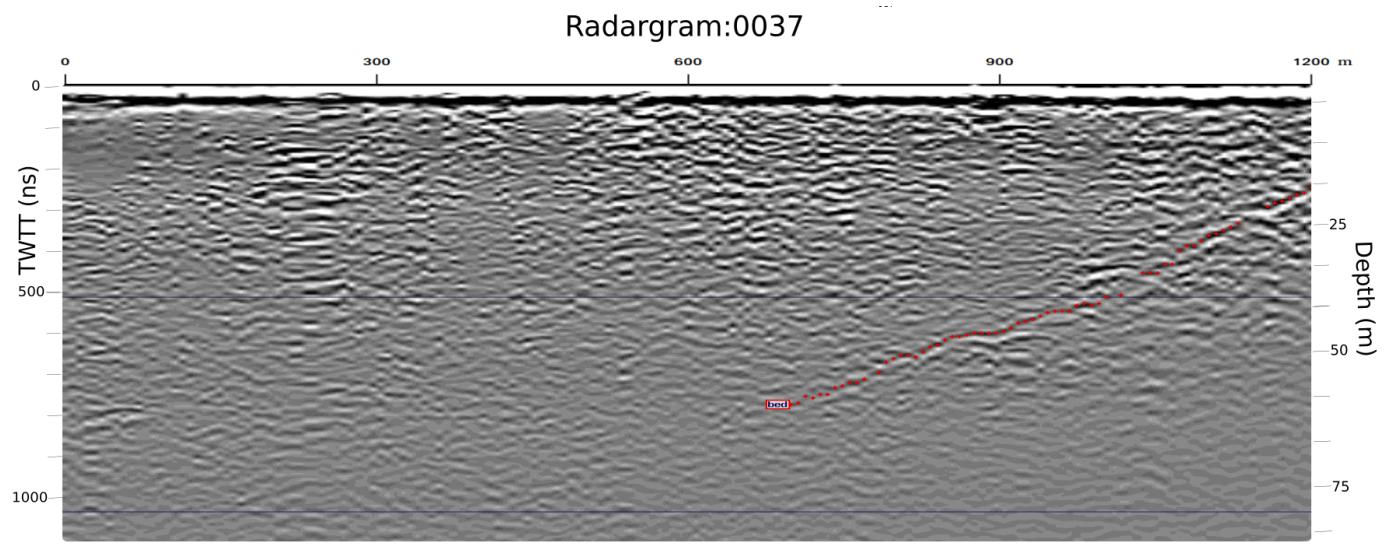

Figure D.19: Interpreted radargram for profile 0037.

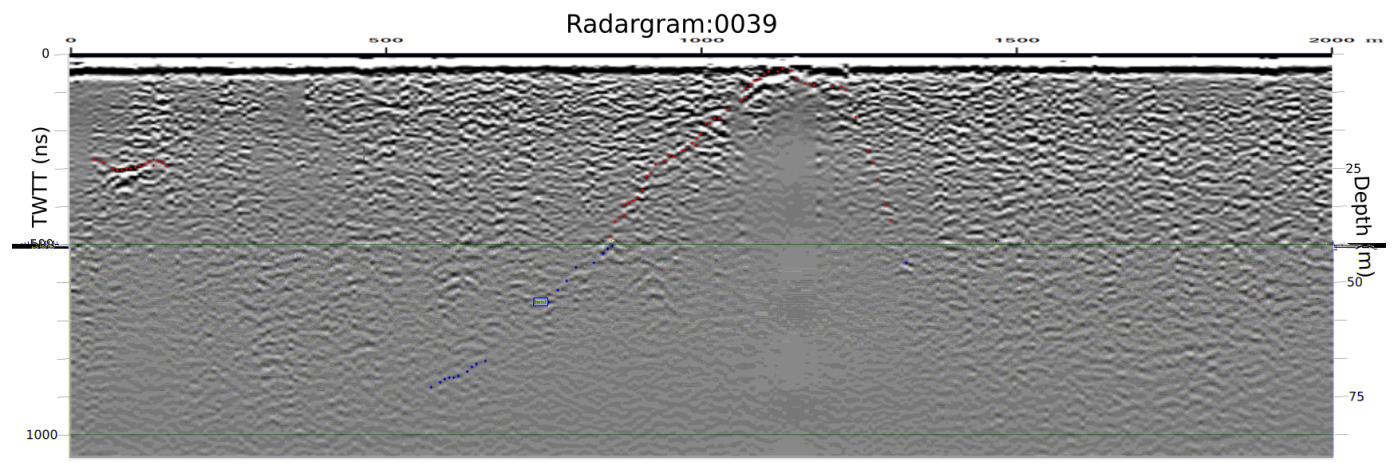

Figure D.20: Interpreted radargram for profile 0039.

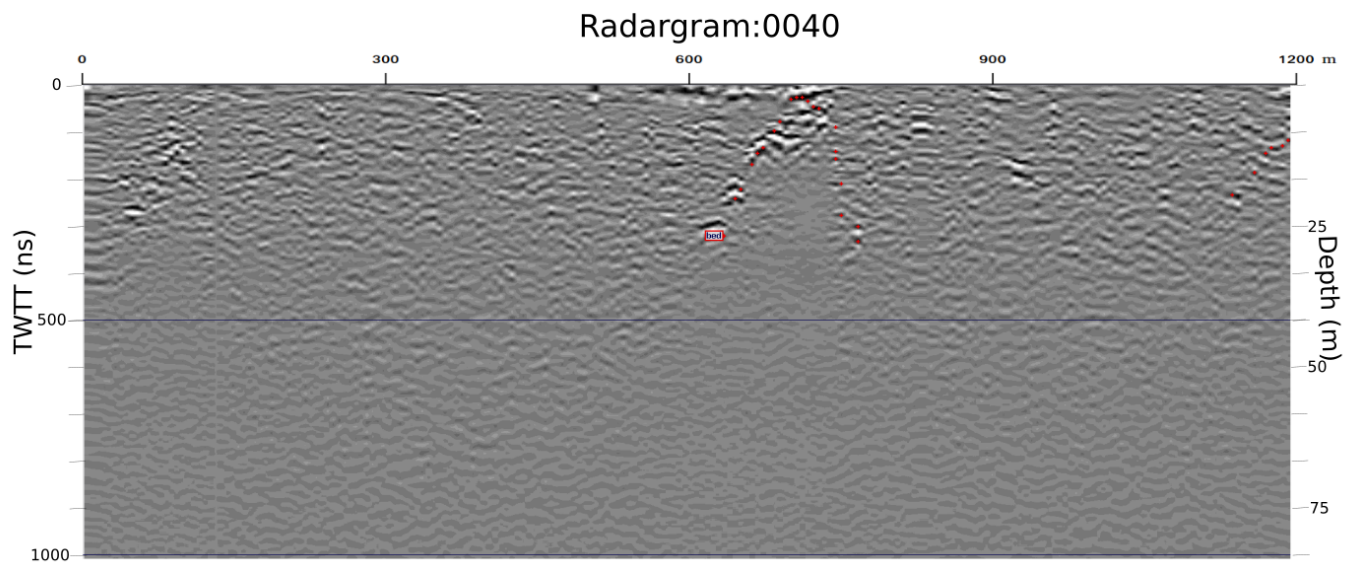

Figure D.21: Interpreted radargram for profile 0040. 


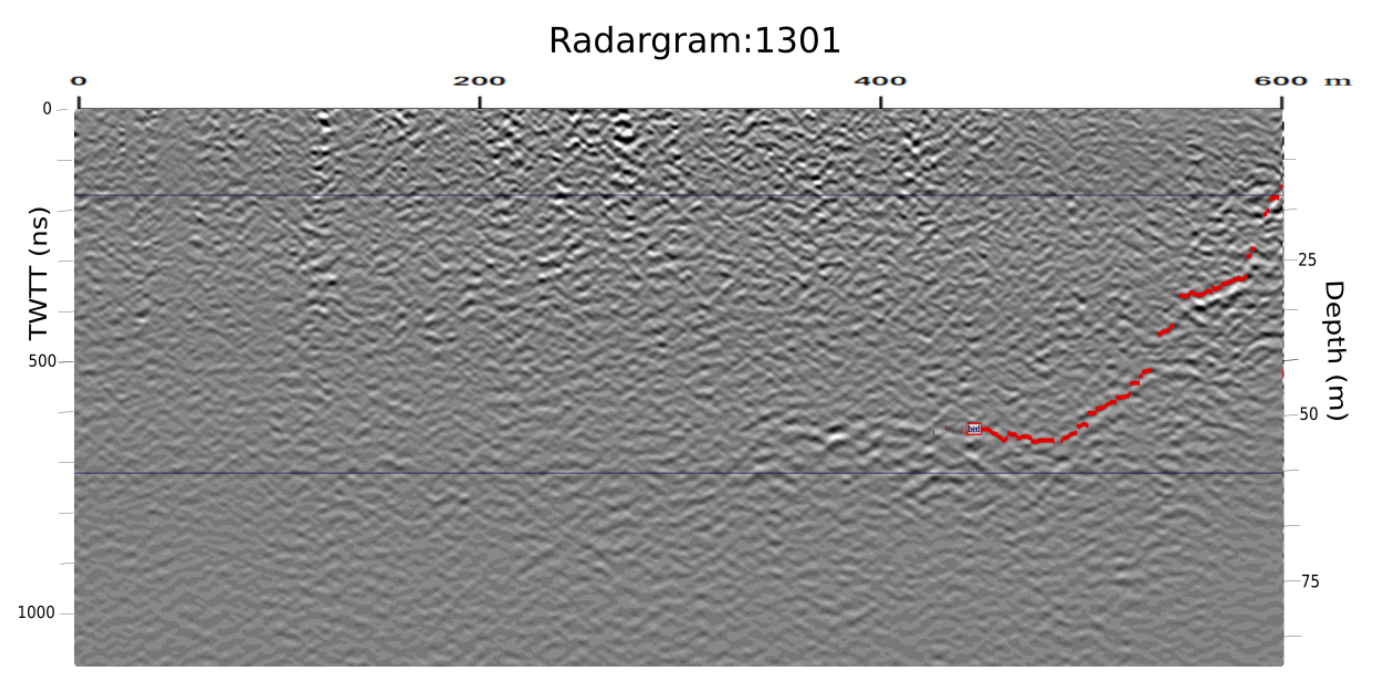

(a)

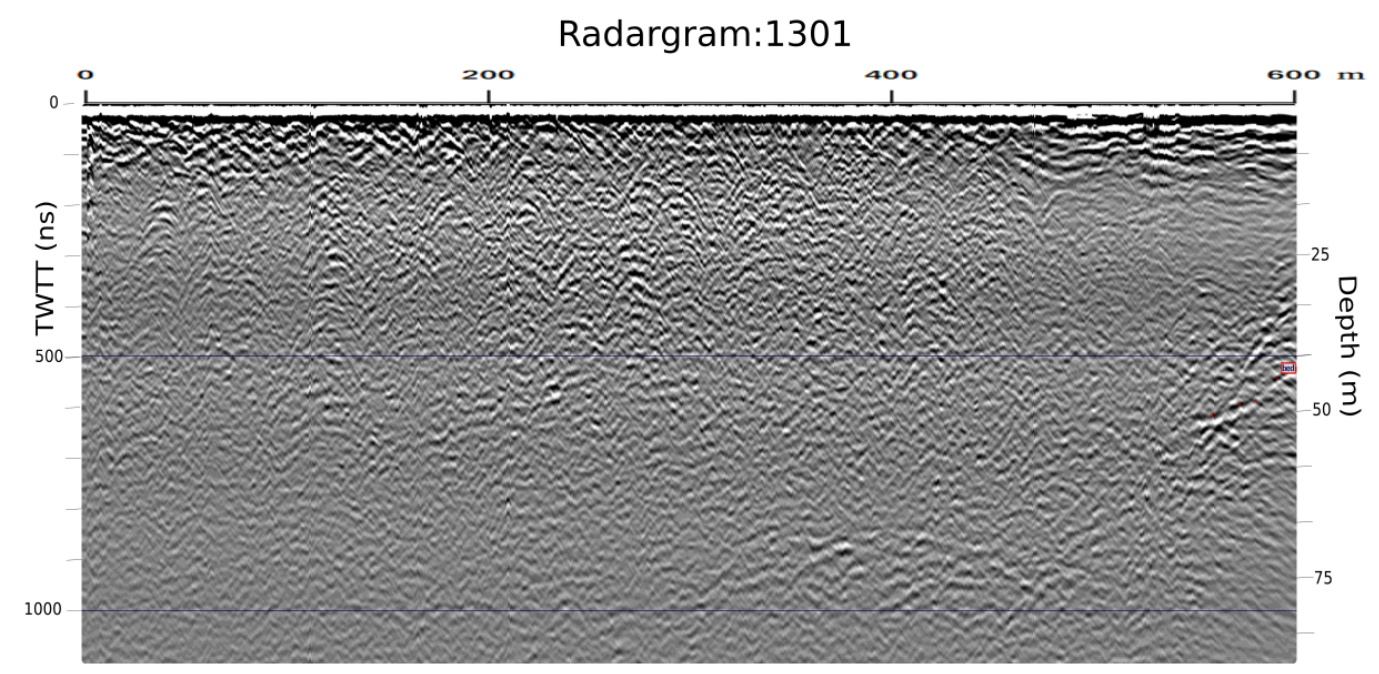

(b)

Figure D.22: Interpreted (a), and non-interpreted (b) radargrams for profile 1301. 


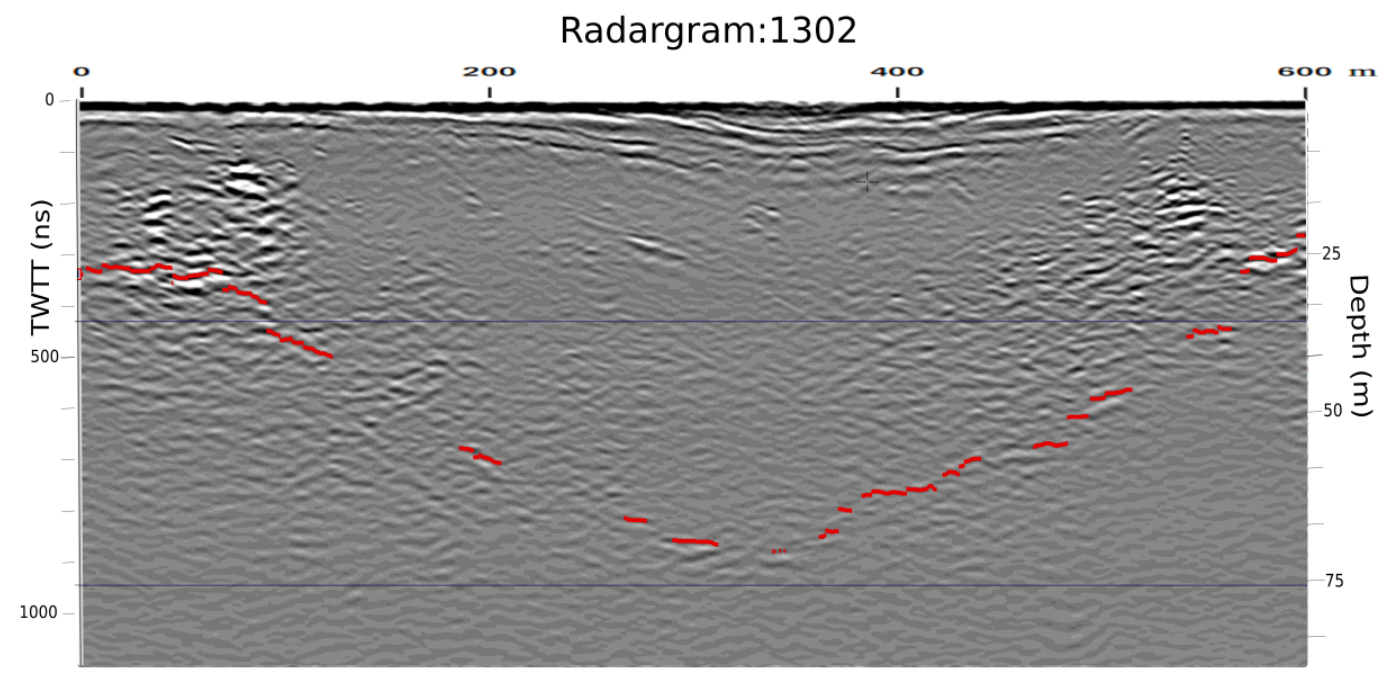

(a)

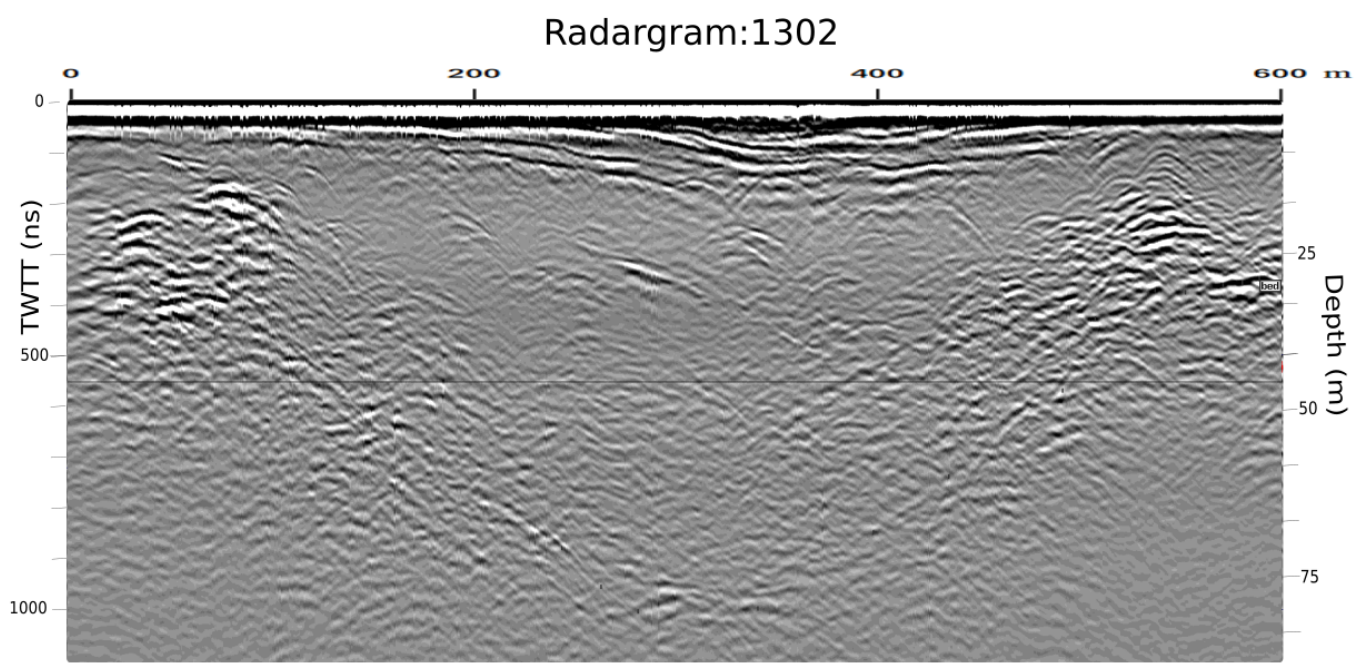

(b)

Figure D.23: Interpreted (a), and non-interpreted (b) radargrams for profile 1302. 


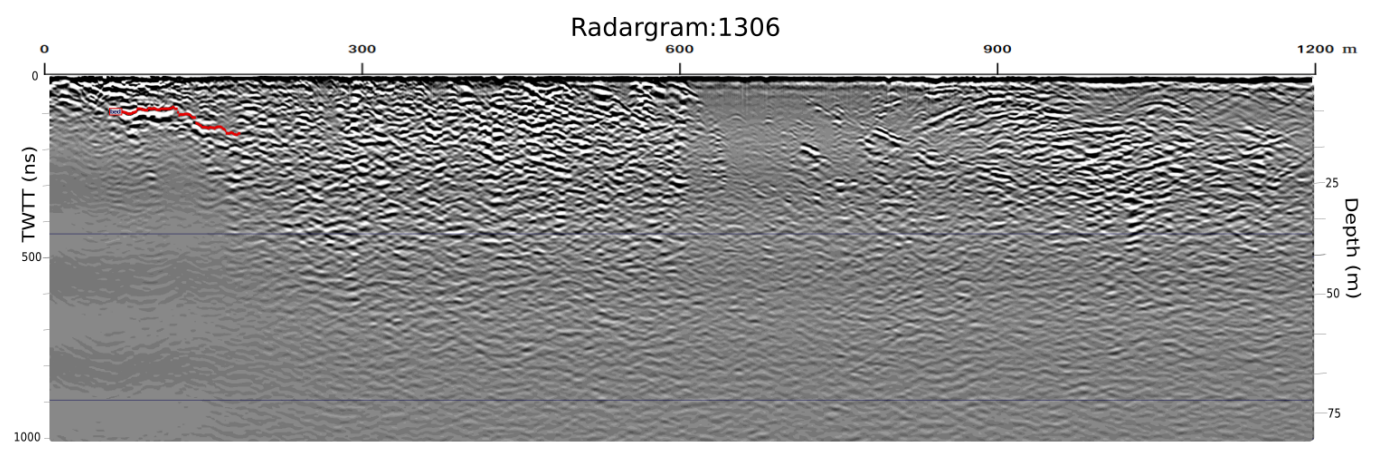

(a)

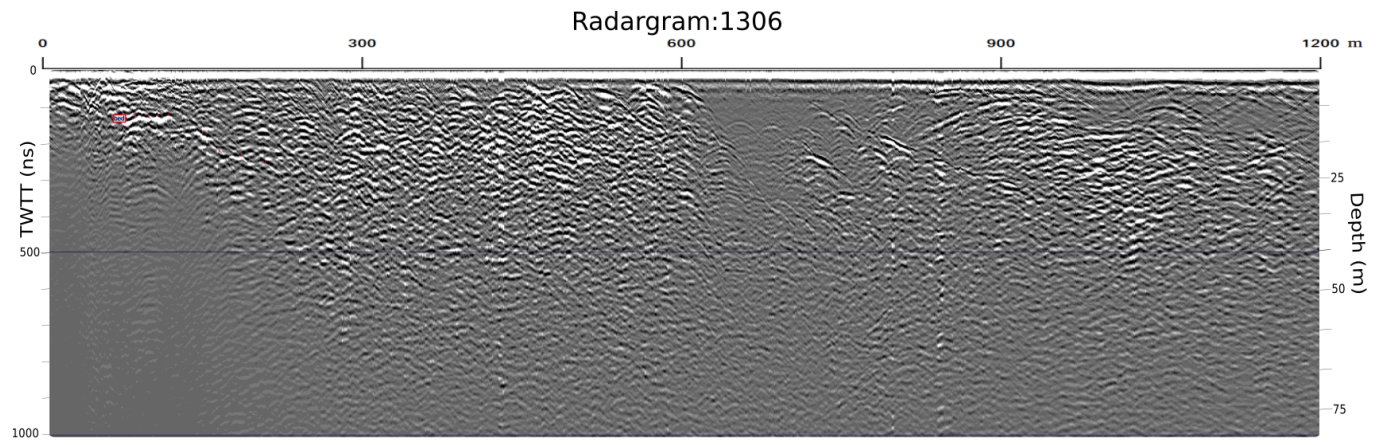

(b)

Figure D.24: Interpreted (a), and non-interpreted (b) radargrams for profile 1306. 


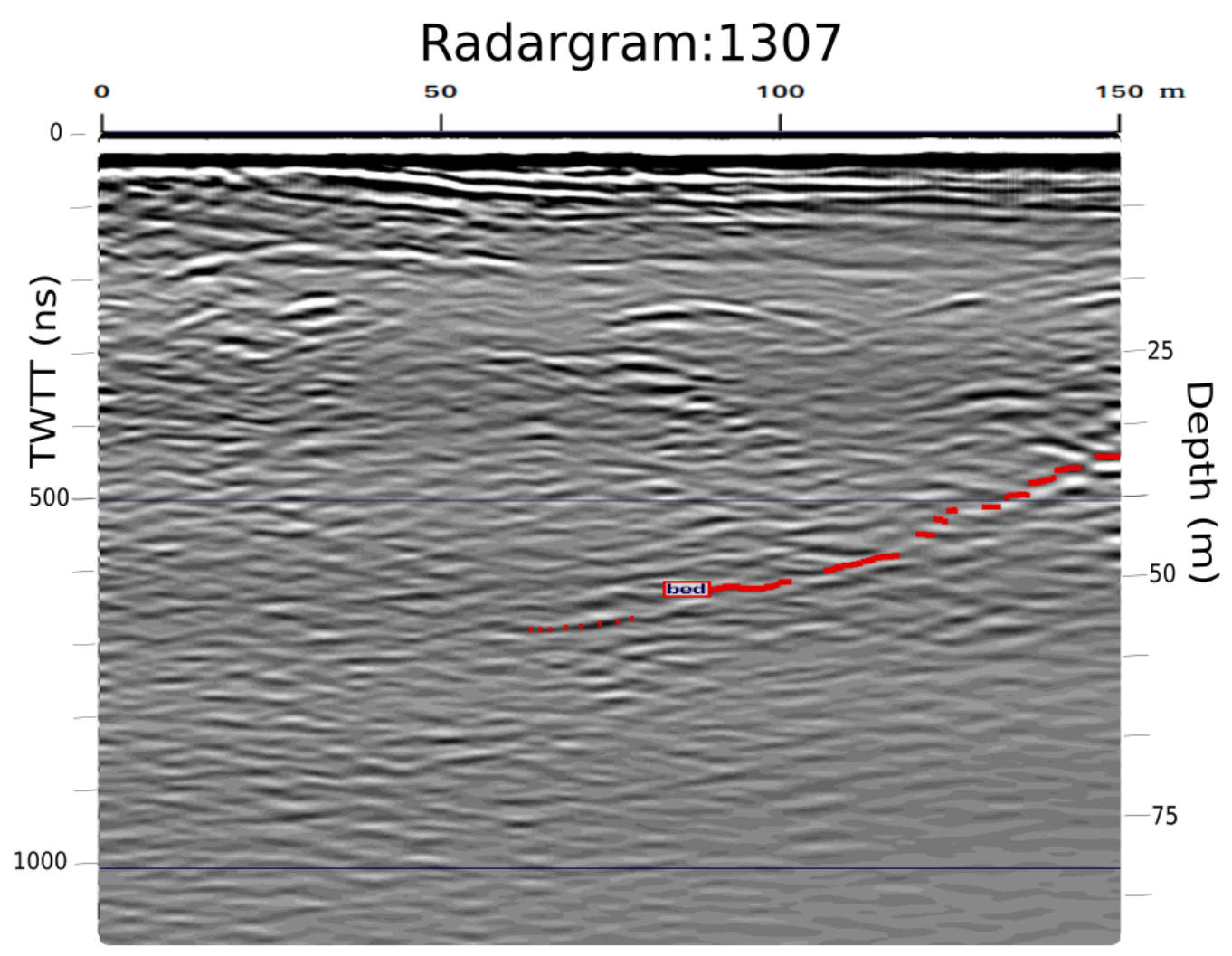

(a)

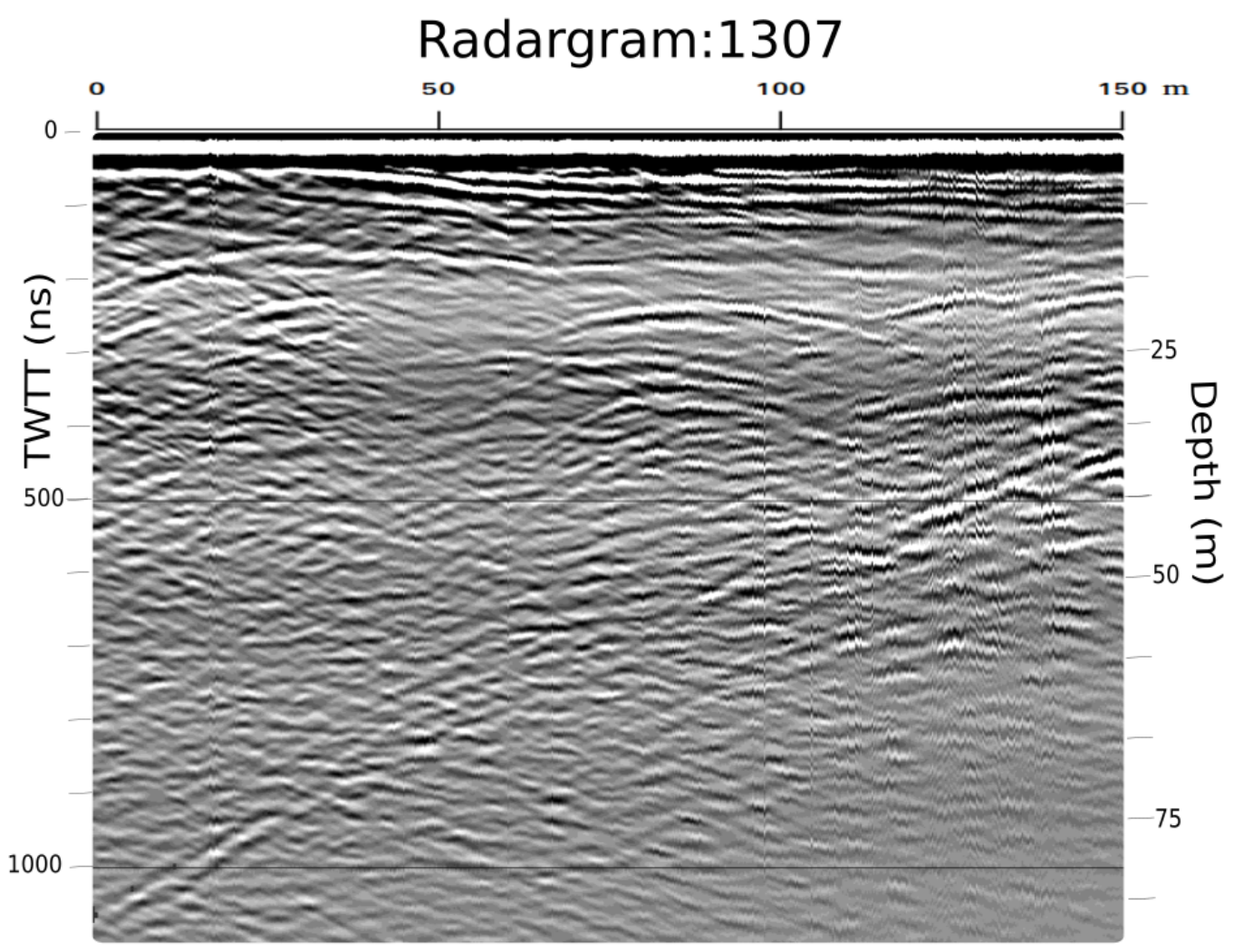

(b)

Figure D.25: Interpreted (a), and non-interpreted (b) radargrams for profile 1307. 


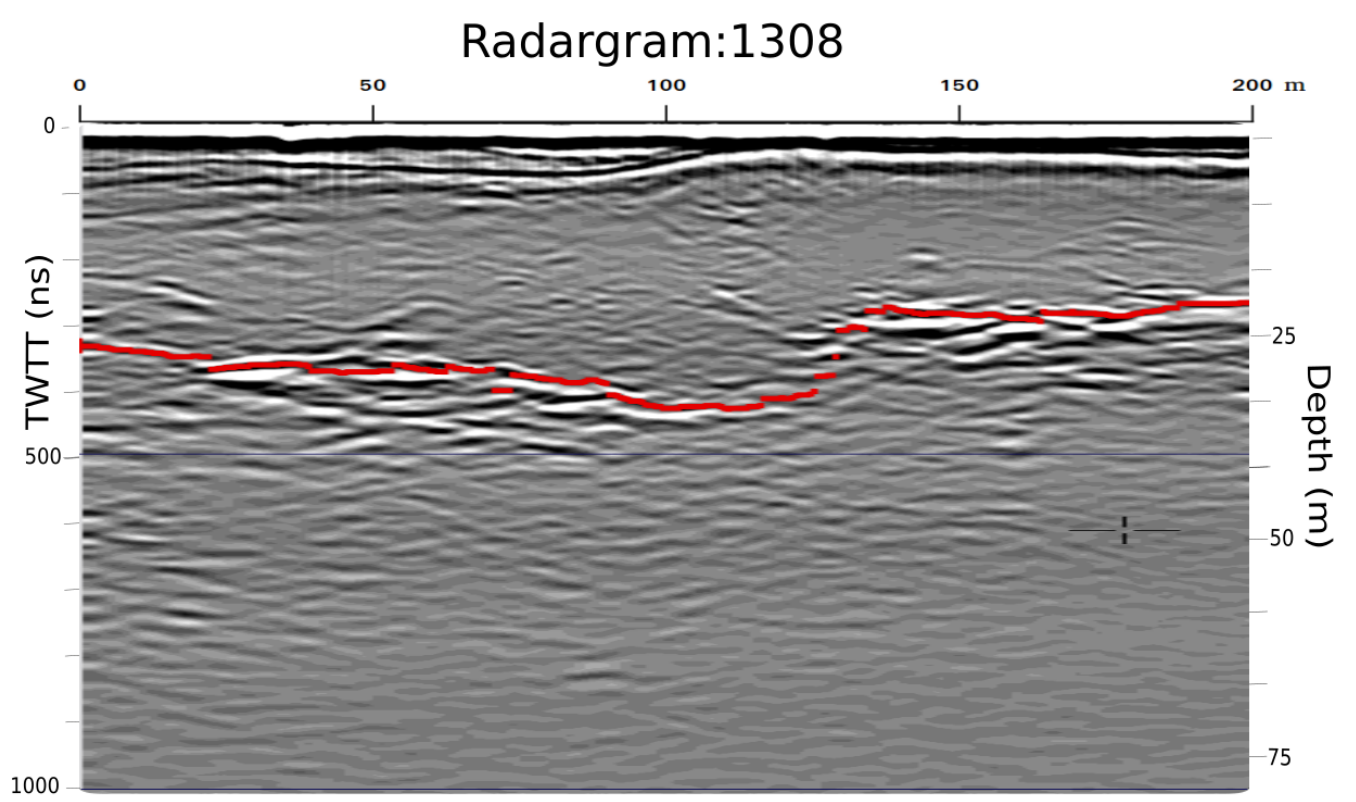

(a)

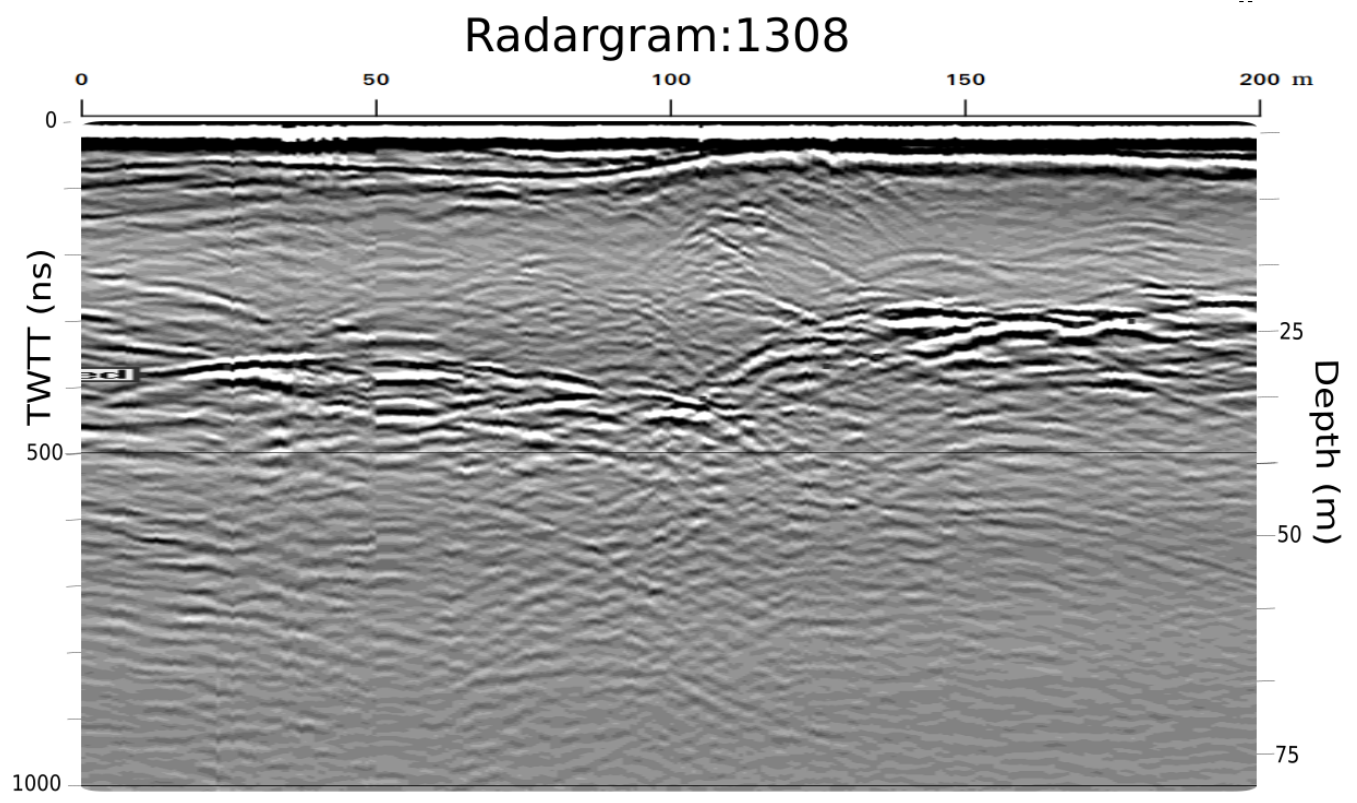

(b)

Figure D.26: Interpreted (a), and non-interpreted (b) radargrams for profile 1308. 


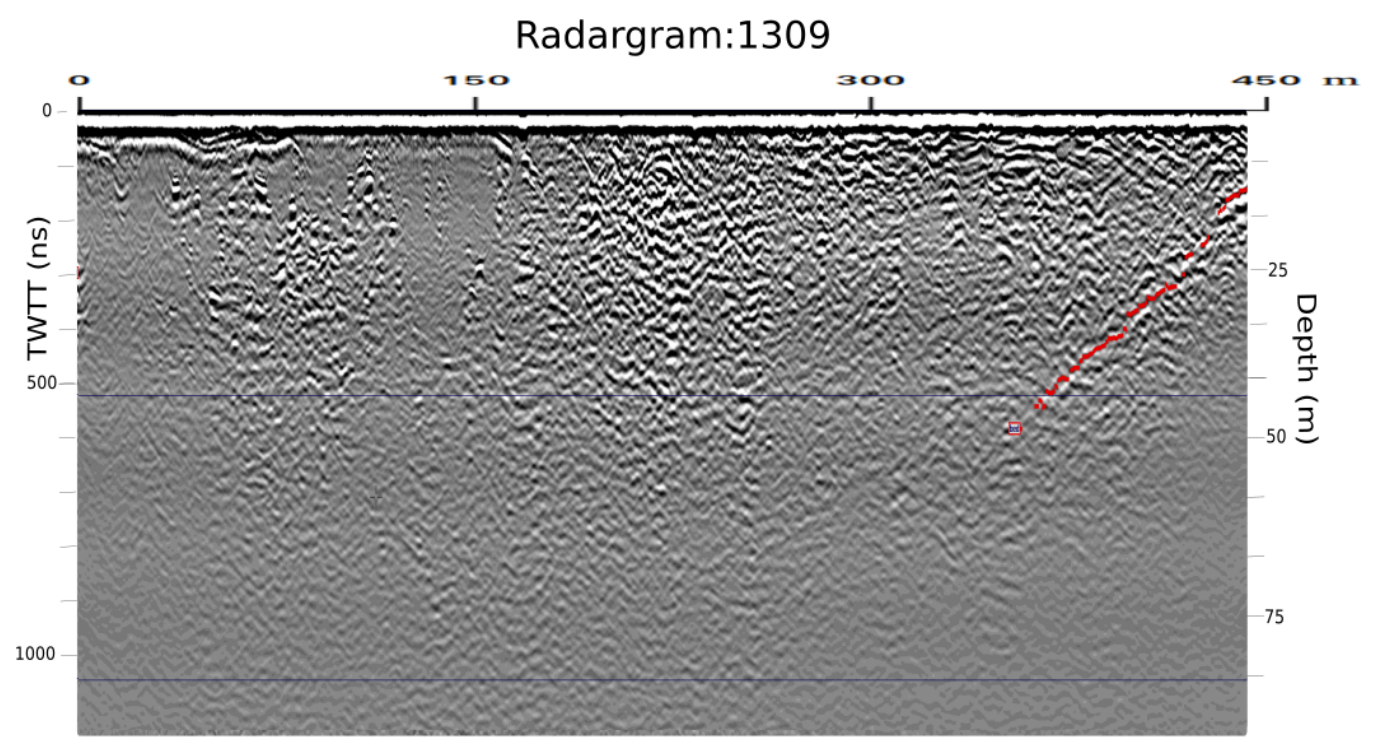

(a)

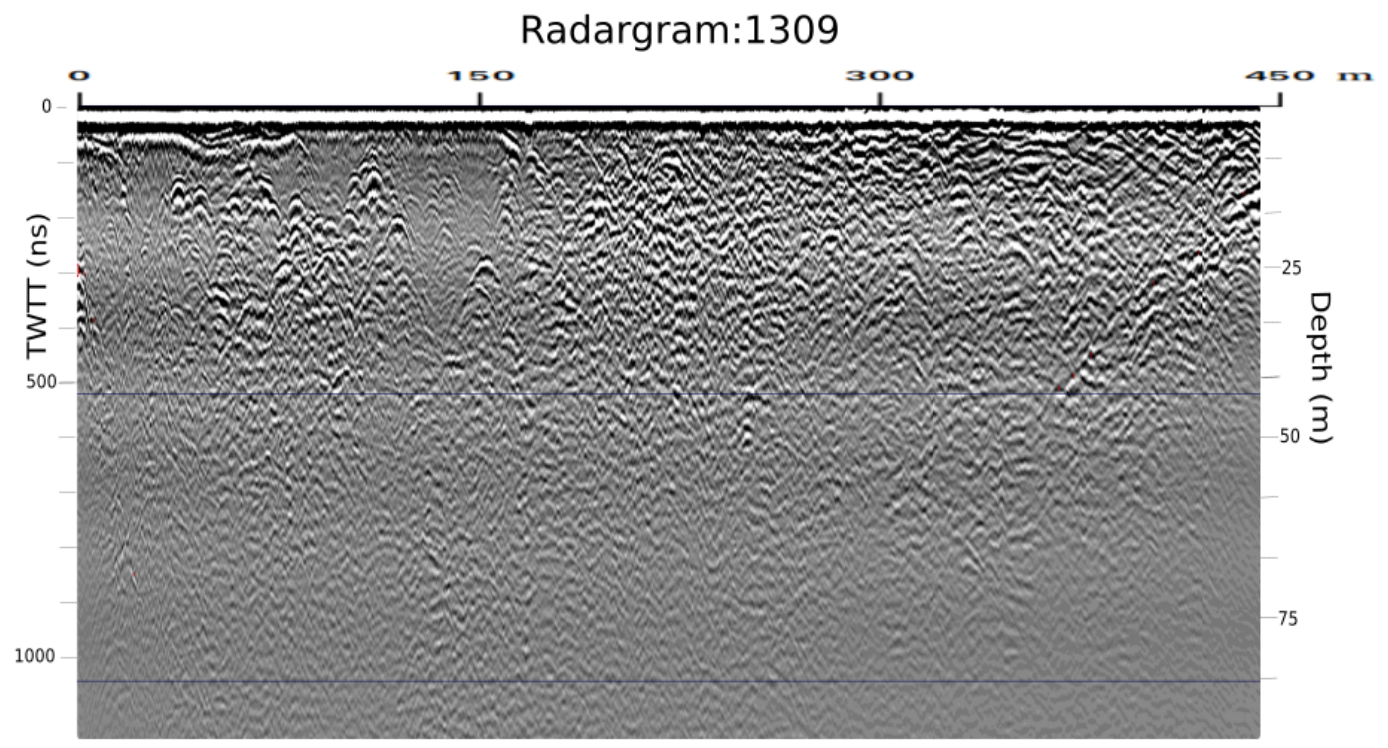

(b)

Figure D.27: Interpreted (a), and non-interpreted (b) radargrams for profile 1309. 


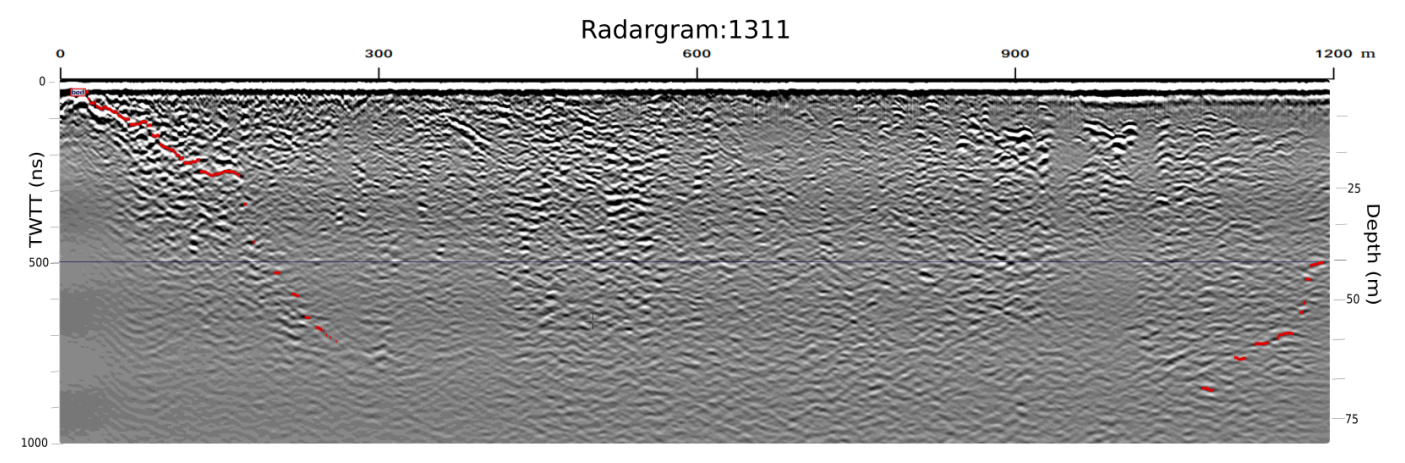

(a)

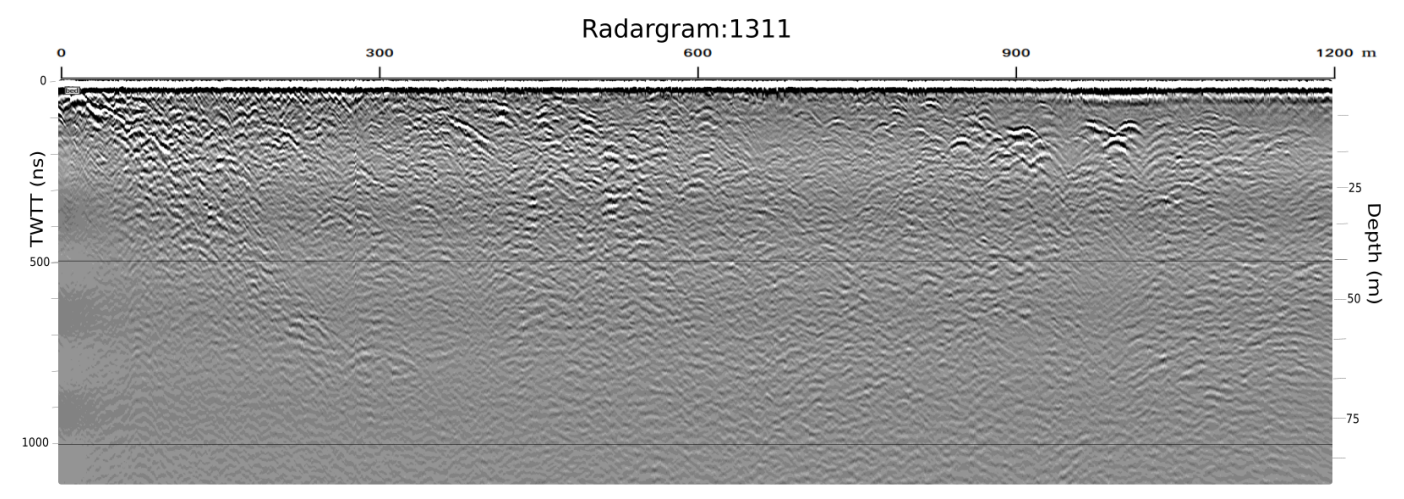

(b)

Figure D.28: Interpreted (a), and non-interpreted (b) radargrams for profile 1311. 


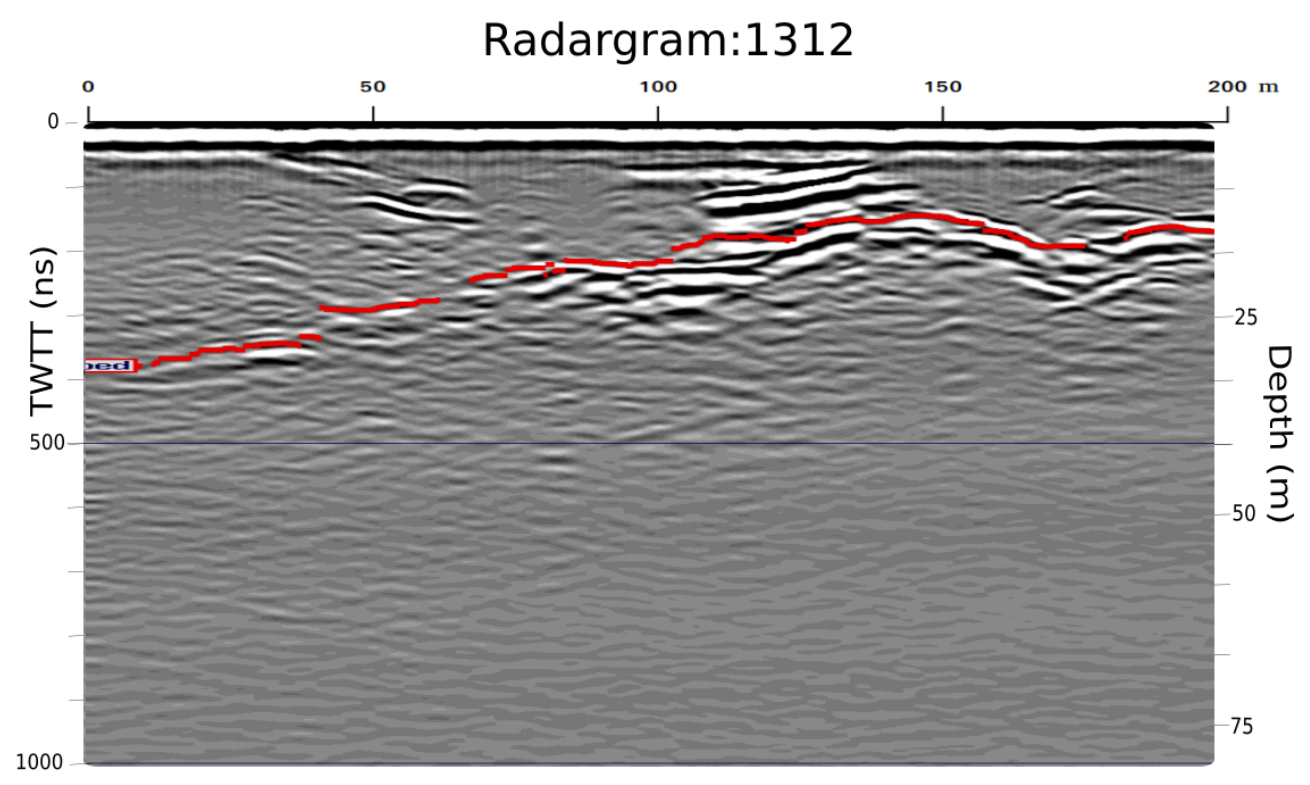

(a)

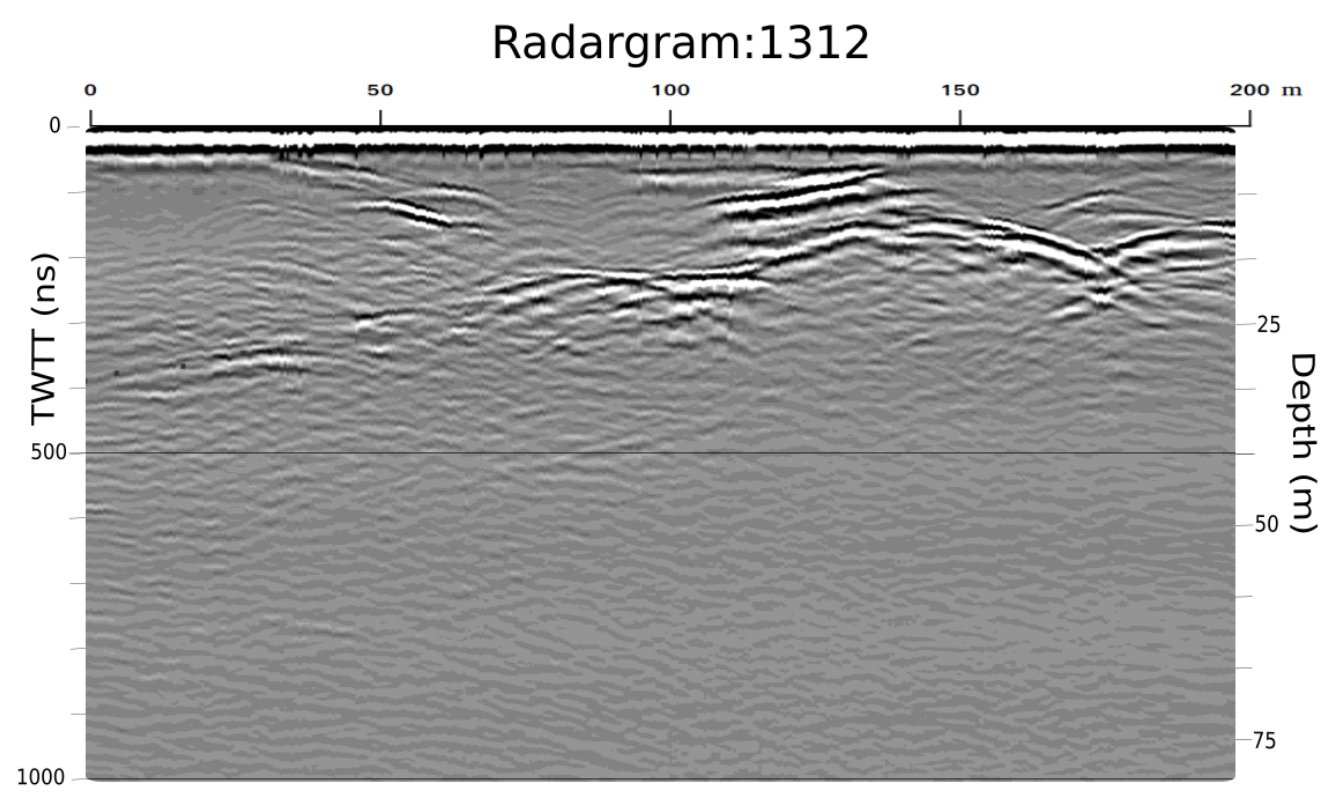

(b)

Figure D.29: Interpreted (a), and non-interpreted (b) radargrams for profile 1312. 


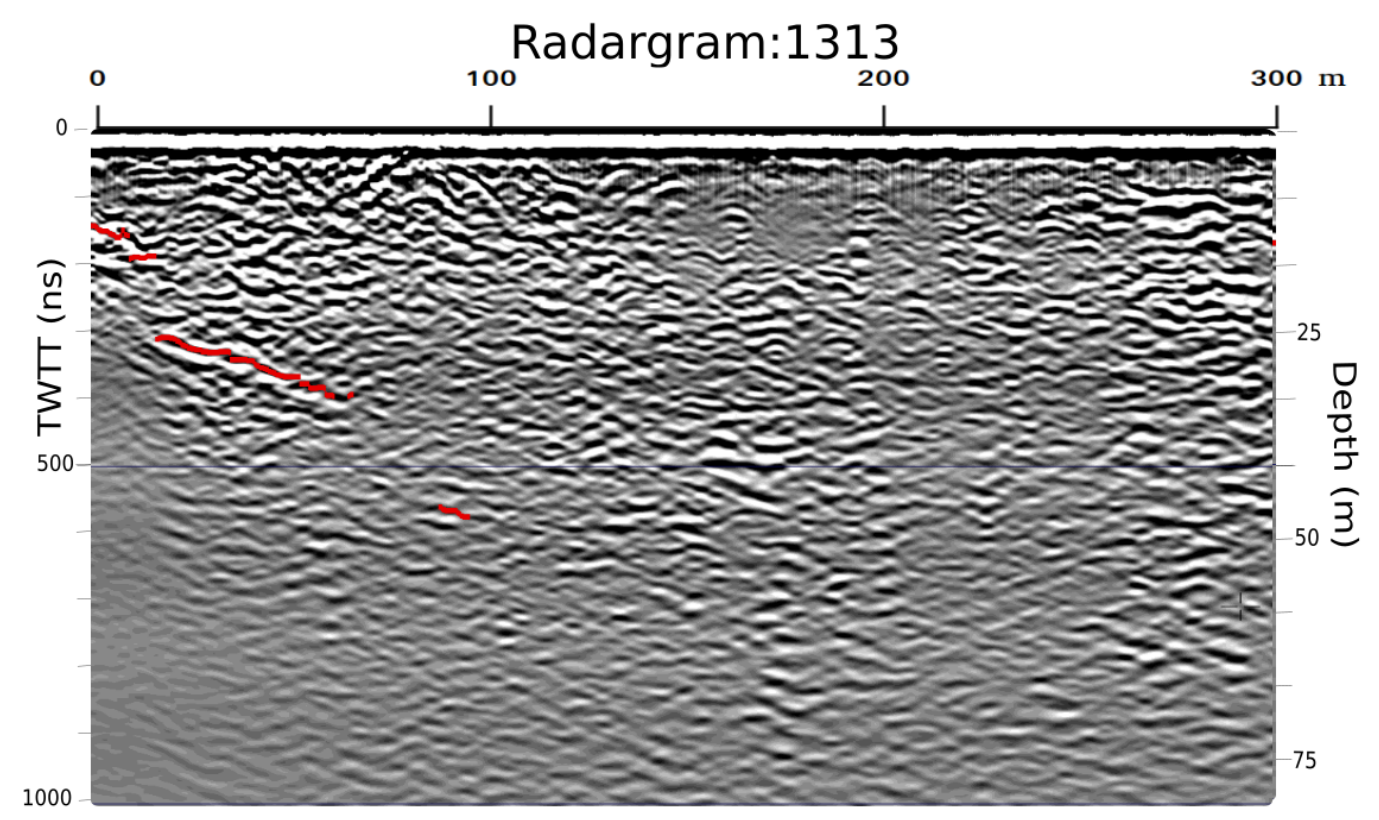

(a)

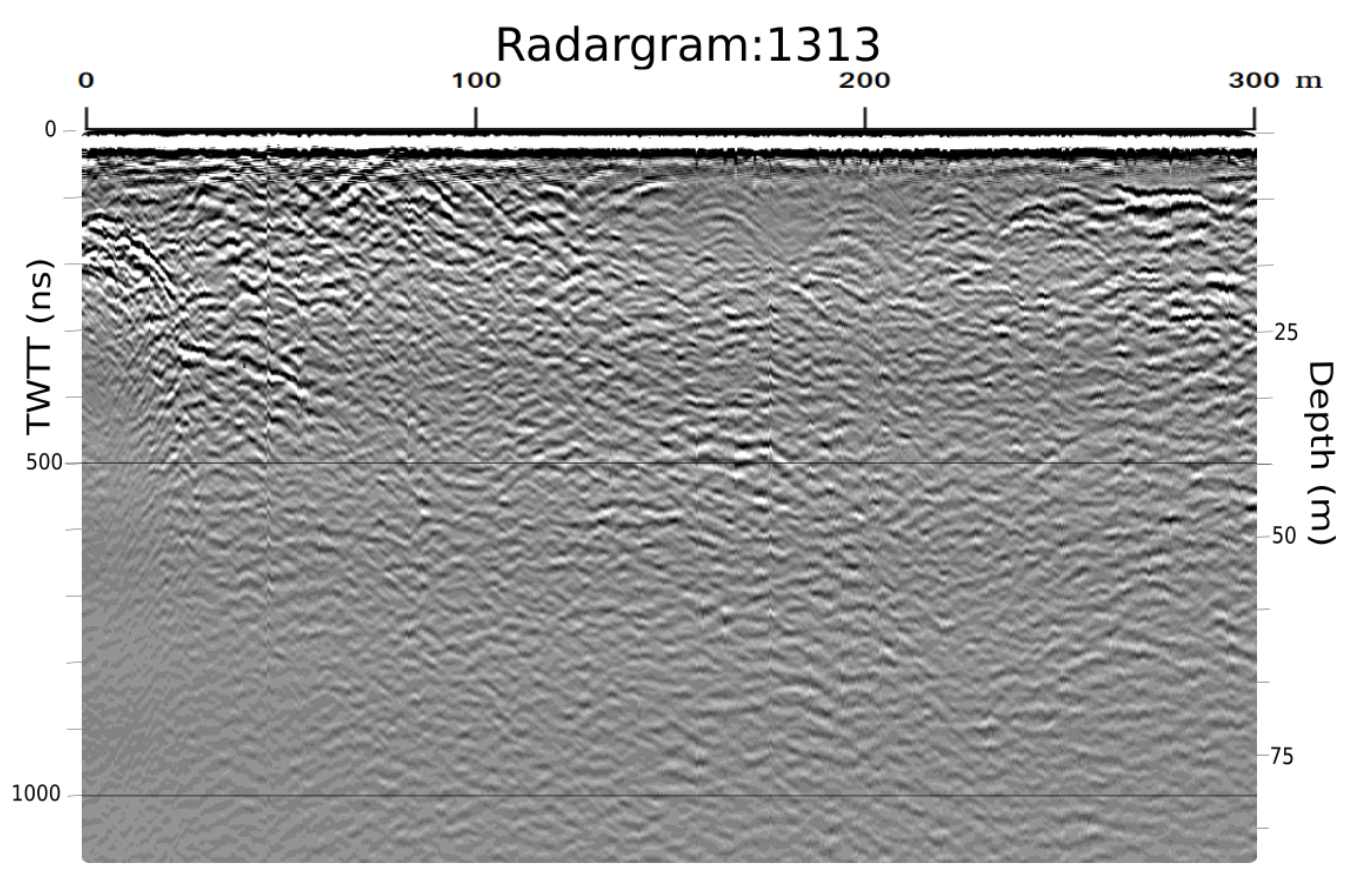

(b)

Figure D.30: Interpreted (a), and non-interpreted (b) radargrams for profile 1313. 


\section{E Supplementary figures}

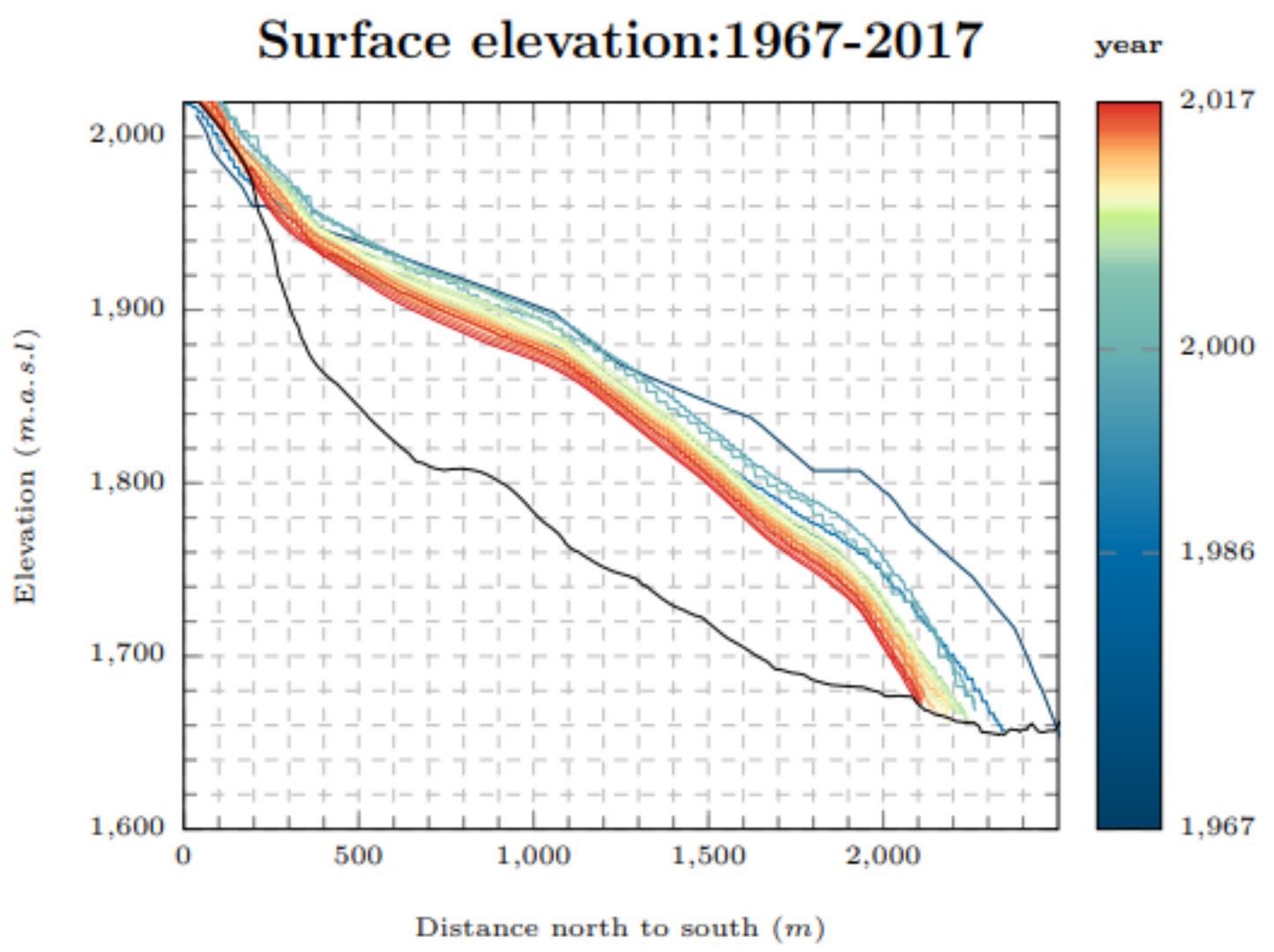

Figure E.1: Surface elevation change history of Brewster Glacier along cross-section line A in Figure 4.5 :1967 to 2017 


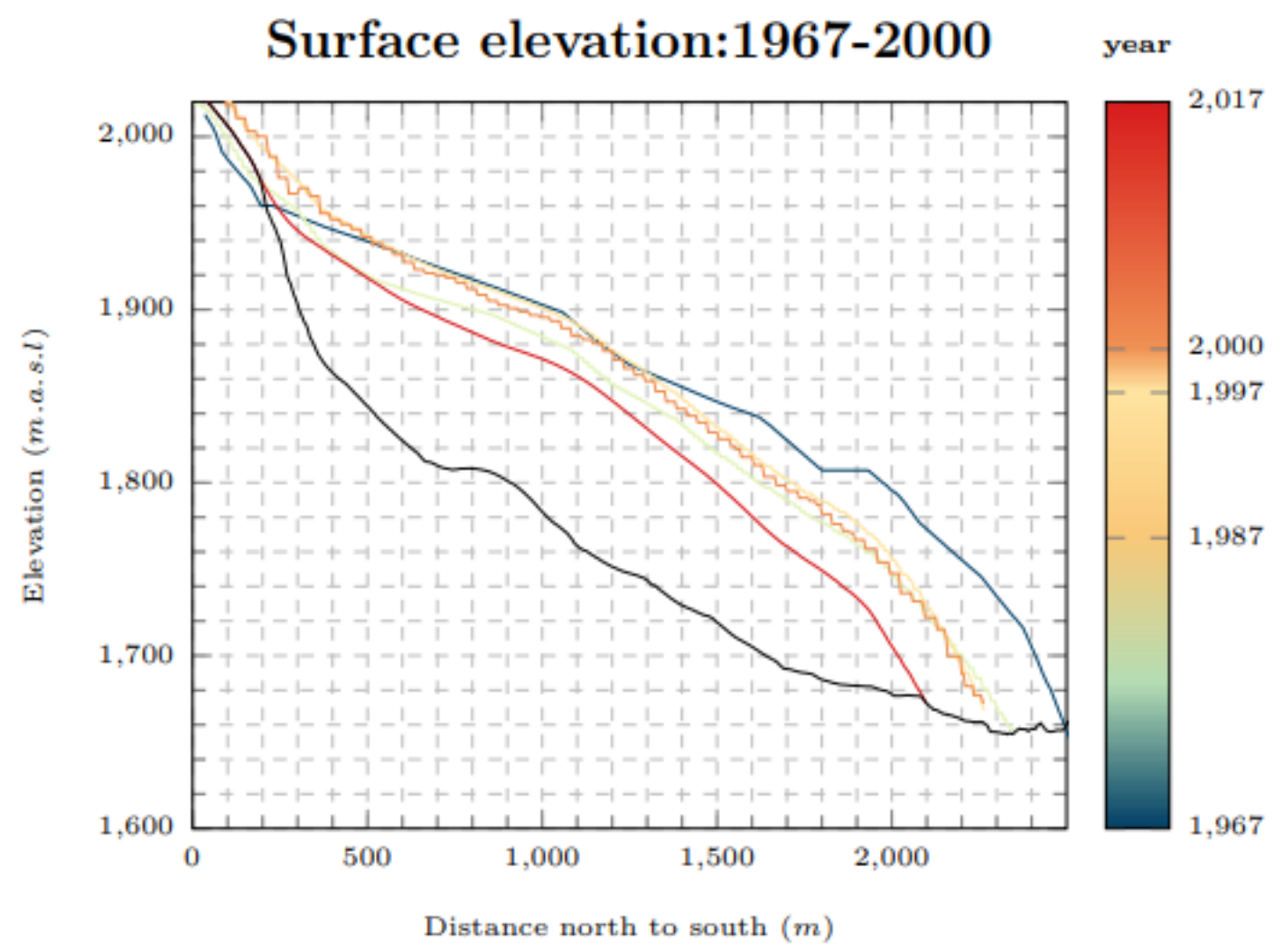

Figure E.2: Surface elevation change history of Brewster Glacier along cross-section line A in Figure 4.5 for years 1967, 1987, 1997, 2000, and 2017. 


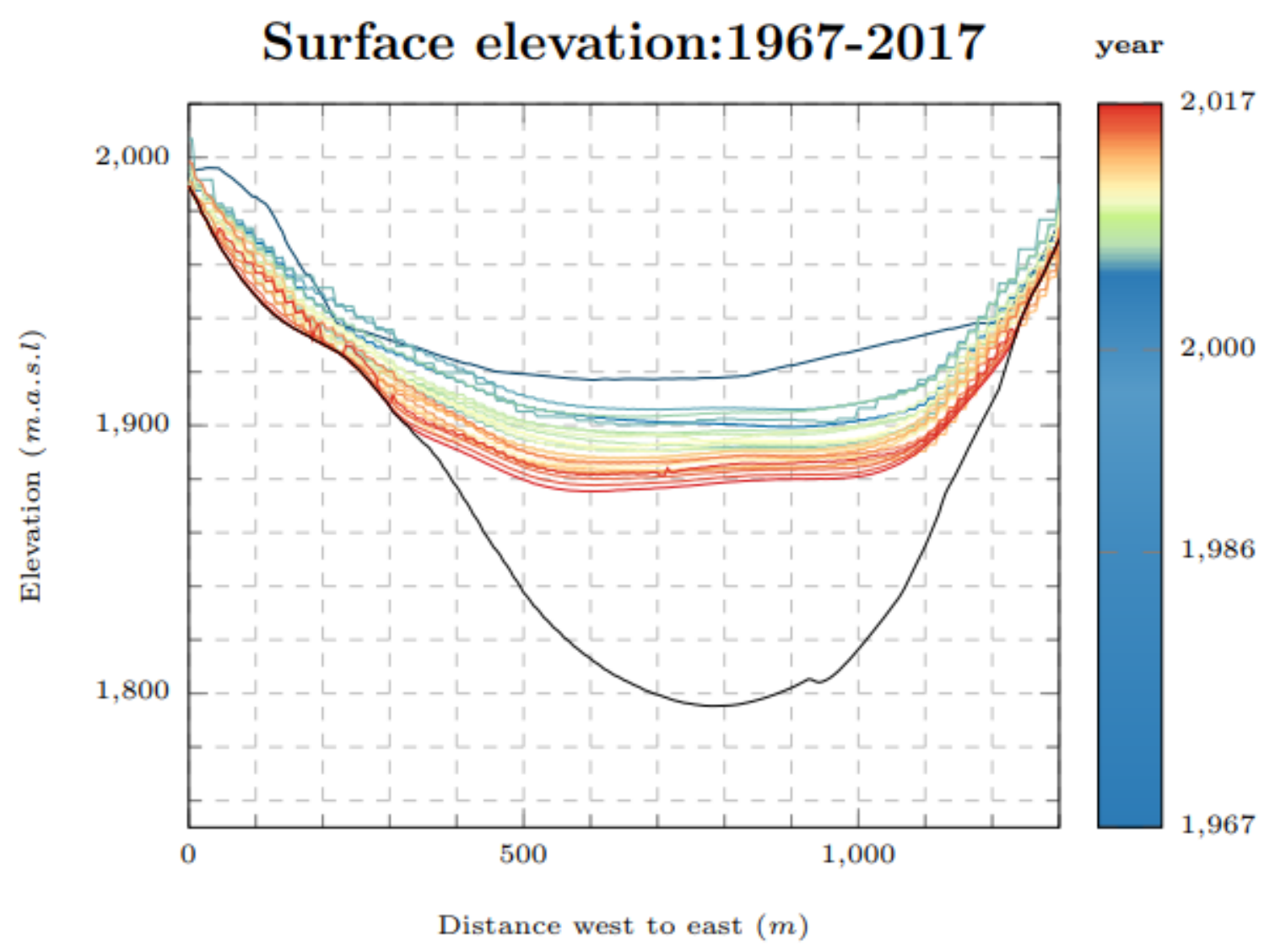

Figure E.3: Surface elevation change history of Brewster Glacier along cross-section line B in Figure 4.5 :1967 to 2017 


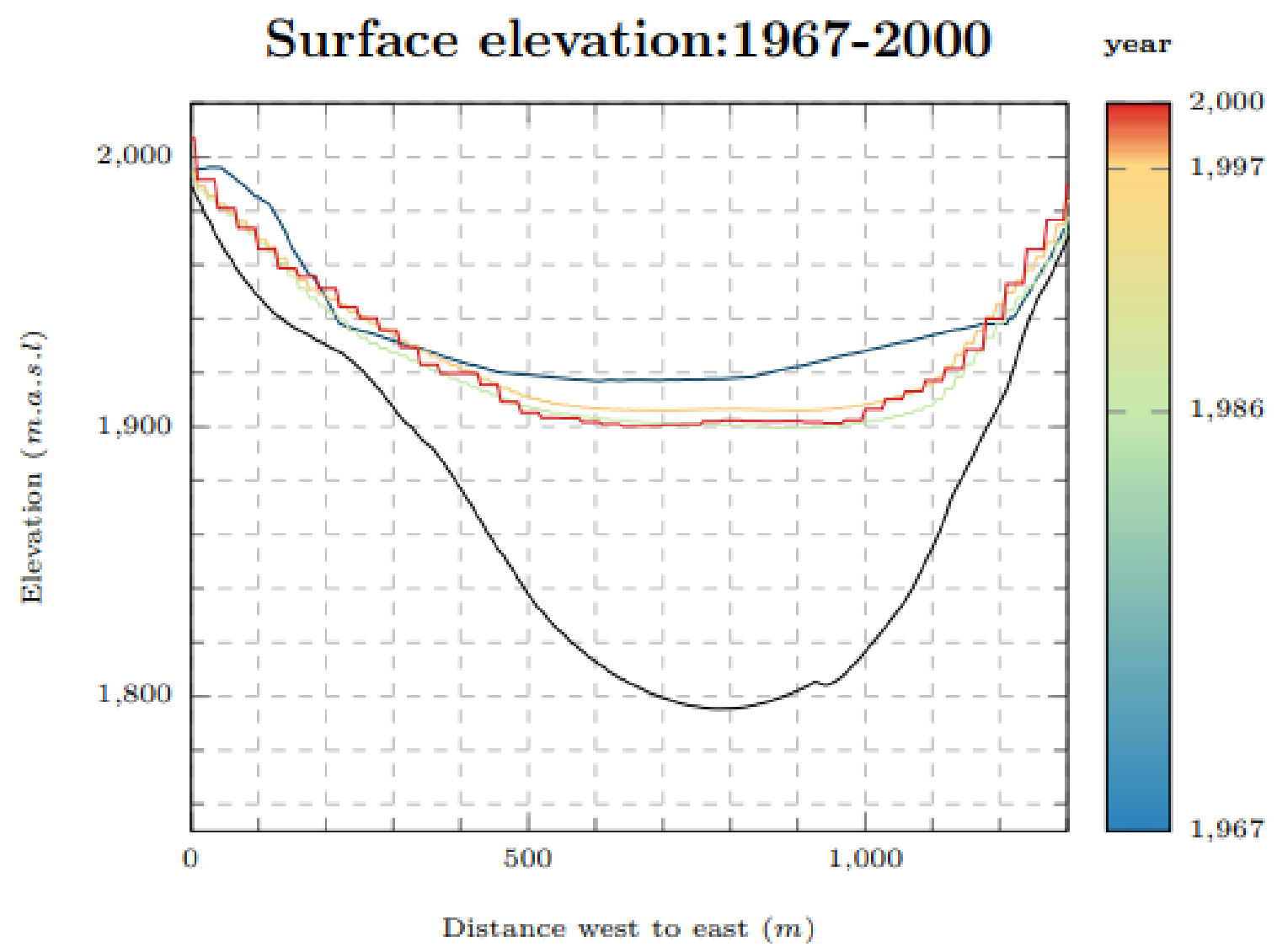

Figure E.4: Surface elevation change history of Brewster Glacier along cross-section line B in Figure 4.5 for years 1967, 1986, 1997, and 2000. 


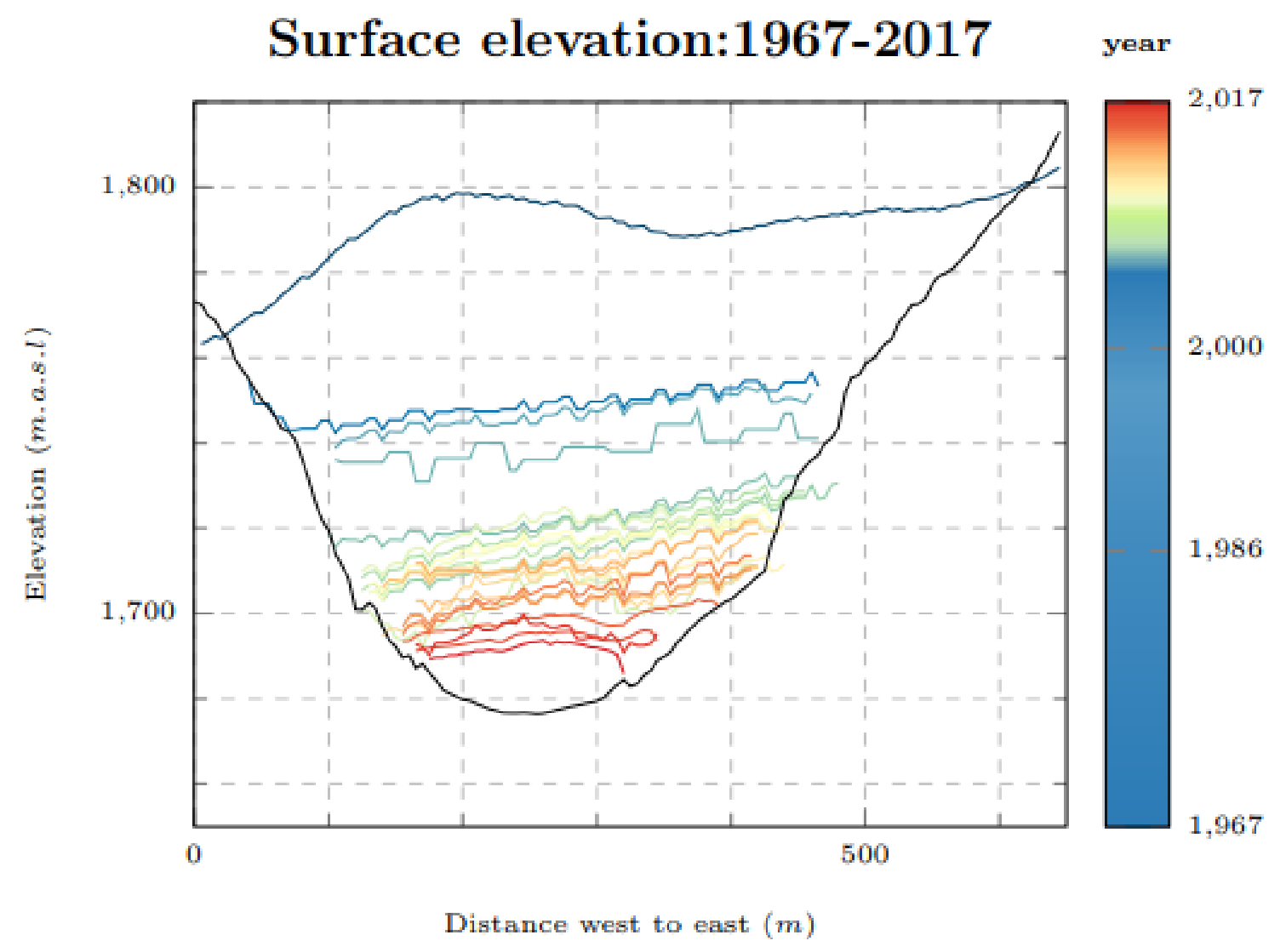

Figure E.5: Surface elevation change history of Brewster Glacier along cross-section line C in Figure 4.5 :1967 to 2017 


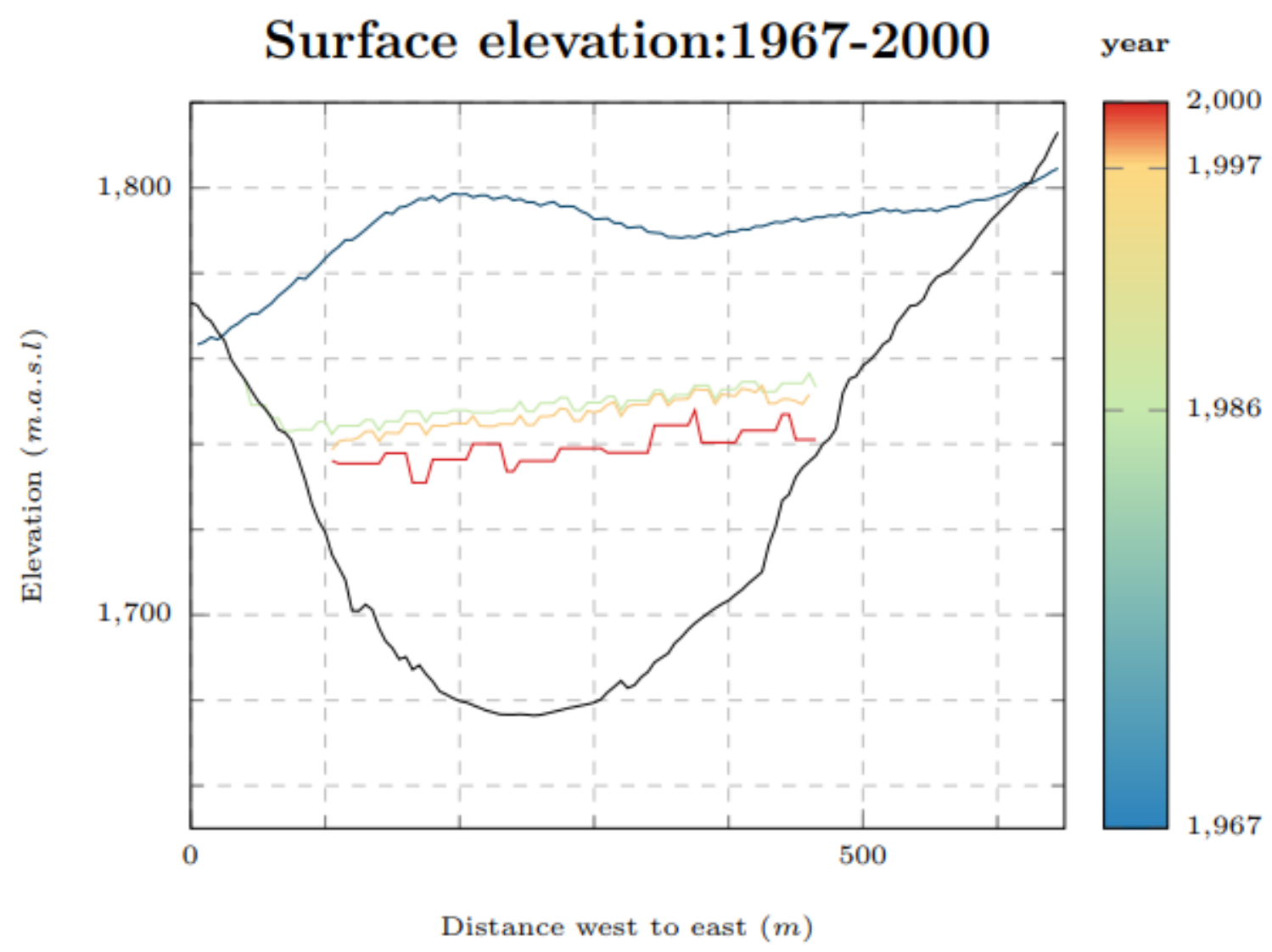

Figure E.6: Surface elevation change history of Brewster Glacier along cross-section line C in Figure 4.5 for years 1967, 1986, 1997, and 2000. 


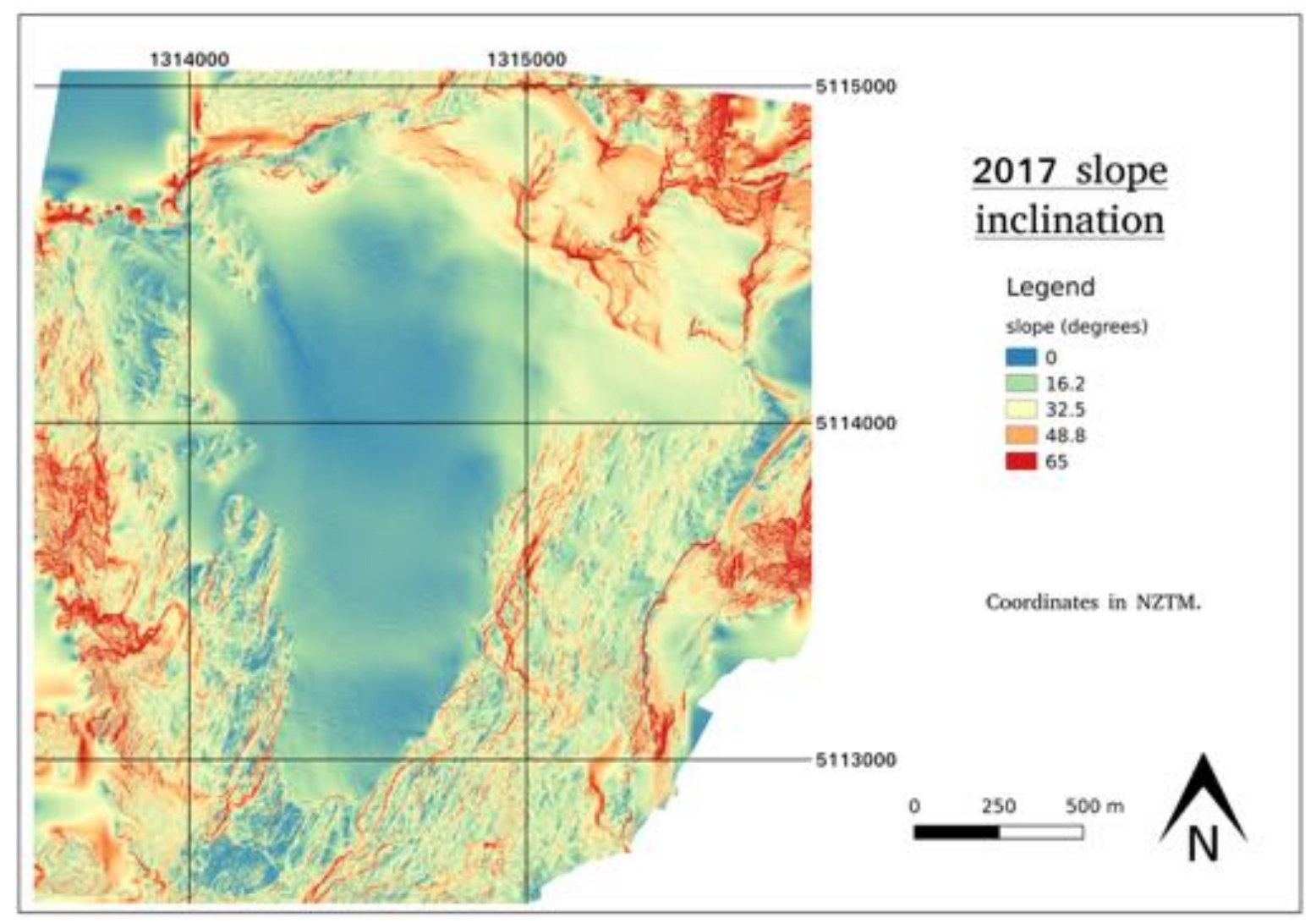

Figure E.7: 2017 slope DEM, derived from the 2017 SfM DEM. 


\section{Bibliography}

Adhikari, S., Marshall, S., and Huybrechts, P. (2009). A comparison of different methods of evaluating glacier response characteristics: application to Glacier AX010, Nepal Himalaya. The Cryosphere Discussions, 3(3):765-804.

Alley, R. B., Clark, P. U., Huybrechts, P., and Joughin, I. (2005). Ice sheet and sea-level changes. Science, 310:456-460.

Anderson, B., Lawson, W., and Owens, I. (2008). Response of Franz Josef Glacier Ka Roimata o Hine Hukatere to climate change. Global and Planetary Change, $63(1): 23-30$.

Anderson, B. and Mackintosh, A. (2006). Temperature change is the major driver of late-glacial and Holocene glacier fluctuations in New Zealand. Geology, 34(2):121124.

Anderson, B. and Mackintosh, A. (2012). Controls on mass balance sensitivity of maritime glaciers in the Southern Alps, New Zealand: The role of debris cover. Journal of Geophysical Research: Earth Surface, 117(F1).

Anderson, B., Mackintosh, A., Stumm, D., George, L., Kerr, T., Winter-Billington, A., and Fitzsimons, S. (2010). Climate sensitivity of a high-precipitation glacier in New Zealand. Journal of Glaciology, 56(195):114-128.

Anderton, P. (1975). Tasman Glacier 1971-73. Ministry of Works and Development for the National Water and Soil Conservation Organisation.

Anderton, P. and Chinn, T. (1978). Ivory Glacier, New Zealand, an IHD representative basin study. Journal of glaciology, 20(82):67-84. 
Andreassen, L. M., Elvehøy, H., Kjøllmoen, B., Engeset, R. V., and Haakensen, N. (2005). Glacier mass-balance and length variation in Norway. Annals of Glaciology, 42(1):317-325.

Arun, P. V. (2013). A comparative analysis of different dem interpolation methods. The Egyptian Journal of Remote Sensing and Space Science, 16(2):133-139.

Basantes-Serrano, R., Rabatel, A., Francou, B., Vincent, C., Maisincho, L., Cáceres, B., Galarraga, R., and Alvarez, D. (2016). Slight mass loss revealed by reanalyzing glacier mass-balance observations on Glacier Antisana $15 \alpha$ (inner tropics) during the 1995-2012 period. Journal of Glaciology, 62(231):124-136.

Basnett, S., Kulkarni, A. V., and Bolch, T. (2013). The influence of debris cover and glacial lakes on the recession of glaciers in Sikkim Himalaya, India. Journal of Glaciology, 59(218):1035-1046.

Benn, D. and Evans, D. J. (2014). Glaciers and glaciation. London, England: Hodder Education.

Benn, D. I. and Evans, D. J. A. (2010). Glaciers and Glaciation. In Glaciers and Glaciation. London, England: Hodder Education.

Berthier, E., Arnaud, Y., Vincent, C., and R/emy, F. (2006). Biases of SRTM in high-mountain areas: Implications for the monitoring of glacier volume changes. Geophysical Research Letters, 33(L08502).

Blachut, T. J. (1971). Mapping and photointerpretation system based on stereoorthophotos. PhD thesis, Juris Verlag.

Blandford, T. R., Humes, K. S., Harshburger, B. J., Moore, B. C., Walden, V. P., and Ye, H. (2008). Seasonal and synoptic variations in near-surface air temperature lapse rates in a mountainous basin. Journal of Applied Meteorology and Climatology, $47(1): 249-261$.

Blewitt, G. (1997). Basics of the GPS technique: observation equations. Geodetic applications of GPS, pages 10-54. 
Bohleber, P., Sold, L., Hardy, D. R., Schwikowski, M., Klenk, P., Fischer, A., Sirguey, P., Cullen, N. J., Potocki, M., Hoffmann, H., et al. (2017). Ground-penetrating radar reveals ice thickness and undisturbed englacial layers at Kilimanjaro's Northern Ice Field. The Cryosphere, 11(1):469-482.

Bohling, G. (2005a). Introduction to geostatistics and variogram analysis. Kansas geological survey. Retrieved from: http://people.ku.edu/gbohling/cpe940/Variograms.pdf.

Bohling, G. (2005b). Kriging. Kansas Geological Survey. Retrieved from: http://people.ku.edu/gbohling/cpe940/Kriging.pdf.

Bolch, T., Buchroithner, M., Pieczonka, T., and Kunert, A. (2008). Planimetric and volumetric glacier changes in the Khumbu Himal, Nepal, since 1962 using Corona, Landsat TM and ASTER data. Journal of Glaciology, 54(187):592-600.

Bristow, C. S. and Jol, H. M. (2003). An introduction to ground penetrating radar (GPR) in sediments. Geological Society, London, Special Publications, 211(1):1-7.

Bristow, C. S., Switzer, A., and Kennedy, D. (2013). Ground penetrating radar. Methods, Treatise of Geomorphology. Maryland Heights, San Diego: Academic, pages $183-194$.

Brodrick (1891). Map of Tasman and Murchison Glaciers. Government Survey. deposited with the Christchurch office of Land Information New Zealand (LINZ).

Brook, M. S. and Paine, S. (2012). Ablation of ice-cored moraine in a humid, maritime climate: fox glacier, new zealand. Geografiska Annaler: Series A, Physical Geography, 94(3):339-349.

Chiles, J.-P. and Delfiner, P. (2009). Geostatistics: modeling spatial uncertainty, volume 497. John Wiley \& Sons.

Chinn, T. (1999). New Zealand glacier response to climate change of the past 2 decades. Global and Planetary Change, 22(1):155-168. 
Chinn, T. (2001). Distribution of the glacial water resources of New Zealand. Journal of Hydrology (NZ), 40(2):139-187.

Chinn, T., Fitzharris, B., Willsman, A., and Salinger, M. (2012). Annual ice volume changes 1976-2008 for the New Zealand Southern Alps. Global and Planetary Change, 92:105-118.

Chinn, T., Winkler, S., Salinger, M., and Haakensen, N. (2005a). Recent glacier advances in Norway and New Zealand: a comparison of their glaciological and meteorological causes. Geografiska Annaler: Series A, Physical Geography, 87(1):141-157.

Chinn, T. J. (1996). New Zealand glacier responses to climate change of the past century. New Zealand Journal of Geology and Geophysics, 39:415-428.

Chinn, T. J., Heydenrych, C., and Salinger, M. J. (2005b). Use of the ELA as a practical method of monitoring glacier response to climate in New Zealand's Southern Alps. Journal of Glaciology, 51(172):85-95.

Chinn, T. J., Kargel, J. S., Leonard, G. J., Haritashya, U. K., and Pleasants, M. (2014). New Zealands glaciers. In Global Land Ice Measurements from Space, pages 675-715. Springer: Berlin, Germany.

Chinn, T. J. H. (1995). Glacier Fluctuations in the Southern Alps of New Zealand Determined from Snowline Elevations. Arctic and Alpine Research, 27(2):187-198.

Clare, G., Fitzharris, B., Chinn, T., and Salinger, M. (2002). Interannual variation in end-of-summer snowlines of the Southern Alps of New Zealand, and relationships with Southern Hemisphere atmospheric circulation and sea surface temperature patterns. International Journal of Climatology, 22(1):107-120.

Clark, M. J. and Randal, J. (2004). A first course in applied statistics.

Cogley, J. G. (2009). Geodetic and direct mass-balance measurements: comparison and joint analysis. Annals of Glaciology, 50(50):96-100. 
Collins, D. N. (1984). Water and Mass Balance Measurements in Glacierised Drainage Basins. Geografiska Annaler. Series A, Physical Geography, 66(3):197-214.

Columbus, J., Siguey, P., and Tenzer, R. (2011). A free fully assessed 15 metre digital elevation model for New Zealand. Survey Quarterly.

Conway, J., Cullen, N., Spronken-Smith, R., and Fitzsimons, S. (2015). All-sky radiation over a glacier surface in the Southern Alps of New Zealand: characterizing cloud effects on incoming shortwave, longwave and net radiation. International Journal of Climatology, 35(5):699-713.

Corr, H., Moore, J. C., and Nicholls, K. W. (1993). Radar absorption due to impurities in antarctic ice. Geophysical research letters, 20(11):1071-1074.

Cox, L. H. and March, R. S. (2004). Comparison of geodetic and glaciological mass-balance techniques, Gulkana Glacier, Alaska, USA. Journal of Glaciology, 50(170):363-370.

Cuffey, K. M. and Paterson, W. S. B. (2010). The physics of glaciers. Academic Press.

Cullen, N. J., Anderson, B., Sirguey, P., Stumm, D., Mackintosh, A., Conway, J. P., Horgan, H. J., Dadic, R., Fitzsimons, S. J., and Lorrey, A. (2016). An 11-year record of mass balance of Brewster Glacier, New Zealand, determined using a geostatistical approach. Journal of Glaciology, pages 1-19.

Cullen, N. J. and Conway, J. P. (2015). A 22 month record of surface meteorology and energy balance from the ablation zone of Brewster Glacier, New Zealand. Journal of Glaciology, 61(229):931-946.

Dadic, R., Mott, R., Lehning, M., and Burlando, P. (2010). Wind influence on snow depth distribution and accumulation over glaciers. Journal of Geophysical Research: Earth Surface, 115(F1).

Dai, A. (2008). Temperature and pressure dependence of the rain-snow phase transition over land and ocean. Geophysical Research Letters, 35(12). 
Dangendorf, S., Marcos, M., Wöppelmann, G., Conrad, C. P., Frederikse, T., and Riva, R. (2017). Reassessment of 20th century global mean sea level rise. Proceedings of the National Academy of Sciences, page 201616007.

Daniels, D. J. (1996). Surface-penetrating radar. Electronics \& Communication Engineering Journal, 8(4):165-182.

Dykes, R. C., Brook, M. S., and Winkler, S. (2010). The contemporary retreat of Tasman Glacier, Southern Alps, New Zealand, and the evolution of Tasman proglacial lake since AD 2000. Erdkunde, pages 141-154.

Dyurgerov, M. B. and Meier, M. F. (2005). Glaciers and the changing Earth system: a 2004 snapshot, volume 58. Institute of Arctic and Alpine Research, University of Colorado Boulder.

Easterling, D. R., Meehl, G. A., Parmesan, C., Changnon, S. A., Karl, T. R., and Mearns, L. O. (2000). Climate extremes: observations, modeling, and impacts. science, 289(5487):2068-2074.

Estey, L. and Weir, S. (2014). Teqc tutorial, basics of teqc use and teqc products.

Fretwell, P., Pritchard, H. D., Vaughan, D. G., Bamber, J., Barrand, N., Bell, R., Bianchi, C., Bingham, R., Blankenship, D., Casassa, G., et al. (2013). Bedmap2: improved ice bed, surface and thickness datasets for antarctica. The Cryosphere, $7(1)$.

Frey, H. and Paul, F. (2012). On the suitability of the SRTM DEM and ASTER GDEM for the compilation of topographic parameters in glacier inventories. International Journal of Applied Earth Observation and Geoinformation, 18:480-490.

Gardner, A. S., Moholdt, G., Cogley, J. G., Wouters, B., Arendt, A. A., Wahr, J., Berthier, E., Hock, R., Pfeffer, W. T., Kaser, G., Ligtenberg, S. R. M., Bolch, T., Sharp, M. J., Hagen, J. O., van den Broeke, M. R., Paul, F., Meier, M. F., Cogley, J. G., Kaser, G., Cogley, J. G., Dyurgerov, M. B., Meier, M. F., Ohmura, A., Jacob, T., Wahr, J., Pfeffer, W. T., Swenson, S., Church, J. A., Zemp, M., 
Hoelzle, M., Haeberli, W., Moholdt, G., Nuth, C., Hagen, J. O., Kohler, J., Sasgen, I., Klemann, V., Martinec, Z., Luthcke, S. B., Arendt, A. A., Rowlands, D. D., McCarthy, J. J., Larsen, C. F., Wouters, B., Chambers, D., Schrama, E. J. O., Gardner, A. S., Moholdt, G., Wouters, B., Gardner, A. S., Bliss, A., Hock, R., Cogley, J. G., Rastner, P., Pritchard, H. D., Ligtenberg, S. R. M., Helsen, M. M., van den Broeke, M. R., Hock, R., de Woul, M., Radić, V., Dyurgerov, M., Rinne, E. J., Bolch, T., Bolch, T., Kääb, A., Berthier, E., Nuth, C., Gardelle, J., Arnaud, Y., Gardelle, J., Berthier, E., Arnaud, Y., Ivins, E. R., Willis, M. J., Melkonian, A. K., Pritchard, M. E., Ramage, J. M., Willis, M. J., Melkonian, A. K., Pritchard, M. E., Rivera, A., Melkonian, A. K., Schiefer, E., Menounos, B., Wheate, R., Berthier, E., Schiefer, E., Clarke, G. K. C., Menounos, B., Remy, F., Rignot, E., Rivera, A., Casassa, G., Gardner, A. S., Moholdt, G., Arendt, A., Wouters, B., Dyurgerov, M. B., Meier, M. F., Cogley, J. G., Adams, W. P., and Shepherd, A. (2013). A reconciled estimate of glacier contributions to sea level rise: 2003 to 2009. Science (New York, N.Y.), 340(6134):852-7.

Gellatly, A. F. (1985). Historical records of glacier fluctuations in Mt Cook National Park, New Zealand: a century of change. Geographical journal, pages 86-99.

Giesen, R. H. and Oerlemans, J. (2013). Climate-model induced differences in the 21st century global and regional glacier contributions to sea-level rise. Climate dynamics, 41(11-12):3283-3300.

Gillett, S. and Cullen, N. J. (2011). Atmospheric controls on summer ablation over Brewster Glacier, New Zealand. International Journal of Climatology, 31(13):20332048.

Goovaerts, P. (1997). Geostatistics for natural resources evaluation. Oxford University Press on Demand.

Granshaw, F. D. and Fountain, A. G. (2006). Glacier change (1958-1998) in the north Cascades national park complex, Washington, USA. Journal of Glaciology, 52(177):251-256. 
Gregory, J. M. and Oerlemans, J. (1998). Simulated future sea-level rise due to glacier melt based on regionally and seasonally resolved temperature changes. Nature, 391(6666):474-476.

Gruber, S., Ludwig, F., and Moore, J. (1996). Application of ground penetrating radar in glaciology and permafrost prospecting. Study paper for the Arctic studies programme at the Arctic centre, Rovaniemi, Finland.

Haast, J. (1864). Notes on the mountains and glaciers of the Canterbury Province, New Zealand. The Journal of the Royal Geographical Society of London, 34:87-96.

Haeberli, W. and Hölzle, M. (1995). Application of inventory data for estimating characteristics of and regional climate-change effects on mountain glaciers: a pilot study with the European Alps. Annals of glaciology, 21(1):206-212.

Hagg, W. J., Braun, L. N., Uvarov, V. N., and Makarevich, K. G. (2004). A comparison of three methods of mass-balance determination in the Tuyuksu glacier region, Tien Shan, Central Asia. Journal of Glaciology, 50(171):505-510.

Haining, R. P., Kerry, R., and Oliver, M. A. (2010). Geography, spatial data analysis, and geostatistics: An overview. . Geographical Analysis, 42(1):7-31.

Harper, A. (1893). Exploration and character of the principal New Zealand glaciers. The Geographical Journal, 1(1):32-42.

Harper, A. P. (1896). Pioneer work in the Alps of New Zealand: a record of the first exploration of the chief glaciers and ranges of the Southern Alps. TF Unwin.

Henderson, R. and Thompson, S. (1999). Extreme rainfalls in the southern alps of new zealand. Journal of Hydrology (NZ), 38(2):309-330.

Herron, M. M. and Langway, C. C. (1980). Firn densification: an empirical model. Journal of Glaciology, 25(93):373-385.

Hessell, J. (1983). Climatic effects on the recession of the Franz Josef Glacier. New Zealand journal of science, 26(3):315-320. 
Hock, R. and Jensen, H. (1999). Application of kriging interpolation for glacier mass balance computations. Geografiska Annaler: Series A, Physical Geography, 81(4):611-619.

Hooke, R. L. (2005). Principles of glacier mechanics. Cambridge university press.

Hooker, B. and Fitzharris, B. (1999). The correlation between climatic parameters and the retreat and advance of Franz Josef Glacier, New Zealand. Global and Planetary Change, 22(1):39-48.

Huss, M. (2013). Density assumptions for converting geodetic glacier volume change to mass change. The Cryosphere, 7(3):877-887.

Huss, M. and Hock, R. (2015). A new model for global glacier change and sea-level rise. Frontiers in Earth Science, 3:54.

Irvine-Fynn, T., Moorman, B., Williams, J., and Walter, F. (2006). Seasonal changes in ground-penetrating radar signature observed at a polythermal glacier, Bylot Island, Canada. Earth Surface Processes and Landforms, 31(7):892-909.

Isaaks, E. H. and Srivastava, R. M. (1989). Applied geostatistics.

Ishikawa, N., Owens, I., and Sturman, A. (1992). Heat balance characteristics during fine periods on the lower parts of the Franz Josef Glacier, South Westland, New Zealand. International Journal of Climatology, 12(4):397-410.

Jacob, T., Wahr, J., Pfeffer, W. T., and Swenson, S. (2012). Recent contributions of glaciers and ice caps to sea level rise. Nature, 482(7386):514.

Jacobel, R. W., Welch, B. C., Osterhouse, D., Pettersson, R., and MacGregor, J. A. (2009). Spatial variation of radar-derived basal conditions on Kamb Ice Stream, West Antarctica. Annals of Glaciology, 50(51):10-16.

Janssen, V. and Rizos, C. (2003). A mixed-mode GPS network processing approach for deformation monitoring applications. Survey Review, 37(287):2-19. 
Jenness, J. S. (2004). Calculating landscape surface area from digital elevation models. Wildlife Society Bulletin, 32(3):829-839.

Jóhannesson, T., Raymond, C., and Waddington, E. (1989a). A simple method for determining the response time of glaciers. In Glacier fluctuations and climatic change, pages 343-352. Springer.

Jóhannesson, T., Raymond, C., and Waddington, E. (1989b). Time-scale for adjustment of glaciers to changes in mass balance. Journal of Glaciology, 35(121):355-369.

Johnston, K., Ver Hoef, J. M., Krivoruchko, K., and Lucas, N. (2001). Using ArcGIS geostatistical analyst, volume 380. Esri Redlands.

Jol, H. M. and Bristow, C. S. (2003). GPR in sediments: advice on data collection, basic processing and interpretation, a good practice guide. Geological Society, London, Special Publications, 211(1):9-27.

Joughin, I. and Alley, R. B. (2011). Stability of the West Antarctic ice sheet in a warming world. Nature Geoscience, 4:506-513.

Kaplan, M. R., Schaefer, J. M., Denton, G. H., Barrell, D. J., Chinn, T. J., Putnam, A. E., Andersen, B. G., Finkel, R. C., Schwartz, R., and Doughty, A. M. (2010). Glacier retreat in New Zealand during the Younger Dryas stadial. Nature, 467(7312):194.

Karim, M. F. and Mimura, N. (2008). Impacts of climate change and sea-level rise on cyclonic storm surge floods in Bangladesh. Global Environmental Change, 18(3):490500.

Kayastha, R. B. and Harrison, S. P. (2008). Changes of the equilibrium-line altitude since the Little Ice Age in the Nepalese Himalaya. Annals of Glaciology, 48(1):93-99.

Kayastha, R. B., Takeuchi, Y., Nakawo, M., and Ageta, Y. (2000). Practical prediction of ice melting beneath various thickness of debris cover on Khumbu Glacier, Nepal, using a positive degree-day factor. IAHS PUBLICATION, pages 71-82. 
Kearey, P., Brooks, M., and Hill, I. (2013). An introduction to geophysical exploration. John Wiley \& Sons.

Kip, A. (1962). Fundamentals of Electricity and Magnetism: Manual. McGraw-Hill series in fundamentals of physics : introductory program. McGraw-Hill Interamericana.

Kirkbride, M. (1989). The influence of sediment budget on geomorphic activity of the tasman glacier, mount cook national park, new zealand.

Kirkbride, M. P. (1993). The temporal significance of transitions from melting to calving termini at glaciers in the central Southern Alps of New Zealand. The Holocene, $3(3): 232-240$.

Kirkbride, M. P. and Warren, C. R. (1999). Tasman Glacier, New Zealand: 20thcentrury thinning and predicted calving retreat. Global and Planetary Change, $22: 11-28$.

Koblet, T., Gärtner-Roer, I., Zemp, M., Jansson, P., Thee, P., Haeberli, W., and Holmlund, P. (2010). Reanalysis of multi-temporal aerial images of Storglaciären, Sweden (1959-99)-Part 1: Determination of length, area, and volume changes. The Cryosphere, 4(3):333-343.

Koenderink, J. J. and Van Doorn, A. J. (1991). Affine structure from motion. JOSA A, 8(2):377-385.

Kuhn, M. (2003). Redistribution of snow and glacier mass balance from a hydrometeorological model. Journal of Hydrology, 282(1):95-103.

Lee, H., CHOI, Y., Ham, G., Yun, S., et al. (2017). Experimental assessment of achievable accuracy of gnss-derived heights from carrier phase-based positioning techniques for ellipsoidally referenced hydrographic surveys.

Leick, A., Rapoport, L., and Tatarnikov, D. (2015). GPS satellite surveying. John Wiley \& Sons. 
Li, J. and Heap, A. D. (2008). A review of spatial interpolation methods for environmental scientists.

Li, J. and Heap, A. D. (2014). Spatial interpolation methods applied in the environmental sciences: A review. Environmental Modelling \& Software, 53:173-189.

Linsbauer, A., Frey, H., Haeberli, W., Machguth, H., Azam, M., and Allen, S. (2016). Modelling glacier-bed overdeepenings and possible future lakes for the glaciers in the HimalayaKarakoram region. Annals of Glaciology, 57(71):119-130.

LINZ (2016). Convert coordinates between NZ coordinate systems.

LINZ (2017). LINZ Data Service.

Loewe, F. (1938). The amount of rime and snowdrift as factors in the mass balance of glaciers. Inst. Ass. of Hydrology Bull., 23:415-421.

Löwy, H. and Leimbach, G. (1910). Eine elektrodynamische Methode zur Erforschung des Erdinnern. na.

Lu, G. Y. and Wong, D. W. (2008). An adaptive inverse-distance weighting spatial interpolation technique. Computers \& Geosciences, 34(9):1044-1055.

Mackintosh, A. N., Anderson, B. M., Lorrey, A. M., Renwick, J. A., Frei, P., and Dean, S. M. (2017). Regional cooling caused recent New Zealand glacier advances in a period of global warming. Nature Communications, 8:14202.

Maisch, M. (2000). The long-term signal of climate change in the Swiss Alps: Glacier retreat since the end of the Little Ice Age and future ice decay scenarios. Geogr. Fis. Dinam. Quat, 23:139-151.

Marzeion, B., Champollion, N., Haeberli, W., Langley, K., Leclercq, P., and Paul, F. (2017). Observation-based estimates of global glacier mass change and its contribution to sea-level change. Surveys in Geophysics, 38(1):105-130.

Maslen, G. (2013). Globe Claritas 2D marine processing. Institute of Geological \& Nuclear Sciences. 
Mason, I. G., Page, S., and Williamson, A. (2010). A 100\% renewable electricity generation system for New Zealand utilising hydro, wind, geothermal and biomass resources. Energy Policy, 38(8):3973-3984.

Matheron, G. (1963). Principles of geostatistics. Economic geology, 58(8):1246-1266.

Matsuoka, K., Pattyn, F., Callens, D., and Conway, H. (2012). Radar characterization of the basal interface across the grounding zone of an ice-rise promontory in East Antarctica. Annals of glaciology, 53(60):29-34.

Matsuoka, T., Fujita, S., and Mae, S. (1997). Dielectric properties of ice containing ionic impurities at microwave frequencies. The Journal of Physical Chemistry B, 101(32):6219-6222.

Mattson, L. (1993). Ablation on debris covered glaciers: an example from the Rakhiot Glacier, Punjab, Himalaya. Intern. Assoc. Hydrol. Sci., 218:289-296.

McClung, D. and Armstrong, R. L. (1993). Temperate glacier time response from field data. Journal of Glaciology, 39(132):323-326.

McColl, S. T., Fuller, I. C., Anderson, B., and Tate, R. (2017). Hillslope failure and paraglacial reworking of sediments in response to glacier retreat, Fox Valley, New Zealand. In EGU General Assembly Conference Abstracts, volume 19, page 170.

McGranahan, G., Balk, D., and Anderson, B. (2007). The rising tide: assessing the risks of climate change and human settlements in low elevation coastal zones. Environment and urbanization, 19(1):17-37.

McKillup, S. and Dyar, M. D. (2010). Geostatistics explained: an introductory guide for earth scientists. Cambridge University Press.

Meier, M. (1961). Mass budget of South Cascade Glacier, 1957-60. US Geological Survey Professional Paper, 424:206-21.

Meier, M. F., Dyurgerov, M. B., Rick, U. K., O’Neel, S., Pfeffer, W. T., Anderson, 
R. S., Anderson, S. P., and Glazovsky, A. F. (2007). Glaciers Dominate Eustatic Sea-Level Rise in the 21st Century. Science, 317:1064-1067.

Miège, C., Forster, R. R., Brucker, L., Koenig, L. S., Solomon, D. K., Paden, J. D., Box, J. E., Burgess, E. W., Miller, J. Z., McNerney, L., et al. (2016). Spatial extent and temporal variability of greenland firn aquifers detected by ground and airborne radars. Journal of Geophysical Research: Earth Surface.

Moorman, B. J. and Michel, F. A. (2000). Glacial hydrological system characterization using ground-penetrating radar. Hydrological Processes, 14(15):2645-2667.

Moran, M., Greenfield, R., Arcone, S., and Delaney, A. (2000). Delineation of a complexly dipping temperate glacier bed using short-pulse radar arrays. Journal of Glaciology, 46(153):274-286.

Müller, F. (1962). Glacier mass-budget studies on Axel Heiberg Island, Canadian arctic archipelago. publisher not identified.

Nakawo, M. and Young, G. J. (1981). Field experiments to determine the effect of a debris layer on ablation of glacier ice. Annals of Glaciology, 2(1):85-91.

NASA (2017). Landsat science.

Nicholls, R. J., Marinova, N., Lowe, J. A., Brown, S., Vellinga, P., De Gusmao, D., Hinkel, J., and Tol, R. S. (2011). Sea-level rise and its possible impacts given a beyond $4 \mathrm{C}$ worldin the twenty-first century. Philosophical Transactions of the Royal Society of London A: Mathematical, Physical and Engineering Sciences, 369(1934):161-181.

Nolan, M., Motkya, R. J., Echelmeyer, K., and Trabant, D. C. (1995). Ice-thickness measurements of Taku Glacier, Alaska, USA, and their relevance to its recent behavior. Journal of Glaciology, 41(139):541-553.

Nolin, A. W. and Payne, M. C. (2007). Classification of glacier zones in western Greenland using albedo and surface roughness from the Multi-angle Imaging SpectroRadiometer (MISR). Remote Sensing of Environment, 107(1):264-275. 
NRCan (2016). Canadian Active Control System Products, Geodetic Survey Division, Geomatics Canada, Natural Resources Canada.

Nye, J. (1960). The response of glaciers and ice-sheets to seasonal and climatic changes. In Proceedings of the Royal Society of London A: Mathematical, Physical and Engineering Sciences, volume 256, pages 559-584. The Royal Society.

Oerlemans, J. (1992). Climate sensitivity of glaciers in southern Norway: application of an energy-balance model to Nigardsbreen, Hellstugubreen and Alfotbreen. Journal of Glaciology, 38(129):223-232.

Oerlemans, J. (2001). Glaciers and climate change. CRC Press.

Oerlemans, J. (2005). Extracting a climate signal from 169 glacier records. Science, 308(5722):675-677.

Oerlemans, J. (2010). The microclimate of valley glaciers. IGITUR, Universiteitsbibliotheek Utrecht.

Oerlemans, J. and Hoogendoorn, N. (1989). Mass-balance gradients and climatic change. Journal of Glaciology, 35(121):399-405.

O'Hare, G., Sturman, A., and Tapper, N. (1997). The Weather and Climate of Australia and New Zealand.

Ohmura, A. (2001). Physical basis for the temperature-based melt-index method. Journal of applied Meteorology, 40(4):753-761.

Östrem, G. (1959). Ice melting under a thin layer of moraine, and the existence of ice cores in moraine ridges. Geografiska Annaler, 41(4):228-230.

Otsu, N. (1975). A threshold selection method from gray-level histograms. Automatica, 11(285-296):23-27.

Paterson, W. S. B. (1994a). The Physics of Glaciers. Pergamon, Tarrytown, N. Y., 3rd edition. 
Paterson, W. S. B. (1994b). Physics of Glaciers, Third Edition.

Piermattei, L., Carturan, L., de Blasi, F., Tarolli, P., Dalla Fontana, G., Vettore, A., and Pfeifer, N. (2016). Suitability of ground-based SfM-MVS for monitoring glacial and periglacial processes. Earth Surface Dynamics, 4(2):425-443.

Piermattei, L., Carturan, L., and Guarnieri, A. (2015). Use of terrestrial photogrammetry based on structure-from-motion for mass balance estimation of a small glacier in the Italian alps. Earth Surface Processes and Landforms, 40(13):1791-1802.

Plewes, L. A. and Hubbard, B. (2001). A review of the use of radio-echo sounding in glaciology. Progress in Physical Geography, 25(2):203-236.

Porter, S. C. (1986). Pattern and forcing of Northern Hemisphere glacier variations during the last millennium. Quaternary Research, 26(1):27-48.

Purdie, H. (2013). Glacier retreat and tourism: Insights from New Zealand. Mountain Research and Development, 33(4):463-472.

Purdie, H., Anderson, B., Chinn, T., Owens, I., Mackintosh, A., and Lawson, W. (2014). Franz Josef and Fox Glaciers, New Zealand: Historic length records. Global and Planetary Change, 121:41-52.

Purdie, H., Bealing, P., Tidey, E., Gomez, C., and Harrison, J. (2016). Bathymetric evolution of Tasman Glacier terminal lake, New Zealand, as determined by remote surveying techniques. Global and Planetary Change, 147:1-11.

Purdie, H., Brook, M., and Fuller, I. (2008). Seasonal variation in ablation and surface velocity on a temperate maritime glacier: Fox Glacier, New Zealand. Arctic, Antarctic, and Alpine Research, 40(1):140-147.

Purdie, H., Gomez, C., and Espiner, S. (2015a). Glacier recession and the changing rockfall hazard: Implications for glacier tourism. New Zealand Geographer, 71(3):189-202. 
Purdie, H., Mackintosh, A., Lawson, W., Anderson, B., Morgenstern, U., Chinn, T., and Mayewski, P. (2011). Interannual variability in net accumulation on Tasman Glacier and its relationship with climate. Global and Planetary Change, 77(3):142152.

Purdie, H., Rack, W., Anderson, B., Kerr, T., Chinn, T., Owens, I., and Linton, M. (2015b). The impact of extreme summer melt on net accumulation of an avalanche fed glacier, as determined by ground-penetrating radar. Geografiska Annaler: Series A, Physical Geography, 97(4):779-791.

Radic, V., Bliss, A., Beedlow, A. C., Hock, R., Miles, E., and Cogley, J. G. (2014). Regional and global projections of twenty-first century glacier mass changes in response to climate scenarios from global climate models. Climate Dynamics, 42(1-2):37-58.

Radić, V. and Hock, R. (2010). Regional and global volumes of glaciers derived from statistical upscaling of glacier inventory data. Journal of Geophysical Research: Earth Surface, 115(F1).

Raper, T. W. C. (1993). Future changes in global mean temperature and sea level. Climate and sea level change: observations, projections and implications, page 111.

Rashid, H. (2010). 3-D Surface-area computation of the state of Jammu \& Kashmir using Shuttle Radar Topographic Mission (SRTM) data in Geographical Information System (GIS). Journal of Geomatics, 4(2):77-82.

Raymond, C., Catania, G. A., Nereson, N., and van der Veen, C. J. (2006). Bed radar reflectivity across the north margin of Whillans Ice Stream, West Antarctica, and implications for margin processes. Journal of Glaciology, 52(176):3-10.

Riebeek, H. (2010). Global warming: Feature articles. retrieved from: https://earthobservatory.nasa.gov/features/globalwarming/page5.php.

Rivoirard, J. and Cours, C. (2003). Course on multivariate geostatistics. Cours C-173, Centre de Géostatistique, Ecole des Mines de Paris, Fontainebleau. 
Salinger, J., Chinn, T., Willsman, A., and Fitzharris, B. (2008). Glacier response to climate change. Water \& Atmosphere, 16(3):16-17.

Salinger, M., Heine, M., and Burrows, C. (1983). Variations of the stocking (Te Wae Wae) Glacier, Mount Cook, and climatic relationships. New Zealand journal of science, 26(3):321-338.

Scaramuzza, P. and Barsi, J. (2005). Landsat 7 scan line corrector-off gap-filled product development. In Proceeding of Pecora, volume 16, pages 23-27.

Schaefer, J. M., Denton, G. H., Kaplan, M., Putnam, A., Finkel, R. C., Barrell, D. J., Andersen, B. G., Schwartz, R., Mackintosh, A., Chinn, T., et al. (2009). Highfrequency Holocene glacier fluctuations in New Zealand differ from the northern signature. science, 324(5927):622-625.

Schwander, J., Sowers, T., Barnola, J.-M., Blunier, T., Fuchs, A., and Malaizé, B. (1997). Age scale of the air in the summit ice: Implication for glacial-interglacial temperature change. Journal of Geophysical Research: Atmospheres, 102(D16):1948319493.

Shumskiy, P. (1960). Density of glacier ice. Journal of Glaciology, 3(27):568-573.

Sinclair, M. R., Wratt, D. S., Henderson, R. D., and Gray, W. R. (1997). Factors affecting the distribution and spillover of precipitation in the Southern Alps of New Zealand A case study. Journal of applied meteorology, 36(5):428-442.

Stern, W. (1930). Principles, methods and results of electrodynamic thickness measurement of glacier ice. Zeitschrift fur Gletscherkunde, 18:24.

Stewart, E. J., Wilson, J., Espiner, S., Purdie, H., Lemieux, C., and Dawson, J. (2016). Implications of climate change for glacier tourism. Tourism Geographies, 18(4):377398.

Stuart, G., Murray, T., Gamble, N., Hayes, K., and Hodson, A. (2003). Characterization of englacial channels by ground-penetrating radar: An example from austre Brøggerbreen, Svalbard. Journal of Geophysical Research: Solid Earth, 108(B11). 
Stumm, D. (2011). The mass balance of selected glaciers of the Southern Alps in New Zealand. PhD thesis, University of Otago.

Suggate, R. (1990). Late pliocene and quaternary glaciations of New Zealand. Quaternary science reviews, 9(2-3):175-197.

Tachikawa, T., Kaku, M., Iwasaki, A., Gesch, D. B., Oimoen, M. J., Zhang, Z., Danielson, J. J., Krieger, T., Curtis, B., Haase, J., et al. (2011). ASTER global digital elevation model version 2-summary of validation results. Technical report, NASA.

Tobler, W. R. (1970). A computer movie simulating urban growth in the Detroit region. Economic geography, 46(sup1):234-240.

UNAVCO (2017). Geoid height calculator. Taken from: https://www.unavco.org/software/geodetic-utilities/geoid-height-calculator/geoidheight-calculator.html.

Van Zyl, J. J. (2001). The Shuttle Radar Topography Mission (SRTM): a breakthrough in remote sensing of topography. Acta Astronautica, 48(5-12):559-565.

Vargo, L. J., Anderson, B. M., Horgan, H. J., Mackintosh, A. N., Lorrey, A. M., and Thornton, M. (2017). Using structure from motion photogrammetry to measure past glacier changes from historic aerial photographs. Journal of Glaciology, 63(242):1105-1118.

Vaughan, D., Comiso, J., Allison, I., Carrasco, J., Kaser, G., Kwok, R., Mote, P., Murray, T., Paul, F., Ren, J., Rignot, E., Solomina, O., Steffen, K., and Zhang, T. (2013a). Observations: Cryosphere. Climate Change 2013: The Physical Science Basis. Contribution of Working Group I to the Fifth Assessment Report of the Intergovernmental Panel on Climate Change, pages 317-382.

Vaughan, D. G., Comiso, J. C., Allison, I., Carrasco, J., Kaser, G., Kwok, R., Mote, P., Murray, T., Paul, F., Ren, J., et al. (2013b). Observations: cryosphere. Climate change, 2103:317-382. 
Vaughan, D. G., Corr, H. F. J., Ferraccioli, F., Frearson, N., O'Hare, A., Mach, D., Holt, J. W., Blankenship, D. D., Morse, D., and Young, D. A. (2006). New boundary conditions for the West Antarctic Ice Sheet: Subglacial topography beneath Pine Island Glacier. Geophysical Res. Lett., 33(L09501).

Wakahama, G. (1968). The metamorphism of wet snow. IAHS Publication, 79:370-379.

Webster, R. and Oliver, M. A. (2007). Geostatistics for environmental scientists. John Wiley \& Sons.

Westoby, M., Brasington, J., Glasser, N., Hambrey, M., and Reynolds, J. (2012). Structure-from-Motionphotogrammetry: A low-cost, effective tool for geoscience applications. Geomorphology, 179:300-314.

Willis, I., Owens, I., Clendon, P., and Lawson, W. (2012). Mass Balance of Brewster Glacier, New Zealand revealed by Geodetic Methods.

Willis, I. C., Arnold, N. S., and Brock, B. W. (2002). Effect of snowpack removal on energy balance, melt and runoff in a small supraglacial catchment. Hydrological Processes, 16(14):2721-2749.

Willis, I. C., Lawson, W., Owens, I., Jacobel, R. W., and Autridge, J. (2009). Subglacial drainage system structure and morphology of Brewster Glacier, New Zealand. Hydrological Processes, 23(3):384-396.

Willsman, A., Chinn, T., and Lorrey, A. (2015). New Zealand Glacier Monitoring: End of Summer Snowline Survey 2013. Report prepared for New Zealand Ministry of Business, Innovation and Employment CHC2015-122, NIWA, Christchurch, New Zealand, 5 .

Wright, J. (2015). Preparing New Zealand for Rising Seas: Certainty and Uncertainty.

Zemp, M., Frey, H., Gartner-Roer, I., Nussbaumer, S. U., Hoelzle, M., Paul, F., Haeberli, W., Denzinger, F., Ahlstrom, A. P., Anderson, B., et al. (2015). Historically unprecedented global glacier decline in the early 21st century. Journal of Glaciology, 61(228):745-762. 
Zemp, M., Hoelzle, M., and Haeberli, W. (2009). Six decades of glacier mass-balance observations: a review of the worldwide monitoring network. Annals of Glaciology, 50(50):101-111.

Zemp, M., Jansson, P., Holmlund, P., Gärtner-Roer, I., Koblet, T., Thee, P., and Haeberli, W. (2010). Reanalysis of multi-temporal aerial images of Storglaciären, Sweden (1959-99)-Part 2: Comparison of glaciological and volumetric mass balances. The Cryosphere, 4(3):345-357.

Zumberge, J. F., Heflin, M. B., Jefferson, D. C., Watkins, M. M., and Webb, F. H. (1997). Precise point positioning for the efficient and robust analysis of GPS data from large networks. J. Geophys. Res., 102(B3):5005-5017. 